- 研究报告・

\title{
蕨类植物不同孢子裂缝类型在中国的分布格局
}

\author{
魏雪苹 1,2 张宪春 ${ }^{1 *}$ \\ 1 (中国科学院植物研究所系统与进化植物学国家重点实验室, 北京 100093) \\ 2 (中国科学院大学, 北京 100049)
}

\begin{abstract}
摘要: 孢子在薑类植物分类及有性生殖过程中具有重要地位, 一般都具有裂缝构造, 常见的是单裂缝和三裂缝, 极少数情况下有多裂缝的变异类型。我们统计了中国莎类2,281种(含种下单位)的孢子裂缝类型, 来探讨两种不同 裂缝类型的分布格局。结果表明: (1)具有单裂缝类型的物种数多于三裂缝类型, 单裂缝与三裂缝物种数目的比值 (单/三比)与纬度和海拔呈正相关。随着温度下降以及降水量的降低, 具单裂缝狍子的物种比例增加。推测具单裂

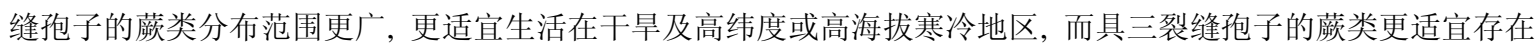
于低纬度或低海拔的温暖地区; (2)偋类植物孢子裂缝类型不是单次起源, 可能存在平行演化。本研究可以为偋类 植物的起源演化与生态适应等研究提供一定的证据。
\end{abstract}

关键词: 单裂缝㐨子; 三裂缝㘧子; 平行演化; 生态适应

\section{Distributional patterns of the monolete and trilete ferns in China}

\author{
Xueping Wei ${ }^{1,2}$, Xianchun Zhang ${ }^{1 *}$ \\ 1 State Key Laboratory of Systematic and Evolutionary Botany, Institute of Botany, Chinese Academy of Sciences, Beijing \\ 100093 \\ 2 Graduate University of Chinese Academy of Sciences, Beijing 100049
}

\begin{abstract}
Spores are important for fern classification and sexual reproduction and they usually have apertures; monolete (bilateral) and trilete (tetrahedral) are the two common types. All of the 2,281 native Chinese fern species (including subspecies and varieties) were included in our survey of monolete and trilete species ratios and their distribution patterns. Result revealed that (1) the number of monolete species was higher than the number of trilete, and there was a positive correlation between the ratio of monolete: trilete species (MTR) and latitude, and also between MTR and altitude. MTR was also shown to increase with decreases in temperature and rainfall. Monolete ferns were found to have larger distributional areas than trilete ones and to be more tolerant to a colder and drier climate. It is hypothesized that monolete ferns have a strong capacity to adapt to an extreme habitat; and that (2) neither monolete nor trilete spore are of single origin as parallel evolution might exist during the evolution of ferns. This study sheds new light on niche adaptation in ferns, as well as the evolution and diversification of ferns.
\end{abstract}

Key words: monolete spores; trilete spores; parallel evolution; niche adaptation

䕬类植物几乎遍布世界各地, 现代蒝类植物在 物种数量及繁茂程度上是以温带及热带为其分布 中心的。在北半球, 我国的石松类和蓱类植物种类 最为丰富, 分布有世界1/5的种类(张宪春, 2012)。孢 子囊是硕类植物最重要的繁殖器官, 孢子囊中的孢 子母细胞通常经过减数分裂, 产生四分体, 分离后 便形成 4 个孢子。在四分体时期, 每个孢子在近极面
和相邻的孢子相接触形成匹分体痕。一般地, 辐射 对称的孢子为三裂缝痕, 左右对称的孢子为单裂缝 痕, 分别形成三裂缝 (trilete) 孢子和单裂缝 (monolete)孢子, 在很少数的情况下, 孢子无裂缝 (alete) (张玉龙等, 1976)。孢子从裂缝处萌发, 长出 假根, 在无裂缝的孢子中, 常从孢壁较薄的地方开 裂。蓱类植物孢子裂缝的类型在蒝类植物系统演化

收稿日期: 2016-08-09; 接受日期: 2016-10-08 
上有着重要的指示意义, 是䓲类植物分类及孢子鉴 定的重要性状(张玉龙, 1963; Warren \& Wagner, 1974)。现在普遍认为三裂缝类型的孢子是原始类 型, 单裂缝孢子是进化类型(Read, 1950; Traverse, 2007)。Ito (1972, 1978)对亚洲11个地点和全球尺度 上64个地点的孢子裂缝类型的分布格局进行了分 析, 指出单裂缝和三裂缝狍子的比例在北半球随着 纬度和海拔的升高而增大, 其中中国只调查了秦 岭, 东北地区和台湾3个地区。Pausas和Sáez (2000) 探讨了欧洲14个地区孢子裂缝类型的分布格局, 指 出单裂缝和三裂缝狍子类型蕨类的数目比例一般 随纬度和海拔的升高而增加。蒝类植物孢子裂缝类 型可以反映植物的进化关系及对生态环境的适应 性。通过对现生蕨类植物狍子与土壤及底层中的狍 粉相对比, 可以探讨气候及环境变化。我国地域辽 阔, 地形复杂, 硕类植物丰富, 对孢子裂缝类型分 布格局的研究可以为研究蒝类植物的适应性进化 提供资料。

\section{1 方法}

根据《中国植物志》(中国植物志编辑委员会, 1959-2004)中的物种名, 查阅资料或在光学显微镜 下观察孢子形态, 得到中国2,281种(含种下单位, 下同)硕类植物的孢子裂缝类型(张玉龙等, 1976; 王全喜和戴锡玲, 2010) (附录1), 其中水龙骨科中 的伏石烣属(Lemmaphyllum)、石韦属(Pyrrosia)和瓦 韦属(Lepisorus)的孢子形态为作者在光学显微镜下 观察得出。根据省/地区、纬度范围、蕨类植物地理 分布区(严岳鸿等, 2013)、不同海拔段以及不同气温 带和等降水量线, 分别统计单裂缝狍子物种数和三 裂缝狍子物种数的比值(MTR：以下简称单/三比值 或 R), 并构建单/三比值在不同纬度带和海拔梯度 的线性回归方程，检测该比值在上述分区的分布格 局。基于目前最新的偋类系统(Smith et al, 2006; Christenhusz et al, 2011; 张宪春等, 2013; 张宪春和 孙久琼, 2015)探讨孢子裂缝类型的进化关系。

\section{2 结果}

\section{1 中国各省(地区)的单/三比值}

2,281 种硕类中具有单裂缝狍子的物种数为 1,689种, 其中木贼科的孢子具有无裂缝或无裂缝 到单裂缝的过渡类型, 均按照单裂缝计数, 三裂缝
的为 592 种, 单裂缝狍子的物种数明显多于三裂缝 物种数, 比值为 2.85 。分别统计了全国各省(地区) 单裂缝三裂缝狍子的物种数, 物种最多的为云南 省, 约 1,230 种, 最少的为天津和宁夏, 为 26 种。单/ 三比值最低的前5位依次为澳门(1.03)、天津(1.36)、 海南(1.55)、香港(1.64)和广东(1.90), 它们的比值均 小于 2 ; 最大的前 5 位依次为新疆 (5.38)、内蒙古 (4.70)、安徽(4.42)、吉林(4.25)、黑龙江(4.15), 它们 的比值均大于 4 (表 1$)$ 。

\section{2 不同纬度带的单/三比值}

从低纬度到高纬度划分 7 个纬度带, 每个纬度 带具有的单、三裂缝孢子的蕨类数目及其单/三比值 见表 2 。其中 $0^{\circ}-20^{\circ} \mathrm{N}$ 的单/三比值最低，为 1.55 , $45^{\circ}-55^{\circ} \mathrm{N}$ 最高, 为 3.82 。构建单/三比值的回归方程 为 $y=0.32 x+1.77\left(\mathrm{r}^{2}=0.76, P<0.01\right)$, 表明单/三比 值与纬度呈现显著的正相关(图1)。

\section{3 不同地理分布区的单/三比值}

单/三比值按照蒝类植物地理分布区统计结果 为华南: 2.09 , 华东: 2.45 , 华北: 2.70 , 西北: 3.12 , 西南: 3.17 , 华中: 3.24 , 东北: 3.67 ; 按照葓类植物 的地理分区，华东亚区: 1.65 , 华南亚区: 1.90 , 泛北 极亚区: 2.79 , 三峡亚区: 2.99, 江淮亚区: 3.75。如果 沿长江流域划分，长江流域及以南地区单/三比值 为 2.64 , 长江流域以北为 3.15 。另外, 我们还统计了 中国生物多样性较高的 4 个热点地区的单/三比值, 秦岭地区: 2.36 , 峨眉山区: 2.4 , 横断山脉: 2.9 , 东 喜马拉雅: 3.37 。

\section{4 不同海拔梯度的单/三比值}

我国拥有广泛的海拔范围。每 $500 \mathrm{~m}$ 为一段, 分 别统计两种孢子类型的物种数和比值(表3)。结果显 示: 单裂缝和三裂缝类型的偋类物种数均随着海拔 的升高迅速增加, 然后缓慢下降。物种数最多的海 拔段为 $1,001-1,500 \mathrm{~m}$ 范围内, 总数近 800 种。单/三 比值随着海拔的升高总体上呈现上升趋势, 其中除 了 $4,500 \mathrm{~m}$ 以上偋类物种数目较少 (仅有 16 种)之外, 单/三比值最小的为 $0-500 \mathrm{~m}$ 海拔段 $(R=2.92)$, 最大 的为3,501-4,000 m $(\mathrm{R}=5.09)$ 。去掉误差点 $(>4,500$ $\mathrm{m})$ 后，构建的单/三比值线性回归方程为 $y=0.28 x+$ $2.76\left(r^{2}=0.88, P<0.001\right)$ (图2)。表现为单/三比值与 海拔呈现显著正相关。

从我国地势三级阶梯来看，第一阶梯(平均海 拔小于 $500 \mathrm{~m}$ )单/三比值为 2.74 , 第二阶梯(平均海 
表1 中国各省(或地区)具有单裂缝和三裂缝孢子的顸类植 物数目及其比例

Table 1 The number and ratio of monolete and trilete ferns in each province/region of China

\begin{tabular}{|c|c|c|c|}
\hline $\begin{array}{l}\text { 省(地区) } \\
\text { Province/region }\end{array}$ & $\begin{array}{l}\text { 单裂缝孢子物 } \\
\text { 种数 } \\
\text { No. of monolete } \\
\text { ferns (N1) }\end{array}$ & $\begin{array}{l}\text { 三裂缝孢子 } \\
\text { 物种数 } \\
\text { No. of trilete } \\
\text { ferns (N2) }\end{array}$ & $\begin{array}{l}\text { 单/三比值 } \\
\text { Ratio of } \\
\text { monolete } \\
\text { and trilete } \\
\text { ferns } \\
(\mathrm{R}=\mathrm{N} 1 / \mathrm{N} 2)\end{array}$ \\
\hline 澳门 Macao & 35 & 34 & 1.03 \\
\hline 天津 Tianjin & 15 & 11 & 1.36 \\
\hline 海南 Hainan & 257 & 166 & 1.55 \\
\hline 香港 Hong Kong & 125 & 76 & 1.64 \\
\hline 广东 Guangdong & 337 & 177 & 1.90 \\
\hline 台湾 Taiwan & 456 & 228 & 2.00 \\
\hline 北京 Beijing & 43 & 20 & 2.15 \\
\hline 广西 Guangxi & 490 & 217 & 2.26 \\
\hline 上海 Shanghai & 38 & 16 & 2.38 \\
\hline 江西 Jiangxi & 290 & 116 & 2.50 \\
\hline 河北 Hebei & 68 & 27 & 2.52 \\
\hline 陕西 Shaanxi & 151 & 57 & 2.65 \\
\hline 福建 Fujian & 272 & 98 & 2.78 \\
\hline 贵州 Guizhou & 574 & 198 & 2.90 \\
\hline 山西 Shanxi & 64 & 22 & 2.91 \\
\hline 河南 Henan & 152 & 52 & 2.92 \\
\hline 甘肃 Gansu & 171 & 58 & 2.95 \\
\hline 重庆 Chongqing & 401 & 136 & 2.95 \\
\hline 浙江 Zhejiang & 319 & 107 & 2.98 \\
\hline 湖北 Hubei & 255 & 85 & 3.00 \\
\hline 四川 Sichuan & 611 & 201 & 3.04 \\
\hline 辽宁 Liaoning & 68 & 22 & 3.10 \\
\hline 湖南 Hunan & 452 & 145 & 3.12 \\
\hline 云南 Yunnan & 934 & 296 & 3.16 \\
\hline 青海 Qinghai & 32 & 10 & 3.20 \\
\hline 宁夏 Ningxia & 20 & 6 & 3.33 \\
\hline 西藏 Xizang & 414 & 123 & 3.37 \\
\hline 山东 Shandong & 68 & 18 & 3.78 \\
\hline 江苏 Jiangsu & 102 & 27 & 3.78 \\
\hline 黑龙江 Heilongjiang & 54 & 13 & 4.15 \\
\hline 吉林 Jilin & 68 & 16 & 4.25 \\
\hline 安徽 Anhui & 137 & 31 & 4.42 \\
\hline $\begin{array}{l}\text { 内蒙古 } \\
\text { Inner Mongolia }\end{array}$ & 47 & 10 & 4.70 \\
\hline 新疆 Xinjiang & 43 & 8 & 5.38 \\
\hline
\end{tabular}

拔 1,000-2,000 m) 单/三比值为 3.28 , 第三阶梯(平均 海拔大于 $4,000 \mathrm{~m})$ 单/三比值为 3.23 。

\section{5 各温度带和等降水量带的单/三比值}

我国不同的温度带中单/三比值依次为热带 1.55 , 亚热带 2.47 , 暖温带 2.61 , 中温带 3.91 , 高寒 区3.28。按照降水量区分单/三比值, 分别为 $0-400$
表2 不同纬度带具单、三裂缝狍子的蕨类物种数及其比值 Table 2 Number of monolete and trilete ferns and the monolete/trilete values along a latitude gradient

\begin{tabular}{llll}
\hline $\begin{array}{l}\text { 北纬 } \\
\begin{array}{l}\text { Latitude } \\
(\mathrm{N})\end{array}\end{array}$ & $\begin{array}{l}\text { 单裂缝孢子 } \\
\text { 蕨类物种数 } \\
\text { Monolete ferns }\end{array}$ & $\begin{array}{l}\text { 三裂缝孢子 } \\
\text { 蕨类物种数 } \\
\text { Trilete ferns }\end{array}$ & $\begin{array}{l}\text { 单/三比值 } \\
\text { Monolete/trilete }\end{array}$ \\
\hline $0^{\circ}-20^{\circ}$ & 257 & 166 & 1.55 \\
$20^{\circ}-25^{\circ}$ & 1,008 & 415 & 2.43 \\
$25^{\circ}-30^{\circ}$ & 991 & 308 & 3.22 \\
$30^{\circ}-35^{\circ}$ & 515 & 147 & 3.50 \\
$35^{\circ}-40^{\circ}$ & 246 & 75 & 3.28 \\
$40^{\circ}-45^{\circ}$ & 102 & 30 & 3.40 \\
$45^{\circ}-55^{\circ}$ & 65 & 17 & 3.82 \\
\hline
\end{tabular}

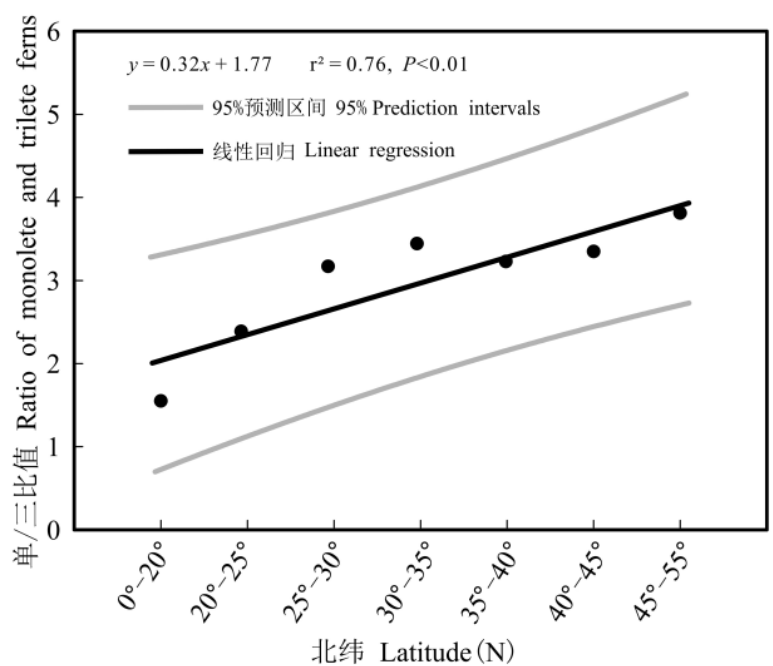

图1 单/三比值在不同纬度带上的线性回归

Fig. 1 Linear regression of monolete/trilete values along a latitude gradient

表3 不同海拔梯度具单、三裂缝孢子的蕨类物种数及其比 值

Table 3 Number of monolete and trilete ferns and the monolete/trilete values along an elevation gradient

\begin{tabular}{llll}
\hline $\begin{array}{l}\text { 海拔 } \\
\text { Elevation } \\
(\mathrm{m})\end{array}$ & $\begin{array}{l}\text { 单裂缝孢子 } \\
\text { 蕨类物种数 } \\
\text { Monolete ferns }\end{array}$ & $\begin{array}{l}\text { 三裂缝㘧子 } \\
\text { 蕨类物种数 } \\
\text { Trilete ferns }\end{array}$ & $\begin{array}{l}\text { 单/三比值 } \\
\text { Monolete } \\
\text { /trilete }\end{array}$ \\
\hline $0-500$ & 315 & 108 & 2.92 \\
$501-1,000$ & 574 & 189 & 3.04 \\
$1001-1,500$ & 608 & 177 & 3.46 \\
$1501-2,000$ & 610 & 138 & 4.42 \\
$2001-2,500$ & 450 & 104 & 4.33 \\
$2501-3,000$ & 342 & 75 & 4.56 \\
$3001-3,500$ & 192 & 41 & 4.68 \\
$3501-4,000$ & 117 & 23 & 5.09 \\
$4001-4,500$ & 44 & 9 & 4.89 \\
$>4,500$ & 11 & 5 & 2.20 \\
\hline
\end{tabular}




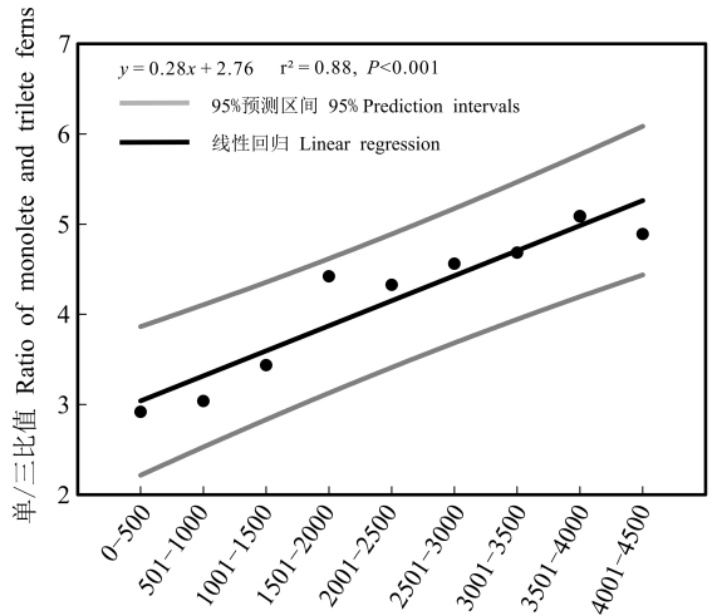

海拔 Elevation $(\mathrm{m})$

图 2 单/三比值在不同海拔梯度上的线性回归

Fig. 2 Linear regression of monolete/trilete values along an elevation gradient mm: 3.92, 400-800 mm: 3.07, 800-1,600 mm: 2.63 。 单/三比值与温度和降水均呈现负相关。

\section{6 孢子裂缝类型的进化关系}

敎类植物的基部类群为木贼科, 其孢子是无裂 缝或无裂缝向单裂缝的过渡状态。瓶尔小草科为三 裂缝孢子, 松叶蕨科为单裂缝狍子, 合囊蕨科既有 三裂缝又有单裂缝狍子。薄囊蕨类中除水龙骨类以 外的科中仅莎草硕科孢子为单裂缝, 双扇硕科有两 种孢子裂缝类型，其余均为三裂缝狍子。

水龙骨类中除真水龙骨类之外的 3 个科即碗硕 科、风尾烣科和鳞始烣科既存在具单裂缝孢子的物 种也存在具三裂缝狍子的物种。真水龙骨类中, 水 龙骨科和金星蕨科中具有两种孢子裂缝类型，其余 的科都是单裂缝狍子(图3)。

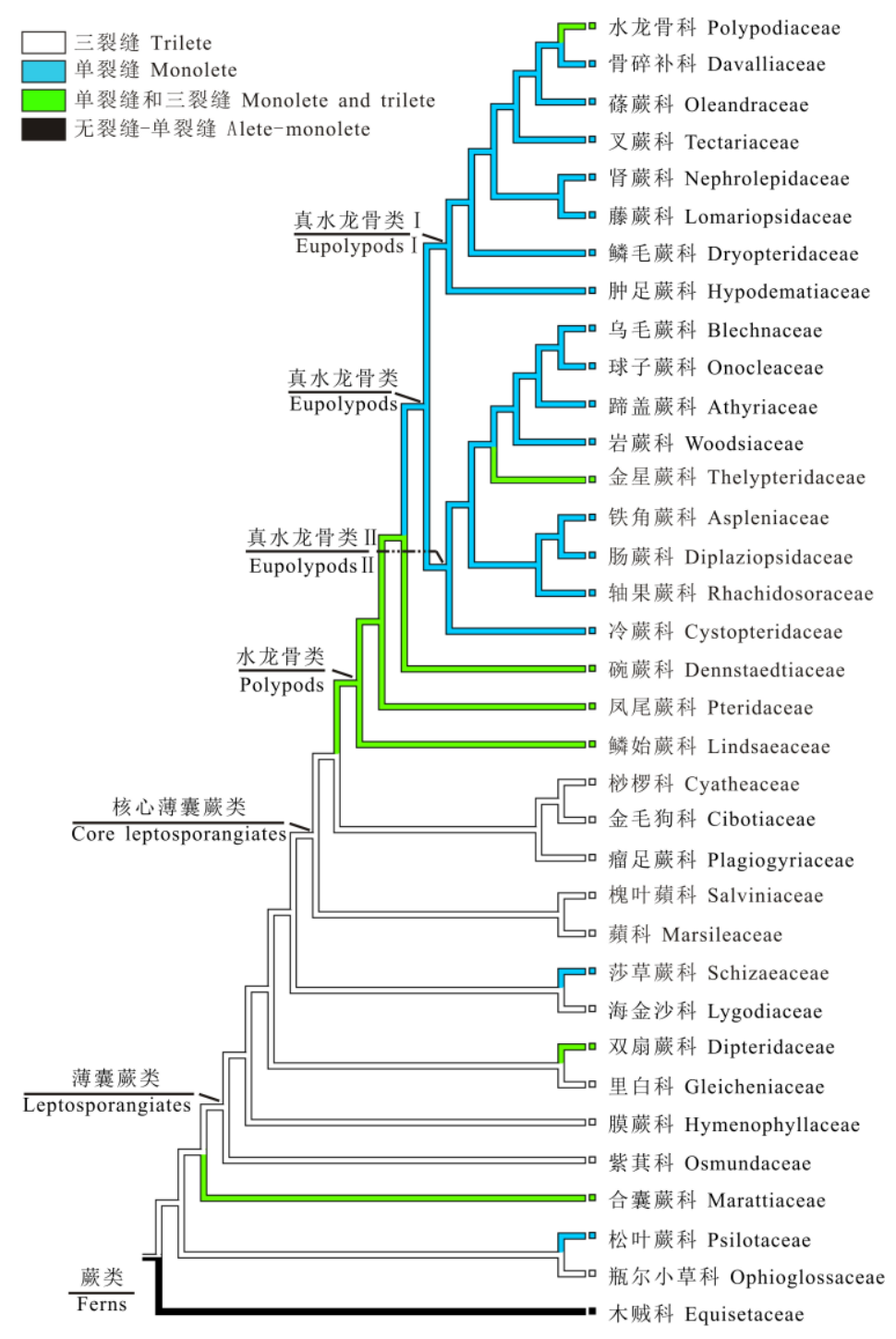

图3 䕋类植物孢子裂缝类型的进化关系 (系统发育关系框架自Smith et al, 2006; 张 宪春和孙久琼, 2015)

Fig. 3 Evolution of fern spore apertures styles (Phylogeny follows Smith et al, 2006; Zhang \& Sun, 2015) 


\section{3 讨论}

基于以上结果可以看出, 在中国随着海拔和纬 度的升高, 单/三比值呈上升趋势, 这与北半球其他 地区的格局一致(Ito，1972，1978; Pausas \& Sáez, 2000)。同一纬度上，中国的单/三比值高于世界大部 分地区(Ito, 1978)。在不同气候带之间, 随着温度下 降，具单裂缝狍子的物种比例增加; 不同降水量下， 随着降水量的减少, 具单裂缝狍子的物种比例增 加。统计数据得出的单/三比值反映了单裂缝或三裂 缝狍子的蒝类植物分布格局的整体趋势, 并不是严 格的数量变化关系。硕类植物乃至整个植物界的物 种分布受到光照、温度、水分、土壤类型等多方面 因素的影响。即使是同一海拔或同一纬度, 其生态 环境也会有所差别, 物种丰富度并不与单一环境因 子呈线性关系(王志恒等, 2004)。海拔高度、纬度区 间、温度带以及等降水量线的划分可以近似地反映 地区间温度、水分等的差异。本研究的结果说明具 单裂缝类型狍子的蒝类植物分布范围更广, 适应低 温干旱的能力更强, 更适宜生活在高海拔的寒冷地 区及干旱地区，而三裂缝狍子的蒴类更适宜生存在 低海拔的温暖地区和湿润地区。

孢子裂缝是孢子母细胞减数分裂形成四分体 时形成的近极痕, 近极痕与配子体的形成有关。在 孢子萌发时, 首先从近极痕处开裂, 长出假根, 其 中三裂缝类型的孢子壁明显裂成3瓣, 假根从裂缝 处伸出, 孢子壁退到细胞基部(王晓楠等, 2006; 黄 笛等, 2009; 邓晰朝, 2016)。单裂缝狍子的狍子壁可 能在萌发初期起到保护作用。Pausas和 Sáez (2000) 指出孢子裂缝类型单/三比值随着海拔与纬度的升 高而增大与多倍化的比例升高相关, 并且与单裂缝 类型的孢子具有较强的迁移能力有关。

秦仁昌系统(秦仁昌, 1978a, b)中的鳞始葓科、

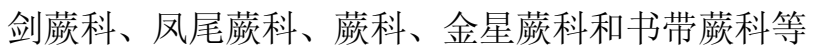
6 个科具有两种孢子裂缝类型。在最新的蓱类系统 中(Smith et al, 2006; Christenhusz et al, 2011; 张宪 春等, 2013; 张宪春和孙久琼, 2015), 除了鳞始蓱科 和金星硕科具有两种裂缝类型的孢子之外, 由于广 义合囊硕科包含了秦仁昌系统中的天星硕科, 广义 双扇硕科包含了秦仁昌系统中的燕尾烣科, 广义碗 蒝科增加了秦仁昌系统的姬硕科、凤尾硕科中的栗

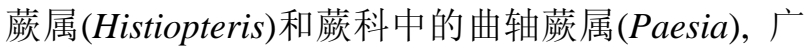

义水龙骨科中包含了秦仁昌系统中的剑烣科和禾 叶硕科, 使得上述 4 个新归并后的科也具有两种裂 缝类型的孢子。广义风尾藓科中包含了秦仁昌系统 中的书带硕科而增加了单裂缝狍子的比例。以上这 些科均为蒝类植物中较为复杂的类群, 其界定与内 部各个类群的相互关系也一直受到学者的关注，仍 需深入研究(Smith et al, 2006; 张宪春等, 2013; Liu, 2016)。在孢子裂缝类型的进化重建图上可以看出, 三裂缝为原始性状，单裂缝为进化性状，这与古孢 粉学的证据是相似的(Traverse, 2007)。但两种裂缝 类型的孢子均不是单次起源，推测蒝类植物在进化 过程中存在平行演化。另外, 由于三裂缝类型孢子 的植物更适宜生活在低海拔和低纬度地区，由此也 可以推断蕨类植物可能为低纬度起源, 并向高纬度 和高海拔地区扩散。

\section{参考文献}

Chang YL, Xi YZ, Zhang JT, Gao GZ, Du NQ, Sun XJ, Kong ZC, Xu R, Ching RC, Wang FH, Shing KH, Yang HQ, Liu BL, Xu TY, Song SR (1976) Spore Morphology of Chinese Pteridophytes. Science Press, Beijing. (in Chinese) [张玉龙, 席以珍，张金谈，高桂珍，杜乃秋，孙湘君，孔昭宸，徐 仁, 秦仁昌, 王伏雄, 邢公侠, 杨慧秋, 刘炳伦, 徐廷玉, 宋书如 (1976) 中国硕类植物狍子形态. 科学出版社, 北 京.]

Chang YL (1963) Studies in the spores morphology of Loxogramme Presl. Acta Botanica Sinica, 11, 26-37. (in Chinese with English abstract) [张玉龙 (1963) 剑蕨属 (Loxogramme)孢子形态的研究. 植物学报, 11, 26-37.]

Ching RC (1978a) The Chinese fern families and genera: systematic arrangement and historical origin. Acta Phytotaxonomica Sinica, 16(3), 1-19. (in Chinese) [秦仁昌 (1978a) 中国蕨类植物科属的系统排列和历史来源. 植物 分类学报, 16(3), 1-19.]

Ching RC (1978b) The Chinese fern families and genera: systematic arrangement and historical origin (cont.). Acta Phytotaxonomica Sinica, 16(4), 16-37. (in Chinese) [秦仁 昌 (1978b) 中国硕类植物科属的系统排列和历史来源 (续). 植物分类学报, 16(4), 16-37.]

Christenhusz MJM, Zhang XC, Schneider H (2011) A linear sequence of extant families and genera of lycophytes and ferns. Phytotaxa, 19, 7-54.

Delecti Florae Reipublicae Popularis Sinicae Agendae Academiae Sinicae (1959-2004) Flora Reipublicae Popularis Sinicae, Tomus 2-6. Science Press, Beijing. (in Chinese) [中国植物志编辑委员会(1959-2004) 中国植物 志, 2-6卷. 科学出版社, 北京.]

Deng XC (2016) Gametophyte development in Onychium 
japonicum and its systematic significance. Guihaia, 36, 96-100. (in Chinese with English abstract) [邓晰朝 (2016) 野雉尾金粉硕配子体发育及其系统学意义.广西植物, 36, 96-100.]

Huang D, Feng YL, Dong L (2009) Studies on gametophyte development and spore propagation of Aleuritopteris argentea. Acta Horticulturae Sinica, 36, 1345-1352. (in Chinese with English abstract) [黄笛, 冯玉兰, 董丽 (2009) 银粉背䔊的配子体发育及孢子繁殖技术的研究. 园艺学报, 36, 1345-1352.]

Ito H (1972) Distribution of monolete and trilete ferns in eastern Asia and northern Oceania. Journal of Japanese Botany, 47, 321-325.

Ito $\mathrm{H}$ (1978) Distribution of two spore patterns in the fern floras of the world (a preliminary survey). Journal of Japanese Botany, 53, 164-168.

Liu HM (2016) Embracing the pteridophyte classification of Ren-Chang Ching using a generic phylogeny of Chinese ferns and lycophytes. Journal of Systematics and Evolution, 54, 307-335.

Pausas JG, Sáez L (2000) Pteridophyte richness in the NE Iberian Peninsula: biogeographic patterns. Plant Ecology, 148, 195-205.

Read CF (1950) Morphology of fern spores and its relation to taxonomy. American Journal of Botany, 37, 673-674.

Smith AR, Pryer KM, Schuettpelz E, Korall P, Schneider H, Wolf PG (2006) A classification for extant ferns. Taxon, 55, 705-731.

Traverse A (2007) Spores/pollen morphology. In: Paleopalynology (ed. Traverse A), pp. 87-154. Springer Netherlands, Dordrecht.

Wang QX, Dai XL (2010) Spores of Polypodiales (Filicales) from China. Science Press, Beijing. (in Chinese) [王全喜, 戴锡玲 (2010) 中国水龙骨目 (真蕨目) 孢子形态的研
究. 科学出版社, 北京.]

Wang XN, Liu BD, Shi L (2006) Studies on the development of gametophyte in Matteuccia orientalis. Journal of Wuhan Botanical Research, 24, 310-315. (in Chinese with English abstract) [王晓楠, 刘保东, 石雷 (2006) 东方荚果烣配子 体发育的研究. 武汉植物学研究, 24, 310-315.]

Wang ZH, Chen AP, Piao SL, Fang JY (2004) Pattern of species richness along an altitudinal gradient on Gaoligong Mountains, Southwest China. Biodiversity Science, 12, 82-88. (in Chinese with English abstract) [王志恒, 陈安平, 朴世龙, 方精云 (2004) 高黎贡山种子植物物种丰富度 沿海拔梯度的变化. 生物多样性, 12, 82-88.]

Warren H, Wagner JR (1974) Structure of spores in relation to fern phylogeny. Annals of the Missouri Botanical Garden, 61, 332-353.

Yan YH, Zhang XC, Ma KP (2013) Pteridophytes in China: Diversity and Distribution. Science Press, Beijing. (in Chinese) [严岳鸿, 张宪春, 马克平 (2013) 中国偋类植物多 样性与地理分布. 科学出版社, 北京.]

Zhang XC (2012) Lycophytes and Ferns of China. Peking University Press, Beijing. (in Chinese) [张宪春 (2012) 中 国石松类和痰类植物. 北京大学出版社, 北京.]

Zhang XC, Sun JQ (2015) A Glossary of Terms and Names of Lycopods and Ferns. China ForestryPublishing House, Beijing. (in Chinese) [张宪春, 孙久琼 (2015) 石松类和蕨类 名词及名称. 中国林业出版社, 北京.]

Zhang XC, Wei R, Liu HM, He LJ, Wang L, Zhang GM (2013) Phylogeny and classification of the extant lycophytes and ferns from China. Chinese Bulletin of Botany, 48, 119-137. (in Chinese with English abstract) [张宪春, 卫然, 刘红梅, 何丽娟, 王丽, 张钢民 (2013) 中国现代石松类和蕨类的 系统发育与分类系统. 植物学报, 48, 119-137.]

\section{附录 Supplementary Material}

附录1 中国蕨类植物孢子裂缝类型汇总

Appendix 1 Spore apertures styles of ferns in China

http://www.biodiversity-science.net/fileup/PDF/w2016219-1.pdf 
魏雪苹，张宪春．偋类植物不同孢子裂缝类型在中国的分布格局．生物多样性，2016，24(10)：1129-1134

http://www. biodiversity - science. net/CN/10. 17520/biods. 2016219

附录 1 中国蕨类植物孢子裂缝类型汇总

Appendix 1 Spore apertures styles of ferns in China

\begin{tabular}{|c|c|c|c|}
\hline $\begin{array}{l}\text { 物种 } \\
\text { Species }\end{array}$ & $\begin{array}{l}\text { 孢子裂缝类型 } \\
\text { Spore apertures styles }\end{array}$ & $\begin{array}{l}\text { 科名 Family (秦仁 } \\
\text { 昌,1978a,b) }\end{array}$ & $\begin{array}{l}\text { 科名 Family (Smith et al., } \\
\text { 2006; Christenhusz et al, } \\
\text { 2011; 张宪春等, 2013) }\end{array}$ \\
\hline 问荆 Equisetum arvense L. & 无裂缝-单裂缝 Alete--monolete & 木贼科 Equisetaceae & 木贼科 Equisetaceae \\
\hline 披散木贼 Equisetum diffusum D. Don & 无裂缝-单裂缝 Alete--monolete & 木贼科 Equisetaceae & 木贼科 Equisetaceae \\
\hline 溪木贼 Equisetum fluviatile L. & 无裂缝-单裂缝 Alete--monolete & 木贼科 Equisetaceae & 木贼科 Equisetaceae \\
\hline 木贼 Equisetum hyemale L. & 无裂缝-单裂缝 Alete--monolete & 木贼科 Equisetaceae & 木贼科 Equisetaceae \\
\hline 无瘤木贼 Equisetum hyemale ssp. affine (Engel.) Calder \& R. L. & 无裂缝-单裂缝 Alete--monolete & 木戌科 Equisetaceae & 木贼科 Equisetaceae \\
\hline \multicolumn{4}{|l|}{ Taylor } \\
\hline 犬问荆 Equisetum palustre L. & 无裂缝-单裂缝 Alete--monolete & 木贼科 Equisetaceae & 木贼科 Equisetaceae \\
\hline 草问荆 Equisetum pratense Ehrhart & 无裂缝-单裂缝 Alete--monolete & 木贼科 Equisetaceae & 木贼科 Equisetaceae \\
\hline 节节草 Equisetum ramosissimum Desf. & 无裂缝-单裂缝 Alete--monolete & 木戌科 Equisetaceae & 木贼科 Equisetaceae \\
\hline 笔管草 Equisetum ramosissimum ssp. Debile (Roxb. ex Vauch.) & 无裂缝-单裂缝 Alete--monolete & 木贼科 Equisetaceae & 木贼科 Equisetaceae \\
\hline \multicolumn{4}{|l|}{ Hauke } \\
\hline 蓷木贼 Equisetum scirpoides Michoux & 无裂缝一单裂缝 Alete--monolete & 木贼科 Equisetaceae & 木贼科 Equisetaceae \\
\hline 林木贼 Equisetum sylvaticum L. & 无裂缝-单裂缝 Alete--monolete & 木戌科 Equisetaceae & 木贼科 Equisetaceae \\
\hline 斑纹木贼 Equisetum variegatum Schleich. ex Weber \& Mohr. & 无裂缝-单裂缝 Alete--monolete & 木贼科 Equisetaceae & 木贼科 Equisetaceae \\
\hline 阿拉斯加木贼 Equisetum variegatum ssp. Alaskanum (A. A. & 无裂缝-单裂缝 Alete--monolete & 木贼科 Equisetaceae & 木贼科 Equisetaceae \\
\hline \multicolumn{4}{|l|}{ Eaton) Hulten } \\
\hline 带状瓶尔小草 Ophioderma pendulum (L.) C.Presl & 三裂缝 Trilete & 瓶尔小草科 Ophioglossaceae & 瓶尔小草科 Ophioglossaceae \\
\hline 高山瓶尔小草 Ophioglossum austro-asiaticum M. Nishida & 三裂缝 Trilete & 瓶尔小草科 Ophioglossaceae & 瓶尔小草科 Ophioglossaceae \\
\hline 小叶瓶尔小草 Ophioglossum nudicaule L. f. & 三裂缝 Trilete & 瓶尔小草科 Ophioglossaceae & 瓶尔小草科 Ophioglossaceae \\
\hline 矩圆叶瓶尔小草 Ophioglossum oblongum H. G. Zhou \& Hua & 三裂缝 Trilete & 瓶尔小草科 Ophioglossaceae & 瓶尔小草科 Ophioglossaceae \\
\hline
\end{tabular}




\begin{tabular}{|c|c|c|c|}
\hline $\begin{array}{l}\text { 物种 } \\
\text { Species }\end{array}$ & $\begin{array}{l}\text { 孢子裂缝类型 } \\
\text { Spore apertures styles }\end{array}$ & $\begin{array}{l}\text { 科名 Family (秦仁 } \\
\text { 昌,1978a, b) }\end{array}$ & $\begin{array}{l}\text { 科名 Family (Smith et al., } \\
\text { 2006; Christenhusz et al, } \\
\text { 2011; 张宪春等, 2013) }\end{array}$ \\
\hline \multicolumn{4}{|r|}{ 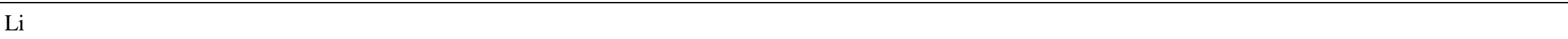 } \\
\hline 针头瓶尔小草 Ophioglossum petiolatum Hook. & 三裂缝 Trilete & 瓶尔小草科 Ophioglossaceae & 瓶尔小草科 Ophioglossaceae \\
\hline 心脏叶瓶尔小草 Ophioglossum reticulatum L. & 三裂缝 Trilete & 瓶尔小草科 Ophioglossaceae & 瓶尔小草科 Ophioglossaceae \\
\hline 狭叶瓶尔小草 Ophioglossum thermale Kom. & 三裂缝 Trilete & 瓶尔小草科 Ophioglossaceae & 瓶尔小草科 Ophioglossaceae \\
\hline 瓶尔小草 Ophioglossum vulgatum L. & 三裂缝 Trilete & 瓶尔小草科 Ophioglossaceae & 瓶尔小草科 Ophioglossaceae \\
\hline $\begin{array}{l}\text { 永仁瓶尔小草 Ophioglossum yongrenense Ching ex Z. R. He \& } \\
\text { W. M. Chu. }\end{array}$ & 三裂缝 Trilete & 瓶尔小草科 Ophioglossaceae & 瓶尔小草科 Ophioglossaceae \\
\hline 七指茨 Helminthostachys zeylanica (L.) Hook. & 三裂缝 Trilete & $\begin{array}{l}\text { 七指茨科 } \\
\text { Helminthostachyaceae }\end{array}$ & 瓶尔小草科 Ophioglossaceae \\
\hline 北方阴地嵚 Botrychium boreale Milde & 三裂缝 Trilete & 阴地茨科 Botrychiaceae & 瓶尔小草科 Ophioglossaceae \\
\hline 薄叶阴地荻 Botrychium daucifolium Wall. ex Hook. \& Grev. & 三裂缝 Trilete & 阴地䓲科 Botrychiaceae & 瓶尔小草科 Ophioglossaceae \\
\hline 台湾阴地嵚 Botrychium formosanum Tagawa & 三裂缝 Trilete & 阴地瘩科 Botrychiaceae & 瓶尔小草科 Ophioglossaceae \\
\hline 华东阴地蕨 Botrychium japonicum (Prantl) Underw. & 三裂缝 Trilete & 阴地蕨科 Botrychiaceae & 瓶尔小草科 Ophioglossaceae \\
\hline 长白山阴地䝫 Botrychium lanceolatum (J. Gmelin) Angstrom & 三裂缝 Trilete & 阴地茨科 Botrychiaceae & 瓶尔小草科 Ophioglossaceae \\
\hline 线毛阴地嵚 Botrychium lanuginosum Wall. ex Hook. \& Grev. & 三裂缝 Trilete & 阴地瘩科 Botrychiaceae & 瓶尔小草科 Ophioglossaceae \\
\hline 扇羽阴地苲 Botrychium lunaria (L.) Sw. & 三裂缝 Trilete & 阴地蕨科 Botrychiaceae & 瓶尔小草科 Ophioglossaceae \\
\hline 日本阴地硕 Botrychium nipponicum Makino & 三裂缝 Trilete & 阴地茨科 Botrychiaceae & 瓶尔小草科 Ophioglossaceae \\
\hline 粗壮阴地嵚 Botrychium robustum (Rupr. ex Milde) Underw. & 三裂缝 Trilete & 阴地蒝科 Botrychiaceae & 瓶尔小草科 Ophioglossaceae \\
\hline 劲直阴地硕 Botrychium strictum Underw. & 三裂缝 Trilete & 阴地蕨科 Botrychiaceae & 瓶尔小草科 Ophioglossaceae \\
\hline 阴地蒴 Botrychium ternatum (Thunb.) Sw. & 三裂缝 Trilete & 阴地茨科 Botrychiaceae & 瓶尔小草科 Ophioglossaceae \\
\hline 蕨其 Botrychium virginianum (L.) Sw. & 三裂缝 Trilete & 阴地葓科 Botrychiaceae & 瓶尔小草科 Ophioglossaceae \\
\hline 松叶菜 Psilotum nudum (L.) Beauv. & 单裂缝 Monolete & 松叶茨科 Psilotaceae & 竹叶烣科 Psilotaceae \\
\hline
\end{tabular}


魏雪苹，张宪春．脄类植物不同狍子裂缝类型在中国的分布格局. 生物多样性，2016，24(10)：1129-1134 http://www biodiversity - science. net/CN/10.17520/biods. 2016219

\begin{tabular}{|c|c|c|c|}
\hline $\begin{array}{l}\text { 物种 } \\
\text { Species }\end{array}$ & $\begin{array}{l}\text { 孢子裂缝类型 } \\
\text { Spore apertures styles }\end{array}$ & $\begin{array}{l}\text { 科名 Family (秦仁 } \\
\text { 昌,1978a, b) }\end{array}$ & $\begin{array}{l}\text { 科名 Family (Smith et al., } \\
\text { 2006; Christenhusz et al, } \\
\text { 2011; 张宪春等, 2013) }\end{array}$ \\
\hline 天星蒴 Christensenia assamica (Griff.) Ching & 单裂㖓 Monolete & 天星锁科 Christenseniaceae & 合囊菜科 Marattiaceae \\
\hline 合囊嵚 Marattia pellucida C. Presl & 单裂缝 Monolete & 合囊蕨科 Marattiaceae & 合囊硕科 Marattiaceae \\
\hline \multirow[t]{2}{*}{ 尖齿观音座莲 Angiopteris acutidentata Ching } & 三裂缝 Trilete & 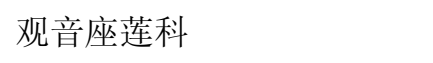 & 合囊蕨科 Marattiaceae \\
\hline & & Angiopteridaceae & \\
\hline \multirow[t]{2}{*}{ 披针观音座莲 Angiopteris caudatiformis Hieron. } & 三裂缝 Trilete & 观音座莲科 & 合囊蕨科 Marattiaceae \\
\hline & & Angiopteridaceae & \\
\hline \multirow[t]{2}{*}{ 长尾观音座莲 Angiopteris caudipinna Ching } & 三裂缝 Trilete & 观音座莲科 & 合囊蕨科 Marattiaceae \\
\hline & & Angiopteridaceae & \\
\hline \multirow[t]{2}{*}{ 琼越观音座蕨 Angiopteris cochinchinensis de Vriese } & 三裂缝 Trilete & 观音座莲科 & 合囊蒴科 Marattiaceae \\
\hline & & Angiopteridaceae & \\
\hline 密脉莲座䔊 Angiopteris confertinervia Ching ex C. Chr. \& & 三裂缝 Trilete & 观音座莲科 & 合囊蕨科 Marattiaceae \\
\hline Tardieu & & Angiopteridaceae & \\
\hline \multirow[t]{2}{*}{ 大脚观音座莲 Angiopteris crassipes Wall. ex de Vriese } & 三裂缝 Trilete & 观音座莲科 & 合囊蒴科 Marattiaceae \\
\hline & & Angiopteridaceae & \\
\hline \multirow[t]{2}{*}{ 滇越莲座嵚 Angiopteris dianyuecola Z. R. He \& W. M. Chu } & 三裂缝 Trilete & 观音座莲科 & 合囊蕨科 Marattiaceae \\
\hline & & Angiopteridaceae & \\
\hline \multirow[t]{2}{*}{ 食用观音座莲 Angiopteris esculenta Ching } & 三裂缝 Trilete & 观音座莲科 & 合囊蒴科 Marattiaceae \\
\hline & & Angiopteridaceae & \\
\hline \multirow[t]{2}{*}{ 纤毛观音座莲 Angiopteris fibrillosa Ching \& Y. X. Lin } & 三裂缝 Trilete & 观音座莲科 & 合囊蕨科 Marattiaceae \\
\hline & & Angiopteridaceae & \\
\hline \multirow[t]{2}{*}{ 福建观音座莲 Angiopteris fokiensis Hieron. } & 三裂缝 Trilete & 观音座莲科 & 合囊硕科 Marattiaceae \\
\hline & & Angiopteridaceae & \\
\hline
\end{tabular}


魏雪苹，张宪春．脄类植物不同狍子裂缝类型在中国的分布格局. 生物多样性，2016，24(10)：1129-1134 http://www biodiversity - science. net/CN/10.17520/biods. 2016219

\begin{tabular}{|c|c|c|c|}
\hline $\begin{array}{l}\text { 物种 } \\
\text { Species }\end{array}$ & $\begin{array}{l}\text { 孢子裂缝类型 } \\
\text { Spore apertures styles }\end{array}$ & $\begin{array}{l}\text { 科名 Family (秦仁 } \\
\text { 昌,1978a, b) }\end{array}$ & $\begin{array}{l}\text { 科名 Family (Smith et al., } \\
\text { 2006; Christenhusz et al, } \\
\text { 2011; 张宪春等, 2013) }\end{array}$ \\
\hline 美丽观音座莲 Angiopteris formosa Ching & 三裂缝 Trilete & $\begin{array}{l}\text { 观音座莲科 } \\
\text { Angiopteridaceae }\end{array}$ & 合囊硕科 Marattiaceae \\
\hline 海南观音座莲 Angiopteris hainanensis Ching & 三裂缝 Trilete & $\begin{array}{l}\text { 观音座莲科 } \\
\text { Angiopteridaceae }\end{array}$ & 合囊蕨科 Marattiaceae \\
\hline 楔基莲座萍 Angiopteris helferiana C. Presl & 三裂缝 Trilete & $\begin{array}{l}\text { 观音座莲科 } \\
\text { Angiopteridaceae }\end{array}$ & 合囊魦科 Marattiaceae \\
\hline 透明脉观音座莲 Angiopteris henryi Hieron. & 三裂缝 Trilete & $\begin{array}{l}\text { 观音座莲科 } \\
\text { Angiopteridaceae }\end{array}$ & 合囊蒴科 Marattiaceae \\
\hline 河口观音座莲 Angiopteris hokouensis Ching & 三裂缝 Trilete & $\begin{array}{l}\text { 观音座莲科 } \\
\text { Angiopteridaceae }\end{array}$ & 合囊蕨科 Marattiaceae \\
\hline 侯氏观音座莲 Angiopteris howii Ching \& Chu H. Wang & 三裂缝 Trilete & $\begin{array}{l}\text { 观音座莲科 } \\
\text { Angiopteridaceae }\end{array}$ & 合囊䕬科 Marattiaceae \\
\hline 广西观音座莲 Angiopteris kwangsiensis Ching & 三裂缝 Trilete & $\begin{array}{l}\text { 观音座莲科 } \\
\text { Angiopteridaceae }\end{array}$ & 合囊蕨科 Marattiaceae \\
\hline 片裂观音座莲 Angiopteris lobulata Ching & 三裂缝 Trilete & $\begin{array}{l}\text { 观音座莲科 } \\
\text { Angiopteridaceae }\end{array}$ & 合囊蒴科 Marattiaceae \\
\hline 观音座莲 Angiopteris lygodiifolia Rosenst. & 三裂缝 Trilete & $\begin{array}{l}\text { 观音座莲科 } \\
\text { Angiopteridaceae }\end{array}$ & 合囊魦科 Marattiaceae \\
\hline 墨脱观音座莲 Angiopteris medogensis Ching \& Y. X. Lin & 三裂缝 Trilete & $\begin{array}{l}\text { 观音座莲科 } \\
\text { Angiopteridaceae }\end{array}$ & 合囊蕨科 Marattiaceae \\
\hline 边生观音座莲 Angiopteris neglecta Ching \& Chu H. Wang & 三裂缝 Trilete & $\begin{array}{l}\text { 观音座莲科 } \\
\text { Angiopteridaceae }\end{array}$ & 合囊媭科 Marattiaceae \\
\hline
\end{tabular}


魏雪苹，张宪春．蕨类植物不同孢子裂缝类型在中国的分布格局．生物多样性，2016，24(10)：1129-1134 http://www biodiversity - science. net/CN/10, 17520/biods. 2016219

\begin{tabular}{|c|c|c|c|}
\hline $\begin{array}{l}\text { 物种 } \\
\text { Species }\end{array}$ & $\begin{array}{l}\text { 孢子裂缝类型 } \\
\text { Spore apertures styles }\end{array}$ & $\begin{array}{l}\text { 科名 Family (秦仁 } \\
\text { 昌,1978a, b) }\end{array}$ & $\begin{array}{l}\text { 科名 Family (Smith et al., } \\
\text { 2006; Christenhusz et al, } \\
\text { 2011; 张宪春等, 2013) }\end{array}$ \\
\hline 倒披针观音座莲 Angiopteris oblanceolata Ching \& Chu H. & 三裂缝 Trilete & 观音座莲科 & 合囊蕨科 Marattiaceae \\
\hline Wang & & Angiopteridaceae & \\
\hline \multirow[t]{2}{*}{ 定心散观音座莲 Angiopteris officinalis Ching } & 三裂缝 Trilete & 观音座莲科 & 合囊蕨科 Marattiaceae \\
\hline & & Angiopteridaceae & \\
\hline \multirow[t]{2}{*}{ 屋氏观音座莲 Angiopteris oldhamii Hieron. } & 三裂缝 Trilete & 观音座莲科 & 合囊硕科 Marattiaceae \\
\hline & & Angiopteridaceae & \\
\hline \multirow[t]{2}{*}{ 兰屿观音座莲 Angiopteris palmiformis (Cav.) C. Chr. } & 三裂缝 Trilete & 观音座莲科 & 合囊蒴科 Marattiaceae \\
\hline & & Angiopteridaceae & \\
\hline 疏脉莲座䓡 Angiopteris paucinervis W. M. Chu \& Z. R. He ex & 三裂缝 Trilete & 观音座莲科 & 合囊蕨科 Marattiaceae \\
\hline Z. R. He & & Angiopteridaceae & \\
\hline \multirow[t]{2}{*}{ 短果观音座莲 Angiopteris rahaoensis Ching } & 三裂缝 Trilete & 观音座莲科 & 合囊硕科 Marattiaceae \\
\hline & & Angiopteridaceae & \\
\hline \multirow[t]{2}{*}{ 疏叶观音座莲 Angiopteris remota Ching \& Chu H. Wang } & 三裂缝 Trilete & 观音座莲科 & 合囊蕨科 Marattiaceae \\
\hline & & Angiopteridaceae & \\
\hline \multirow[t]{2}{*}{ 强壮观音座莲 Angiopteris robusta Ching } & 三裂缝 Trilete & 观音座莲科 & 合囊蕨科 Marattiaceae \\
\hline & & Angiopteridaceae & \\
\hline \multirow[t]{2}{*}{ 边位观音座莲 Angiopteris sakuraii Hieron. } & 三裂缝 Trilete & 观音座莲科 & 合囊硕科 Marattiaceae \\
\hline & & Angiopteridaceae & \\
\hline \multirow[t]{2}{*}{ 法斗莲座蕨 Angiopteris sparsisora Ching } & 三裂缝 Trilete & 观音座莲科 & 合囊硕科 Marattiaceae \\
\hline & & Angiopteridaceae & \\
\hline \multirow[t]{2}{*}{ 楔形观音座莲 Angiopteris subcuneata Ching } & 三裂缝 Trilete & 观音座莲科 & 合囊蕨科 Marattiaceae \\
\hline & & Angiopteridaceae & \\
\hline
\end{tabular}


魏雪苹，张宪春．脄类植物不同狍子裂缝类型在中国的分布格局. 生物多样性，2016，24(10)：1129-1134 http://www biodiversity - science net/CN/10.17520/biods. 2016219

\begin{tabular}{|c|c|c|c|}
\hline $\begin{array}{l}\text { 物种 } \\
\text { Species }\end{array}$ & $\begin{array}{l}\text { 孢子裂缝类型 } \\
\text { Spore apertures styles }\end{array}$ & $\begin{array}{l}\text { 科名 Family (秦仁 } \\
\text { 昌,1978a, b) }\end{array}$ & $\begin{array}{l}\text { 科名 Family (Smith et al., } \\
\text { 2006; Christenhusz et al, } \\
\text { 2011; 张宪春等, 2013) }\end{array}$ \\
\hline 亚全缘观音座莲 Angiopteris subintegra Ching & 三裂缝 Trilete & $\begin{array}{l}\text { 观音座莲科 } \\
\text { Angiopteridaceae }\end{array}$ & 合囊硕科 Marattiaceae \\
\hline 台湾观音座莲 Angiopteris taiwanensis Ching & 三裂缝 Trilete & $\begin{array}{l}\text { 观音座莲科 } \\
\text { Angiopteridaceae }\end{array}$ & 合囊蕨科 Marattiaceae \\
\hline 长假脉观音座莲 Angiopteris venulosa Ching & 三裂缝 Trilete & $\begin{array}{l}\text { 观音座莲科 } \\
\text { Angiopteridaceae }\end{array}$ & 合囊蕨科 Marattiaceae \\
\hline 西藏观音座莲 Angiopteris wallichiana C. Presl & 三裂缝 Trilete & $\begin{array}{l}\text { 观音座莲科 } \\
\text { Angiopteridaceae }\end{array}$ & 合囊撂科 Marattiaceae \\
\hline 王氏莲座蕨 Angiopteris wangii Ching & 三裂缝 Trilete & $\begin{array}{l}\text { 观音座莲科 } \\
\text { Angiopteridaceae }\end{array}$ & 合囊硕科 Marattiaceae \\
\hline 云南观音座莲 Angiopteris yunnanensis Hieron. & 三裂缝 Trilete & $\begin{array}{l}\text { 观音座莲科 } \\
\text { Angiopteridaceae }\end{array}$ & 合囊䕬科 Marattiaceae \\
\hline 二回原始观音座莲 Archangiopteris bipinnata Ching & 三裂缝 Trilete & $\begin{array}{l}\text { 观音座莲科 } \\
\text { Angiopteridaceae }\end{array}$ & 合囊蕨科 Marattiaceae \\
\hline 享利原始观音座莲 Archangiopteris henryi Christ \& Gies. & 三裂缝 Trilete & $\begin{array}{l}\text { 观音座莲科 } \\
\text { Angiopteridaceae }\end{array}$ & 合囊蒴科 Marattiaceae \\
\hline 河口原始观音座莲 Archangiopteris hokouensis Ching & 三裂缝 Trilete & $\begin{array}{l}\text { 观音座莲科 } \\
\text { Angiopteridaceae }\end{array}$ & 合囊魦科 Marattiaceae \\
\hline 伊藤氏原始观音座莲 Archangiopteris itoi W. C. Shieh & 三裂缝 Trilete & $\begin{array}{l}\text { 观音座莲科 } \\
\text { Angiopteridaceae }\end{array}$ & 合囊蕨科 Marattiaceae \\
\hline 尖叶原始观音座莲 Archangiopteris tonkinensis (Hayata) Ching & 三裂缝 Trilete & $\begin{array}{l}\text { 观音座莲科 } \\
\text { Angiopteridaceae }\end{array}$ & 合囊蕨科 Marattiaceae \\
\hline
\end{tabular}




\begin{tabular}{|c|c|c|c|}
\hline $\begin{array}{l}\text { 物种 } \\
\text { Species }\end{array}$ & $\begin{array}{l}\text { 孢子裂缝类型 } \\
\text { Spore apertures styles }\end{array}$ & $\begin{array}{l}\text { 科名 Family (秦仁 } \\
\text { 昌,1978a, b) }\end{array}$ & $\begin{array}{l}\text { 科名 Family (Smith et al., } \\
\text { 2006; Christenhusz et al, } \\
\text { 2011; 张宪春等, 2013) }\end{array}$ \\
\hline 狭叶紫萁 Osmunda angustifolia Ching & 三裂缝 Trilete & 紫其科 Osmundaceae & 紫其科 Osmundaceae \\
\hline 粗齿紫其 Osmunda banksiifolia (C. Presl) Kuhn & 三裂缝 Trilete & 紫萁科 Osmundaceae & 紫萁科 Osmundaceae \\
\hline 桂皮紫萁 Osmunda cinnamomea $\mathrm{L}$ & 三裂缝 Trilete & 紫其科 Osmundaceae & 紫其科 Osmundaceae \\
\hline 线紫其 Osmunda claytoniana L. & 三裂缝 Trilete & 紫其科 Osmundaceae & 紫其科 Osmundaceae \\
\hline 紫其 Osmunda japonica Thunb. & 三裂缝 Trilete & 紫萁科 Osmundaceae & 紫萁科 Osmundaceae \\
\hline 宽叶紫基 Osmunda javanica Blume & 三裂缝 Trilete & 紫其科 Osmundaceae & 紫其科 Osmundaceae \\
\hline 华南紫其 Osmunda vachellii Hook. & 三裂缝 Trilete & 紫其科 Osmundaceae & 紫其科 Osmundaceae \\
\hline 粤紫其 Osmunda × mildei C. Chr. & 三裂缝 Trilete & 紫萁科 Osmundaceae & 紫萁科 Osmundaceae \\
\hline 长片蕨 Abrodictyum cumingii C. Presl & 三裂缝 Trilete & 膜硕科 Hymenophyllaceae & 膜蕨科 Hymenophyllaceae \\
\hline 毛杆薕 Callistopteris apiifolia Copel. & 三裂缝 Trilete & 膜蕨科 Hymenophyllaceae & 膜嵚科 Hymenophyllaceae \\
\hline 爪哇厚叶蒴 Cephalomanes javanicum (Blume) Bosch & 三裂缝 Trilete & 膜蕨科 Hymenophyllaceae & 膜蕨科 Hymenophyllaceae \\
\hline 南洋假脉蕨 Crepidomanes bipunctatum (Poir.) Copel. & 三裂缝 Trilete & 膜蕨科 Hymenophyllaceae & 膜蕨科 Hymenophyllaceae \\
\hline 海南假脉嵚 Crepidomanes hainanense Ching & 三裂缝 Trilete & 膜蕨科 Hymenophyllaceae & 膜蕨科 Hymenophyllaceae \\
\hline 边内假脉蕨 Crepidomanes intramarginale (Hook. \& Grev.) & 三裂缝 Trilete & 膜蕨科 Hymenophyllaceae & 膜蕨科 Hymenophyllaceae \\
\hline \multicolumn{4}{|l|}{ Copel. } \\
\hline 阔边假脉嵚 Crepidomanes latemarginale (A. A. Eaton) Copel. & 三裂缝 Trilete & 膜硕科 Hymenophyllaceae & 膜蕨科 Hymenophyllaceae \\
\hline 荔波假脉蒴 Crepidomanes liboense P. S. Wang & 三裂缝 Trilete & 膜鄀科 Hymenophyllaceae & 膜嵚科 Hymenophyllaceae \\
\hline 峨眉假脉葓 Crepidomanes omeiense Ching \& P. S. Chiu & 三裂缝 Trilete & 膜鄀科 Hymenophyllaceae & 膜嵚科 Hymenophyllaceae \\
\hline 边上假脉荻 Crepidomanes pinnatifidum Ching \& P. S. Chiu & 三裂缝 Trilete & 膜鄀科 Hymenophyllaceae & 膜蕨科 Hymenophyllaceae \\
\hline 皱叶假脉蕒 Crepidomanes plicatum (Bosch) Ching & 三裂缝 Trilete & 膜䓲科 Hymenophyllaceae & 膜蕨科 Hymenophyllaceae \\
\hline 长柄假脉嵚 Crepidomanes racemulosum (Bosch) Ching & 三裂缝 Trilete & 膜鄀科 Hymenophyllaceae & 膜嵚科 Hymenophyllaceae \\
\hline 天童假脉蕨 Crepidomanes tiendongense Ching \& C. F. Zhang & 三裂缝 Trilete & 膜蕨科 Hymenophyllaceae & 膜蕨科 Hymenophyllaceae \\
\hline
\end{tabular}




\begin{tabular}{|c|c|c|c|}
\hline $\begin{array}{l}\text { 物种 } \\
\text { Species }\end{array}$ & $\begin{array}{l}\text { 孢子裂缝类型 } \\
\text { Spore apertures styles }\end{array}$ & $\begin{array}{l}\text { 科名 Family (秦仁 } \\
\text { 昌,1978a, b) }\end{array}$ & $\begin{array}{l}\text { 科名 Family (Smith et al., } \\
\text { 2006; Christenhusz et al, } \\
\text { 2011; 张宪春等, 2013) }\end{array}$ \\
\hline 扁枝假脉茨 Crepidomanes zayuense Ching \& S. K. Wu & 三裂缝 Trilete & 膜蕨科 Hymenophyllaceae & 膜荻科 Hymenophyllaceae \\
\hline 厚边蒴 Crepidopteris humilis (Forst.) Copel. & 三裂缝 Trilete & 膜硕科 Hymenophyllaceae & 膜硕科 Hymenophyllaceae \\
\hline 毛边硕 Didymoglossum wallii (Thwait.) Copel. & 三裂缝 Trilete & 膜蕨科 Hymenophyllaceae & 膜蕨科 Hymenophyllaceae \\
\hline 广东团扇茨 Gonocormus matthewii (Christ) Ching & 三裂缝 Trilete & 膜荻科 Hymenophyllaceae & 膜茨科 Hymenophyllaceae \\
\hline 团扇蒴 Gonocormus minutus (Blume) Bosch & 三裂缝 Trilete & 膜蕨科 Hymenophyllaceae & 膜嵚科 Hymenophyllaceae \\
\hline 节节团扇硕 Gonocormus prolifer (Blume) Prantl & 三裂缝 Trilete & 膜鄀科 Hymenophyllaceae & 膜蕨科 Hymenophyllaceae \\
\hline 华南膜蒴 Hymenophyllum austrosinicum Ching & 三裂缝 Trilete & 膜蕨科 Hymenophyllaceae & 膜茨科 Hymenophyllaceae \\
\hline 华东膜硕 Hymenophyllum barbatum (Bosch) Baker & 三裂缝 Trilete & 膜硕科 Hymenophyllaceae & 膜硕科 Hymenophyllaceae \\
\hline 台湾膜蕨 Hymenophyllum devolii Lai & 三裂缝 Trilete & 膜蕨科 Hymenophyllaceae & 膜蕨科 Hymenophyllaceae \\
\hline 顶果膜萍 Hymenophyllum khasianum Hook. \& Baker & 三裂缝 Trilete & 膜荻科 Hymenophyllaceae & 膜茨科 Hymenophyllaceae \\
\hline 微齿膜蕨 Hymenophyllum minutidenticulatum Ching \& P. S. & 三裂缝 Trilete & 膜鄀科 Hymenophyllaceae & 膜蕨科 Hymenophyllaceae \\
\hline \multicolumn{4}{|l|}{ Chiu } \\
\hline 峨眉膜蕨 Hymenophyllum omeiense Christ & 三裂缝 Trilete & 膜鄀科 Hymenophyllaceae & 膜蕨科 Hymenophyllaceae \\
\hline 小叶膜蕨 Hymenophyllum oxyodon Baker & 三裂缝 Trilete & 膜荻科 Hymenophyllaceae & 膜嵚科 Hymenophyllaceae \\
\hline 宽片膜荻 Hymenophyllum simonsianum Hook. & 三裂缝 Trilete & 膜蕨科 Hymenophyllaceae & 膜蕨科 Hymenophyllaceae \\
\hline 尾叶膜鄀 Hymenophyllum urofrons Ching \& C. F. Zhang & 三裂缝 Trilete & 膜蕨科 Hymenophyllaceae & 膜蕨科 Hymenophyllaceae \\
\hline 蕗藃 Mecodium badium (Hook. \& Grev.) Copel. & 三裂缝 Trilete & 膜硕科 Hymenophyllaceae & 膜硕科 Hymenophyllaceae \\
\hline 皱叶蕗蕨 Mecodium corrugatum (Christ) Copel. & 三裂缝 Trilete & 膜蕨科 Hymenophyllaceae & 膜茨科 Hymenophyllaceae \\
\hline 毛蕗硕 Mecodium exsertum (Wall. ex Hook.) Copel. & 三裂缝 Trilete & 膜蕨科 Hymenophyllaceae & 膜硕科 Hymenophyllaceae \\
\hline 爪哇蕗硕 Mecodium javanicum (Spreng.) Copel. & 三裂缝 Trilete & 膜蕨科 Hymenophyllaceae & 膜蕨科 Hymenophyllaceae \\
\hline 金佛山蕗藓 Mecodium jinfoshanense Ching \& Z. Y. Liu & 三裂缝 Trilete & 膜蕨科 Hymenophyllaceae & 膜蕨科 Hymenophyllaceae \\
\hline 鳞蕗濒 Mecodium levingei (C. B. Clarke) Copel. & 三裂缝 Trilete & 膜蕨科 Hymenophyllaceae & 膜苵科 Hymenophyllaceae \\
\hline
\end{tabular}




\begin{tabular}{|c|c|c|c|}
\hline $\begin{array}{l}\text { 物种 } \\
\text { Species }\end{array}$ & $\begin{array}{l}\text { 孢子裂缝类型 } \\
\text { Spore apertures styles }\end{array}$ & $\begin{array}{l}\text { 科名 Family (秦仁 } \\
\text { 昌,1978a, b) }\end{array}$ & $\begin{array}{l}\text { 科名 Family (Smith et al., } \\
\text { 2006; Christenhusz et al, } \\
\text { 2011; 张宪春等, 2013) }\end{array}$ \\
\hline 线叶蕗蒴 Mecodium lineatum Ching \& P. S. Chiu & 三裂缝 Trilete & 膜鄀科 Hymenophyllaceae & 膜烣科 Hymenophyllaceae \\
\hline 罗浮蕗媭 Mecodium lofoushanense Ching \& P. S. Chiu & 三裂缝 Trilete & 膜茨科 Hymenophyllaceae & 膜硕科 Hymenophyllaceae \\
\hline 庐山蕗蕨 Mecodium lushanense Ching \& P. S. Chiu & 三裂缝 Trilete & 膜蕨科 Hymenophyllaceae & 膜蕨科 Hymenophyllaceae \\
\hline 长毛蕗茨 Mecodium oligosorum (Makino) H. Ito & 三裂缝 Trilete & 膜嵚科 Hymenophyllaceae & 膜茨科 Hymenophyllaceae \\
\hline 羽叶蕗菜 Mecodium paramnioides H. G. Zhou \& W. M. Chu & 三裂缝 Trilete & 膜硕科 Hymenophyllaceae & 膜硕科 Hymenophyllaceae \\
\hline 多果蕗蕨 Mecodium polyanthos (Sw.) Copel. & 三裂缝 Trilete & 膜鄀科 Hymenophyllaceae & 膜蕨科 Hymenophyllaceae \\
\hline 吊罗蕗蒴 Mecodium productum (Kunze) Copel. & 三裂缝 Trilete & 膜茨科 Hymenophyllaceae & 膜茨科 Hymenophyllaceae \\
\hline 琉球蕗蒴 Mecodium riukiuense (Christ) Copel. & 三裂缝 Trilete & 膜硕科 Hymenophyllaceae & 膜硕科 Hymenophyllaceae \\
\hline 撕苍蕗菜 Mecodium stenochladum Ching \& P. S. Chiu & 三裂缝 Trilete & 膜蕨科 Hymenophyllaceae & 膜蕨科 Hymenophyllaceae \\
\hline 四川蕗薜 Mecodium szechuanense Ching \& P. S. Chiu & 三裂缝 Trilete & 膜葓科 Hymenophyllaceae & 膜茨科 Hymenophyllaceae \\
\hline 爪哇厚壁菜 Meringium blandum (Racib) Copel. & 三裂缝 Trilete & 膜硕科 Hymenophyllaceae & 膜硕科 Hymenophyllaceae \\
\hline 厚壁蕨 Meringium denticulatum (Sw.) Copel. & 三裂缝 Trilete & 膜蕨科 Hymenophyllaceae & 膜蕨科 Hymenophyllaceae \\
\hline 南洋厚壁嵚 Meringium holochilum (Bosch) Copel. & 三裂缝 Trilete & 膜葓科 Hymenophyllaceae & 膜茨科 Hymenophyllaceae \\
\hline 叉脉单叶假脉蔹 Microgonium bimarginatum Bosch. & 三裂缝 Trilete & 膜荻科 Hymenophyllaceae & 膜嵚科 Hymenophyllaceae \\
\hline 短柄单叶假脉蕨 Microgonium motleyi Bosch. & 三裂缝 Trilete & 膜蕨科 Hymenophyllaceae & 膜蕨科 Hymenophyllaceae \\
\hline 单叶假脉蕨 Microgonium sublimbatum (K. Muller) Bosch & 三裂缝 Trilete & 膜嵚科 Hymenophyllaceae & 膜茨科 Hymenophyllaceae \\
\hline 盾形单叶假脉茨 Microgonium tahitense (Nadealld) Tindale & 三裂缝 Trilete & 膜鄀科 Hymenophyllaceae & 膜鄀科 Hymenophyllaceae \\
\hline 指状细口团扇荻 Microtrichomanes digitatum (Sw.) Copel. & 三裂缝 Trilete & 膜鄀科 Hymenophyllaceae & 膜鄀科 Hymenophyllaceae \\
\hline 细口团扇蕨 Microtrichomanes nitidulum (Bosch) Copel. & 三裂缝 Trilete & 膜蕨科 Hymenophyllaceae & 膜蕨科 Hymenophyllaceae \\
\hline 大球杆毛锁 Nesopteris grandis (Copel.) Copel. & 三裂缝 Trilete & 膜烣科 Hymenophyllaceae & 膜茨科 Hymenophyllaceae \\
\hline 球杆毛嵚 Nesopteris thysanostoma (Makino) Copel. & 三裂缝 Trilete & 膜鄀科 Hymenophyllaceae & 膜蕨科 Hymenophyllaceae \\
\hline 毛叶薜 Pleuromanes pallidum (Blume) C. Presl & 三裂缝 Trilete & 膜茨科 Hymenophyllaceae & 膜蕨科 Hymenophyllaceae \\
\hline
\end{tabular}




\begin{tabular}{|c|c|c|c|}
\hline $\begin{array}{l}\text { 物种 } \\
\text { Species }\end{array}$ & $\begin{array}{l}\text { 孢子裂缝类型 } \\
\text { Spore apertures styles }\end{array}$ & $\begin{array}{l}\text { 科名 Family (秦仁 } \\
\text { 昌,1978a, b) }\end{array}$ & $\begin{array}{l}\text { 科名 Family (Smith et al., } \\
\text { 2006; Christenhusz et al, } \\
\text { 2011; 张宪春等, 2013) }\end{array}$ \\
\hline 直长筒蕨 Selenodesmium cupressoides (Desv.) Copel. & 三裂缝 Trilete & 膜蕨科 Hymenophyllaceae & 膜薜科 Hymenophyllaceae \\
\hline 弯长筒蒝 Selenodesmium recurvum Ching \& P. S. Chiu & 三裂缝 Trilete & 膜蕨科 Hymenophyllaceae & 膜䓲科 Hymenophyllaceae \\
\hline 广西长筒脒 Selenodesmium siamense (Christ) Ching \& Chu H. & 三裂缝 Trilete & 膜䓲科 Hymenophyllaceae & 膜䓲科 Hymenophyllaceae \\
\hline \multicolumn{4}{|l|}{ Wang } \\
\hline 瓶蕨 Vandenboschia auriculata (Blume) Copel. & 三裂缝 Trilete & 膜䓲科 Hymenophyllaceae & 膜嵚科 Hymenophyllaceae \\
\hline 管苍瓶蕨 Vandenboschia birmanica (Bedd.) Ching & 三裂缝 Trilete & 膜嵚科 Hymenophyllaceae & 膜嵚科 Hymenophyllaceae \\
\hline 墨兰瓶蕨 Vandenboschia cystoseiroides (Christ ex Tardien \& C. & 三裂缝 Trilete & 膜蕨科 Hymenophyllaceae & 膜䓲科 Hymenophyllaceae \\
\hline \multicolumn{4}{|l|}{ Chr.) Ching } \\
\hline 城口瓶䔊 Vandenboschia fargesii (Christ) Ching & 三裂缝 Trilete & 膜蕨科 Hymenophyllaceae & 膜嵚科 Hymenophyllaceae \\
\hline 罗浮山瓶蕨 Vandenboschia lofoushanensis Ching & 三裂缝 Trilete & 膜蕨科 Hymenophyllaceae & 膜蕨科 Hymenophyllaceae \\
\hline 大叶瓶䕬 Vandenboschia maxima (Blume) Copel. & 三裂缝 Trilete & 膜蒝科 Hymenophyllaceae & 膜蒝科 Hymenophyllaceae \\
\hline 南海瓶嵚 Vandenboschia radicans (Sw.) Copel. & 三裂缝 Trilete & 膜蓱科 Hymenophyllaceae & 膜嵚科 Hymenophyllaceae \\
\hline 宽叶瓶嵚 Vandenboschia schmidtiana (Zenker ex Taschner) & 三裂缝 Trilete & 膜蕨科 Hymenophyllaceae & 膜茨科 Hymenophyllaceae \\
\hline \multicolumn{4}{|l|}{ Copel. } \\
\hline 琉球瓶蕨 Vandenboschia subclathrata K. Iwats. & 三裂缝 Trilete & 膜䓲科 Hymenophyllaceae & 膜䓲科 Hymenophyllaceae \\
\hline 大芒萁 Dicranopteris ampla Ching \& Chiu in Ching \& Chu H. & 三裂缝 Trilete & 里白科 Gleichniaceae & 里白科 Gleicheniaceae \\
\hline \multicolumn{4}{|l|}{ Wang } \\
\hline 乔芒其 Dicranopteris gigantea Ching & 三裂缝 Trilete & 里白科 Gleichniaceae & 里白科 Gleicheniaceae \\
\hline 铁芒萁 Dicranopteris linearis (Burm. f. ) Underw. & 三裂缝 Trilete & 里白科 Gleichniaceae & 里白科 Gleicheniaceae \\
\hline 芒其 Dicranopteris pedata (Houtt.) Nakaike & 三裂缝 Trilete & 里白科 Gleichniaceae & 里白科 Gleicheniaceae \\
\hline 大羽芒萁 Dicranopteris splendida (Hand.-Mazz.) Ching & 三裂缝 Trilete & 里白科 Gleichniaceae & 里白科 Gleicheniaceae \\
\hline 台湾芒萁 Dicranopteris taiwanensis Ching \& P. S. Chiu & 三裂缝 Trilete & 里白科 Gleichniaceae & 里白科 Gleicheniaceae \\
\hline
\end{tabular}




\begin{tabular}{|c|c|c|c|}
\hline $\begin{array}{l}\text { 物种 } \\
\text { Species }\end{array}$ & $\begin{array}{l}\text { 孢子裂缝类型 } \\
\text { Spore apertures styles }\end{array}$ & $\begin{array}{l}\text { 科名 Family (秦仁 } \\
\text { 昌,1978a, b) }\end{array}$ & $\begin{array}{l}\text { 科名 Family (Smith et al., } \\
\text { 2006; Christenhusz et al, } \\
\text { 2011; 张宪春等, 2013) }\end{array}$ \\
\hline 阔片里白 Diplopterygium blotianum (C. Chr.) Nakai & 三裂缝 Trilete & 里白科 Gleichniaceae & 里白科 Gleicheniaceae \\
\hline 粤里白 Diplopterygium cantonense (Ching) Ching & 三裂缝 Trilete & 里白科 Gleichniaceae & 里白科 Gleicheniaceae \\
\hline 中华里白 Diplopterygium chinense (Rosenst.) De Vol & 三裂缝 Trilete & 里白科 Gleichniaceae & 里白科 Gleicheniaceae \\
\hline \multicolumn{2}{|l|}{ X. C. Zhang } & 里白科 Gleichniaceae & 里白科 Gleicheniaceae \\
\hline 大里白 Diplopterygium giganteum (Wall. ex Hook.) Nakai & 三裂缝 Trilete & 里白科 Gleichniaceae & 里白科 Gleicheniaceae \\
\hline 里白 Diplopterygium glaucum (Thunb. ex Houtt.) Nakai & 三裂缝 Trilete & 里白科 Gleichniaceae & 里白科 Gleicheniaceae \\
\hline 参差里白 Diplopterygium irregulare W. M. Chu \& Z. R. He & 三裂缝 Trilete & 里白科 Gleichniaceae & 里白科 Gleicheniaceae \\
\hline 光里白 Diplopterygium laevissimum (Christ) Nakai & 三裂缝 Trilete & 里白科 Gleichniaceae & 里白科 Gleicheniaceae \\
\hline 绿里白 Diplopterygium maximum (Ching) Ching \& H. S. Kung & 三裂缝 Trilete & 里白科 Gleichniaceae & 里白科 Gleicheniaceae \\
\hline 红毛里白 Diplopterygium rufopilosum (Ching \& P. S. Chiu) & 三裂缝 Trilete & 里白科 Gleichniaceae & 里白科 Gleicheniaceae \\
\hline \multicolumn{4}{|l|}{ Ching ex X. C. Zhang } \\
\hline \multicolumn{3}{|l|}{ Zhang } & 里白科 Gleicheniaceae \\
\hline 假芒萁 Sticherus laevigatus C. Presl & 三裂缝 Trilete & 里白科 Gleichniaceae & 里白科 Gleicheniaceae \\
\hline 燕尾蕨 Cheiropleuria bicuspis (Blume) C. Presl & 三裂缝 Trilete & 燕尾蕨科 Cheiropleuriaceae & 双扇硕科 Dipteridaceae \\
\hline 整叶燕尾嵚 Cheiropleuria integrifolia (D. C. Eaton ex Hook.) & 三裂缝 Trilete & 燕尾蕨科 Cheiropleuriaceae & 双扇硕科 Dipteridaceae \\
\hline \multicolumn{4}{|l|}{ M. Kato, Y. Yatabe, Sahashi \& N. Murak. } \\
\hline 中华双扇蕨 Dipteris chinensis Christ & 单裂缝 Monolete & 双扇蒴科 Dipteridaceae & 双扇荻科 Dipteridaceae \\
\hline 双扇鄀 Dipteris conjugata (Kaulf. ) Reinw. & 单裂缝 Monolete & 双扇嵚科 Dipteridaceae & 双扇蕨科 Dipteridaceae \\
\hline 喜马拉雅双扇蕨 Dipteris wallichii (R. Brown) T. Moore & 单裂缝 Monolete & 双扇蒴科 Dipteridaceae & 双扇蒴科 Dipteridaceae \\
\hline 海南海金沙 Lygodium circinnatum (Burm.) Sw. & 三裂缝 Trilete & 海金沙科 Lygodiaceae & 海金沙科 Lygodiaceae \\
\hline
\end{tabular}




\begin{tabular}{|c|c|c|c|}
\hline $\begin{array}{l}\text { 物种 } \\
\text { Species }\end{array}$ & $\begin{array}{l}\text { 孢子裂缝类型 } \\
\text { Spore apertures styles }\end{array}$ & $\begin{array}{l}\text { 科名 Family (秦仁 } \\
\text { 昌,1978a, b) }\end{array}$ & $\begin{array}{l}\text { 科名 Family (Smith et al., } \\
\text { 2006; Christenhusz et al, } \\
\text { 2011; 张宪春等, 2013) }\end{array}$ \\
\hline 曲轴海金沙 Lygodium flexuosum (L.) Sw. & 三裂缝 Trilete & 海金沙科 Lygodiaceae & 海金沙科 Lygodiaceae \\
\hline 海金沙 Lygodium japonicum (Thunb.) Sw. & 三裂缝 Trilete & 海金沙科 Lygodiaceae & 海金沙科 Lygodiaceae \\
\hline 掌叶海金沙 Lygodium longifolium (Willd.) Sw. & 三裂缝 Trilete & 海金沙科 Lygodiaceae & 海金沙科 Lygodiaceae \\
\hline 网脉海金沙 Lygodium merrillii Copel. & 三裂缝 Trilete & 海金沙科 Lygodiaceae & 海金沙科 Lygodiaceae \\
\hline 小叶海金沙 Lygodium microphyllum (Cav.) R.Br & 三裂缝 Trilete & 海金沙科 Lygodiaceae & 海金沙科 Lygodiaceae \\
\hline 羽裂海金沙 Lygodium polystachyum Wall. ex T. Moore & 三裂缝 Trilete & 海金沙科 Lygodiaceae & 海金沙科 Lygodiaceae \\
\hline 柳叶海金沙 Lygodium salicifolium C. Presl & 三裂缝 Trilete & 海金沙科 Lygodiaceae & 海金沙科 Lygodiaceae \\
\hline 云南海金沙 Lygodium yunnanense Ching & 三裂缝 Trilete & 海金沙科 Lygodiaceae & 海金沙科 Lygodiaceae \\
\hline 分枝莎草硕 Schizaea dichotoma (L.) Sm. & 单裂缝 Monolete & 莎草葓科 Schizaeaceae & 莎草硕科 Schizaeaceae \\
\hline 莎草茨 Schizaea digitata (L.) Sw. & 单裂缝 Monolete & 莎草葓科 Schizaeaceae & 莎草蓱科 Schizaeaceae \\
\hline 埃及蘋 Marsilea aegyptiaca Willd. & 三裂缝 Trilete & 蘋科 Marsileaceae & 蘋科 Marsileaceae \\
\hline 南国田字草 Marsilea crenata C. Presl & 三裂缝 Trilete & 蘋科 Marsileaceae & 蘋科 Marsileaceae \\
\hline 蘋 Marsilea quadrifolia L. & 三裂缝 Trilete & 蘋科 Marsileaceae & 蘋科 Marsileaceae \\
\hline 细叶满江红 Azolla filiculoides Lam. & 三裂缝 Trilete & 满江红科 Azollaceae & 槐叶蘋科 Salviniaceae \\
\hline 满江红 Azolla pinnata ssp. asiatica R. M. K. Saunders \& K. & 三裂缝 Trilete & 满江红科 Azollaceae & 槐叶蘋科 Salviniaceae \\
\hline \multicolumn{4}{|l|}{ Fowler } \\
\hline 勺叶槐叶蘋 Salvinia cuculata Roxb. ex Bory & 三裂缝 Trilete & 槐叶蘋科 Salviniaceae & 槐叶蘋科 Salviniaceae \\
\hline 槐叶蘋 Salvinia natans (L.) All. & 三裂缝 Trilete & 槐叶蘋科 Salviniaceae & 槐叶蘋科 Salviniaceae \\
\hline 瘤足蕨 Plagiogyria adnata (Blume) Bedd. & 三裂缝 Trilete & 瘤足蕨科 Plagiogyriaceae & 瘤足蕨科 Plagiogyriaceae \\
\hline 峨嵋瘤足瞢 Plagiogyria assurgens Christ & 三裂缝 Trilete & 瘤足蕨科 Plagiogyriaceae & 瘤足蕨科 Plagiogyriaceae \\
\hline 华中瘤足蕨 Plagiogyria euphlebia (Kunze) Mett. & 三裂缝 Trilete & 瘤足蕨科 Plagiogyriaceae & 瘤足蕨科 Plagiogyriaceae \\
\hline 镰羽瘤足蒴 Plagiogyria falcata Copel. & 三裂缝 Trilete & 瘤足蕨科 Plagiogyriaceae & 瘤足蕨科 Plagiogyriaceae \\
\hline
\end{tabular}




\begin{tabular}{|c|c|c|c|}
\hline $\begin{array}{l}\text { 物种 } \\
\text { Species }\end{array}$ & $\begin{array}{l}\text { 孢子裂缝类型 } \\
\text { Spore apertures styles }\end{array}$ & $\begin{array}{l}\text { 科名 Family (秦仁 } \\
\text { 昌,1978a,b) }\end{array}$ & $\begin{array}{l}\text { 科名 Family (Smith et al., } \\
\text { 2006; Christenhusz et al, } \\
\text { 2011; 张宪春等, 2013) }\end{array}$ \\
\hline 粉背瘤足葓 Plagiogyria glauca (Blume) Mett. & 三裂缝 Trilete & 瘤足蕨科 Plagiogyriaceae & 瘤足蕨科 Plagiogyriaceae \\
\hline 华东瘤足蒴 Plagiogyria japonica Nakai & 三裂缝 Trilete & 瘤足偋科 Plagiogyriaceae & 瘤足葓科 Plagiogyriaceae \\
\hline 密羽瘤足葓 Plagiogyria pycnophylla (Kunze) Mett. & 三裂缝 Trilete & 瘤足偋科 Plagiogyriaceae & 瘤足烣科 Plagiogyriaceae \\
\hline 耳形瘤足葓 Plagiogyria stenoptera (Hance) Diels & 三裂缝 Trilete & 瘤足菜科 Plagiogyriaceae & 瘤足硕科 Plagiogyriaceae \\
\hline 金毛狗蒴 Cibotium barometz (L.) J.Sm. & 三裂缝 Trilete & 蚌壳蓱科 Dicksoniaceae & 金毛狗科 cibotiaceae \\
\hline 台湾金狗毛萨 Cibotium taiwanense C. M. Kuo & 三裂缝 Trilete & 蚌壳蒴科 Dicksoniaceae & 金毛狗科 cibotiaceae \\
\hline 毛叶杪椤 Alsophila andersonii Scott ex Bedd. & 三裂缝 Trilete & 杪椤科 Cyatheaceae & 杪椤科 Cyatheaceae \\
\hline 滇南杪椤 Alsophila austro-yunnanensis S. G. Lu & 三裂缝 Trilete & 杪椤科 Cyatheaceae & 桫椤科 Cyatheaceae \\
\hline 中华杪椤 Alsophila costularis Baker & 三裂缝 Trilete & 杪椤科 Cyatheaceae & 杪椤科 Cyatheaceae \\
\hline 粗齿杪椤 Alsophila denticulata Baker & 三裂缝 Trilete & 杪椤科 Cyatheaceae & 杪椤科 Cyatheaceae \\
\hline 兰屿杪椤 Alsophila fenicis (Copel.) C. Chr. & 三裂缝 Trilete & 杪椤科 Cyatheaceae & 杪椤科 Cyatheaceae \\
\hline 大叶黑杪椤 Alsophila gigantea Wall. ex Hook. & 三裂缝 Trilete & 杪椤科 Cyatheaceae & 杪椤科 Cyatheaceae \\
\hline 西亚杪椤 Alsophila khasyana T. Moore ex Kuhn & 三裂缝 Trilete & 杪椤科 Cyatheaceae & 杪椤科 Cyatheaceae \\
\hline 阴生杪椤 Alsophila latebrosa Wall. ex Hook. & 三裂缝 Trilete & 椒椤科 Cyatheaceae & 椒椤科 Cyatheaceae \\
\hline 南洋杪椤 Alsophila loheri (Christ) R. M. Tryon & 三裂缝 Trilete & 杪椤科 Cyatheaceae & 杪椤科 Cyatheaceae \\
\hline 小黑杪椤 Alsophila metteniana Hance & 三裂缝 Trilete & 杪椤科 Cyatheaceae & 杪椤科 Cyatheaceae \\
\hline 黑杪椤 Alsophila podophylla Hook. & 三裂缝 Trilete & 杪椤科 Cyatheaceae & 杪椤科 Cyatheaceae \\
\hline 杪椤 Alsophila spinulosa (Wall. ex Hook.) Tryon & 三裂缝 Trilete & 杪椤科 Cyatheaceae & 杪椤科 Cyatheaceae \\
\hline 白杪椤 Sphaeropteris brunoniana (Hook.) R. M. Tryon & 三裂缝 Trilete & 杪椤科 Cyatheaceae & 杪椤科 Cyatheaceae \\
\hline 笔筒树 Sphaeropteris lepifera (J. Sm. ex Hook.) R. M. Tryon & 三裂缝 Trilete & 杪椤科 Cyatheaceae & 杪椤科 Cyatheaceae \\
\hline 华南鳞始蒴 Lindsaea austrosinica Ching & 三裂缝 Trilete & 鳞始蒴科 Lindsaeaceae & 鳞始蕨科 Lindsaeaceae \\
\hline 钱氏鳞始烣 Lindsaea chienii Ching & 三裂缝 Trilete & 鳞始䔊科 Lindsaeaceae & 鳞始蕨科 Lindsaeaceae \\
\hline
\end{tabular}


魏雪苹，张宪春．蒴类植物不同狍子裂缝类型在中国的分布格局. 生物多样性，2016，24(10)：1129-1134 http://www. biodiversity - science. net/CN/10. 17520/biods. 2016219

\begin{tabular}{|c|c|c|c|}
\hline $\begin{array}{l}\text { 物种 } \\
\text { Species }\end{array}$ & $\begin{array}{l}\text { 孢子裂缝类型 } \\
\text { Spore apertures styles }\end{array}$ & $\begin{array}{l}\text { 科名 Family (秦仁 } \\
\text { 昌,1978a, b) }\end{array}$ & $\begin{array}{l}\text { 科名 Family (Smith et al., } \\
\text { 2006; Christenhusz et al, } \\
\text { 2011; 张宪春等, 2013) }\end{array}$ \\
\hline 碎叶鳞始蕨 Lindsaea chingii C. Chr. & 三裂缝 Trilete & 鳞始葓科 Lindsaeaceae & 鳞始菜科 Lindsaeaceae \\
\hline 网脉鳞始蒴 Lindsaea cultrata (Willd.) Sw. & 三裂缝 Trilete & 鳞始蕨科 Lindsaeaceae & 鳞始蕨科 Lindsaeaceae \\
\hline 线片鳞始蕨 Lindsaea eberhardtii (Christ) K. U. Kramer & 三裂缝 Trilete & 鳞始葓科 Lindsaeaceae & 鳞始蕨科 Lindsaeaceae \\
\hline 剑叶鳞始菜 Lindsaea ensifolia Sw. & 三裂缝 Trilete & 鳞始硕科 Lindsaeaceae & 鳞始硕科 Lindsaeaceae \\
\hline 异叶鳞始痰 Lindsaea heterophylla Dryand. & 三裂缝 Trilete & 鳞始蕨科 Lindsaeaceae & 鳞始葓科 Lindsaeaceae \\
\hline 爪哇鳞始痰 Lindsaea javanensis Blume & 三裂缝 Trilete & 鳞始蕨科 Lindsaeaceae & 鳞始葓科 Lindsaeaceae \\
\hline 细叶鳞始蕨 Lindsaea kawabatae Sa. Kurata & 三裂缝 Trilete & 鳞始葓科 Lindsaeaceae & 鳞始葓科 Lindsaeaceae \\
\hline 两广鳞始菜 Lindsaea liankwangensis Ching & 三裂缝 Trilete & 鳞始葓科 Lindsaeaceae & 鳞始葓科 Lindsaeaceae \\
\hline 海南深裂鳞始蕨 Lindsaea lobata var. hainaniana K. U. Kramer & 三裂缝 Trilete & 鳞始葓科 Lindsaeaceae & 鳞始蕨科 Lindsaeaceae \\
\hline 长柄鳞始蒝 Lindsaea longipetiolata Ching & 三裂缝 Trilete & 鳞始蕨科 Lindsaeaceae & 鳞始硕科 Lindsaeaceae \\
\hline 亮叶鳞始濒 Lindsaea lucida Blume & 三裂缝 Trilete & 鳞始蒝科 Lindsaeaceae & 鳞始硕科 Lindsaeaceae \\
\hline 蔓生鳞始蒴 Lindsaea merrillii Copel. & 三裂缝 Trilete & 鳞始葓科 Lindsaeaceae & 鳞始蕨科 Lindsaeaceae \\
\hline $\begin{array}{l}\text { 攀缘鳞始茨 Lindsaea merrillii var. yaeyamensis (Tagawa) W. } \\
\text { C. Shieh }\end{array}$ & 三裂缝 Trilete & 鳞始葓科 Lindsaeaceae & 鳞始葓科 Lindsaeaceae \\
\hline 鳞始硕 Lindsaea odorata Roxb. & 三裂缝 Trilete & 鳞始葓科 Lindsaeaceae & 鳞始蕨科 Lindsaeaceae \\
\hline $\begin{array}{l}\text { 日本鳞始蕨 Lindsaea odorata var. japonica (Baker) K. U. } \\
\text { Kramer }\end{array}$ & 三裂缝 Trilete & 鳞始蕨科 Lindsaeaceae & 鳞始蕨科 Lindsaeaceae \\
\hline 团叶鳞始蕨 Lindsaea orbiculata (Lam.) Mett. & 三裂缝 Trilete & 鳞始蕨科 Lindsaeaceae & 鳞始葓科 Lindsaeaceae \\
\hline $\begin{array}{l}\text { 润片鳞始蕨 Lindsaea orbiculata var. recedens (Ching) W. C. } \\
\text { Shieh }\end{array}$ & 三裂缝 Trilete & 鳞始蕨科 Lindsaeaceae & 鳞始鄺科 Lindsaeaceae \\
\hline $\begin{array}{l}\text { 方柄鳞始葓 Lindsaea securifolia var. kusukusensis (Hayata) W. } \\
\text { C. Shieh }\end{array}$ & 三裂缝 Trilete & 鳞始葓科 Lindsaeaceae & 鳞始蒝科 Lindsaeaceae \\
\hline
\end{tabular}




\begin{tabular}{|c|c|c|c|}
\hline $\begin{array}{l}\text { 物种 } \\
\text { Species }\end{array}$ & $\begin{array}{l}\text { 孢子裂缝类型 } \\
\text { Spore apertures styles }\end{array}$ & $\begin{array}{l}\text { 科名 Family (秦仁 } \\
\text { 昌,1978a, b) }\end{array}$ & $\begin{array}{l}\text { 科名 Family (Smith et al., } \\
\text { 2006; Christenhusz et al, } \\
\text { 2011; 张宪春等, 2013) }\end{array}$ \\
\hline 阔片乌蕨 Sphenomeris biflora (Kaulf.) Tagawa & 单裂缝 Monolete & 鳞始葓科 Lindsaeaceae & 鳞始蕨科 Lindsaeaceae \\
\hline 乌䕬 Sphenomeris chinensis (L.) Maxon & 单裂缝 Monolete & 鳞始蕨科 Lindsaeaceae & 鳞始硕科 Lindsaeaceae \\
\hline 细叶达边硕 Tapeinidium gracile (Blume) Alderw. & 单裂缝 Monolete & 鳞始蕨科 Lindsaeaceae & 鳞始蕨科 Lindsaeaceae \\
\hline 达边蒝 Tapeinidium pinnatum (Cav.) C. Chr. & 单裂缝 Monolete & 鳞始葓科 Lindsaeaceae & 鳞始蕨科 Lindsaeaceae \\
\hline 二羽达边瞢 Tapeinidium pinnatum var. biserratum (Blume) W. & 单裂缝 Monolete & 鳞始蕨科 Lindsaeaceae & 鳞始硕科 Lindsaeaceae \\
\hline \multicolumn{4}{|l|}{ C. Shieh } \\
\hline 顶生碗茨 Dennstaedtia appendiculata (Wall.) J. Sm. & 三裂缝 Trilete & 碗硕科 Dennstaedtiaceae & 碗蕨科 Dennstaedtiaceae \\
\hline 峨山碗菜 Dennstaedtia elwesii (Bedd.) Bedd. & 三裂缝 Trilete & 碗濒科 Dennstaedtiaceae & 碗硕科 Dennstaedtiaceae \\
\hline 台湾碗嵚 Dennstaedtia formosae Christ & 三裂缝 Trilete & 碗蕨科 Dennstaedtiaceae & 碗蕨科 Dennstaedtiaceae \\
\hline 细毛碗嵚 Dennstaedtia hirsuta (Sw.) Mett. ex Miq. & 三裂缝 Trilete & 碗蒴科 Dennstaedtiaceae & 碗蕨科 Dennstaedtiaceae \\
\hline 薄叶碗蒴 Dennstaedtia leptophylla Hayata & 三裂缝 Trilete & 碗蕨科 Dennstaedtiaceae & 碗蕨科 Dennstaedtiaceae \\
\hline 乌柄碗蕨 Dennstaedtia melanostipes Ching & 三裂缝 Trilete & 碗蕨科 Dennstaedtiaceae & 碗蕨科 Dennstaedtiaceae \\
\hline 碗䕬 Dennstaedtia scabra (Wall. ex Hook.) T. Moore & 三裂缝 Trilete & 碗蕨科 Dennstaedtiaceae & 碗蕨科 Dennstaedtiaceae \\
\hline 光叶碗荻 Dennstaedtia scabra var. glabrescens (Ching) C. Chr. & 三裂缝 Trilete & 碗蕨科 Dennstaedtiaceae & 碗蕨科 Dennstaedtiaceae \\
\hline 刺柄碗荻 Dennstaedtia scandens (Blume) T. Moore & 三裂缝 Trilete & 碗蕨科 Dennstaedtiaceae & 碗蕨科 Dennstaedtiaceae \\
\hline 溪洞碗硕 Dennstaedtia wilfordii $\quad$ (T. Moore) Christ & 三裂缝 Trilete & 碗蕨科 Dennstaedtiaceae & 碗蕨科 Dennstaedtiaceae \\
\hline 浅杯鳞盖蒴 Microlepia ampla Ching & 三裂缝 Trilete & 碗蕨科 Dennstaedtiaceae & 碗蕨科 Dennstaedtiaceae \\
\hline 光叶鳞盖蕨 Microlepia calvescens (Wall. ex Hook.) C. Presl & 三裂缝 Trilete & 碗鄀科 Dennstaedtiaceae & 碗蕨科 Dennstaedtiaceae \\
\hline 羽叶鳞盖硕 Microlepia calvescens var. intramarginalis & 三裂缝 Trilete & 碗蕨科 Dennstaedtiaceae & 碗蕨科 Dennstaedtiaceae \\
\hline \multicolumn{4}{|l|}{ (Tagawa) W. C. Shieh } \\
\hline 尾头鳞盖藓 Microlepia caudifolia Ching & 三裂缝 Trilete & 碗蕨科 Dennstaedtiaceae & 碗鄀科 Dennstaedtiaceae \\
\hline 秦氏鳞盖蕨 Microlepia chingii B. S. Wang & 三裂缝 Trilete & 碗葓科 Dennstaedtiaceae & 碗蕨科 Dennstaedtiaceae \\
\hline
\end{tabular}




\begin{tabular}{|c|c|c|c|}
\hline $\begin{array}{l}\text { 物种 } \\
\text { Species }\end{array}$ & $\begin{array}{l}\text { 孢子裂缝类型 } \\
\text { Spore apertures styles }\end{array}$ & $\begin{array}{l}\text { 科名 Family (秦仁 } \\
\text { 昌,1978a, b) }\end{array}$ & $\begin{array}{l}\text { 科名 Family (Smith et al., } \\
\text { 2006; Christenhusz et al, } \\
\text { 2011; 张宪春等, 2013) }\end{array}$ \\
\hline 赤水鳞盖蕨 Microlepia chishuiensis P. S. Wang & 三裂缝 Trilete & 碗蕨科 Dennstaedtiaceae & 碗锁科 Dennstaedtiaceae \\
\hline 金果鳞盖蒴 Microlepia chrysocarpa Ching & 三裂缝 Trilete & 碗䕬科 Dennstaedtiaceae & 碗硕科 Dennstaedtiaceae \\
\hline 革质鳞盖蕨 Microlepia crassa Ching & 三裂缝 Trilete & 碗蕨科 Dennstaedtiaceae & 碗蕨科 Dennstaedtiaceae \\
\hline 圆齿鳞盖嵚 Microlepia crenata Ching & 三裂缝 Trilete & 碗茨科 Dennstaedtiaceae & 碗蕨科 Dennstaedtiaceae \\
\hline 隆脉鳞盖苵 Microlepia crenatoserrata Ching & 三裂缝 Trilete & 碗䕬科 Dennstaedtiaceae & 碗蕨科 Dennstaedtiaceae \\
\hline 正鳞盖荻 Microlepia critica Ching & 三裂缝 Trilete & 碗屏科 Dennstaedtiaceae & 碗蕨科 Dennstaedtiaceae \\
\hline 长托鳞盖䓡 Microlepia firma Mett. ex Kuhn & 三裂缝 Trilete & 碗葓科 Dennstaedtiaceae & 碗烣科 Dennstaedtiaceae \\
\hline 线羽鳞盖嵚 Microlepia formosana Ching & 三裂缝 Trilete & 碗颗科 Dennstaedtiaceae & 碗萍科 Dennstaedtiaceae \\
\hline 阴脉鳞盖蕨 Microlepia ganlanbaensis Ching & 三裂缝 Trilete & 碗蕨科 Dennstaedtiaceae & 碗蕨科 Dennstaedtiaceae \\
\hline 乔大鳞盖蕨 Microlepia gigantea Ching & 三裂缝 Trilete & 碗蕨科 Dennstaedtiaceae & 碗蕨科 Dennstaedtiaceae \\
\hline 光盖鳞盖蕨 Microlepia glabra Ching & 三裂缝 Trilete & 碗嵚科 Dennstaedtiaceae & 碗蕨科 Dennstaedtiaceae \\
\hline 海南鳞盖蕨 Microlepia hainanensis Ching & 三裂缝 Trilete & 碗蕨科 Dennstaedtiaceae & 碗蕨科 Dennstaedtiaceae \\
\hline 华南鳞盖蕨 Microlepia hancei Prantl & 三裂缝 Trilete & 碗蕨科 Dennstaedtiaceae & 碗蕨科 Dennstaedtiaceae \\
\hline 草叶鳞盖鄀 Microlepia herbacea Ching \& C. Chr. & 三裂缝 Trilete & 碗屏科 Dennstaedtiaceae & 碗蕨科 Dennstaedtiaceae \\
\hline 刚毛鳞盖硕 Microlepia hispida C. Chr. & 三裂缝 Trilete & 碗蕨科 Dennstaedtiaceae & 碗鄀科 Dennstaedtiaceae \\
\hline 虎克鳞盖蕨 Microlepia hookeriana (Wall. ex Hook.) C. Presl & 三裂缝 Trilete & 碗蕨科 Dennstaedtiaceae & 碗蕨科 Dennstaedtiaceae \\
\hline 中型鳞盖蕨 Microlepia intermedia Ching & 三裂缝 Trilete & 碗蒴科 Dennstaedtiaceae & 碗蕨科 Dennstaedtiaceae \\
\hline 西南鳞盖睰 Microlepia khasiyana (Hook.) C. Presl & 三裂缝 Trilete & 碗屏科 Dennstaedtiaceae & 碗蕨科 Dennstaedtiaceae \\
\hline 克氏鳞盖蕨 Microlepia krameri C. M. Kuo & 三裂缝 Trilete & 碗蕨科 Dennstaedtiaceae & 碗蕨科 Dennstaedtiaceae \\
\hline 毛阔叶鳞盖蕨 Microlepia kurzii (C. B. Clarke) Bedd. & 三裂缝 Trilete & 碗茨科 Dennstaedtiaceae & 碗烣科 Dennstaedtiaceae \\
\hline 黎平鳞盖硕 Microlepia lipingensis P. S. Wang & 三裂缝 Trilete & 碗屏科 Dennstaedtiaceae & 碗蕨科 Dennstaedtiaceae \\
\hline 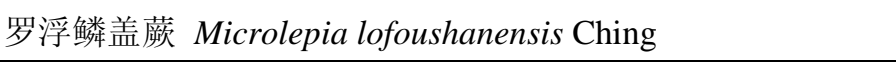 & 三裂缝 Trilete & 碗蒴科 Dennstaedtiaceae & 碗蕨科 Dennstaedtiaceae \\
\hline
\end{tabular}




\begin{tabular}{|c|c|c|c|}
\hline $\begin{array}{l}\text { 物种 } \\
\text { Species }\end{array}$ & $\begin{array}{l}\text { 孢子裂缝类型 } \\
\text { Spore apertures styles }\end{array}$ & $\begin{array}{l}\text { 科名 Family (秦仁 } \\
\text { 昌,1978a, b) }\end{array}$ & $\begin{array}{l}\text { 科名 Family (Smith et al., } \\
\text { 2006; Christenhusz et al, } \\
\text { 2011; 张宪春等, 2013) }\end{array}$ \\
\hline 边缘鳞盖蕒 Microlepia marginata (Panz.) C. Chr. & 三裂缝 Trilete & 碗屏科 Dennstaedtiaceae & 碗蕨科 Dennstaedtiaceae \\
\hline 二回羽状变种 Microlepia marginata var. bipinnata Makino & 三裂缝 Trilete & 碗䕬科 Dennstaedtiaceae & 碗硕科 Dennstaedtiaceae \\
\hline 毛叶鳞盖菜 Microlepia marginata var. villosa (C. Presl) Y. C. & 三裂缝 Trilete & 碗蕨科 Dennstaedtiaceae & 碗蕨科 Dennstaedtiaceae \\
\hline \multicolumn{4}{|l|}{$\mathrm{Wu}$} \\
\hline 岭南鳞盖媭 Microlepia matthewii Christ & 三裂缝 Trilete & 碗烣科 Dennstaedtiaceae & 碗嵚科 Dennstaedtiaceae \\
\hline 墨脱鳞盖蔴 Microlepia medogensis Ching \& Y. X. Lin & 三裂缝 Trilete & 碗烣科 Dennstaedtiaceae & 碗蕨科 Dennstaedtiaceae \\
\hline 膜质鳞盖嵚 Microlepia membranacea B. S. Wang & 三裂缝 Trilete & 碗葓科 Dennstaedtiaceae & 碗烣科 Dennstaedtiaceae \\
\hline 皖南鳞盖荻 Microlepia modesta Ching & 三裂缝 Trilete & 碗薕科 Dennstaedtiaceae & 碗蕨科 Dennstaedtiaceae \\
\hline 团羽鳞盖蕨 Microlepia obtusiloba Hayata & 三裂缝 Trilete & 碗蕨科 Dennstaedtiaceae & 碗蕨科 Dennstaedtiaceae \\
\hline 峨眉鳞盖蕨 Microlepia omeiensis Ching & 三裂缝 Trilete & 碗屏科 Dennstaedtiaceae & 碗蕨科 Dennstaedtiaceae \\
\hline 淡秆鳞盖藃 Microlepia pallida Ching & 三裂缝 Trilete & 碗烣科 Dennstaedtiaceae & 碗蕨科 Dennstaedtiaceae \\
\hline 多毛鳞盖蕨 Microlepia pilosissima Ching & 三裂缝 Trilete & 碗蕨科 Dennstaedtiaceae & 碗蕨科 Dennstaedtiaceae \\
\hline 褐毛鳞盖蕨 Microlepia pilosula C. Presl & 三裂缝 Trilete & 碗茨科 Dennstaedtiaceae & 碗蕨科 Dennstaedtiaceae \\
\hline 阔叶鳞盖葓 Microlepia platyphylla (D. Don) J. Sm. & 三裂缝 Trilete & 碗烣科 Dennstaedtiaceae & 碗蕨科 Dennstaedtiaceae \\
\hline 假粗毛鳞盖蕨 Microlepia pseudostrigosa Makino & 三裂缝 Trilete & 碗蕨科 Dennstaedtiaceae & 碗蕨科 Dennstaedtiaceae \\
\hline 斜方鳞盖蕨 Microlepia rhomboidea C. Presl & 三裂缝 Trilete & 碗嵚科 Dennstaedtiaceae & 碗濒科 Dennstaedtiaceae \\
\hline 深杯鳞盖鄀 Microlepia scyphoformis Ching \& Chu H. Wang & 三裂缝 Trilete & 碗烣科 Dennstaedtiaceae & 碗蕨科 Dennstaedtiaceae \\
\hline 热带鳞盖蕨 Microlepia speluncae (L.) T. Moore & 三裂缝 Trilete & 碗屏科 Dennstaedtiaceae & 碗蕨科 Dennstaedtiaceae \\
\hline 广西鳞盖蒴 Microlepia straminea Ching & 三裂缝 Trilete & 碗葓科 Dennstaedtiaceae & 碗烣科 Dennstaedtiaceae \\
\hline 粗毛鳞盖荻 Microlepia strigosa (Thunb.) C. Presl & 三裂缝 Trilete & 碗蕨科 Dennstaedtiaceae & 碗蕨科 Dennstaedtiaceae \\
\hline 滇西鳞盖鄀 Microlepia subspeluncae Ching & 三裂缝 Trilete & 碗烣科 Dennstaedtiaceae & 碗鄀科 Dennstaedtiaceae \\
\hline 亚粗毛鳞盖蕨 Microlepia substrigosa Tagawa & 三裂缝 Trilete & 碗蕨科 Dennstaedtiaceae & 碗蕨科 Dennstaedtiaceae \\
\hline
\end{tabular}




\begin{tabular}{|c|c|c|c|}
\hline $\begin{array}{l}\text { 物种 } \\
\text { Species }\end{array}$ & $\begin{array}{l}\text { 孢子裂缝类型 } \\
\text { Spore apertures styles }\end{array}$ & $\begin{array}{l}\text { 科名 Family (秦仁 } \\
\text { 昌,1978a, b) }\end{array}$ & $\begin{array}{l}\text { 科名 Family (Smith et al., } \\
\text { 2006; Christenhusz et al, } \\
\text { 2011; 张宪春等, 2013) }\end{array}$ \\
\hline 尖山鳞盖鄀 Microlepia subtrichosticha Ching & 三裂缝 Trilete & 碗䯾科 Dennstaedtiaceae & 碗烣科 Dennstaedtiaceae \\
\hline 四川鳞盖葓 Microlepia szechuanica Ching & 三裂缝 Trilete & 碗蒴科 Dennstaedtiaceae & 碗蒴科 Dennstaedtiaceae \\
\hline 台湾鳞盖蕨 Microlepia taiwaniana Tagawa & 三裂缝 Trilete & 碗蕨科 Dennstaedtiaceae & 碗蕨科 Dennstaedtiaceae \\
\hline 膜叶鳞盖蕨 Microlepia tenella Ching & 三裂缝 Trilete & 碗濒科 Dennstaedtiaceae & 碗蕨科 Dennstaedtiaceae \\
\hline 薄叶鳞盖媭 Microlepia tenera Christ & 三裂缝 Trilete & 碗濒科 Dennstaedtiaceae & 碗颗科 Dennstaedtiaceae \\
\hline 针毛鳞盖蔴 Microlepia trapeziformis (Roxb.) Kuhn & 三裂缝 Trilete & 碗蕨科 Dennstaedtiaceae & 碗鄀科 Dennstaedtiaceae \\
\hline 毛果鳞盖莜 Microlepia trichocarpa Hayata & 三裂缝 Trilete & 碗蒴科 Dennstaedtiaceae & 碗偋科 Dennstaedtiaceae \\
\hline 亮毛鳞盖硕 Microlepia trichoclada Ching & 三裂缝 Trilete & 碗硕科 Dennstaedtiaceae & 碗硕科 Dennstaedtiaceae \\
\hline 毛囊鳞盖蕨 Microlepia trichosora Ching & 三裂缝 Trilete & 碗蕨科 Dennstaedtiaceae & 碗蕨科 Dennstaedtiaceae \\
\hline 浓毛鳞盖萨 Microlepia tripinnata Ching & 三裂缝 Trilete & 碗濒科 Dennstaedtiaceae & 碗蕨科 Dennstaedtiaceae \\
\hline 密毛鳞盖蕨 Microlepia villosa (D. Don) Ching & 三裂缝 Trilete & 碗硕科 Dennstaedtiaceae & 碗硕科 Dennstaedtiaceae \\
\hline 温塘鳞盖蕨 Microlepia wentongensis B. S. Wang & 三裂缝 Trilete & 碗蕨科 Dennstaedtiaceae & 碗蕨科 Dennstaedtiaceae \\
\hline 毛盖鳞盖蒴 Microlepia $\times$ hirtiindusiata P. S. Wang & 三裂缝 Trilete & 碗蕨科 Dennstaedtiaceae & 碗偋科 Dennstaedtiaceae \\
\hline 徭山稀子葓 Monachosorum elegans Ching & 三裂缝 Trilete & 稀子葓科 Monachosoraceae & 碗硕科 Dennstaedtiaceae \\
\hline 尾叶稀子㓹 Monachosorum flagellare (Maxim.) Hayata & 三裂缝 Trilete & 稀子蕨科 Monachosoraceae & 碗蕨科 Dennstaedtiaceae \\
\hline $\begin{array}{l}\text { 华中稀子蕂 Monachosorum flagellare var. nipponicum } \\
\text { (Makino) Tagawa }\end{array}$ & 三裂缝 Trilete & 稀子䯾科 Monachosoraceae & 碗嵚科 Dennstaedtiaceae \\
\hline 大叶稀子葓 Monachosorum subdigitatum (Blume) Kuhn & 三裂缝 Trilete & 稀子硕科 Monachosoraceae & 碗蕨科 Dennstaedtiaceae \\
\hline 岩穴蕨 Ptilopteris maximowiczii (Baker) Hance & 三裂缝 Trilete & 稀子蕨科 Monachosoraceae & 碗鄀科 Dennstaedtiaceae \\
\hline 台湾曲轴䝫 Paesia taiwanensis W. C. Shieh & 单裂缝 Monolete & 蕨科 Pteridiaceae & 碗蕨科 Dennstaedtiaceae \\
\hline $\begin{array}{l}\text { 蕨 Pteridium aquilinum var. latiusculum (Desv.) Underw. ex A. } \\
\text { Heller }\end{array}$ & 三裂缝 Trilete & 蕨科 Pteridiaceae & 碗嵚科 Dennstaedtiaceae \\
\hline
\end{tabular}




\begin{tabular}{|c|c|c|c|}
\hline $\begin{array}{l}\text { 物种 } \\
\text { Species }\end{array}$ & $\begin{array}{l}\text { 孢子裂缝类型 } \\
\text { Spore apertures styles }\end{array}$ & $\begin{array}{l}\text { 科名 Family (秦仁 } \\
\text { 昌,1978a, b) }\end{array}$ & $\begin{array}{l}\text { 科名 Family (Smith et al., } \\
\text { 2006; Christenhusz et al, } \\
\text { 2011; 张宪春等, 2013) }\end{array}$ \\
\hline 食偋 Pteridium esculentum (Forst.) Cokayne & 三裂缝 Trilete & 偋科 Pteridiaceae & 碗锁科 Dennstaedtiaceae \\
\hline 镰羽蒝 Pteridium falcatum Ching & 三裂缝 Trilete & 偋科 Pteridiaceae & 碗硕科 Dennstaedtiaceae \\
\hline 毛轴蕨 Pteridium revolutum (Blume) Nakai & 三裂缝 Trilete & 蕨科 Pteridiaceae & 碗蕨科 Dennstaedtiaceae \\
\hline 台湾姬菜 Hypolepis alte-gracillima Hayata & 单裂缝 Monolete & 姬薕科 Hypolepidaceae & 碗蕨科 Dennstaedtiaceae \\
\hline 大姬蕨 Hypolepis gigantea Ching & 单裂缝 Monolete & 姬蕨科 Hypolepidaceae & 碗蕨科 Dennstaedtiaceae \\
\hline 腺毛姬蕨 Hypolepis glandulosopilosa H. G. Zhou \& Hua Li & 单裂缝 Monolete & 姬鄀科 Hypolepidaceae & 碗蕨科 Dennstaedtiaceae \\
\hline 姬薮 Hypolepis punctata (Thunb.) Mett. ex Kuhn & 单裂缝 Monolete & 姬葓科 Hypolepidaceae & 碗烣科 Dennstaedtiaceae \\
\hline 粗壮姬硕 Hypolepis robusta W. M. Chu & 单裂缝 Monolete & 姬颐科 Hypolepidaceae & 碗萍科 Dennstaedtiaceae \\
\hline 栗硕 Histiopteris incisa (Thunb.) J. Sm. & 单裂缝 Monolete & 凤尾蕨科 Pteridaceae & 碗蕨科 Dennstaedtiaceae \\
\hline 卤蕨 Acrostichum aureum $\mathrm{L}$. & 三裂缝 Trilete & 卤偋科 Acrostichaceae & 凤尾烣科 Pteridaceae \\
\hline 尖叶卤硕 Acrostichum speciosum Willd. & 三裂缝 Trilete & 卤蒝科 Acrostichaceae & 凤尾葓科 Pteridaceae \\
\hline 粗梗水荻 Ceratopteris pteridoides (Hook.) Hieron. & 三裂缝 Trilete & 水蕒科 Parkeriaceae & 凤尾蕨科 Pteridaceae \\
\hline 水兴 Ceratopteris thalictroides (L.) Brongn. & 三裂缝 Trilete & 水蕨科 Parkeriaceae & 凤尾罝科 Pteridaceae \\
\hline 猪鬛风尾蒝 Pteris actiniopteroides Christ & 三裂缝 Trilete & 凤尾㸝科 Pteridaceae & 凤尾葓科 Pteridaceae \\
\hline 红秆风尾荻 Pteris amoena Blume & 三裂缝 Trilete & 凤尾蕨科 Pteridaceae & 凤尾蕨科 Pteridaceae \\
\hline 细叶风尾茨 Pteris angustipinna Tagawa & 三裂缝 Trilete & 凤尾嵚科 Pteridaceae & 凤尾瞢科 Pteridaceae \\
\hline 线裂凤尾媭 Pteris angustipinnula Ching \& S. H. Wu & 三裂缝 Trilete & 凤尾烣科 Pteridaceae & 凤尾媭科 Pteridaceae \\
\hline 紫轴风尾鳜 Pteris aspericaulis Wall. ex Agardh & 三裂缝 Trilete & 凤尾蕨科 Pteridaceae & 凤尾嵚科 Pteridaceae \\
\hline 高原凤尾蕨 Pteris aspericaulis var. cuspigera Ching & 三裂缝 Trilete & 凤尾蕨科 Pteridaceae & 凤尾蕨科 Pteridaceae \\
\hline 高山风尾嵚 Pteris aspericaulis var. subindivisa (Clarke) Ching & 三裂缝 Trilete & 凤尾烣科 Pteridaceae & 凤尾葓科 Pteridaceae \\
\hline 三色凤尾嵚 Pteris aspericaulis var. tricolor Moore & 三裂缝 Trilete & 凤尾蕨科 Pteridaceae & 凤尾蒴科 Pteridaceae \\
\hline 华南风尾嵚 Pteris austrosinica (Ching) Ching & 三裂缝 Trilete & 凤尾嵚科 Pteridaceae & 凤尾锁科 Pteridaceae \\
\hline
\end{tabular}




\begin{tabular}{|c|c|c|c|}
\hline $\begin{array}{l}\text { 物种 } \\
\text { Species }\end{array}$ & $\begin{array}{l}\text { 孢子裂缝类型 } \\
\text { Spore apertures styles }\end{array}$ & $\begin{array}{l}\text { 科名 Family (秦仁 } \\
\text { 昌,1978a, b) }\end{array}$ & $\begin{array}{l}\text { 科名 Family (Smith et al., } \\
\text { 2006; Christenhusz et al, } \\
\text { 2011; 张宪春等, 2013) }\end{array}$ \\
\hline 白沙风尾蕨 Pteris baksaensis Ching & 三裂缝 Trilete & 凤尾嵚科 Pteridaceae & 凤尾硕科 Pteridaceae \\
\hline 长柄凤尾嵚 Pteris bella Tagawa & 三裂缝 Trilete & 凤尾喏科 Pteridaceae & 凤尾葓科 Pteridaceae \\
\hline 狭眼凤尾蕨 Pteris biaurita L. & 三裂缝 Trilete & 凤尾葓科 Pteridaceae & 凤尾媭科 Pteridaceae \\
\hline 波密凤尾蒴 Pteris bomiensis Ching \& S. K. Wu & 三裂缝 Trilete & 凤尾嵚科 Pteridaceae & 凤尾嵚科 Pteridaceae \\
\hline 条纹凤尾蕨 Pteris cadieri Christ & 三裂缝 Trilete & 凤尾烣科 Pteridaceae & 凤尾葓科 Pteridaceae \\
\hline 海南凤尾嵚 Pteris cadieri var. hainanensis (Ching) S. H. Wu & 三裂缝 Trilete & 凤尾葓科 Pteridaceae & 凤尾葓科 Pteridaceae \\
\hline 密脉凤尾嵚 Pteris confertinervia Ching & 三裂缝 Trilete & 凤尾葓科 Pteridaceae & 凤尾锁科 Pteridaceae \\
\hline 厚叶风尾嵚 Pteris crassiuscula Ching \& Chu H. Wang & 三裂缝 Trilete & 凤尾烣科 Pteridaceae & 凤尾硕科 Pteridaceae \\
\hline 凤尾䕬 Pteris cretica var. intermedia (Christ) C. Chr. & 三裂缝 Trilete & 凤尾硕科 Pteridaceae & 凤尾锁科 Pteridaceae \\
\hline $\begin{array}{l}\text { 粗糙风尾蕨 Pteris cretica var. laeta (Wall. ex Ettingsh.) C. } \\
\text { Chr. \& Tardieu }\end{array}$ & \multicolumn{2}{|c|}{ Chr. \& Tardieu } & 凤尾蕨科 Pteridaceae \\
\hline 珠叶风尾蕨 Pteris cryptogrammoides Ching & 三裂缝 Trilete & 凤尾烣科 Pteridaceae & 凤尾锁科 Pteridaceae \\
\hline 指叶风尾嵚 Pteris dactylina Hook. & 三裂缝 Trilete & 凤尾嵚科 Pteridaceae & 凤尾锁科 Pteridaceae \\
\hline 成忠风尾菜 Pteris dangiana X. Y. Wang \& P. S. Wang & 三裂缝 Trilete & 凤尾㸝科 Pteridaceae & 凤尾硕科 Pteridaceae \\
\hline 多羽风尾茨 Pteris decrescens Christ & 三裂缝 Trilete & 凤尾烣科 Pteridaceae & 凤尾锁科 Pteridaceae \\
\hline 大明风尾蕨 Pteris decrescens var. parviloba (Christ) C. Chr. \& & 三裂缝 Trilete & 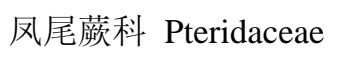 & 凤尾蕨科 Pteridaceae \\
\hline \multicolumn{4}{|l|}{ Tardieu } \\
\hline 岩凤尾蒴 Pteris deltodon Baker & 三裂缝 Trilete & 凤尾屏科 Pteridaceae & 凤尾葓科 Pteridaceae \\
\hline 刺齿半边旗 Pteris dispar Kunze & 三裂缝 Trilete & 凤尾嵚科 Pteridaceae & 凤尾锁科 Pteridaceae \\
\hline 疏羽半边旗 Pteris dissitifolia Baker & 三裂缝 Trilete & 凤尾烣科 Pteridaceae & 凤尾葓科 Pteridaceae \\
\hline 剑叶凤尾瞢 Pteris ensiformis Burm. f. & 三裂缝 Trilete & 凤尾烣科 Pteridaceae & 凤尾葓科 Pteridaceae \\
\hline 叉羽风尾蕨 Pteris ensiformis var. furcans Ching & 三裂缝 Trilete & 凤尾烣科 Pteridaceae & 凤尾葓科 Pteridaceae \\
\hline
\end{tabular}


魏雪苹，张宪春．蒴类植物不同狍子裂缝类型在中国的分布格局. 生物多样性，2016，24(10)：1129-1134 http://www. biodiversity - science. net/CN/10. 17520/biods. 2016219

\begin{tabular}{|c|c|c|c|}
\hline $\begin{array}{l}\text { 物种 } \\
\text { Species }\end{array}$ & $\begin{array}{l}\text { 孢子裂缝类型 } \\
\text { Spore apertures styles }\end{array}$ & $\begin{array}{l}\text { 科名 Family (秦仁 } \\
\text { 昌,1978a, b) }\end{array}$ & $\begin{array}{l}\text { 科名 Family (Smith et al., } \\
\text { 2006; Christenhusz et al, } \\
\text { 2011; 张宪春等, 2013) }\end{array}$ \\
\hline 少羽风尾硕 Pteris ensiformis var. merrillii (C. Chr.) S. H. Wu & 三裂缝 Trilete & 凤尾硕科 Pteridaceae & 凤尾菜科 Pteridaceae \\
\hline 白羽风尾嵚 Pteris ensiformis var. victoriae Baker & 三裂缝 Trilete & 凤尾蒴科 Pteridaceae & 凤尾蓱科 Pteridaceae \\
\hline 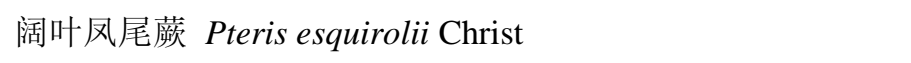 & 三裂缝 Trilete & 凤尾蕨科 Pteridaceae & 凤尾眇科 Pteridaceae \\
\hline $\begin{array}{l}\text { 刺柄凤尾蕨 Pteris esquirolii var. muricatula (Ching) Ching \& } \\
\text { S. H. Wu }\end{array}$ & 三裂缝 Trilete & 凤尾蕨科 Pteridaceae & 凤尾嵚科 Pteridaceae \\
\hline 溪边风尾嵚 Pteris excelsa Gaud. & 三裂缝 Trilete & 凤尾菜科 Pteridaceae & 凤尾蒴科 Pteridaceae \\
\hline 变异凤尾锁 Pteris excelsa var. inaequalis (Baker) S. H. Wu & 三裂缝 Trilete & 凤尾蕨科 Pteridaceae & 凤尾眇科 Pteridaceae \\
\hline 傅氏凤尾嵚 Pteris fauriei Hieron. & 三裂缝 Trilete & 凤尾蕨科 Pteridaceae & 凤尾蒝科 Pteridaceae \\
\hline 百越风尾粆 Pteris fauriei var. chinensis Ching \& S. H. Wu & 三裂缝 Trilete & 凤尾䓲科 Pteridaceae & 凤尾䕬科 Pteridaceae \\
\hline 疏裂风尾蒴 Pteris finotii Christ & 三裂缝 Trilete & 凤尾蕨科 Pteridaceae & 凤尾鰀科 Pteridaceae \\
\hline 美丽风尾硕 Pteris formosana Baker & 三裂缝 Trilete & 凤尾蒴科 Pteridaceae & 凤尾蒝科 Pteridaceae \\
\hline 鸡爪凤尾蒴 Pteris gallinopes Ching & 三裂缝 Trilete & 凤尾蕨科 Pteridaceae & 凤尾䕬科 Pteridaceae \\
\hline 细弱风尾蒴 Pteris gracillima Ching \& S. K. Wu & 三裂缝 Trilete & 凤尾蕨科 Pteridaceae & 凤尾蕨科 Pteridaceae \\
\hline 林下凤尾濒 Pteris grevilleana Wall. ex Agardh & 三裂缝 Trilete & 凤尾嵚科 Pteridaceae & 凤尾蒝科 Pteridaceae \\
\hline 白斑风尾蒝 Pteris grevilleana var. ornata Alderw. & 三裂缝 Trilete & 凤尾蕨科 Pteridaceae & 凤尾偋科 Pteridaceae \\
\hline 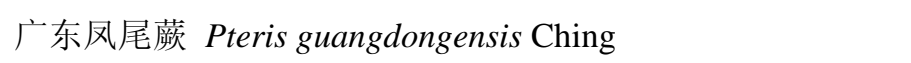 & 三裂缝 Trilete & 凤尾蒴科 Pteridaceae & 凤尾菜科 Pteridaceae \\
\hline 贵州凤尾嵚 Pteris guizhouensis Ching & 三裂缝 Trilete & 凤尾蕨科 Pteridaceae & 凤尾蒴科 Pteridaceae \\
\hline 狭叶凤尾蕨 Pteris henryi Christ & 三裂缝 Trilete & 凤尾䓲科 Pteridaceae & 凤尾蒴科 Pteridaceae \\
\hline 长尾风尾荻 Pteris heteromorpha Fée & 三裂缝 Trilete & 凤尾茨科 Pteridaceae & 凤尾偋科 Pteridaceae \\
\hline 胡氏凤尾菜 Pteris hui Ching & 三裂缝 Trilete & 凤尾䕋科 Pteridaceae & 凤尾菜科 Pteridaceae \\
\hline 全缘凤尾蒴 Pteris insignis Mett. ex Kuhn & 三裂缝 Trilete & 凤尾蕨科 Pteridaceae & 凤尾蒴科 Pteridaceae \\
\hline 城户凤尾蒴 Pteris kidoi Sa. Kurata & 三裂缝 Trilete & 凤尾蕨科 Pteridaceae & 凤尾蒴科 Pteridaceae \\
\hline
\end{tabular}




\begin{tabular}{|c|c|c|c|}
\hline $\begin{array}{l}\text { 物种 } \\
\text { Species }\end{array}$ & $\begin{array}{l}\text { 孢子裂缝类型 } \\
\text { Spore apertures styles }\end{array}$ & $\begin{array}{l}\text { 科名 Family (秦仁 } \\
\text { 昌,1978a, b) }\end{array}$ & $\begin{array}{l}\text { 科名 Family (Smith et al., } \\
\text { 2006; Christenhusz et al, } \\
\text { 2011; 张宪春等, 2013) }\end{array}$ \\
\hline 平羽风尾荻 Pteris kiuschiuensis Hieron. & 三裂缝 Trilete & 凤尾蕨科 Pteridaceae & 凤尾菜科 Pteridaceae \\
\hline 华中凤尾蕨 Pteris kiuschiuensis var. centrochinensis Ching \& & 三裂缝 Trilete & 凤尾蒴科 Pteridaceae & 凤尾蓱科 Pteridaceae \\
\hline \multicolumn{4}{|l|}{ S. H. Wu } \\
\hline 龙泉凤尾蕨 Pteris laurisilvicola Sa. Kurata & 三裂缝 Trilete & 凤尾鄀科 Pteridaceae & 凤尾鄀科 Pteridaceae \\
\hline 荔波凤尾蕨 Pteris liboensis P. S. Wang & 三裂缝 Trilete & 凤尾蕨科 Pteridaceae & 凤尾鄀科 Pteridaceae \\
\hline 线羽凤尾葓 Pteris linearis Poir. & 三裂缝 Trilete & 凤尾䓲科 Pteridaceae & 凤尾蕨科 Pteridaceae \\
\hline 三轴凤尾蕨 Pteris longipes D. Don & 三裂缝 Trilete & 凤尾蕨科 Pteridaceae & 凤尾鄀科 Pteridaceae \\
\hline 长叶凤尾濒 Pteris longipinna Hayata & 三裂缝 Trilete & 凤尾蕨科 Pteridaceae & 凤尾蒝科 Pteridaceae \\
\hline 翠绿凤尾嵚 Pteris longipinnula Wall. ex Agardh & 三裂缝 Trilete & 凤尾䓲科 Pteridaceae & 凤尾蕨科 Pteridaceae \\
\hline 两广凤尾嵚 Pteris maclurei Ching & 三裂缝 Trilete & 凤尾蕨科 Pteridaceae & 凤尾茨科 Pteridaceae \\
\hline 岭南风尾眇 Pteris maclurioides Ching & 三裂缝 Trilete & 凤尾蕨科 Pteridaceae & 凤尾蕨科 Pteridaceae \\
\hline 墨脱凤尾兴 Pteris medogensis Ching \& S. K. Wu & 三裂缝 Trilete & 凤尾䓲科 Pteridaceae & 凤尾蕨科 Pteridaceae \\
\hline 琼南风尾兴 Pteris morii Masam. & 三裂缝 Trilete & 凤尾蕨科 Pteridaceae & 凤尾茨科 Pteridaceae \\
\hline 井栏凤尾䕬 Pteris multifida Poir. & 三裂缝 Trilete & 凤尾蕨科 Pteridaceae & 凤尾蕨科 Pteridaceae \\
\hline 日本凤尾䕬 Pteris nipponica W. C. Shieh & 三裂缝 Trilete & 凤尾蕨科 Pteridaceae & 凤尾茨科 Pteridaceae \\
\hline 江西风尾兴 Pteris obtusiloba Ching \& S. H. Wu & 三裂缝 Trilete & 凤尾蕨科 Pteridaceae & 凤尾茨科 Pteridaceae \\
\hline 华西凤尾蕨 Pteris occidentalisinica Ching & 三裂缝 Trilete & 凤尾蕨科 Pteridaceae & 凤尾鄀科 Pteridaceae \\
\hline 斜羽凤尾䝫 Pteris oshimensis Hieron. & 三裂缝 Trilete & 凤尾䓲科 Pteridaceae & 凤尾茨科 Pteridaceae \\
\hline 尾头凤尾嵚 Pteris oshimensis var. paraemeiensis Ching & 三裂缝 Trilete & 凤尾蕨科 Pteridaceae & 凤尾茨科 Pteridaceae \\
\hline 稀羽风尾蕨 Pteris paucipinnula X. Y. Wang \& P. S. Wang & 三裂缝 Trilete & 凤尾蕨科 Pteridaceae & 凤尾茨科 Pteridaceae \\
\hline 栗柄凤尾菜 Pteris plumbea Christ & 三裂缝 Trilete & 凤尾蕨科 Pteridaceae & 凤尾蒝科 Pteridaceae \\
\hline 假指状风尾媭 Pteris pseudodactylina Ching \& S. K. Wu & 三裂缝 Trilete & 凤尾蕨科 Pteridaceae & 凤尾茨科 Pteridaceae \\
\hline
\end{tabular}




\begin{tabular}{|c|c|c|c|}
\hline $\begin{array}{l}\text { 物种 } \\
\text { Species }\end{array}$ & $\begin{array}{l}\text { 孢子裂缝类型 } \\
\text { Spore apertures styles }\end{array}$ & $\begin{array}{l}\text { 科名 Family (秦仁 } \\
\text { 昌,1978a, b) }\end{array}$ & $\begin{array}{l}\text { 科名 Family (Smith et al., } \\
\text { 2006; Christenhusz et al, } \\
\text { 2011; 张宪春等, 2013) }\end{array}$ \\
\hline 单叶凤尾蒴 Pteris pseudopellucida Ching & 三裂缝 Trilete & 凤尾烣科 Pteridaceae & 凤尾硕科 Pteridaceae \\
\hline 柔毛凤尾蒴 Pteris puberula Ching & 三裂缝 Trilete & 凤尾喏科 Pteridaceae & 凤尾葓科 Pteridaceae \\
\hline 方柄凤尾䕬 Pteris quadristipitis X. Y. Wang \& P. S. Wang & 三裂缝 Trilete & 凤尾葓科 Pteridaceae & 凤尾锁科 Pteridaceae \\
\hline 五叶凤尾蕒 Pteris quinquefoliata (Copel.) Ching & 三裂缝 Trilete & 凤尾嵚科 Pteridaceae & 凤尾嵚科 Pteridaceae \\
\hline 红毛凤尾䕬 Pteris rufopilosa Ching \& Y. X. Lin & 三裂缝 Trilete & 凤尾烣科 Pteridaceae & 凤尾葓科 Pteridaceae \\
\hline 琉球凤尾蓱 Pteris ryukyuensis Tagawa & 三裂缝 Trilete & 凤尾葓科 Pteridaceae & 凤尾葓科 Pteridaceae \\
\hline 三都风尾䲞 Pteris sanduensis X. Y. Wang \& P. S. Wang & 三裂缝 Trilete & 凤尾葓科 Pteridaceae & 凤尾锁科 Pteridaceae \\
\hline 红柄凤尾葓 Pteris scabristipes Tagawa & 三裂缝 Trilete & 凤尾脒科 Pteridaceae & 凤尾莏科 Pteridaceae \\
\hline 半边旗 Pteris semipinnata $\mathrm{L}$. & 三裂缝 Trilete & 凤尾硕科 Pteridaceae & 凤尾锁科 Pteridaceae \\
\hline 有刺凤尾䕬 Pteris setulosocostulata Hayata & 三裂缝 Trilete & 凤尾蕨科 Pteridaceae & 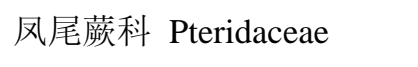 \\
\hline 石棉风尾蒝 Pteris shimianensis H. S. Kung & 三裂缝 Trilete & 凤尾㸝科 Pteridaceae & 凤尾硕科 Pteridaceae \\
\hline 四川风尾蕨 Pteris sichuanensis H. S. Kung & 三裂缝 Trilete & 凤尾烣科 Pteridaceae & 凤尾锁科 Pteridaceae \\
\hline 中华凤尾蕨 Pteris sinensis Ching & 三裂缝 Trilete & 凤尾嵚科 Pteridaceae & 凤尾锁科 Pteridaceae \\
\hline 隆林凤尾硕 Pteris splendida Ching & 三裂缝 Trilete & 凤尾㸝科 Pteridaceae & 凤尾硕科 Pteridaceae \\
\hline 细羽风尾荻 Pteris splendida var. longlinensis Ching \& S. H. & 三裂缝 Trilete & 凤尾蕨科 Pteridaceae & 凤尾嵚科 Pteridaceae \\
\hline \multicolumn{4}{|l|}{$\mathrm{Wu}$} \\
\hline 狭羽风尾嵚 Pteris stenophylla Wall. ex Hook. \& Grev. & 三裂缝 Trilete & 凤尾烣科 Pteridaceae & 凤尾葓科 Pteridaceae \\
\hline 预海风尾䕬 Pteris subquinata Wall. ex Agardh & 三裂缝 Trilete & 凤尾屏科 Pteridaceae & 凤尾葓科 Pteridaceae \\
\hline 台湾风尾蕨 Pteris taiwanensis Ching & 三裂缝 Trilete & 凤尾嵚科 Pteridaceae & 凤尾锁科 Pteridaceae \\
\hline 西藏风尾蟩 Pteris tibetica Ching & 三裂缝 Trilete & 凤尾烣科 Pteridaceae & 凤尾葓科 Pteridaceae \\
\hline 三叉凤尾薑 Pteris tripartita Sw. & 三裂缝 Trilete & 凤尾薕科 Pteridaceae & 凤尾葓科 Pteridaceae \\
\hline 波叶风尾蕨 Pteris undulatipinna Ching & 三裂缝 Trilete & 凤尾烣科 Pteridaceae & 凤尾葓科 Pteridaceae \\
\hline
\end{tabular}




\begin{tabular}{|c|c|c|c|}
\hline $\begin{array}{l}\text { 物种 } \\
\text { Species }\end{array}$ & $\begin{array}{l}\text { 孢子裂缝类型 } \\
\text { Spore apertures styles }\end{array}$ & $\begin{array}{l}\text { 科名 Family (秦仁 } \\
\text { 昌,1978a, b) }\end{array}$ & $\begin{array}{l}\text { 科名 Family (Smith et al., } \\
\text { 2006; Christenhusz et al, } \\
\text { 2011; 张宪春等, 2013) }\end{array}$ \\
\hline 爪哇凤尾偋 Pteris venusta Kunze & 三裂缝 Trilete & 凤尾硕科 Pteridaceae & 凤尾䓲科 Pteridaceae \\
\hline 绿轴风尾嵚 Pteris viridissima Ching & 三裂缝 Trilete & 凤尾蒴科 Pteridaceae & 凤尾硕科 Pteridaceae \\
\hline 蜈蚣草 Pteris vittata $\mathrm{L}$. & 三裂缝 Trilete & 凤尾蕨科 Pteridaceae & 凤尾蕨科 Pteridaceae \\
\hline 鸡冠风尾蒴 Pteris vittata f. cristata Ching & 三裂缝 Trilete & 凤尾薕科 Pteridaceae & 凤尾硕科 Pteridaceae \\
\hline 西南凤尾蒴 Pteris wallichiana Agardh & 三裂缝 Trilete & 凤尾硕科 Pteridaceae & 凤尾硕科 Pteridaceae \\
\hline 圆头风尾蕨 Pteris wallichiana var. obtusa S. H. Wu & 三裂缝 Trilete & 凤尾䓲科 Pteridaceae & 凤尾蕨科 Pteridaceae \\
\hline 云南风尾铞 Pteris wallichiana var. yunnanensis (Christ) Ching & 三裂缝 Trilete & 凤尾蕨科 Pteridaceae & 凤尾眇科 Pteridaceae \\
\hline \multicolumn{4}{|l|}{$\&$ S. H. Wu } \\
\hline 栗轴风尾橧 Pteris wangiana Ching & 三裂缝 Trilete & 凤尾烣科 Pteridaceae & 凤尾蒝科 Pteridaceae \\
\hline 乌来风尾蕨 Pteris $\times$ wulaiensis C. M. Kuo & 三裂缝 Trilete & 凤尾薕科 Pteridaceae & 凤尾蒝科 Pteridaceae \\
\hline 西畴凤尾菜 Pteris xichouensis W. M. Chu \& Z. R. He & 三裂缝 Trilete & 凤尾硕科 Pteridaceae & 凤尾蒝科 Pteridaceae \\
\hline 竹叶硕 Taenitis blechnoides (Willd.) Sw. & 三裂缝 Trilete & 竹叶蒴科 Taenitidaceae & 凤尾嵚科 Pteridaceae \\
\hline 薄叶翠偋 Anogramma leptophylla (L.) Link & 三裂缝 Trilete & 裸子薕科 Hemionitidaceae & 凤尾蒝科 Pteridaceae \\
\hline 翠蒝 Anogramma microphylla (Hook.) Diels & 三裂缝 Trilete & 裸子䔊科 Hemionitidaceae & 凤尾硕科 Pteridaceae \\
\hline 尖齿风Ү嵚 Coniogramme affinis Hieron. & 三裂缝 Trilete & 裸子蕨科 Hemionitidaceae & 凤尾茨科 Pteridaceae \\
\hline 尾尖风Y蕨 Coniogramme caudiformis Ching \& K. H. Shing & 三裂缝 Trilete & 裸子鄀科 Hemionitidaceae & 凤尾眇科 Pteridaceae \\
\hline 峨眉风Y蕨 Coniogramme emeiensis Ching \& K. H. Shing & 三裂缝 Trilete & 裸子䕋科 Hemionitidaceae & 凤尾硕科 Pteridaceae \\
\hline 镰羽风Y偋 Coniogramme falcipinna Ching \& K. H. Shing & 三裂缝 Trilete & 裸子䕋科 Hemionitidaceae & 凤尾茨科 Pteridaceae \\
\hline 单网风Y蕨 Coniogramme fauriei Hieron. & 三裂缝 Trilete & 裸子蕨科 Hemionitidaceae & 凤尾茨科 Pteridaceae \\
\hline 全缘风Y蕨 Coniogramme fraxinea (D. Don) Fée ex Diels & 三裂缝 Trilete & 裸子蕨科 Hemionitidaceae & 凤尾蒝科 Pteridaceae \\
\hline 普通风Y䓡 Coniogramme intermedia Hieron. & 三裂缝 Trilete & 裸子蕨科 Hemionitidaceae & 凤尾蒝科 Pteridaceae \\
\hline 无毛风Y蒴 Coniogramme intermedia var. glabra Ching & 三裂缝 Trilete & 裸子蕨科 Hemionitidaceae & 凤尾蒝科 Pteridaceae \\
\hline
\end{tabular}




\begin{tabular}{|c|c|c|c|}
\hline $\begin{array}{l}\text { 物种 } \\
\text { Species }\end{array}$ & $\begin{array}{l}\text { 孢子裂缝类型 } \\
\text { Spore apertures styles }\end{array}$ & $\begin{array}{l}\text { 科名 Family (秦仁 } \\
\text { 昌,1978a, b) }\end{array}$ & $\begin{array}{l}\text { 科名 Family (Smith et al., } \\
\text { 2006; Christenhusz et al, } \\
\text { 2011; 张宪春等, 2013) }\end{array}$ \\
\hline 风Y萨 Coniogramme japonica (Thunb.) Diels & 三裂缝 Trilete & 裸子蕨科 Hemionitidaceae & 凤尾硕科 Pteridaceae \\
\hline $\begin{array}{l}\text { 井冈山风Y硕 Coniogramme jinggangshanensis Ching \& K. H. } \\
\text { Shing }\end{array}$ & 三裂缝 Trilete & 裸子屏科 Hemionitidaceae & 凤尾嵚科 Pteridaceae \\
\hline 海南风Y蕨 Coniogramme macrophylla (Blume) Hieron. & 三裂缝 Trilete & 裸子蕨科 Hemionitidaceae & 凤尾葓科 Pteridaceae \\
\hline 卵羽风Y蕨 Coniogramme ovata S. K. Wu ex K. H. Shing & 三裂缝 Trilete & 裸子蕨科 Hemionitidaceae & 凤尾葓科 Pteridaceae \\
\hline 心基风Y葓 Coniogramme petelotii Tardieu & 三裂缝 Trilete & 裸子䔊科 Hemionitidaceae & 凤尾葓科 Pteridaceae \\
\hline 直角风Y钼 Coniogramme procera Fée & 三裂缝 Trilete & 裸子蕨科 Hemionitidaceae & 凤尾锁科 Pteridaceae \\
\hline 骨齿风Y葓 Coniogramme pubescens Hieron. & 三裂缝 Trilete & 裸子蓱科 Hemionitidaceae & 凤尾硕科 Pteridaceae \\
\hline 黑轴风Y屏 Coniogramme robusta Christ & 三裂缝 Trilete & 裸子蕨科 Hemionitidaceae & 凤尾锁科 Pteridaceae \\
\hline $\begin{array}{l}\text { 棕轴风Y蕨 Coniogramme robusta var. rependula Ching ex K. } \\
\text { H. Shing }\end{array}$ & 三裂缝 Trilete & 裸子葓科 Hemionitidaceae & 凤尾烣科 Pteridaceae \\
\hline $\begin{array}{l}\text { 黄轴风Y蕨 Coniogramme robusta var. splendens Ching ex K. } \\
\text { H. Shing }\end{array}$ & 三裂缝 Trilete & 裸子锁科 Hemionitidaceae & 凤尾锁科 Pteridaceae \\
\hline 乳头风Y葓 Coniogramme rosthornii Hieron. & 三裂缝 Trilete & 裸子硕科 Hemionitidaceae & 凤尾硕科 Pteridaceae \\
\hline 紫秆凤Y偋 Coniogramme rubicaulis Ching ex K. H. Shing & 三裂缝 Trilete & 裸子蕨科 Hemionitidaceae & 凤尾锁科 Pteridaceae \\
\hline 澜沧风Ү蕨 Coniogramme serrulata (Blume) Fee & 三裂缝 Trilete & 裸子蕨科 Hemionitidaceae & 凤尾瞢科 Pteridaceae \\
\hline 紫柄风Y蕨 Coniogramme sinensis Ching & 三裂缝 Trilete & 裸子蕨科 Hemionitidaceae & 凤尾葓科 Pteridaceae \\
\hline 上毛凤Y蕨 Coniogramme suprapilosa Ching & 三裂缝 Trilete & 裸子蕨科 Hemionitidaceae & 凤尾葓科 Pteridaceae \\
\hline 美丽风Y偋 Coniogramme venusta Ching ex K. H. Shing & 三裂缝 Trilete & 裸子蕨科 Hemionitidaceae & 凤尾锁科 Pteridaceae \\
\hline 疏网风Y葓 Coniogramme wilsonii Hieron. & 三裂缝 Trilete & 裸子葓科 Hemionitidaceae & 凤尾葓科 Pteridaceae \\
\hline 川西金毛裸蘐 Paragymnopteris bipinnata (Christ) K. H. Shing & 三裂缝 Trilete & 裸子蒝科 Hemionitidaceae & 凤尾葓科 Pteridaceae \\
\hline 耳羽金毛裸硕 Paragymnopteris bipinnata var. auriculata & 三裂缝 Trilete & 裸子葓科 Hemionitidaceae & 凤尾葓科 Pteridaceae \\
\hline
\end{tabular}




\begin{tabular}{|c|c|c|c|}
\hline $\begin{array}{l}\text { 物种 } \\
\text { Species }\end{array}$ & $\begin{array}{l}\text { 孢子裂缝类型 } \\
\text { Spore apertures styles }\end{array}$ & $\begin{array}{l}\text { 科名 Family (秦仁 } \\
\text { 昌,1978a, b) }\end{array}$ & $\begin{array}{l}\text { 科名 Family (Smith et al., } \\
\text { 2006; Christenhusz et al, } \\
\text { 2011; 张宪春等, 2013) }\end{array}$ \\
\hline \multicolumn{4}{|l|}{ (Franch.) K. H. Shing } \\
\hline 滇西金毛裸蒴 Paragymnopteris delavayi (Baker) K. H. Shing & 三裂缝 Trilete & 裸子䯾科 Hemionitidaceae & 凤尾蕨科 Pteridaceae \\
\hline 欧洲金毛裸蕨 Paragymnopteris marantae (L.) K. H. Shing & 三裂缝 Trilete & 裸子蕨科 Hemionitidaceae & 凤尾蕨科 Pteridaceae \\
\hline 中间金毛裸蕨 Paragymnopteris marantae var. intermedia & 三裂缝 Trilete & 裸子蕨科 Hemionitidaceae & 凤尾蕨科 Pteridaceae \\
\hline \multicolumn{4}{|l|}{ (Ching) K. H. Shing } \\
\hline 三角金毛裸荻 Paragymnopteris sargentii (Christ) K. H. Shing & 三裂缝 Trilete & 裸子蕨科 Hemionitidaceae & 凤尾蕨科 Pteridaceae \\
\hline 金毛裸荻 Paragymnopteris vestita (Wall. ex C. Presl) K. H. & 三裂缝 Trilete & 裸子蕨科 Hemionitidaceae & 凤尾蕨科 Pteridaceae \\
\hline \multicolumn{4}{|l|}{ Shing } \\
\hline 拟泽泻蕨 Parahemionitis cordata (Roxb. ex Hook. \& Grev.) & 三裂缝 Trilete & 裸子蕨科 Hemionitidaceae & 凤尾蕨科 Pteridaceae \\
\hline \multicolumn{4}{|l|}{ Fraser-Jenk. } \\
\hline 粉叶硕 Pityrogramme calomelanos (L.) Link & 三裂缝 Trilete & 裸子蕨科 Hemionitidaceae & 凤尾蕨科 Pteridaceae \\
\hline 白边粉背菜 Aleuritopteris albomarginata (C. B. Clarke) Ching & 三裂缝 Trilete & 中国蕨科 Sinopteridaceae & 凤尾蕨科 Pteridaceae \\
\hline 粉背蕨 Aleuritopteris anceps (Blanford) Panigrahi & 三裂缝 Trilete & 中国蕨科 Sinopteridaceae & 凤尾蕨科 Pteridaceae \\
\hline 银粉背鄀 Aleuritopteris argentea (Gmel.) Fée & 三裂缝 Trilete & 中国蕨科 Sinopteridaceae & 凤尾蕨科 Pteridaceae \\
\hline 陕西粉背蕨 Aleuritopteris argentea var. obscura (Christ) Ching & 三裂缝 Trilete & 中国鄀科 Sinopteridaceae & 凤尾蕨科 Pteridaceae \\
\hline 金粉背蕨 Aleuritopteris chrysophylla (Hook.) Ching & 三裂缝 Trilete & 中国蕨科 Sinopteridaceae & 凤尾蕨科 Pteridaceae \\
\hline 薄叶粉背蕨 Aleuritopteris dalhousieae (Hook.) Ching & 三裂缝 Trilete & 中国蕨科 Sinopteridaceae & 凤尾茨科 Pteridaceae \\
\hline 无盖粉背䕬 Aleuritopteris doniana S. K. Wu & 三裂缝 Trilete & 中国鄀科 Sinopteridaceae & 凤尾蕨科 Pteridaceae \\
\hline 中间粉背蕨 Aleuritopteris dubia (C. Hope) Ching & 三裂缝 Trilete & 中国蕨科 Sinopteridaceae & 凤尾萨科 Pteridaceae \\
\hline 裸叶粉背蕨 Aleuritopteris duclouxii (Christ) Ching & 三裂缝 Trilete & 中国蕨科 Sinopteridaceae & 凤尾蕨科 Pteridaceae \\
\hline 硫磺粉背菜 Aleuritopteris duclouxii var. sulphurea Ching & 三裂缝 Trilete & 中国鄀科 Sinopteridaceae & 凤尾蕨科 Pteridaceae \\
\hline 杜氏粉背硕 Aleuritopteris duthiei (Baker) Ching & 三裂缝 Trilete & 中国蕨科 Sinopteridaceae & 凤尾蕨科 Pteridaceae \\
\hline
\end{tabular}




\begin{tabular}{|c|c|c|c|}
\hline $\begin{array}{l}\text { 物种 } \\
\text { Species }\end{array}$ & $\begin{array}{l}\text { 狍子裂缝类型 } \\
\text { Spore apertures styles }\end{array}$ & $\begin{array}{l}\text { 科名 Family (秦仁 } \\
\text { 昌,1978a, b) }\end{array}$ & $\begin{array}{l}\text { 科名 Family (Smith et al., } \\
\text { 2006; Christenhusz et al, } \\
\text { 2011; 张宪春等, 2013) }\end{array}$ \\
\hline 黑柄粉背嵚 Aleuritopteris ebenipes X. C. Zhang & 三裂缝 Trilete & 中国葓科 Sinopteridaceae & 凤尾硕科 Pteridaceae \\
\hline 台湾粉背蕨 Aleuritopteris formosana (Hayata) Tagawa & 三裂缝 Trilete & 中国偋科 Sinopteridaceae & 凤尾硕科 Pteridaceae \\
\hline 贡山粉背蒴 Aleuritopteris gongshanensis G. M. Zhang & 三裂缝 Trilete & 中国蕨科 Sinopteridaceae & 凤尾蒴科 Pteridaceae \\
\hline 阔盖粉背蒴 Aleuritopteris grisea (Blanford) Panigrahi & 三裂缝 Trilete & 中国蕨科 Sinopteridaceae & 凤尾鬹科 Pteridaceae \\
\hline 克氏粉背蒝 Aleuritopteris krameri (Franch. \& Sav.) Ching & 三裂缝 Trilete & 中国葓科 Sinopteridaceae & 凤尾硕科 Pteridaceae \\
\hline 华北粉背蒝 Aleuritopteris kuhnii (Milde) Ching & 三裂缝 Trilete & 中国葓科 Sinopteridaceae & 凤尾硕科 Pteridaceae \\
\hline 丽江粉背葓 Aleuritopteris likiangensis Ching ex S. K. Wu & 三裂缝 Trilete & 中国蕨科 Sinopteridaceae & 凤尾藓科 Pteridaceae \\
\hline 雪白粉背莜 Aleuritopteris niphobola (C. Chr.) Ching & 三裂缝 Trilete & 中国葓科 Sinopteridaceae & 凤尾硕科 Pteridaceae \\
\hline 无粉雪白粉背蕨 Aleuritopteris niphobola var. concolor Ching & 三裂缝 Trilete & 中国蕨科 Sinopteridaceae & 凤尾蒴科 Pteridaceae \\
\hline 矮粉背蕨 Aleuritopteris pygmaea Ching ex S. K. Wu & 三裂缝 Trilete & 中国蕨科 Sinopteridaceae & 凤尾鬹科 Pteridaceae \\
\hline 黔桂粉背眇 Aleuritopteris qianguiensis W. M. Chu et H. G. & 三裂缝 Trilete & 中国蕨科 Sinopteridaceae & 凤尾锁科 Pteridaceae \\
\hline \multicolumn{4}{|l|}{ Zhou } \\
\hline 莲座粉背嵚 Aleuritopteris rosulata (C. Chr.) Ching & 三裂缝 Trilete & 中国蕨科 Sinopteridaceae & 凤尾锁科 Pteridaceae \\
\hline 棕毛粉背葓 Aleuritopteris rufa (D. Don) Ching & 三裂缝 Trilete & 中国葓科 Sinopteridaceae & 凤尾硕科 Pteridaceae \\
\hline 西畴粉背媭 Aleuritopteris sichouensis Ching \& S. K. Wu & 三裂缝 Trilete & 中国蕨科 Sinopteridaceae & 凤尾蒴科 Pteridaceae \\
\hline 美丽粉背䁤 Aleuritopteris speciosa Ching \& S. K. Wu & 三裂缝 Trilete & 中国蕨科 Sinopteridaceae & 凤尾嵚科 Pteridaceae \\
\hline 毛叶粉背偋 Aleuritopteris squamosa (C. Hope \& C. H. Wright) & 三裂缝 Trilete & 中国蒝科 Sinopteridaceae & 凤尾蕨科 Pteridaceae \\
\hline \multicolumn{4}{|l|}{ Ching } \\
\hline 线毛粉背屏 Aleuritopteris subvillosa (Hook.) Ching & 三裂缝 Trilete & 中国蕨科 Sinopteridaceae & 凤尾嵚科 Pteridaceae \\
\hline $\begin{array}{l}\text { 西藏粉背硕 Aleuritopteris subvillosa var. tibetica (Ching \& S. } \\
\text { K. Wu) H. S. Kung }\end{array}$ & 三裂缝 Trilete & 中国蕨科 Sinopteridaceae & 凤尾蒝科 Pteridaceae \\
\hline 阔羽粉背烣 Aleuritopteris tamburii (Hook.) Ching & 三裂缝 Trilete & 中国屏科 Sinopteridaceae & 凤尾葓科 Pteridaceae \\
\hline
\end{tabular}




\begin{tabular}{|c|c|c|c|}
\hline $\begin{array}{l}\text { 物种 } \\
\text { Species }\end{array}$ & $\begin{array}{l}\text { 孢子裂缝类型 } \\
\text { Spore apertures styles }\end{array}$ & $\begin{array}{l}\text { 科名 Family (秦仁 } \\
\text { 昌,1978a, b) }\end{array}$ & $\begin{array}{l}\text { 科名 Family (Smith et al., } \\
\text { 2006; Christenhusz et al, } \\
\text { 2011; 张宪春等, 2013) }\end{array}$ \\
\hline 金爪粉背媭 Aleuritopteris veitchii (Christ) Ching & 三裂缝 Trilete & 中国蕨科 Sinopteridaceae & 凤尾硕科 Pteridaceae \\
\hline 雅䶭粉背茨 Aleuritopteris yalungensis H. S. Kung & 三裂缝 Trilete & 中国蕨科 Sinopteridaceae & 凤尾茨科 Pteridaceae \\
\hline 疏羽碎米锁 Cheilosoria belangeri (Bory) Ching \& K. H. Shing & 三裂缝 Trilete & 中国烣科 Sinopteridaceae & 凤尾茨科 Pteridaceae \\
\hline 毛轴碎米硕 Cheilosoria chusana (Hook.) Ching \& K. H. Shing & 三裂缝 Trilete & 中国蕨科 Sinopteridaceae & 凤尾茨科 Pteridaceae \\
\hline 脆叶碎米蒴 Cheilosoria fragilis (Hook.) Ching \& K. H. Shing & 三裂缝 Trilete & 中国蕨科 Sinopteridaceae & 凤尾茨科 Pteridaceae \\
\hline 大理碎米嵚 Cheilosoria hancockii (Baker) Ching \& K. H. & 三裂缝 Trilete & 中国蒝科 Sinopteridaceae & 凤尾蓟科 Pteridaceae \\
\hline \multicolumn{4}{|l|}{ Shing } \\
\hline 川藏碎米蒝 Cheilosoria insignis (Ching) Ching \& K. H. Shing & 三裂缝 Trilete & 中国萨科 Sinopteridaceae & 凤尾蒴科 Pteridaceae \\
\hline 碎米蔹 Cheilosoria mysurensis (Wall. ex Hook.) Ching \& K. H. & 三裂缝 Trilete & 中国蕨科 Sinopteridaceae & 凤尾茨科 Pteridaceae \\
\hline \multicolumn{4}{|l|}{ Shing } \\
\hline 平羽碎米葓 Cheilosoria patula (Baker) P. S. Wang & 三裂缝 Trilete & 中国萨科 Sinopteridaceae & 凤尾嵚科 Pteridaceae \\
\hline 薄叶碎米嵚 Cheilosoria tenuifolia (Burm. f.) Trev. & 三裂缝 Trilete & 中国蕨科 Sinopteridaceae & 凤尾茨科 Pteridaceae \\
\hline 高山珠嵚 Cryptogramma brunoniana Wall. ex Hook. \& Grev. & 三裂缝 Trilete & 中国蕨科 Sinopteridaceae & 凤尾蕨科 Pteridaceae \\
\hline 陕西珠硕 Cryptogramma brunoniana var. sinensis (Christ) G. & 三裂缝 Trilete & 中国蒝科 Sinopteridaceae & 凤尾硕科 Pteridaceae \\
\hline \multicolumn{4}{|l|}{ M. Zhang } \\
\hline 稀叶珠蒴 Cryptogramma stelleri (Gmel.) Prantl & 三裂缝 Trilete & 中国蕨科 Sinopteridaceae & 凤尾蕨科 Pteridaceae \\
\hline 黑心菜 Doryopteris concolor (Langsd. \& Fisch.) Kuhn & 三裂缝 Trilete & 中国疹科 Sinopteridaceae & 凤尾蓟科 Pteridaceae \\
\hline 戟叶黑心蒝 Doryopteris ludens (Wall. ex Hook.) J. Sm. & 三裂缝 Trilete & 中国蒝科 Sinopteridaceae & 凤尾蓟科 Pteridaceae \\
\hline 中华隐囊嵚 Notholaena chinensis Baker & 三裂缝 Trilete & 中国蕨科 Sinopteridaceae & 凤尾茨科 Pteridaceae \\
\hline 隐囊菜 Notholaena hirsuta (Poir.) Desv. & 三裂缝 Trilete & 中国蕨科 Sinopteridaceae & 凤尾茨科 Pteridaceae \\
\hline 狭叶金粉蒝 Onychium angustifolium Ching & 三裂缝 Trilete & 中国蕨科 Sinopteridaceae & 凤尾蓟科 Pteridaceae \\
\hline 黑足金粉偋 Onychium contiguum C. Hope & 三裂缝 Trilete & 中国蒝科 Sinopteridaceae & 凤尾蕨科 Pteridaceae \\
\hline
\end{tabular}




\begin{tabular}{|c|c|c|c|}
\hline $\begin{array}{l}\text { 物种 } \\
\text { Species }\end{array}$ & $\begin{array}{l}\text { 孢子裂缝类型 } \\
\text { Spore apertures styles }\end{array}$ & $\begin{array}{l}\text { 科名 Family (秦仁 } \\
\text { 昌,1978a, b) }\end{array}$ & $\begin{array}{l}\text { 科名 Family (Smith et al., } \\
\text { 2006; Christenhusz et al, } \\
\text { 2011; 张宪春等, 2013) }\end{array}$ \\
\hline 独龙江金粉菜 Onychium dulongjiangenseW. M. Chu & 三裂缝 Trilete & 中国葓科 Sinopteridaceae & 凤尾硕科 Pteridaceae \\
\hline 金粉菜 Onychium intermedia (Desv.) C. Chr. & 三裂缝 Trilete & 中国蓱科 Sinopteridaceae & 凤尾葓科 Pteridaceae \\
\hline 野雉尾金粉偋 Onychium japonicum (Thunb.) Kunze & 三裂缝 Trilete & 中国葓科 Sinopteridaceae & 凤尾锁科 Pteridaceae \\
\hline 栗柄金粉葓 Onychium japonicum var. lucidum (D. Don) Christ & 三裂缝 Trilete & 中国葓科 Sinopteridaceae & 凤尾硕科 Pteridaceae \\
\hline 木坪金粉葓 Onychium moupinense Ching & 三裂缝 Trilete & 中国蓱科 Sinopteridaceae & 凤尾葓科 Pteridaceae \\
\hline 湖北金粉蕨 Onychium moupinense var. ipii (Ching) K. H. & 三裂缝 Trilete & 中国蕨科 Sinopteridaceae & 凤尾葓科 Pteridaceae \\
\hline \multicolumn{4}{|l|}{ Shing } \\
\hline 繁羽金粉蒝 Onychium plumosum Ching & 三裂缝 Trilete & 中国葓科 Sinopteridaceae & 凤尾硕科 Pteridaceae \\
\hline 金粉菜 Onychium siliculosum (Desv.) C. Chr. & 三裂缝 Trilete & 中国屏科 Sinopteridaceae & 凤尾硕科 Pteridaceae \\
\hline 蚀盖金粉葓 Onychium tenuifrons Ching & 三裂缝 Trilete & 中国鄀科 Sinopteridaceae & 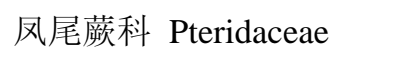 \\
\hline 西藏金粉硕 Onychium tibeticum Ching \& S. K. Wu & 三裂缝 Trilete & 中国葓科 Sinopteridaceae & 凤尾硕科 Pteridaceae \\
\hline 四川旱葓 Pellaea connectens $\mathrm{C} . \mathrm{Chr}$. & 三裂缝 Trilete & 中国葓科 Sinopteridaceae & 凤尾葓科 Pteridaceae \\
\hline 三角羽旱蒝 Pellaea hastata (Thunb.) Prantl & 三裂缝 Trilete & 中国葓科 Sinopteridaceae & 凤尾硕科 Pteridaceae \\
\hline 滇西旱蒝 Pellaea mairei Brause & 三裂缝 Trilete & 中国葓科 Sinopteridaceae & 凤尾硕科 Pteridaceae \\
\hline 旱蕨 Pellaea nitidula (Hook.) Baker & 三裂缝 Trilete & 中国烣科 Sinopteridaceae & 凤尾锁科 Pteridaceae \\
\hline 宜昌旱蒴 Pellaea patula (Baker) Ching & 三裂缝 Trilete & 中国蕨科 Sinopteridaceae & 凤尾瞢科 Pteridaceae \\
\hline 凤尾早嵚 Pellaea paupercula (Christ) Ching & 三裂缝 Trilete & 中国蓱科 Sinopteridaceae & 凤尾葓科 Pteridaceae \\
\hline 西南旱蒴 Pellaea smithii C. Chr. & 三裂缝 Trilete & 中国硕科 Sinopteridaceae & 凤尾葓科 Pteridaceae \\
\hline 禾秆旱蓱 Pellaea straminea Ching & 三裂缝 Trilete & 中国蕨科 Sinopteridaceae & 凤尾蕨科 Pteridaceae \\
\hline 西藏旱葓 Pellaea straminea var. tibetica Ching & 三裂缝 Trilete & 中国葓科 Sinopteridaceae & 凤尾葓科 Pteridaceae \\
\hline 毛旱葓 Pellaea trichophylla (Baker) Ching & 三裂缝 Trilete & 中国葓科 Sinopteridaceae & 凤尾葓科 Pteridaceae \\
\hline 云南旱蕨 Pellaea yunnanensis Ching & 三裂缝 Trilete & 中国蕨科 Sinopteridaceae & 凤尾葓科 Pteridaceae \\
\hline
\end{tabular}




\begin{tabular}{|c|c|c|c|}
\hline $\begin{array}{l}\text { 物种 } \\
\text { Species }\end{array}$ & $\begin{array}{l}\text { 孢子裂缝类型 } \\
\text { Spore apertures styles }\end{array}$ & $\begin{array}{l}\text { 科名 Family (秦仁 } \\
\text { 昌,1978a, b) }\end{array}$ & $\begin{array}{l}\text { 科名 Family (Smith et al., } \\
\text { 2006; Christenhusz et al, } \\
\text { 2011; 张宪春等, 2013) }\end{array}$ \\
\hline 小叶中国蕨 Sinopteris albofusca (Baker) Ching & 三裂缝 Trilete & 中国蕨科 Sinopteridaceae & 凤尾锁科 Pteridaceae \\
\hline 中国蒝 Sinopteris grevilleoides (Christ) C. Chr. \& Ching & 三裂缝 Trilete & 中国偋科 Sinopteridaceae & 凤尾䔻科 Pteridaceae \\
\hline 毛足铁线蕨 Adiantum bonatianum Brause & 三裂缝 Trilete & 铁线䕬科 Adiantaceae & 凤尾䕬科 Pteridaceae \\
\hline 无芒铁线蕨 Adiantum bonatianum var. subaristatum Ching & 三裂缝 Trilete & 铁线蕨科 Adiantaceae & 凤尾蕨科 Pteridaceae \\
\hline 圆齿铁线溦 Adiantum breviserratum (Ching) Ching \& Y. X. & 三裂缝 Trilete & 铁线罝科 Adiantaceae & 凤尾硕科 Pteridaceae \\
\hline \multicolumn{4}{|l|}{ Lin } \\
\hline 团羽铁线菜 Adiantum capillus-junonis Rupr. & 三裂缝 Trilete & 铁线屏科 Adiantaceae & 凤尾蕨科 Pteridaceae \\
\hline 铁线嵚 Adiantum capillus-veneris $\mathrm{L}$. & 三裂缝 Trilete & 铁线屏科 Adiantaceae & 凤尾蕨科 Pteridaceae \\
\hline 条裂铁线茨 Adiantum capillus-veneris f. dissectum (Mart. \& & 三裂缝 Trilete & 铁线偋科 Adiantaceae & 凤尾蒝科 Pteridaceae \\
\hline \multicolumn{4}{|l|}{ Galeot.) Ching } \\
\hline 鞭叶铁线䝫 Adiantum caudatum L. & 三裂缝 Trilete & 铁线蕨科 Adiantaceae & 凤尾蕨科 Pteridaceae \\
\hline 北江铁线葓 Adiantum chienii Ching & 三裂缝 Trilete & 铁线䓲科 Adiantaceae & 凤尾瞢科 Pteridaceae \\
\hline 白背铁线蕨 Adiantum davidii Franch. & 三裂缝 Trilete & 铁线蕨科 Adiantaceae & 凤尾蕨科 Pteridaceae \\
\hline 长刺铁线蕨 Adiantum davidii var. longispinum Ching & 三裂缝 Trilete & 铁线屏科 Adiantaceae & 凤尾蕨科 Pteridaceae \\
\hline 长尾铁线蕨 Adiantum diaphanum Blume & 三裂缝 Trilete & 铁线偋科 Adiantaceae & 凤尾蕨科 Pteridaceae \\
\hline 月芽铁线蕨 Adiantum edentulum Christ & 三裂缝 Trilete & 铁线蕨科 Adiantaceae & 凤尾蕨科 Pteridaceae \\
\hline 鹤庆铁线脄 Adiantum edentulum f. muticum (Ching) Y. X. Lin & 三裂缝 Trilete & 铁线䕬科 Adiantaceae & 凤尾蕨科 Pteridaceae \\
\hline 蜀铁线蒴 Adiantum edentulum f. refractum (Christ) Y. X. Lin & 三裂缝 Trilete & 铁线偋科 Adiantaceae & 凤尾瞢科 Pteridaceae \\
\hline 普通铁线荻 Adiantum edgeworthii Hook. & 三裂缝 Trilete & 铁线蕨科 Adiantaceae & 凤尾鄀科 Pteridaceae \\
\hline 肾盖铁线䁤 Adiantum erythrochlamys Diels & 三裂缝 Trilete & 铁线蕨科 Adiantaceae & 凤尾硕科 Pteridaceae \\
\hline 冯氏铁线蒴 Adiantum fengianum Ching & 三裂缝 Trilete & 铁线偋科 Adiantaceae & 凤尾蒴科 Pteridaceae \\
\hline 长盖铁线蕨 Adiantum fimbriatum Christ & 三裂缝 Trilete & 铁线䕬科 Adiantaceae & 凤尾䯾科 Pteridaceae \\
\hline
\end{tabular}




\begin{tabular}{|c|c|c|c|}
\hline $\begin{array}{l}\text { 物种 } \\
\text { Species }\end{array}$ & $\begin{array}{l}\text { 狍子裂缝类型 } \\
\text { Spore apertures styles }\end{array}$ & $\begin{array}{l}\text { 科名 Family (秦仁 } \\
\text { 昌,1978a, b) }\end{array}$ & $\begin{array}{l}\text { 科名 Family (Smith et al., } \\
\text { 2006; Christenhusz et al, } \\
\text { 2011; 张宪春等, 2013) }\end{array}$ \\
\hline 陕西铁线睰 Adiantum fimbriatum var. shensiense (Ching) & 三裂缝 Trilete & 铁线蕨科 Adiantaceae & 凤尾茨科 Pteridaceae \\
\hline \multicolumn{4}{|l|}{ Ching \& Y. X. Lin } \\
\hline 扇叶铁线蕨 Adiantum flabellulatum $\mathrm{L}$. & 三裂缝 Trilete & 铁线葓科 Adiantaceae & 凤尾嵚科 Pteridaceae \\
\hline 深山铁线蕨 Adiantum formosanum Tagawa & 三裂缝 Trilete & 铁线鳜科 Adiantaceae & 凤尾茨科 Pteridaceae \\
\hline 白严铁线蒴 Adiantum gravesii Hance & 三裂缝 Trilete & 铁线蒴科 Adiantaceae & 凤尾硕科 Pteridaceae \\
\hline 圆柄铁线烣 Adiantum induratum Christ & 三裂缝 Trilete & 铁线荻科 Adiantaceae & 凤尾硕科 Pteridaceae \\
\hline 仙霞铁线颐 Adiantum juxtapositum Ching & 三裂缝 Trilete & 铁线蓟科 Adiantaceae & 凤尾嵚科 Pteridaceae \\
\hline 奥铁线烣 Adiantum lianxianense Ching \& Y. X. Lin & 三裂缝 Trilete & 铁线蒴科 Adiantaceae & 凤尾硕科 Pteridaceae \\
\hline 假鞭叶铁线䕬 Adiantum malesianum Ghatak & 三裂缝 Trilete & 铁线偋科 Adiantaceae & 凤尾嵚科 Pteridaceae \\
\hline 小铁线蓟 Adiantum mariesii Baker & 三裂缝 Trilete & 铁线鳜科 Adiantaceae & 凤尾鰙科 Pteridaceae \\
\hline 孟连铁线菜 Adiantum menglianense Y. Y. Qian & 三裂缝 Trilete & 铁线嵚科 Adiantaceae & 凤尾硕科 Pteridaceae \\
\hline 单盖铁线偋 Adiantum monochlamys D. C. Eaton & 三裂缝 Trilete & 铁线葓科 Adiantaceae & 凤尾钼科 Pteridaceae \\
\hline 灰背铁线䕬 Adiantum myriosorum Baker & 三裂缝 Trilete & 铁线鳜科 Adiantaceae & 凤尾锁科 Pteridaceae \\
\hline 掌叶铁线媭 Adiantum pedatum L. & 三裂缝 Trilete & 铁线藃科 Adiantaceae & 凤尾硕科 Pteridaceae \\
\hline 半月形铁线烣 Adiantum philippense L. & 三裂缝 Trilete & 铁线偋科 Adiantaceae & 凤尾嵚科 Pteridaceae \\
\hline 毛叶铁线䕬 Adiantum pubescens Schkuhr & 三裂缝 Trilete & 铁线蒴科 Adiantaceae & 凤尾嵚科 Pteridaceae \\
\hline 荷叶铁线蒴 Adiantum reniforme var. sinense Y. X. Lin & 三裂缝 Trilete & 铁线蒴科 Adiantaceae & 凤尾硕科 Pteridaceae \\
\hline 陇南铁线瞢 Adiantum roborowskii Maxim. & 三裂缝 Trilete & 铁线䓲科 Adiantaceae & 凤尾硕科 Pteridaceae \\
\hline 峨眉铁线蔟 Adiantum roborowskii f. faberi (Baker) Y. X. Lin & 三裂缝 Trilete & 铁线偋科 Adiantaceae & 凤尾嵚科 Pteridaceae \\
\hline $\begin{array}{l}\text { 台湾高山铁线蕨 Adiantum roborowskii var. taiwanianum } \\
\text { (Tagawa) W. C. Shieh }\end{array}$ & 三裂缝 Trilete & 铁线葓科 Adiantaceae & 凤尾茨科 Pteridaceae \\
\hline 苍山铁线蕨 Adiantum sinicum Ching & 三裂缝 Trilete & 铁线葓科 Adiantaceae & 凤尾葓科 Pteridaceae \\
\hline
\end{tabular}




\begin{tabular}{|c|c|c|c|}
\hline $\begin{array}{l}\text { 物种 } \\
\text { Species }\end{array}$ & $\begin{array}{l}\text { 孢子裂缝类型 } \\
\text { Spore apertures styles }\end{array}$ & $\begin{array}{l}\text { 科名 Family (秦仁 } \\
\text { 昌,1978a, b) }\end{array}$ & $\begin{array}{l}\text { 科名 Family (Smith et al., } \\
\text { 2006; Christenhusz et al, } \\
\text { 2011; 张宪春等, 2013) }\end{array}$ \\
\hline 翅柄铁线眇 Adiantum soboliferum Wall. ex Hook. & 三裂缝 Trilete & 铁线葓科 Adiantaceae & 凤尾硕科 Pteridaceae \\
\hline 西藏铁线烣 Adiantum tibeticum Ching & 三裂缝 Trilete & 铁线蒴科 Adiantaceae & 凤尾葓科 Pteridaceae \\
\hline 细叶铁线偋 Adiantum venustum D. Don & 三裂缝 Trilete & 铁线䕋科 Adiantaceae & 凤尾锁科 Pteridaceae \\
\hline $\begin{array}{l}\text { 钝齿铁线萨 Adiantum venustum var. wuliangense Ching \& Y. } \\
\text { X. Lin }\end{array}$ & 三裂缝 Trilete & 铁线葓科 Adiantaceae & 凤尾蒴科 Pteridaceae \\
\hline 美叶车前蕨 Antrophyum callifolium Blume & 三裂缝 Trilete & 车前茨科 Antrophyaceae & 凤尾藃科 Pteridaceae \\
\hline 栗色车前葓 Antrophyum castaneum H. Ito & 三裂缝 Trilete & 车前茨科 Antrophyaceae & 凤尾锁科 Pteridaceae \\
\hline 革叶车前蒝 Antrophyum coriaceum (D. Don) Wall. ex T. & 三裂缝 Trilete & 车前蒴科 Antrophyaceae & 凤尾硕科 Pteridaceae \\
\hline \multicolumn{4}{|l|}{ Moore } \\
\hline 台湾车前䲞 Antrophyum formosanum Hieron. & 三裂缝 Trilete & 车前茨科 Antrophyaceae & 凤尾锶科 Pteridaceae \\
\hline 车前蒝 Antrophyum henryi Hieron. & 三裂缝 Trilete & 车前瞢科 Antrophyaceae & 凤尾硕科 Pteridaceae \\
\hline 长柄车前蒴 Antrophyum obovatum Baker & 三裂缝 Trilete & 车前䕬科 Antrophyaceae & 凤尾锁科 Pteridaceae \\
\hline 无柄车前葓 Antrophyum parvulum Blume & 三裂缝 Trilete & 车前茨科 Antrophyaceae & 凤尾锁科 Pteridaceae \\
\hline 兰屿车前䕬 Antrophyum sessilifolium (Cav.) Spreng. & 三裂缝 Trilete & 车前蒴科 Antrophyaceae & 凤尾硕科 Pteridaceae \\
\hline 书带车前蒝 Antrophyum vittarioides Baker & 三裂缝 Trilete & 车前䕬科 Antrophyaceae & 凤尾锁科 Pteridaceae \\
\hline 剑叶书带锁 Haplopteris amboinensis (Fée) X. C. Zhang & 单裂缝 Monolete & 书带茨科 Vittariaceae & 凤尾瞢科 Pteridaceae \\
\hline 姬书带瞢 Haplopteris anguste-elongata (Hayata) E. H. Crane & 单裂缝 Monolete & 书带蓱科 Vittariaceae & 凤尾葓科 Pteridaceae \\
\hline 带状书带䓡 Haplopteris doniana (Mett. ex Hieron.) E. H. Crane & 单裂缝 Monolete & 书带蓱科 Vittariaceae & 凤尾葓科 Pteridaceae \\
\hline 唇边书带蓝 Haplopteris elongata (Sw.) E. H. Crane. & 单裂缝 Monolete & 书带蓱科 Vittariaceae & 凤尾锁科 Pteridaceae \\
\hline 书带蒝 Haplopteris flexuosa (Fée) E. H. Crane. & 单裂缝 Monolete & 书带菜科 Vittariaceae & 凤尾葓科 Pteridaceae \\
\hline 平肋书带蒴 Haplopteris fudzinoi (Makino) E. H. Crane. & 单裂缝 Monolete & 书带蓱科 Vittariaceae & 凤尾葓科 Pteridaceae \\
\hline 海南书带蒝 Haplopteris hainanensis (C. Chr. ex Ching) E. H. & 单裂缝 Monolete & 书带痰科 Vittariaceae & 凤尾葓科 Pteridaceae \\
\hline
\end{tabular}




\begin{tabular}{|c|c|c|c|}
\hline $\begin{array}{l}\text { 物种 } \\
\text { Species }\end{array}$ & $\begin{array}{l}\text { 孢子裂缝类型 } \\
\text { Spore apertures styles }\end{array}$ & $\begin{array}{l}\text { 科名 Family (秦仁 } \\
\text { 昌,1978a, b) }\end{array}$ & $\begin{array}{l}\text { 科名 Family (Smith et al., } \\
\text { 2006; Christenhusz et al, } \\
\text { 2011; 张宪春等, 2013) }\end{array}$ \\
\hline \multicolumn{4}{|l|}{ Crane } \\
\hline 喜马拉雅书带鰀 Haplopteris himalayensis (Ching) E. H. Crane & 单裂缝 Monolete & 书带锁科 Vittariaceae & 凤尾蕨科 Pteridaceae \\
\hline 线叶书带蕨 Haplopteris linearifolia (Ching) X. C. Zhang & 单裂缝 Monolete & 书带蕨科 Vittariaceae & 凤尾蕨科 Pteridaceae \\
\hline 中囊书带䔋 Haplopteris mediosora (Hayata) X. C. Zhang & 单裂缝 Monolete & 书带锁科 Vittariaceae & 凤尾蕨科 Pteridaceae \\
\hline 曲鳞书带莜 Haplopteris plurisulcata (Ching) X. C. Zhang & 单裂缝 Monolete & 书带葓科 Vittariaceae & 凤尾硕科 Pteridaceae \\
\hline 锡金书带鄀 Haplopteris sikkimensis (Kuhn) E. H. Crane & 单裂缝 Monolete & 书带鄀科 Vittariaceae & 凤尾蕨科 Pteridaceae \\
\hline 广叶书带偋 Haplopteris taeniophylla (Copel.) E. H. Crane. & 单裂缝 Monolete & 书带嵚科 Vittariaceae & 凤尾蕨科 Pteridaceae \\
\hline 连狍一条线蒝 Monogramma paradoxa (Fée) Bedd. & 三裂缝 Trilete & 书带硕科 Vittariaceae & 凤尾硕科 Pteridaceae \\
\hline 针叶鄀 Vaginularia trichoidea Fée & 三裂缝 Trilete & 书带蕨科 Vittariaceae & 凤尾蕨科 Pteridaceae \\
\hline 亮毛蕨 Acystopteris japonica (Luerss.) Nakai & 单裂缝 Monolete & 蹄盖蕨科 Athyriaceae & 冷蕨科 Cystopteridaceae \\
\hline $\begin{array}{l}\text { 台湾亮毛嵚 Acystopteris taiwaniana (Tagawa) L. Love \& D. } \\
\text { Love }\end{array}$ & 单裂缝 Monolete & 蹄盖荻科 Athyriaceae & 冷蕨科 Cystopteridaceae \\
\hline 禾秆亮毛嵚 Acystopteris tenuisecta (Blume) Tagawa & 单裂缝 Monolete & 蹄盖蕨科 Athyriaceae & 冷蕨科 Cystopteridaceae \\
\hline 光叶茨 Cystoathyrium chinense Ching & 单裂缝 Monolete & 蹄盖茨科 Athyriaceae & 冷蕨科 Cystopteridaceae \\
\hline 皱狍冷蕨 Cystopteris dickieana Sim & 单裂缝 Monolete & 蹄盖蕨科 Athyriaceae & 冷鄀科 Cystopteridaceae \\
\hline 冷硕 Cystopteris fragilis (L.) Bernh. & 单裂缝 Monolete & 蹄盖蕨科 Athyriaceae & 冷蕨科 Cystopteridaceae \\
\hline 贵州冷硕 Cystopteris guizhouensis X. Y. Wang \& P. S. Wang & 单裂缝 Monolete & 蹄盖蕨科 Athyriaceae & 冷蕨科 Cystopteridaceae \\
\hline 西宁冷硕 Cystopteris kansuana C. Chr. & 单裂缝 Monolete & 蹄盖荻科 Athyriaceae & 冷鄀科 Cystopteridaceae \\
\hline 卷叶冷蕨 Cystopteris modesta Ching & 单裂缝 Monolete & 蹄盖荻科 Athyriaceae & 冷蕨科 Cystopteridaceae \\
\hline 高山冷蒴 Cystopteris montana (Lam.) Bernh. ex Desv. & 单裂缝 Monolete & 蹄盖蕨科 Athyriaceae & 冷蕨科 Cystopteridaceae \\
\hline 宝兴冷蒴 Cystopteris moupinensis Franch. & 单裂缝 Monolete & 蹄盖嵚科 Athyriaceae & 冷蕨科 Cystopteridaceae \\
\hline 膜叶冷葓 Cystopteris pellucida (Franch.) Ching ex C. Chr. & 单裂缝 Monolete & 蹄盖蕨科 Athyriaceae & 冷鄀科 Cystopteridaceae \\
\hline
\end{tabular}




\begin{tabular}{|c|c|c|c|}
\hline $\begin{array}{l}\text { 物种 } \\
\text { Species }\end{array}$ & $\begin{array}{l}\text { 孢子裂缝类型 } \\
\text { Spore apertures styles }\end{array}$ & $\begin{array}{l}\text { 科名 Family (秦仁 } \\
\text { 昌,1978a, b) }\end{array}$ & $\begin{array}{l}\text { 科名 Family (Smith et al., } \\
\text { 2006; Christenhusz et al, } \\
\text { 2011; 张宪春等, 2013) }\end{array}$ \\
\hline 欧洲冷蕨 Cystopteris sudetica A. Braun \& Milde & 单裂缝 Monolete & 蹄盖茨科 Athyriaceae & 冷䓲科 Cystopteridaceae \\
\hline 藏冷藃 Cystopteris tibetica Z. R. Wang & 单裂缝 Monolete & 蹄盖烣科 Athyriaceae & 冷硕科 Cystopteridaceae \\
\hline 欧洲羽节蕨 Gymnocarpium dryopteris (L.) Newman & 单裂缝 Monolete & 蹄盖蕨科 Athyriaceae & 冷蕨科 Cystopteridaceae \\
\hline 东亚羽节䕬 Gymnocarpium oyamense (Baker) Ching & 单裂缝 Monolete & 蹄盖茨科 Athyriaceae & 冷蒴科 Cystopteridaceae \\
\hline 羽节菜 Gymnocarpium remote-pinnatum (Hayata) Ching & 单裂缝 Monolete & 蹄盖烣科 Athyriaceae & 冷蒴科 Cystopteridaceae \\
\hline 密腺羽节蕨 Gymnocarpium robertianum (Hoffm.) Newman & 单裂缝 Monolete & 蹄盖鄀科 Athyriaceae & 冷鄀科 Cystopteridaceae \\
\hline 阿里山铁角䕬 Asplenium adiantifrons (Hayata) Ching & 单裂缝 Monolete & 铁角葓科 Aspleniaceae & 铁角蒴科 Aspleniaceae \\
\hline 革叶铁角菜 Asplenium adiantoides (L.) C. Chr. & 单裂缝 Monolete & 铁角葓科 Aspleniaceae & 铁角葓科 Aspleniaceae \\
\hline 黑色铁角䕬 Asplenium adiantum-nigrum var. yuanum (Ching) & 单裂缝 Monolete & 铁角葓科 Aspleniaceae & 铁角偋科 Aspleniaceae \\
\hline \multicolumn{4}{|l|}{ Ching } \\
\hline 合生铁角萨 Asplenium adnatum Copel. & 单裂缝 Monolete & 铁角偋科 Aspleniaceae & 铁角偋科 Aspleniaceae \\
\hline 高山铁角偋 Asplenium aitchisonii Fraser-Jenk. \& Reichstein & 单裂缝 Monolete & 铁角偋科 Aspleniaceae & 铁角偋科 Aspleniaceae \\
\hline 有翅铁角蒴 Asplenium alatulum Ching & 单裂缝 Monolete & 铁角葓科 Aspleniaceae & 铁角䲞科 Aspleniaceae \\
\hline 阿尔泰铁角葓 Asplenium altajense (Kom.) Grubov & 单裂缝 Monolete & 铁角葓科 Aspleniaceae & 铁角葓科 Aspleniaceae \\
\hline 无配铁角偋 Asplenium apogamum N. Murak. \& Hatan. & 单裂缝 Monolete & 铁角偋科 Aspleniaceae & 铁角偋科 Aspleniaceae \\
\hline 尖齿铁角蓟 Asplenium argutum Ching & 单裂缝 Monolete & 铁角葓科 Aspleniaceae & 铁角䲞科 Aspleniaceae \\
\hline 黑鳞铁角葓 Asplenium asterolepis Ching & 单裂缝 Monolete & 铁角葓科 Aspleniaceae & 铁角葓科 Aspleniaceae \\
\hline 华南铁角睰 Asplenium austrochinense Ching & 单裂缝 Monolete & 铁角茨科 Aspleniaceae & 铁角魦科 Aspleniaceae \\
\hline 马尔康铁角蕨 Asplenium barkamense Ching & 单裂缝 Monolete & 铁角蕨科 Aspleniaceae & 铁角蕨科 Aspleniaceae \\
\hline 南方铁角硕 Asplenium belangeri (Bory) Kunze & 单裂缝 Monolete & 铁角葓科 Aspleniaceae & 铁角葓科 Aspleniaceae \\
\hline 华北铁角菜 Asplenium borealichinense Ching \& S. H. Wu & 单裂缝 Monolete & 铁角葓科 Aspleniaceae & 铁角葓科 Aspleniaceae \\
\hline 大盖铁角蒴 Asplenium bullatum Wall. ex Mett. & 单裂缝 Monolete & 铁角偋科 Aspleniaceae & 铁角偋科 Aspleniaceae \\
\hline
\end{tabular}




\begin{tabular}{|c|c|c|c|}
\hline $\begin{array}{l}\text { 物种 } \\
\text { Species }\end{array}$ & $\begin{array}{l}\text { 孢子裂缝类型 } \\
\text { Spore apertures styles }\end{array}$ & $\begin{array}{l}\text { 科名 Family (秦仁 } \\
\text { 昌,1978a, b) }\end{array}$ & $\begin{array}{l}\text { 科名 Family (Smith et al., } \\
\text { 2006; Christenhusz et al, } \\
\text { 2011; 张宪春等, 2013) }\end{array}$ \\
\hline 线柄钱角䕬 Asplenium capillipes Makino & 单裂缝 Monolete & 铁角䓲科 Aspleniaceae & 铁角蒴科 Aspleniaceae \\
\hline 贡山铁角蒝 Asplenium changputungense Ching & 单裂缝 Monolete & 铁角蓱科 Aspleniaceae & 铁角葓科 Aspleniaceae \\
\hline 齿果铁角蕨 Asplenium cheilosorum Kunze ex Mett. & 单裂缝 Monolete & 铁角蕨科 Aspleniaceae & 铁角蕨科 Aspleniaceae \\
\hline 城口铁角蕨 Asplenium chengkouense Ching ex H. S. Kung & 单裂缝 Monolete & 铁角偋科 Aspleniaceae & 铁角偋科 Aspleniaceae \\
\hline 线裂铁角硕 Asplenium coenobiale Hance & 单裂缝 Monolete & 铁角屏科 Aspleniaceae & 铁角蒴科 Aspleniaceae \\
\hline 相似铁角蕨 Asplenium consimile Ching ex S. H. Wu & 单裂缝 Monolete & 铁角蕨科 Aspleniaceae & 铁角蕨科 Aspleniaceae \\
\hline 毛轴铁角薕 Asplenium crinicaule Hance & 单裂缝 Monolete & 铁角偋科 Aspleniaceae & 铁角蕒科 Aspleniaceae \\
\hline 乌来铁角蒝 Asplenium cuneatiforme Christ & 单裂缝 Monolete & 铁角屏科 Aspleniaceae & 铁角葓科 Aspleniaceae \\
\hline 德钦铁角蕨 Asplenium deqenense Ching & 单裂缝 Monolete & 铁角蕨科 Aspleniaceae & 铁角蕨科 Aspleniaceae \\
\hline 独龙江铁角蕨 Asplenium dulongjiangense Y. F. Deng & 单裂缝 Monolete & 铁角蕨科 Aspleniaceae & 铁角蕨科 Aspleniaceae \\
\hline 重齿铁角睰 Asplenium duplicatoserratum Ching ex S. H. Wu & 单裂缝 Monolete & 铁角茨科 Aspleniaceae & 铁角偋科 Aspleniaceae \\
\hline 剑叶铁角蕨 Asplenium ensiforme Wall. ex Hook. \& Grev. & 单裂缝 Monolete & 铁角蕨科 Aspleniaceae & 铁角蕨科 Aspleniaceae \\
\hline 线叶铁角蕨 Asplenium ensiforme f. stenophyllum (Bedd.) Ching & 单裂缝 Monolete & 铁角蕨科 Aspleniaceae & 铁角蕨科 Aspleniaceae \\
\hline 切边铁角荻 Asplenium excisum C. Presl & 单裂缝 Monolete & 铁角蕨科 Aspleniaceae & 铁角偋科 Aspleniaceae \\
\hline 镰叶铁角䓲 Asplenium falcatum Lam. & 单裂缝 Monolete & 铁角蕨科 Aspleniaceae & 铁角蕨科 Aspleniaceae \\
\hline 复齿铁角蕨 Asplenium filipes Copel. & 单裂缝 Monolete & 铁角蕨科 Aspleniaceae & 铁角蕨科 Aspleniaceae \\
\hline 网脉铁角蕨 Asplenium finlaysonianum Wall. ex Hook. & 单裂缝 Monolete & 铁角蒴科 Aspleniaceae & 铁角蒴科 Aspleniaceae \\
\hline 南海铁角蕨 Asplenium formosae Christ & 单裂缝 Monolete & 铁角蕨科 Aspleniaceae & 铁角蕨科 Aspleniaceae \\
\hline 线毛铁角蕨 Asplenium furfuraceum Ching & 单裂缝 Monolete & 铁角蕨科 Aspleniaceae & 铁角蕨科 Aspleniaceae \\
\hline 乌木铁角䝫 Asplenium fuscipes Baker & 单裂缝 Monolete & 铁角偋科 Aspleniaceae & 铁角偋科 Aspleniaceae \\
\hline 腺齿铁角莜 Asplenium glanduliserrulatum Ching ex S. H. Wu & 单裂缝 Monolete & 铁角蕨科 Aspleniaceae & 铁角蒴科 Aspleniaceae \\
\hline 厚叶铁角䲞 Asplenium griffithianum Hook. & 单裂缝 Monolete & 铁角䓲科 Aspleniaceae & 铁角䓲科 Aspleniaceae \\
\hline
\end{tabular}




\begin{tabular}{|c|c|c|c|}
\hline $\begin{array}{l}\text { 物种 } \\
\text { Species }\end{array}$ & $\begin{array}{l}\text { 孢子裂缝类型 } \\
\text { Spore apertures styles }\end{array}$ & $\begin{array}{l}\text { 科名 Family (秦仁 } \\
\text { 昌,1978a, b) }\end{array}$ & $\begin{array}{l}\text { 科名 Family (Smith et al., } \\
\text { 2006; Christenhusz et al, } \\
\text { 2011; 张宪春等, 2013) }\end{array}$ \\
\hline 撕裂铁角硕 Asplenium gueinzianum Mett. ex Kuhn & 单裂缝 Monolete & 铁角葓科 Aspleniaceae & 铁角硕科 Aspleniaceae \\
\hline 海南铁角蕨 Asplenium hainanense Ching & 单裂缝 Monolete & 铁角葓科 Aspleniaceae & 铁角葓科 Aspleniaceae \\
\hline 河北铁角蕨 Asplenium hebeiense Ching \& S. H. Wu & 单裂缝 Monolete & 铁角蕨科 Aspleniaceae & 铁角蕨科 Aspleniaceae \\
\hline 肾羽铁角嵚 Asplenium humistratum Ching ex H. S. Kung & 单裂缝 Monolete & 铁角葓科 Aspleniaceae & 铁角偋科 Aspleniaceae \\
\hline 虎尾铁角葓 Asplenium incisum Thunb. & 单裂缝 Monolete & 铁角蕨科 Aspleniaceae & 铁角葓科 Aspleniaceae \\
\hline 贵阳铁角蕨 Asplenium interjectum Christ & 单裂缝 Monolete & 铁角蕨科 Aspleniaceae & 铁角魦科 Aspleniaceae \\
\hline 康定铁角䝫 Asplenium kangdingense Ching \& H. S. Kung & 单裂缝 Monolete & 铁角葓科 Aspleniaceae & 铁角偋科 Aspleniaceae \\
\hline 江苏铁角䓡 Asplenium kiangsuense Ching ex Y. X. Jing & 单裂缝 Monolete & 铁角葓科 Aspleniaceae & 铁角葓科 Aspleniaceae \\
\hline 古玛丽铁角菜 Asplenium kukkonenii Viane \& Reichstein & 单裂缝 Monolete & 铁角蕨科 Aspleniaceae & 铁角蕨科 Aspleniaceae \\
\hline 乌柄铁角䲞 Asplenium laui Ching & 单裂缝 Monolete & 铁角葓科 Aspleniaceae & 铁角䲞科 Aspleniaceae \\
\hline 雷波铁角萨 Asplenium leiboense Ching & 单裂缝 Monolete & 铁角葓科 Aspleniaceae & 铁角葓科 Aspleniaceae \\
\hline 裂叶铁角蕨 Asplenium lobulatum Mett. ex Kuhn & 单裂缝 Monolete & 铁角蕨科 Aspleniaceae & 铁角蕨科 Aspleniaceae \\
\hline 南海铁角蕨 Asplenium loriceum Christ & 单裂缝 Monolete & 铁角蕨科 Aspleniaceae & 铁角偋科 Aspleniaceae \\
\hline 江南铁角蒴 Asplenium loxogrammoides Christ & 单裂缝 Monolete & 铁角茨科 Aspleniaceae & 铁角偋科 Aspleniaceae \\
\hline 兰屿铁角硕 Asplenium matsumurae Christ ex Matsum. & 单裂缝 Monolete & 铁角蕨科 Aspleniaceae & 铁角蕨科 Aspleniaceae \\
\hline 滇南铁角蕨 Asplenium microtum Maxon & 单裂缝 Monolete & 铁角蕨科 Aspleniaceae & 铁角偋科 Aspleniaceae \\
\hline 宝兴铁角鳜 Asplenium moupinense Franch. & 单裂缝 Monolete & 铁角蕨科 Aspleniaceae & 铁角魦科 Aspleniaceae \\
\hline 大羽铁角荻 Asplenium neolaserpitiifolium Tardieu \& Ching & 单裂缝 Monolete & 铁角茨科 Aspleniaceae & 铁角魦科 Aspleniaceae \\
\hline 多羽铁角蕨 Asplenium neomultijugum Ching ex S. H. Wu & 单裂缝 Monolete & 铁角蕨科 Aspleniaceae & 铁角蕨科 Aspleniaceae \\
\hline 郎木铁角蕨 Asplenium neovarians Ching & 单裂缝 Monolete & 铁角偋科 Aspleniaceae & 铁角䲞科 Aspleniaceae \\
\hline 西北铁角蕨 Asplenium nesii Christ & 单裂缝 Monolete & 铁角蕨科 Aspleniaceae & 铁角魦科 Aspleniaceae \\
\hline 倒挂铁角蕨 Asplenium normale D. Don & 单裂缝 Monolete & 铁角葓科 Aspleniaceae & 铁角濒科 Aspleniaceae \\
\hline
\end{tabular}




\begin{tabular}{|c|c|c|c|}
\hline $\begin{array}{l}\text { 物种 } \\
\text { Species }\end{array}$ & $\begin{array}{l}\text { 孢子裂缝类型 } \\
\text { Spore apertures styles }\end{array}$ & $\begin{array}{l}\text { 科名 Family (秦仁 } \\
\text { 昌,1978a, b) }\end{array}$ & $\begin{array}{l}\text { 科名 Family (Smith et al., } \\
\text { 2006; Christenhusz et al, } \\
\text { 2011; 张宪春等, 2013) }\end{array}$ \\
\hline 绿秆铁角罝 Asplenium obscurum Blume & 单裂缝 Monolete & 铁角䕬科 Aspleniaceae & 铁角蒴科 Aspleniaceae \\
\hline 东南铁角葓 Asplenium oldhami Hance & 单裂缝 Monolete & 铁角嵚科 Aspleniaceae & 铁角葓科 Aspleniaceae \\
\hline 少羽铁角蕨 Asplenium paucijugum Ching & 单裂缝 Monolete & 铁角蕨科 Aspleniaceae & 铁角蕨科 Aspleniaceae \\
\hline 北京铁角蕨 Asplenium pekinense Hance & 单裂缝 Monolete & 铁角屏科 Aspleniaceae & 铁角蒴科 Aspleniaceae \\
\hline 透明铁角葓 Asplenium pellucidum Lam. & 单裂缝 Monolete & 铁角屏科 Aspleniaceae & 铁角蒴科 Aspleniaceae \\
\hline 西南铁角蕨 Asplenium praemorsum Sw. & 单裂缝 Monolete & 铁角蕨科 Aspleniaceae & 铁角蕨科 Aspleniaceae \\
\hline 长叶铁角偋 Asplenium prolongatum Hook. & 单裂缝 Monolete & 铁角偋科 Aspleniaceae & 铁角蕒科 Aspleniaceae \\
\hline 内丘铁角蒝 Asplenium propinquum Ching & 单裂缝 Monolete & 铁角屏科 Aspleniaceae & 铁角葓科 Aspleniaceae \\
\hline 西藏铁角硕 Asplenium pseudofontanum Kossinsky & 单裂缝 Monolete & 铁角蕨科 Aspleniaceae & 铁角蕨科 Aspleniaceae \\
\hline 假大羽铁角睰 Asplenium pseudolaserpitiifolium Ching & 单裂缝 Monolete & 铁角偋科 Aspleniaceae & 铁角鬹科 Aspleniaceae \\
\hline $\begin{array}{l}\text { 假倒挂铁角蕨 Asplenium pseudonormale W. M. Chu \& X. C. } \\
\text { Zhang ex W. M. Chu }\end{array}$ & 单裂缝 Monolete & 铁角蕨科 Aspleniaceae & 铁角蕨科 Aspleniaceae \\
\hline 斜裂铁角嵚 Asplenium pseudopraemorsum Ching & 单裂缝 Monolete & 铁角偋科 Aspleniaceae & 铁角䔕科 Aspleniaceae \\
\hline 两广铁角蕨 Asplenium pseudowrightii Ching & 单裂缝 Monolete & 铁角偋科 Aspleniaceae & 铁角偋科 Aspleniaceae \\
\hline 镇康铁角硕 Asplenium quercicola Ching & 单裂缝 Monolete & 铁角蕨科 Aspleniaceae & 铁角蕨科 Aspleniaceae \\
\hline 微凹铁角蕨 Asplenium retusulum Ching & 单裂缝 Monolete & 铁角蕨科 Aspleniaceae & 铁角蕨科 Aspleniaceae \\
\hline 骨碎补铁角蕨 Asplenium ritoense Hayata & 单裂缝 Monolete & 铁角蒴科 Aspleniaceae & 铁角蒴科 Aspleniaceae \\
\hline 瑞丽铁角蕨 Asplenium rockii C. Chr. & 单裂缝 Monolete & 铁角蕨科 Aspleniaceae & 铁角蕨科 Aspleniaceae \\
\hline 卵叶铁角蕨 Asplenium ruta-muraria L. & 单裂缝 Monolete & 铁角蕨科 Aspleniaceae & 铁角蕨科 Aspleniaceae \\
\hline 岭南铁角䝫 Asplenium sampsonii Hance & 单裂缝 Monolete & 铁角偋科 Aspleniaceae & 铁角偋科 Aspleniaceae \\
\hline 华中铁角茨 Asplenium sarelii Hook. & 单裂缝 Monolete & 铁角蕨科 Aspleniaceae & 铁角蒴科 Aspleniaceae \\
\hline 石生铁角蕨 Asplenium saxicola Rosent. & 单裂缝 Monolete & 铁角蕨科 Aspleniaceae & 铁角蕨科 Aspleniaceae \\
\hline
\end{tabular}




\begin{tabular}{|c|c|c|c|}
\hline $\begin{array}{l}\text { 物种 } \\
\text { Species }\end{array}$ & $\begin{array}{l}\text { 孢子裂缝类型 } \\
\text { Spore apertures styles }\end{array}$ & $\begin{array}{l}\text { 科名 Family (秦仁 } \\
\text { 昌,1978a, b) }\end{array}$ & $\begin{array}{l}\text { 科名 Family (Smith et al., } \\
\text { 2006; Christenhusz et al, } \\
\text { 2011; 张宪春等, 2013) }\end{array}$ \\
\hline 狭叶铁角蕨 Asplenium scortechinii Bedd. & 单裂缝 Monolete & 铁角䓲科 Aspleniaceae & 铁角蒴科 Aspleniaceae \\
\hline 半变异铁角葓 Asplenium semivarians Viane \& Reichst. & 单裂缝 Monolete & 铁角嵚科 Aspleniaceae & 铁角葓科 Aspleniaceae \\
\hline 叉叶铁角蒴 Asplenium septentrionale (L.) Hoffm. & 单裂缝 Monolete & 铁角蕨科 Aspleniaceae & 铁角蕨科 Aspleniaceae \\
\hline 华东铁角薑 Asplenium serratissimum Ching ex S. H. Wu & 单裂缝 Monolete & 铁角屏科 Aspleniaceae & 铁角蒴科 Aspleniaceae \\
\hline 兰屿铁角葓 Asplenium serricula Fée & 单裂缝 Monolete & 铁角屏科 Aspleniaceae & 铁角蒴科 Aspleniaceae \\
\hline 四国铁角硕 Asplenium shikokianum Makino & 单裂缝 Monolete & 铁角蕨科 Aspleniaceae & 铁角蕨科 Aspleniaceae \\
\hline 匙形铁角茨 Asplenium spathulinum J. Sm. & 单裂缝 Monolete & 铁角偋科 Aspleniaceae & 铁角蕒科 Aspleniaceae \\
\hline 黑边铁角蒝 Asplenium speluncae Christ & 单裂缝 Monolete & 铁角屏科 Aspleniaceae & 铁角葓科 Aspleniaceae \\
\hline 圆齿铁角蕨 Asplenium subcrenatum Ching ex S. H. Wu & 单裂缝 Monolete & 铁角蕨科 Aspleniaceae & 铁角蕨科 Aspleniaceae \\
\hline 掌裂铁角蕨 Asplenium subdigitatum Ching & 单裂缝 Monolete & 铁角蕨科 Aspleniaceae & 铁角鬹科 Aspleniaceae \\
\hline $\begin{array}{l}\text { 拟大羽铁角蕨 Asplenium sublaserpitiifolium Ching ex Tardieu } \\
\text { \& Ching }\end{array}$ & 单裂缝 Monolete & 铁角蕨科 Aspleniaceae & 铁角蕨科 Aspleniaceae \\
\hline 长柄铁角蕨 Asplenium sublongum Ching ex S. H. Wu & 单裂缝 Monolete & 铁角偋科 Aspleniaceae & 铁角偋科 Aspleniaceae \\
\hline 小铁角蕨 Asplenium subnormale Copel. & 单裂缝 Monolete & 铁角偋科 Aspleniaceae & 铁角偋科 Aspleniaceae \\
\hline 圆叶铁角硕 Asplenium suborbiculare Ching & 单裂缝 Monolete & 铁角蕨科 Aspleniaceae & 铁角蕨科 Aspleniaceae \\
\hline $\begin{array}{l}\text { 疏羽铁角葓 Asplenium subtenuifolium (Christ) Ching \& S. H. } \\
\text { Wu }\end{array}$ & 单裂缝 Monolete & 铁角蕨科 Aspleniaceae & 铁角蕨科 Aspleniaceae \\
\hline 大瑶山铁角蕨 Asplenium subtrapezoideum Ching ex S. H. Wu & 单裂缝 Monolete & 铁角蕨科 Aspleniaceae & 铁角蕨科 Aspleniaceae \\
\hline 天全铁角蕨 Asplenium szechuanense Ching & 单裂缝 Monolete & 铁角蕨科 Aspleniaceae & 铁角蕨科 Aspleniaceae \\
\hline 台湾铁角蕨 Asplenium taiwanense Ching ex S. H. Wu & 单裂缝 Monolete & 铁角偋科 Aspleniaceae & 铁角偋科 Aspleniaceae \\
\hline 膜连铁角蕨 Asplenium tenerum Forst. & 单裂缝 Monolete & 铁角蕨科 Aspleniaceae & 铁角蒴科 Aspleniaceae \\
\hline 细茎铁角蕨 Asplenium tenuicaule Hayata & 单裂缝 Monolete & 铁角蕨科 Aspleniaceae & 铁角蕨科 Aspleniaceae \\
\hline
\end{tabular}


魏雪苹，张宪春．蒴类植物不同狍子裂缝类型在中国的分布格局. 生物多样性，2016，24(10)：1129-1134 http://www. biodiversity - science. net/CN/10. 17520/biods. 2016219

\begin{tabular}{|c|c|c|c|}
\hline $\begin{array}{l}\text { 物种 } \\
\text { Species }\end{array}$ & $\begin{array}{l}\text { 孢子裂缝类型 } \\
\text { Spore apertures styles }\end{array}$ & $\begin{array}{l}\text { 科名 Family (秦仁 } \\
\text { 昌,1978a, b) }\end{array}$ & $\begin{array}{l}\text { 科名 Family (Smith et al., } \\
\text { 2006; Christenhusz et al, } \\
\text { 2011; 张宪春等, 2013) }\end{array}$ \\
\hline 钝齿铁角䕋 Asplenium tenuicaule var. subvarians (Ching) & 单裂缝 Monolete & 铁角蕨科 Aspleniaceae & 铁角葓科 Aspleniaceae \\
\hline \multicolumn{4}{|l|}{ Viane } \\
\hline 细裂铁角䁤 Asplenium tenuifolium D. Don & 单裂缝 Monolete & 铁角蕨科 Aspleniaceae & 铁角蕨科 Aspleniaceae \\
\hline 新竹铁角蕨 Asplenium tenuissimum Hayata & 单裂缝 Monolete & 铁角屏科 Aspleniaceae & 铁角屏科 Aspleniaceae \\
\hline 天目铁角蒝 Asplenium tianmushanense Ching & 单裂缝 Monolete & 铁角屏科 Aspleniaceae & 铁角蒝科 Aspleniaceae \\
\hline 天山铁角睰 Asplenium tianshanense Ching & 单裂缝 Monolete & 铁角蕨科 Aspleniaceae & 铁角蕨科 Aspleniaceae \\
\hline 都匀铁角偋 Asplenium toramanum Makino & 单裂缝 Monolete & 铁角屏科 Aspleniaceae & 铁角屏科 Aspleniaceae \\
\hline 蒙自铁角蒝 Asplenium trapezoideum Ching & 单裂缝 Monolete & 铁角屏科 Aspleniaceae & 铁角锁科 Aspleniaceae \\
\hline 铁角蕨 Asplenium trichomanes L. & 单裂缝 Monolete & 铁角蕨科 Aspleniaceae & 铁角蕨科 Aspleniaceae \\
\hline 喜钻亚种 Asplenium trichomanes ssp. inexpectans Lovis & 单裂缝 Monolete & 铁角蕨科 Aspleniaceae & 铁角屏科 Aspleniaceae \\
\hline 粗轴亚种 Asplenium trichomanes ssp. pachyrachis (Christ) & 单裂缝 Monolete & 铁角鳜科 Aspleniaceae & 铁角屏科 Aspleniaceae \\
\hline \multicolumn{4}{|l|}{ Lovis \& Reichst. } \\
\hline $\begin{array}{l}\text { 四倍亚种 Asplenium trichomanes ssp. quadrivalens D. E. } \\
\text { Mever. }\end{array}$ & \multicolumn{2}{|c|}{ Meyer. } & 铁角蕨科 Aspleniaceae \\
\hline $\begin{array}{l}\text { 哈如变种 Asplenium trichomanes var. harovii Moore emend. } \\
\text { Midle }\end{array}$ & 单裂缝 Monolete & 铁角蕨科 Aspleniaceae & 铁角蕨科 Aspleniaceae \\
\hline 台南铁角硕 Asplenium trigonopterum Kunze & 单裂缝 Monolete & 铁角偋科 Aspleniaceae & 铁角屏科 Aspleniaceae \\
\hline 三翅铁角硕 Asplenium tripteropus Nakai & 单裂缝 Monolete & 铁角蓀科 Aspleniaceae & 铁角蕨科 Aspleniaceae \\
\hline \multicolumn{4}{|l|}{ Clarke } \\
\hline 半边铁角茨 Asplenium unilaterale Lam. & 单裂缝 Monolete & 铁角薾科 Aspleniaceae & 铁角蕨科 Aspleniaceae \\
\hline 变异铁角蕨 Asplenium varians Wall. ex Hook. \& Grev. & 单裂缝 Monolete & 铁角厥科 Aspleniaceae & 铁角屏科 Aspleniaceae \\
\hline
\end{tabular}




\begin{tabular}{|c|c|c|c|}
\hline $\begin{array}{l}\text { 物种 } \\
\text { Species }\end{array}$ & $\begin{array}{l}\text { 孢子裂缝类型 } \\
\text { Spore apertures styles }\end{array}$ & $\begin{array}{l}\text { 科名 Family (秦仁 } \\
\text { 昌,1978a, b) }\end{array}$ & $\begin{array}{l}\text { 科名 Family (Smith et al., } \\
\text { 2006; Christenhusz et al, } \\
\text { 2011; 张宪春等, 2013) }\end{array}$ \\
\hline 欧亚铁角葓 Asplenium viride Huds. & 单裂缝 Monolete & 铁角蓟科 Aspleniaceae & 铁角硕科 Aspleniaceae \\
\hline 闽浙铁角葓 Asplenium wilfordii Mett. ex Kuhn & 单裂缝 Monolete & 铁角蒴科 Aspleniaceae & 铁角葓科 Aspleniaceae \\
\hline 狭翅铁角蒝 Asplenium wrightii A. A. Eaton ex Hook. & 单裂缝 Monolete & 铁角藃科 Aspleniaceae & 铁角锁科 Aspleniaceae \\
\hline 疏齿铁角䁤 Asplenium wrightioides Christ & 单裂缝 Monolete & 铁角蕨科 Aspleniaceae & 铁角蕨科 Aspleniaceae \\
\hline 东海铁角葓 Asplenium $\times$ castaneoviride Baker & 单裂缝 Monolete & 铁角蓟科 Aspleniaceae & 铁角烣科 Aspleniaceae \\
\hline 王氏铁角钼 Asplenium × wangii C. M. Kuo & 单裂缝 Monolete & 铁角蓟科 Aspleniaceae & 铁角荻科 Aspleniaceae \\
\hline 新疆铁角蕨 Asplenium xinjiangense Ching & 单裂缝 Monolete & 铁角䓲科 Aspleniaceae & 铁角荻科 Aspleniaceae \\
\hline 胎生铁角蕨 Asplenium yoshinagae Makino & 单裂缝 Monolete & 铁角葓科 Aspleniaceae & 铁角媭科 Aspleniaceae \\
\hline $\begin{array}{l}\text { 印度铁角蕨 Asplenium yoshinagae var. indicum (Sledge) Ching } \\
\& \mathrm{~S} . \mathrm{K} . \mathrm{Wu}\end{array}$ & 单裂缝 Monolete & 铁角偋科 Aspleniaceae & 铁角葓科 Aspleniaceae \\
\hline 云南铁角蕒 Asplenium yunnanense Franch. & 单裂缝 Monolete & 铁角蕨科 Aspleniaceae & 铁角蕨科 Aspleniaceae \\
\hline 细辛蕨 Boniniella cardiophylla (Hance) Tagawa & 单裂缝 Monolete & 铁角烣科 Aspleniaceae & 铁角烣科 Aspleniaceae \\
\hline 过山蕨 Camptosorus sibiricus Rupr. & 单裂缝 Monolete & 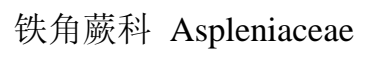 & 铁角䓴科 Aspleniaceae \\
\hline 药蕨 Ceterach officinarum (L.) DC. & 单裂缝 Monolete & 铁角鳜科 Aspleniaceae & 铁角媭科 Aspleniaceae \\
\hline 大叶苍山蕨 Ceterachopsis magnifica Ching & 单裂缝 Monolete & 铁角䓲科 Aspleniaceae & 铁角烣科 Aspleniaceae \\
\hline 疏脉苍山蕨 Ceterachopsis paucivenosa (Ching) Ching & 单裂缝 Monolete & 铁角蕨科 Aspleniaceae & 铁角蕨科 Aspleniaceae \\
\hline $\begin{array}{l}\text { 俅江苍山脄 Ceterachopsis qiujiangensis Ching \& S. H. Fu ex } \\
\text { Ching \& S. H. Wu }\end{array}$ & 单裂缝 Monolete & 铁角蕨科 Aspleniaceae & 铁角蕨科 Aspleniaceae \\
\hline 大鳞巢偋 Neottopteris antiqua (Makino) Masam. & 单裂缝 Monolete & 铁角蓟科 Aspleniaceae & 铁角媭科 Aspleniaceae \\
\hline 狭翅巢硕 Neottopteris antrophyoides (Christ) Ching & 单裂缝 Monolete & 铁角蒴科 Aspleniaceae & 铁角媭科 Aspleniaceae \\
\hline $\begin{array}{l}\text { 鸡冠巢蕨 Neottopteris antrophyoides var. cristata Ching \& S. } \\
\mathrm{H} . \mathrm{Wu}\end{array}$ & 单裂缝 Monolete & 铁角葓科 Aspleniaceae & 铁角䓴科 Aspleniaceae \\
\hline
\end{tabular}




\begin{tabular}{|c|c|c|c|}
\hline $\begin{array}{l}\text { 物种 } \\
\text { Species }\end{array}$ & $\begin{array}{l}\text { 孢子裂缝类型 } \\
\text { Spore apertures styles }\end{array}$ & $\begin{array}{l}\text { 科名 Family (秦仁 } \\
\text { 昌,1978a, b) }\end{array}$ & $\begin{array}{l}\text { 科名 Family (Smith et al., } \\
\text { 2006; Christenhusz et al, } \\
\text { 2011; 张宪春等, 2013) }\end{array}$ \\
\hline 狭鳞巢葓 Neottopteris grevillei (Wall. ex Hook. \& Grev.) J. Sm. & 单裂缝 Monolete & 铁角䓲科 Aspleniaceae & 铁角蕨科 Aspleniaceae \\
\hline 扁柄巢葓 Neottopteris humbertii (Tardieu) Tagawa & 单裂缝 Monolete & 铁角蓱科 Aspleniaceae & 铁角葓科 Aspleniaceae \\
\hline 阔足巢蔴 Neottopteris latibasis Ching & 单裂缝 Monolete & 铁角蕨科 Aspleniaceae & 铁角蕨科 Aspleniaceae \\
\hline 阔翅巢蕨 Neottopteris latipes Ching ex S. H. Wu & 单裂缝 Monolete & 铁角偋科 Aspleniaceae & 铁角偋科 Aspleniaceae \\
\hline 长柄巢嵚 Neottopteris longistipes Ching ex S. H. Wu & 单裂缝 Monolete & 铁角屏科 Aspleniaceae & 铁角蒴科 Aspleniaceae \\
\hline 巢蕨 Neottopteris nidus (L.) J. Sm. & 单裂缝 Monolete & 铁角蕨科 Aspleniaceae & 铁角蕨科 Aspleniaceae \\
\hline 长叶巢蕨 Neottopteris phyllitidis (D. Don) J. Sm. & 单裂缝 Monolete & 铁角偋科 Aspleniaceae & 铁角蕒科 Aspleniaceae \\
\hline 尖头巢蕨 Neottopteris salwinensis Ching & 单裂缝 Monolete & 铁角屏科 Aspleniaceae & 铁角葓科 Aspleniaceae \\
\hline 狭叶巢蕨 Neottopteris simonsiana (Hook.) J. Sm. & 单裂缝 Monolete & 铁角蕨科 Aspleniaceae & 铁角蕨科 Aspleniaceae \\
\hline 黑鳞巢蕨 Neottopteris subantiqua Ching ex S. H. Wu & 单裂缝 Monolete & 铁角䓲科 Aspleniaceae & 铁角鬹科 Aspleniaceae \\
\hline 东北对开偋 Phyllitis japonica Kom. & 单裂缝 Monolete & 铁角䔊科 Aspleniaceae & 铁角蒝科 Aspleniaceae \\
\hline 水鳖蕨 Sinephropteris delavayi (Franch.) Mickel & 单裂缝 Monolete & 铁角蕨科 Aspleniaceae & 铁角蕨科 Aspleniaceae \\
\hline 川黔肠嵚 Diplaziopsis cavaleriana (Christ) C. Chr. & 单裂缝 Monolete & 蹄盖鳜科 Athyriaceae & 肠偋科 Diplaziopsidaceae \\
\hline 肠菜 Diplaziopsis javanica (Blume) C. Chr. & 单裂缝 Monolete & 蹄盖蒴科 Athyriaceae & 肠蒴科 Diplaziopsidaceae \\
\hline 脆叶轴果蕨 Rhachidosorus blotianus Ching & 单裂缝 Monolete & 蹄盖蕨科 Athyriaceae & 轴果蕨科 Rhachidosoraceae \\
\hline 喜钲轴果钼 Rhachidosorus consimilis Ching & 单裂缝 Monolete & 蹄盖蒴科 Athyriaceae & 轴果蕨科 Rhachidosoraceae \\
\hline 轴果菜 Rhachidosorus mesosorus (Makino) Ching & 单裂缝 Monolete & 蹄盖蒝科 Athyriaceae & 轴果硕科 Rhachidosoraceae \\
\hline 台湾轴果蕨 Rhachidosorus pulcher (Tagawa) Ching & 单裂缝 Monolete & 蹄盖蕨科 Athyriaceae & 轴果蕨科 Rhachidosoraceae \\
\hline 云贵轴果蕨 Rhachidosorus truncatus Ching & 单裂缝 Monolete & 蹄盖蕨科 Athyriaceae & 轴果蕨科 Rhachidosoraceae \\
\hline 星毛蕨 Ampelopteris prolifera (Retz.) Copel. & 单裂缝 Monolete & 金星蕨科 Thelypteridaceae & 金星蕨科 Thelypteridaceae \\
\hline 耳羽钩毛蕨 Cyclogramma auriculata (J. Sm.) Ching & 单裂缝 Monolete & 金星蕨科 Thelypteridaceae & 金星颌科 Thelypteridaceae \\
\hline 焕镛钩毛谥 Cyclogramma chunii (Ching) Tagawa & 单裂缝 Monolete & 金星蕨科 Thelypteridaceae & 金星蕨科 Thelypteridaceae \\
\hline
\end{tabular}


魏雪苹，张宪春．蒴类植物不同狍子裂缝类型在中国的分布格局. 生物多样性，2016，24(10)：1129-1134 http://www. biodiversity - science. net/CN/10. 17520/biods. 2016219

\begin{tabular}{|c|c|c|c|}
\hline $\begin{array}{l}\text { 物种 } \\
\text { Species }\end{array}$ & $\begin{array}{l}\text { 孢子裂缝类型 } \\
\text { Spore apertures styles }\end{array}$ & $\begin{array}{l}\text { 科名 Family (秦仁 } \\
\text { 昌,1978a, b) }\end{array}$ & $\begin{array}{l}\text { 科名 Family (Smith et al., } \\
\text { 2006; Christenhusz et al, } \\
\text { 2011; 张宪春等, 2013) }\end{array}$ \\
\hline 无量山钩毛蔹 Cyclogramma costularisora Ching ex K. H. & 单裂缝 Monolete & 金星烣科 Thelypteridaceae & 金星蒴科 Thelypteridaceae \\
\hline \multicolumn{4}{|l|}{ Shing } \\
\hline 小叶钩毛蕨 Cyclogramma flexilis (Christ) Tagawa & 单裂缝 Monolete & 金星蕨科 Thelypteridaceae & 金星蕨科 Thelypteridaceae \\
\hline 狭基钩毛茨 Cyclogramma leveillei (Christ) Ching & 单裂缝 Monolete & 金星蕨科 Thelypteridaceae & 金星蒴科 Thelypteridaceae \\
\hline 滇东钩毛蕨 Cyclogramma neoauriculata (Ching) Tagawa & 单裂缝 Monolete & 金星葓科 Thelypteridaceae & 金星䔊科 Thelypteridaceae \\
\hline 峨眉钩毛嵚 Cyclogramma omeiensis (Baker) Tagawa & 单裂缝 Monolete & 金星蕨科 Thelypteridaceae & 金星蕨科 Thelypteridaceae \\
\hline 西藏钩毛硕 Cyclogramma tibetica Ching \& S. K. Wu & 单裂缝 Monolete & 金星葓科 Thelypteridaceae & 金星蒴科 Thelypteridaceae \\
\hline 缩羽毛蕨 Cyclosorus abbreviatus Ching \& K. H. Shing ex K. H. & 单裂缝 Monolete & 金星蕨科 Thelypteridaceae & 金星蕨科 Thelypteridaceae \\
\hline \multicolumn{4}{|l|}{ Shing \& J. F. Cheng } \\
\hline 渐尖毛蕨 Cyclosorus acuminatus (Houtt.) Nakai & 单裂缝 Monolete & 金星蓟科 Thelypteridaceae & 金星蒴科 Thelypteridaceae \\
\hline 锐尖毛蕨 Cyclosorus acutissimus Ching ex K. H. Shing \& J. F. & 单裂缝 Monolete & 金星蒴科 Thelypteridaceae & 金星硕科 Thelypteridaceae \\
\hline \multicolumn{4}{|l|}{ Cheng } \\
\hline 线羽毛嵚 Cyclosorus angustipinnus (Ching) K. H. Shing & 单裂缝 Monolete & 金星蕨科 Thelypteridaceae & 金星蕨科 Thelypteridaceae \\
\hline 狭羽毛嵚 Cyclosorus angustus Ching & 单裂缝 Monolete & 金星蒴科 Thelypteridaceae & 金星硕科 Thelypteridaceae \\
\hline 干旱毛硕 Cyclosorus aridus (D. Don) Tagawa & 单裂缝 Monolete & 金星蕨科 Thelypteridaceae & 金星蕨科 Thelypteridaceae \\
\hline 下延毛䕬 Cyclosorus attenuatus Ching ex K. H. Shing & 单裂缝 Monolete & 金星葓科 Thelypteridaceae & 金星蕨科 Thelypteridaceae \\
\hline 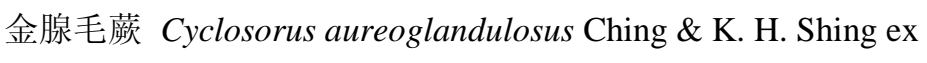 & 单裂缝 Monolete & 金星蕨科 Thelypteridaceae & 金星蕨科 Thelypteridaceae \\
\hline \multicolumn{4}{|l|}{ Ching \& C. F. Zhang } \\
\hline 短柄毛蕨 Cyclosorus brevipes Ching \& K. H. Shing & 单裂缝 Monolete & 金星蕨科 Thelypteridaceae & 金星蕨科 Thelypteridaceae \\
\hline 多耳毛葓 Cyclosorus caii Ching ex K. H. Shing & 单裂缝 Monolete & 金星硕科 Thelypteridaceae & 金星硕科 Thelypteridaceae \\
\hline 三合毛蓝 Cyclosorus calvescens Ching & 单裂缝 Monolete & 金星蕨科 Thelypteridaceae & 金星蕨科 Thelypteridaceae \\
\hline 苍南毛蕨 Cyclosorus cangnanensis K. H. Shing \& C. F. & 单裂缝 Monolete & 金星葓科 Thelypteridaceae & 金星蕨科 Thelypteridaceae \\
\hline
\end{tabular}




\begin{tabular}{|c|c|c|c|}
\hline $\begin{array}{l}\text { 物种 } \\
\text { Species }\end{array}$ & $\begin{array}{l}\text { 孢子裂缝类型 } \\
\text { Spore apertures styles }\end{array}$ & $\begin{array}{l}\text { 科名 Family (秦仁 } \\
\text { 昌,1978a, b) }\end{array}$ & $\begin{array}{l}\text { 科名 Family (Smith et al., } \\
\text { 2006; Christenhusz et al, } \\
\text { 2011; 张宪春等, 2013) }\end{array}$ \\
\hline \multicolumn{4}{|l|}{ Zhang } \\
\hline 程氏毛荻 Cyclosorus chengii Ching ex K. H. Shing \& J. F. & 单裂缝 Monolete & 金星蕨科 Thelypteridaceae & 金星蕨科 Thelypteridaceae \\
\hline \multicolumn{4}{|l|}{ Cheng } \\
\hline 秦氏毛蕨 Cyclosorus chingii Z. Y. Liu ex Ching \& Z. Y. Liu & 单裂缝 Monolete & 金星蕨科 Thelypteridaceae & 金星蕨科 Thelypteridaceae \\
\hline 慈利毛蒴 Cyclosorus ciliensis K. H. Shing & 单裂缝 Monolete & 金星硕科 Thelypteridaceae & 金星媭科 Thelypteridaceae \\
\hline 棒腺毛蓱 Cyclosorus clavatus K. H. Shing & 单裂缝 Monolete & 金星葓科 Thelypteridaceae & 金星蒴科 Thelypteridaceae \\
\hline 狭缩毛蕨 Cyclosorus contractus Ching ex K. H. Shing & 单裂缝 Monolete & 金星蕨科 Thelypteridaceae & 金星蕨科 Thelypteridaceae \\
\hline 鳞柄毛蕨 Cyclosorus crinipes (Hook.) Ching & 单裂缝 Monolete & 金星媭科 Thelypteridaceae & 金星茨科 Thelypteridaceae \\
\hline 狭基毛蕨 Cyclosorus cuneatus Ching ex K. H. Shing & 单裂缝 Monolete & 金星葓科 Thelypteridaceae & 金星濒科 Thelypteridaceae \\
\hline 大明山毛蕨 Cyclosorus damingshanensis Ching ex K. H. Shing & 单裂缝 Monolete & 金星藣科 Thelypteridaceae & 金星烣科 Thelypteridaceae \\
\hline 光盖毛嵚 Cyclosorus decipiens Ching & 单裂缝 Monolete & 金星硕科 Thelypteridaceae & 金星硕科 Thelypteridaceae \\
\hline 德化毛菜 Cyclosorus dehuaensis Ching \& K. H. Shing & 单裂缝 Monolete & 金星葓科 Thelypteridaceae & 金星蓟科 Thelypteridaceae \\
\hline 齿牙毛嵚 Cyclosorus dentatus (Forssk.) Ching & 单裂缝 Monolete & 金星媭科 Thelypteridaceae & 金星茨科 Thelypteridaceae \\
\hline 疏羽毛蒝 Cyclosorus dissitus Ching ex K. H. Shing & 单裂缝 Monolete & 金星硕科 Thelypteridaceae & 金星藃科 Thelypteridaceae \\
\hline 独龙江毛蕨 Cyclosorus dulongjiangensis W. M. Chu & 单裂缝 Monolete & 金星葓科 Thelypteridaceae & 金星蒴科 Thelypteridaceae \\
\hline 广叶毛濒 Cyclosorus ensifer (Tagawa) W. C. Shieh & 单裂缝 Monolete & 金星颐科 Thelypteridaceae & 金星烣科 Thelypteridaceae \\
\hline 河池毛嵚 Cyclosorus euphlebius Ching & 单裂缝 Monolete & 金星媭科 Thelypteridaceae & 金星蕨科 Thelypteridaceae \\
\hline 展羽毛菜 Cyclosorus evolutus (Bedd.) Ching & 单裂缝 Monolete & 金星葓科 Thelypteridaceae & 金星媭科 Thelypteridaceae \\
\hline 高大毛蕨 Cyclosorus excelsior Ching \& K. H. Shing & 单裂缝 Monolete & 金星蕨科 Thelypteridaceae & 金星蕨科 Thelypteridaceae \\
\hline 平基毛茨 Cyclosorus flaccidus Ching \& Z. Y. Liu & 单裂缝 Monolete & 金星莜科 Thelypteridaceae & 金星蒴科 Thelypteridaceae \\
\hline 岑叶毛蒴 Cyclosorus fraxinifolius Ching & 单裂缝 Monolete & 金星葓科 Thelypteridaceae & 金星蒴科 Thelypteridaceae \\
\hline 福建毛蒴 Cyclosorus fukienensis Ching & 单裂缝 Monolete & 金星硕科 Thelypteridaceae & 金星蕨科 Thelypteridaceae \\
\hline
\end{tabular}




\begin{tabular}{|c|c|c|c|}
\hline $\begin{array}{l}\text { 物种 } \\
\text { Species }\end{array}$ & $\begin{array}{l}\text { 孢子裂缝类型 } \\
\text { Spore apertures styles }\end{array}$ & $\begin{array}{l}\text { 科名 Family (秦仁 } \\
\text { 昌,1978a, b) }\end{array}$ & $\begin{array}{l}\text { 科名 Family (Smith et al., } \\
\text { 2006; Christenhusz et al, } \\
\text { 2011; 张宪春等, 2013) }\end{array}$ \\
\hline 高雄毛嵚 Cyclosorus gaoxiongensis Ching ex K. H. Shing & 单裂缝 Monolete & 金星蕨科 Thelypteridaceae & 金星蕨科 Thelypteridaceae \\
\hline 光羽毛嵚 Cyclosorus glabellus Ching (mon.nud.) & 单裂缝 Monolete & 金星葓科 Thelypteridaceae & 金星烣科 Thelypteridaceae \\
\hline 光叶毛蕨 Cyclosorus glabrescens Ching ex K. H. Shing & 单裂缝 Monolete & 金星蕨科 Thelypteridaceae & 金星蕨科 Thelypteridaceae \\
\hline 大毛偋 Cyclosorus grandissimus Ching \& K. H. Shing & 单裂缝 Monolete & 金星颐科 Thelypteridaceae & 金星茨科 Thelypteridaceae \\
\hline 粗齿毛蒴 Cyclosorus grossodentatus Ching ex K. H. Shing & 单裂缝 Monolete & 金星葓科 Thelypteridaceae & 金星蒴科 Thelypteridaceae \\
\hline 古斯塔毛蕨 Cyclosorus gustavii (Bedd.) Ching & 单裂缝 Monolete & 金星蒴科 Thelypteridaceae & 金星蕨科 Thelypteridaceae \\
\hline 海南毛茨 Cyclosorus hainanensis Ching & 单裂缝 Monolete & 金星锁科 Thelypteridaceae & 金星茨科 Thelypteridaceae \\
\hline 异果毛菜 Cyclosorus heterocarpus (Blume) Ching & 单裂缝 Monolete & 金星硕科 Thelypteridaceae & 金星蒝科 Thelypteridaceae \\
\hline 毛脚毛蕨 Cyclosorus hirtipes K. H. Shing \& C. F. Zhang & 单裂缝 Monolete & 金星蕨科 Thelypteridaceae & 金星蕨科 Thelypteridaceae \\
\hline 毛囊毛蕨 Cyclosorus hirtisorus (C. Chr.) Ching & 单裂缝 Monolete & 金星藣科 Thelypteridaceae & 金星嵚科 Thelypteridaceae \\
\hline 河口毛嵚 Cyclosorus hokouensis Ching & 单裂缝 Monolete & 金星硕科 Thelypteridaceae & 金星硕科 Thelypteridaceae \\
\hline 学显毛蕨 Cyclosorus houi Ching & 单裂缝 Monolete & 金星蕨科 Thelypteridaceae & 金星蕨科 Thelypteridaceae \\
\hline 毛蕨 Cyclosorus interruptus (Willd.) H. Ito & 单裂缝 Monolete & 金星蕨科 Thelypteridaceae & 金星蕨科 Thelypteridaceae \\
\hline 闽台毛蔴 Cyclosorus jaculosus (Christ) H. Ito & 单裂缝 Monolete & 金星媭科 Thelypteridaceae & 金星茨科 Thelypteridaceae \\
\hline 景洪毛蕨 Cyclosorus jinghongensis Ching ex K. H. Shing & 单裂缝 Monolete & 金星蕨科 Thelypteridaceae & 金星蕨科 Thelypteridaceae \\
\hline 九龙山毛鄀 Cyclosorus jiulongshanensis P.S. Chiu \& Yao ex & 单裂缝 Monolete & 金星蕨科 Thelypteridaceae & 金星蕨科 Thelypteridaceae \\
\hline \multicolumn{4}{|l|}{ Ching } \\
\hline 酬州毛蕨 Cyclosorus kuizhouensis K. H. Shing & 单裂缝 Monolete & 金星蒴科 Thelypteridaceae & 金星萩科 Thelypteridaceae \\
\hline 细柄毛蕨 Cyclosorus kuliangensis (Ching) K. H. Shing & 单裂缝 Monolete & 金星蕨科 Thelypteridaceae & 金星蕨科 Thelypteridaceae \\
\hline 贵州毛蕨 Cyclosorus kweichowensis Ching ex K. H. Shing & 单裂缝 Monolete & 金星锁科 Thelypteridaceae & 金星茨科 Thelypteridaceae \\
\hline 宽羽毛薑 Cyclosorus latipinnus (Hook. ex Bak.in Hook. \& & 单裂缝 Monolete & 金星蕨科 Thelypteridaceae & 金星蕨科 Thelypteridaceae \\
\hline
\end{tabular}




\begin{tabular}{|c|c|c|c|}
\hline $\begin{array}{l}\text { 物种 } \\
\text { Species }\end{array}$ & $\begin{array}{l}\text { 孢子裂缝类型 } \\
\text { Spore apertures styles }\end{array}$ & $\begin{array}{l}\text { 科名 Family (秦仁 } \\
\text { 昌,1978a, b) }\end{array}$ & $\begin{array}{l}\text { 科名 Family (Smith et al., } \\
\text { 2006; Christenhusz et al, } \\
\text { 2011; 张宪春等, 2013) }\end{array}$ \\
\hline 心祁毛蕨 Cyclosorus laui Ching & 单裂缝 Monolete & 金星蕨科 Thelypteridaceae & 金星茨科 Thelypteridaceae \\
\hline 雷波毛菜 Cyclosorus leipoensis Ching \& H. S. Kung ex K. H. & 单裂缝 Monolete & 金星烚科 Thelypteridaceae & 金星烣科 Thelypteridaceae \\
\hline \multicolumn{4}{|l|}{ Shing } \\
\hline 龙栖山毛蒴 Cyclosorus longqishanensis K. H. Shing & 单裂缝 Monolete & 金星罝科 Thelypteridaceae & 金星鄀科 Thelypteridaceae \\
\hline 阔羽毛菜 Cyclosorus macrophyllus Ching \& Z. Y. Lin & 单裂缝 Monolete & 金星硕科 Thelypteridaceae & 金星蒴科 Thelypteridaceae \\
\hline 墨脱毛蒴 Cyclosorus medogensis Ching \& S. K. Wu & 单裂缝 Monolete & 金星葓科 Thelypteridaceae & 金星蒴科 Thelypteridaceae \\
\hline 冕宁毛茨 Cyclosorus mianningensis Ching ex K. H. Shing & 单裂缝 Monolete & 金星锁科 Thelypteridaceae & 金星茨科 Thelypteridaceae \\
\hline 美丽毛嵚 Cyclosorus molliusculus (Wall. ex Kuhn) Ching & 单裂缝 Monolete & 金星硕科 Thelypteridaceae & 金星蔜科 Thelypteridaceae \\
\hline 多囊毛嵚 Cyclosorus multisorus Ching ex K. H. Shing & 单裂缝 Monolete & 金星葓科 Thelypteridaceae & 金星茨科 Thelypteridaceae \\
\hline 南平毛蒴 Cyclosorus nanpingensis Ching & 单裂缝 Monolete & 金星藣科 Thelypteridaceae & 金星嵚科 Thelypteridaceae \\
\hline 南溪毛硕 Cyclosorus nanxiensis Ching ex K. H. Shing & 单裂缝 Monolete & 金星硕科 Thelypteridaceae & 金星硕科 Thelypteridaceae \\
\hline 峨眉毛蓱 Cyclosorus omeigensis Ching & 单裂缝 Monolete & 金星葓科 Thelypteridaceae & 金星嵚科 Thelypteridaceae \\
\hline 对羽毛嵚 Cyclosorus oppositipinnus Ching \& Z. Y. Liu & 单裂缝 Monolete & 金星莜科 Thelypteridaceae & 金星茨科 Thelypteridaceae \\
\hline 腺脉毛菜 Cyclosorus opulentus (Kaulf. ) Nakai & 单裂缝 Monolete & 金星硕科 Thelypteridaceae & 金星硕科 Thelypteridaceae \\
\hline 东方毛蒴 Cyclosorus orientalis Ching ex K. H. Shing & 单裂缝 Monolete & 金星葓科 Thelypteridaceae & 金星茨科 Thelypteridaceae \\
\hline 蝶状毛蕨 Cyclosorus papilio (C. Hope) Ching & 单裂缝 Monolete & 金星颐科 Thelypteridaceae & 金星嵚科 Thelypteridaceae \\
\hline 蝶羽毛蓱 Cyclosorus papilionaceus K. H. Shing \& C. F. & 单裂缝 Monolete & 金星葓科 Thelypteridaceae & 金星烣科 Thelypteridaceae \\
\hline \multicolumn{4}{|l|}{ Zhang } \\
\hline 宽顶毛蕨 Cyclosorus paracuminatus Ching ex K. H. Shing \& J. & 单裂缝 Monolete & 金星蕨科 Thelypteridaceae & 金星茨科 Thelypteridaceae \\
\hline \multicolumn{4}{|l|}{ F. Cheng } \\
\hline 长尾毛蓱 Cyclosorus paralatipinnus Ching ex K. H. Shing & 单裂缝 Monolete & 金星锁科 Thelypteridaceae & 金星蒴科 Thelypteridaceae \\
\hline 岳麓山毛蒴 Cyclosorus pararidus Ching ex K. H. Shing & 单裂缝 Monolete & 金星硕科 Thelypteridaceae & 金星疹科 Thelypteridaceae \\
\hline
\end{tabular}




\begin{tabular}{|c|c|c|c|}
\hline $\begin{array}{l}\text { 物种 } \\
\text { Species }\end{array}$ & $\begin{array}{l}\text { 孢子裂缝类型 } \\
\text { Spore apertures styles }\end{array}$ & $\begin{array}{l}\text { 科名 Family (秦仁 } \\
\text { 昌,1978a, b) }\end{array}$ & $\begin{array}{l}\text { 科名 Family (Smith et al., } \\
\text { 2006; Christenhusz et al, } \\
\text { 2011; 张宪春等, 2013) }\end{array}$ \\
\hline 华南毛瞢 Cyclosorus parasiticus (L.) Farwell & 单裂缝 Monolete & 金星蕨科 Thelypteridaceae & 金星菜科 Thelypteridaceae \\
\hline 小叶毛蒝 Cyclosorus parvifolius Ching & 单裂缝 Monolete & 金星烚科 Thelypteridaceae & 金星蒴科 Thelypteridaceae \\
\hline 龙胜毛蒴 Cyclosorus parvilobus Ching \& K. H. Shing & 单裂缝 Monolete & 金星茨科 Thelypteridaceae & 金星蕨科 Thelypteridaceae \\
\hline 齿片毛菜 Cyclosorus pauciserratus Ching \& C. F. Zhang & 单裂缝 Monolete & 金星蕨科 Thelypteridaceae & 金星蕨科 Thelypteridaceae \\
\hline 屏山毛菜 Cyclosorus pingshanensis Ching \& H. S. Kung & 单裂缝 Monolete & 金星硕科 Thelypteridaceae & 金星蒴科 Thelypteridaceae \\
\hline 无腺毛嵚 Cyclosorus procurrens (Mett.) Ching & 单裂缝 Monolete & 金星葓科 Thelypteridaceae & 金星蒴科 Thelypteridaceae \\
\hline 兰屿大叶毛葓 Cyclosorus productus (Kaulf. ) Ching & 单裂缝 Monolete & 金星硕科 Thelypteridaceae & 金星蒴科 Thelypteridaceae \\
\hline 越北毛菜 Cyclosorus proximus Ching \& Chu H. Wang & 单裂缝 Monolete & 金星硕科 Thelypteridaceae & 金星蒝科 Thelypteridaceae \\
\hline 假干旱毛菜 Cyclosorus pseudoaridus Ching ex K. H. Shing & 单裂缝 Monolete & 金星葓科 Thelypteridaceae & 金星茨科 Thelypteridaceae \\
\hline 楔形毛荻 Cyclosorus pseudocunneatus Ching ex K. H. Shing & 单裂缝 Monolete & 金星瞢科 Thelypteridaceae & 金星䕬科 Thelypteridaceae \\
\hline 狭叶毛蕨 Cyclosorus pumilis Ching ex K. H. Shing & 单裂缝 Monolete & 金星嵚科 Thelypteridaceae & 金星蒝科 Thelypteridaceae \\
\hline 矮毛蒝 Cyclosorus pygmaeus Ching \& C. F. Zhang & 单裂缝 Monolete & 金星茨科 Thelypteridaceae & 金星蕨科 Thelypteridaceae \\
\hline 石生毛睰 Cyclosorus rupicola Ching \& K. H. Shing & 单裂缝 Monolete & 金星蕨科 Thelypteridaceae & 金星蕨科 Thelypteridaceae \\
\hline 三都毛濒 Cyclosorus sanduensis K. H. Shing \& P. S. Wang & 单裂缝 Monolete & 金星嵚科 Thelypteridaceae & 金星蒝科 Thelypteridaceae \\
\hline 䊅叶毛偋 Cyclosorus scaberulus Ching & 单裂缝 Monolete & 金星茨科 Thelypteridaceae & 金星蕨科 Thelypteridaceae \\
\hline 锯齿毛茨 Cyclosorus serrifer Ching ex K. H. Shing & 单裂缝 Monolete & 金星薑科 Thelypteridaceae & 金星蕨科 Thelypteridaceae \\
\hline 石门毛葓 Cyclosorus simenensis K. H. Shing \& C. M. Zhang & 单裂缝 Monolete & 金星硕科 Thelypteridaceae & 金星蒴科 Thelypteridaceae \\
\hline 拟渐尖毛蕨 Cyclosorus sino-acuminatus Ching \& Z. Y. Liu & 单裂缝 Monolete & 金星蕨科 Thelypteridaceae & 金星蒴科 Thelypteridaceae \\
\hline 中华齿状毛嵚 Cyclosorus sinodentatus Ching \& Z. Y. Liu & 单裂缝 Monolete & 金星硕科 Thelypteridaceae & 金星蒴科 Thelypteridaceae \\
\hline 疏囊毛嵚 Cyclosorus sparsisorus Ching ex K. H. Shing & 单裂缝 Monolete & 金星硕科 Thelypteridaceae & 金星蕨科 Thelypteridaceae \\
\hline $\begin{array}{l}\text { 狭脚毛蕨 Cyclosorus stenopes Ching \& K. H. Shing ex K. H. } \\
\text { Shing }\end{array}$ & 单裂缝 Monolete & 金星茨科 Thelypteridaceae & 金星蒴科 Thelypteridaceae \\
\hline
\end{tabular}




\begin{tabular}{|c|c|c|c|}
\hline $\begin{array}{l}\text { 物种 } \\
\text { Species }\end{array}$ & $\begin{array}{l}\text { 孢子裂缝类型 } \\
\text { Spore apertures styles }\end{array}$ & $\begin{array}{l}\text { 科名 Family (秦仁 } \\
\text { 昌,1978a, b) }\end{array}$ & $\begin{array}{l}\text { 科名 Family (Smith et al., } \\
\text { 2006; Christenhusz et al, } \\
\text { 2011; 张宪春等, 2013) }\end{array}$ \\
\hline 假渐尖毛睰 Cyclosorus subacuminatus Ching ex K. H. Shing \& & 单裂缝 Monolete & 金星藣科 Thelypteridaceae & 金星硕科 Thelypteridaceae \\
\hline \multicolumn{4}{|l|}{ J. F. Cheng } \\
\hline 短尖毛蕨 Cyclosorus subacutus Ching & 单裂缝 Monolete & 金星蕨科 Thelypteridaceae & 金星蕨科 Thelypteridaceae \\
\hline 巨型毛茨 Cyclosorus subelatus (Baker) Ching & 单裂缝 Monolete & 金星偋科 Thelypteridaceae & 金星蕨科 Thelypteridaceae \\
\hline 万金毛嵚 Cyclosorus subnamburensis Ching ex K. H. Shing & 单裂缝 Monolete & 金星硕科 Thelypteridaceae & 金星硕科 Thelypteridaceae \\
\hline 秦宁毛硕 Cyclosorus tarningensis Ching & 单裂缝 Monolete & 金星蒴科 Thelypteridaceae & 金星蕨科 Thelypteridaceae \\
\hline 顶育毛嵚 Cyclosorus terminans (J. Sm. ex Hook.) K. H. Shing & 单裂缝 Monolete & 金星钼科 Thelypteridaceae & 金星蕨科 Thelypteridaceae \\
\hline 河边毛蕨 Cyclosorus transitorius Ching \& K. H. Shing & 单裂缝 Monolete & 金星硕科 Thelypteridaceae & 金星硕科 Thelypteridaceae \\
\hline 截裂毛蕨 Cyclosorus truncatus (Poir.) Farwell & 单裂缝 Monolete & 金星蕨科 Thelypteridaceae & 金星蕨科 Thelypteridaceae \\
\hline 黄志毛蕨 Cyclosorus wangii Ching & 单裂缝 Monolete & 金星蕨科 Thelypteridaceae & 金星蕨科 Thelypteridaceae \\
\hline 望谟毛嵚 Cyclosorus wangmoensis K. H. Shing \& P. S. Wang & 单裂缝 Monolete & 金星藃科 Thelypteridaceae & 金星蒴科 Thelypteridaceae \\
\hline 温州毛蕨 Cyclosorus wenzhouensis K. H. Shing \& C. F. Zhang & 单裂缝 Monolete & 金星蕨科 Thelypteridaceae & 金星蕨科 Thelypteridaceae \\
\hline 武陵毛蔴 Cyclosorus wulingshanensis C. M. Zhang & 单裂缝 Monolete & 金星蕨科 Thelypteridaceae & 金星蕨科 Thelypteridaceae \\
\hline 云南毛嵚 Cyclosorus yunnanensis Ching ex K. H. Shing & 单裂缝 Monolete & 金星藃科 Thelypteridaceae & 金星蕨科 Thelypteridaceae \\
\hline 朝芳毛荻 Cyclosorus zhangii K. H. Shing & 单裂缝 Monolete & 金星蕨科 Thelypteridaceae & 金星蕨科 Thelypteridaceae \\
\hline 圣蕨 Dictyocline griffithii T. Moore & 单裂缝 Monolete & 金星蕨科 Thelypteridaceae & 金星蕨科 Thelypteridaceae \\
\hline 羽裂圣苲 Dictyocline griffithii var. wilfordii ( Hook.) T. Moore & 单裂缝 Monolete & 金星颐科 Thelypteridaceae & 金星鄀科 Thelypteridaceae \\
\hline 闽浙圣蕨 Dictyocline mingchegensis Ching & 单裂缝 Monolete & 金星蕨科 Thelypteridaceae & 金星鄀科 Thelypteridaceae \\
\hline 戟叶圣蕨 Dictyocline sagittifolia Ching & 单裂缝 Monolete & 金星蕨科 Thelypteridaceae & 金星蕨科 Thelypteridaceae \\
\hline 峨眉方秆蕨 Glaphyropteridopsis emeiensis Y. X. Lin & 单裂缝 Monolete & 金星蕨科 Thelypteridaceae & 金星蕨科 Thelypteridaceae \\
\hline 毛囊方秆硕 Glaphyropteridopsis eriocarpa Ching & 单裂缝 Monolete & 金星蒴科 Thelypteridaceae & 金星鄀科 Thelypteridaceae \\
\hline 方秆蒴 Glaphyropteridopsis erubescens (Hook.) Ching & 单裂缝 Monolete & 金星葓科 Thelypteridaceae & 金星蕨科 Thelypteridaceae \\
\hline
\end{tabular}




\begin{tabular}{|c|c|c|c|}
\hline $\begin{array}{l}\text { 物种 } \\
\text { Species }\end{array}$ & $\begin{array}{l}\text { 孢子裂缝类型 } \\
\text { Spore apertures styles }\end{array}$ & $\begin{array}{l}\text { 科名 Family (秦仁 } \\
\text { 昌,1978a, b) }\end{array}$ & $\begin{array}{l}\text { 科名 Family (Smith et al., } \\
\text { 2006; Christenhusz et al, } \\
\text { 2011; 张宪春等, 2013) }\end{array}$ \\
\hline $\begin{array}{l}\text { 金佛山方秆偋 Glaphyropteridopsis jinfushanensis Ching \& Y. } \\
\text { X. Lin }\end{array}$ & 单裂缝 Monolete & 金星蕨科 Thelypteridaceae & 金星蕨科 Thelypteridaceae \\
\hline 柔弱方秆葓 Glaphyropteridopsis mollis Ching \& Y. X. Lin & 单裂缝 Monolete & 金星茨科 Thelypteridaceae & 金星蕨科 Thelypteridaceae \\
\hline 粉红方秆葓 Glaphyropteridopsis rufostraminea (Christ) Ching & 单裂缝 Monolete & 金星蕨科 Thelypteridaceae & 金星蕨科 Thelypteridaceae \\
\hline 四川方秆葓 Glaphyropteridopsis sichuanensisY. X. Lin & 单裂缝 Monolete & 金星硕科 Thelypteridaceae & 金星蒴科 Thelypteridaceae \\
\hline 大叶方秆硕 Glaphyropteridopsis splendens Ching & 单裂缝 Monolete & 金星硕科 Thelypteridaceae & 金星蒴科 Thelypteridaceae \\
\hline $\begin{array}{l}\text { 柔毛方秆蕨 Glaphyropteridopsis villosa Ching \& W. M. Chu ex } \\
\text { Y. X. Lin }\end{array}$ & 单裂缝 Monolete & 金星蒴科 Thelypteridaceae & 金星茨科 Thelypteridaceae \\
\hline 华中获脒 Leptogramma centrochinensis Ching ex Y. X. Lin & 单裂缝 Monolete & 金星硕科 Thelypteridaceae & 金星蒝科 Thelypteridaceae \\
\hline 喜马拉雅获蕨 Leptogramma himalaica Ching & 单裂缝 Monolete & 金星蕨科 Thelypteridaceae & 金星蕨科 Thelypteridaceae \\
\hline 惠水获硕 Leptogramma huishuiensis Ching ex Y. X. Lin & 单裂缝 Monolete & 金星嵚科 Thelypteridaceae & 金星蒝科 Thelypteridaceae \\
\hline 中间获蕨 Leptogramma intermedia Ching ex Y. X. Lin & 单裂缝 Monolete & 金星茨科 Thelypteridaceae & 金星蕨科 Thelypteridaceae \\
\hline 金佛山获蒴 Leptogramma jinfoshanensis Ching \& Z. Y. Liu & 单裂缝 Monolete & 金星蕨科 Thelypteridaceae & 金星蕨科 Thelypteridaceae \\
\hline 毛叶获嵚 Leptogramma pozoi (Lag.) Ching & 单裂缝 Monolete & 金星嵚科 Thelypteridaceae & 金星蒝科 Thelypteridaceae \\
\hline 峨眉获蒴 Leptogramma scallanii (Christ) Ching & 单裂缝 Monolete & 金星茨科 Thelypteridaceae & 金星蕨科 Thelypteridaceae \\
\hline 中华获䓲 Leptogramma sinica Ching ex Y. X. Lin & 单裂缝 Monolete & 金星薑科 Thelypteridaceae & 金星蕨科 Thelypteridaceae \\
\hline 小叶获蕨 Leptogramma tottoides H. Ito & 单裂缝 Monolete & 金星蒴科 Thelypteridaceae & 金星蒝科 Thelypteridaceae \\
\hline 雅安获嵚 Leptogramma yahanensis Ching ex Y. X. Lin & 单裂缝 Monolete & 金星蕨科 Thelypteridaceae & 金星蒴科 Thelypteridaceae \\
\hline 细裂针毛嵚 Macrothelypteris contingens Ching & 单裂缝 Monolete & 金星谓科 Thelypteridaceae & 金星蕨科 Thelypteridaceae \\
\hline 针毛濒 Macrothelypteris oligophlebia (Baker) Ching & 单裂缝 Monolete & 金星硕科 Thelypteridaceae & 金星蕨科 Thelypteridaceae \\
\hline $\begin{array}{l}\text { 长沙针毛蕨 Macrothelypteris oligophlebia var. changshaensis } \\
\text { (Ching) K. H. Shing }\end{array}$ & 单裂缝 Monolete & 金星茨科 Thelypteridaceae & 金星偋科 Thelypteridaceae \\
\hline
\end{tabular}




\begin{tabular}{|c|c|c|c|}
\hline $\begin{array}{l}\text { 物种 } \\
\text { Species }\end{array}$ & $\begin{array}{l}\text { 孢子裂缝类型 } \\
\text { Spore apertures styles }\end{array}$ & $\begin{array}{l}\text { 科名 Family (秦仁 } \\
\text { 昌,1978a, b) }\end{array}$ & $\begin{array}{l}\text { 科名 Family (Smith et al., } \\
\text { 2006; Christenhusz et al, } \\
\text { 2011; 张宪春等, 2013) }\end{array}$ \\
\hline 雅致针毛蕨 Macrothelypteris oligophlebia var. elegans (Koidz.) & 单裂缝 Monolete & 金星蕨科 Thelypteridaceae & 金星蕨科 Thelypteridaceae \\
\hline \multicolumn{4}{|l|}{ Ching } \\
\hline 树形针毛蕨 Macrothelypteris ornata (Bedd.) Ching & 单裂缝 Monolete & 金星媭科 Thelypteridaceae & 金星蕨科 Thelypteridaceae \\
\hline 杪椤针毛䕬 Macrothelypteris polypodioides (Hook.) Holttum & 单裂缝 Monolete & 金星颐科 Thelypteridaceae & 金星茨科 Thelypteridaceae \\
\hline 刚鳞针毛蒝 Macrothelypteris setigera (Blume) Ching & 单裂缝 Monolete & 金星葓科 Thelypteridaceae & 金星烣科 Thelypteridaceae \\
\hline 普通针毛荻 Macrothelypteris torresiana (Gaud.) Ching & 单裂缝 Monolete & 金星蒴科 Thelypteridaceae & 金星蕨科 Thelypteridaceae \\
\hline 翠绿针毛嵚 Macrothelypteris viridifrons (Tagawa) Ching & 单裂缝 Monolete & 金星锁科 Thelypteridaceae & 金星茨科 Thelypteridaceae \\
\hline 龙津偋 Mesopteris tonkinensis (C. Chr.) Ching & 单裂缝 Monolete & 金星硕科 Thelypteridaceae & 金星烣科 Thelypteridaceae \\
\hline 微毛凸轴硕 Metathelypteris adscendens (Ching) Ching & 单裂缝 Monolete & 金星蕨科 Thelypteridaceae & 金星蕨科 Thelypteridaceae \\
\hline 迷人凸轴荻 Metathelypteris decipiens (C. B. Clarke) Ching & 单裂缝 Monolete & 金星蕨科 Thelypteridaceae & 金星蕨科 Thelypteridaceae \\
\hline 三角叶凸轴甍 Metathelypteris deltoideofrons Ching ex W. M. & 单裂缝 Monolete & 金星媭科 Thelypteridaceae & 金星嵚科 Thelypteridaceae \\
\hline \multicolumn{4}{|l|}{ Chu \& S. G. Lu } \\
\hline 薄叶凸轴蕨 Metathelypteris flaccida (Blume) Ching & 单裂缝 Monolete & 金星蕨科 Thelypteridaceae & 金星蕨科 Thelypteridaceae \\
\hline 有腺凸轴蒾 Metathelypteris glandulifera Ching ex K. H. Shing & 单裂缝 Monolete & 金星媭科 Thelypteridaceae & 金星茨科 Thelypteridaceae \\
\hline 具腺凸轴鄀 Metathelypteris glandulosa $\mathrm{H}$. G. Zhou \& Hua Li & 单裂缝 Monolete & 金星蕨科 Thelypteridaceae & 金星蕨科 Thelypteridaceae \\
\hline 凸轴鄀 Metathelypteris gracilescens (Blume) Ching & 单裂缝 Monolete & 金星蕨科 Thelypteridaceae & 金星蕨科 Thelypteridaceae \\
\hline 林下凸轴鄀 Metathelypteris hattorii (H. Ito) Ching & 单裂缝 Monolete & 金星罝科 Thelypteridaceae & 金星嵚科 Thelypteridaceae \\
\hline 疏羽凸轴荻 Metathelypteris laxa (Franch. \& Sav.) Ching & 单裂缝 Monolete & 金星蒴科 Thelypteridaceae & 金星蕨科 Thelypteridaceae \\
\hline 有柄凸轴荻 Metathelypteris petiolulata Ching ex K. H. Shing & 单裂缝 Monolete & 金星蕨科 Thelypteridaceae & 金星蕨科 Thelypteridaceae \\
\hline 鲜绿凸轴荻 Metathelypteris singalanensis (Baker) Ching & 单裂缝 Monolete & 金星锁科 Thelypteridaceae & 金星茨科 Thelypteridaceae \\
\hline 乌来凸轴鄀 Metathelypteris uraiensis (Rosenst.) Ching & 单裂缝 Monolete & 金星蒴科 Thelypteridaceae & 金星蕨科 Thelypteridaceae \\
\hline 西藏凸轴蕨 Metathelypteris uraiensis var. tibetica (Ching \& & 单裂缝 Monolete & 金星蒴科 Thelypteridaceae & 金星嵚科 Thelypteridaceae \\
\hline
\end{tabular}




\begin{tabular}{|c|c|c|c|}
\hline $\begin{array}{l}\text { 物种 } \\
\text { Species }\end{array}$ & $\begin{array}{l}\text { 孢子裂缝类型 } \\
\text { Spore apertures styles }\end{array}$ & $\begin{array}{l}\text { 科名 Family (秦仁 } \\
\text { 昌,1978a, b) }\end{array}$ & $\begin{array}{l}\text { 科名 Family (Smith et al., } \\
\text { 2006; Christenhusz et al, } \\
\text { 2011; 张宪春等, 2013) }\end{array}$ \\
\hline \multicolumn{4}{|l|}{ S.K. Wu) K.H. Shing } \\
\hline 武夷山凸轴烣 Metathelypteris wuyishanica Ching & 单裂缝 Monolete & 金星藣科 Thelypteridaceae & 金星茨科 Thelypteridaceae \\
\hline 钝角金星蕨 Parathelypteris angulariloba (Ching) Ching & 单裂缝 Monolete & 金星蕨科 Thelypteridaceae & 金星蕨科 Thelypteridaceae \\
\hline 狭叶金星硕 Parathelypteris angustifrons (Miq.) Ching & 单裂缝 Monolete & 金星蒴科 Thelypteridaceae & 金星蕨科 Thelypteridaceae \\
\hline 长根金星䕬 Parathelypteris beddomei (Baker) Ching & 单裂缝 Monolete & 金星硕科 Thelypteridaceae & 金星硕科 Thelypteridaceae \\
\hline 狭脚金星嵚 Parathelypteris borealis (Hara) K. H. Shing & 单裂缝 Monolete & 金星蒴科 Thelypteridaceae & 金星蕨科 Thelypteridaceae \\
\hline 台湾金星蕨 Parathelypteris castanea (Tagawa) Ching & 单裂缝 Monolete & 金星钼科 Thelypteridaceae & 金星蕨科 Thelypteridaceae \\
\hline 马蹄金星荹 Parathelypteris cystopteroides (A. A. Eaton) Ching & 单裂缝 Monolete & 金星硕科 Thelypteridaceae & 金星硕科 Thelypteridaceae \\
\hline 金星荻 Parathelypteris glanduligera (Kunze) Ching & 单裂缝 Monolete & 金星蕨科 Thelypteridaceae & 金星蕨科 Thelypteridaceae \\
\hline 矮小金星蒴 Parathelypteris grammitoides (Christ) Ching & 单裂缝 Monolete & 金星葓科 Thelypteridaceae & 金星嵚科 Thelypteridaceae \\
\hline 毛脚金星蕨 Parathelypteris hirsutipes (C. B. Clarke) Ching & 单裂缝 Monolete & 金星藃科 Thelypteridaceae & 金星蒴科 Thelypteridaceae \\
\hline 滇越金星蕨 Parathelypteris indochinensis (Christ) Ching & 单裂缝 Monolete & 金星蕨科 Thelypteridaceae & 金星蕨科 Thelypteridaceae \\
\hline 光脚金星蕨 Parathelypteris japonica (Baker) Ching & 单裂缝 Monolete & 金星蕨科 Thelypteridaceae & 金星蕨科 Thelypteridaceae \\
\hline $\begin{array}{l}\text { 光叶金星蕨 Parathelypteris japonica var. glabrata (Ching) K. } \\
\text { H. Shing }\end{array}$ & 单裂缝 Monolete & 金星蕨科 Thelypteridaceae & 金星蕨科 Thelypteridaceae \\
\hline $\begin{array}{l}\text { 禾秆金星蕨 Parathelypteris japonica var. musashiensis } \\
\text { (Hiyama) Jiang }\end{array}$ & 单裂缝 Monolete & 金星嵚科 Thelypteridaceae & 金星蕨科 Thelypteridaceae \\
\hline 中日金星㓹 Parathelypteris nipponica (Franch. \& Sav.) Ching & 单裂缝 Monolete & 金星蕨科 Thelypteridaceae & 金星鄀科 Thelypteridaceae \\
\hline 长毛金星㓹 Parathelypteris petelotii (Ching) Ching & 单裂缝 Monolete & 金星蕨科 Thelypteridaceae & 金星蕨科 Thelypteridaceae \\
\hline 有齿金星嵚 Parathelypteris serrutula (Ching) Ching & 单裂缝 Monolete & 金星莜科 Thelypteridaceae & 金星嵚科 Thelypteridaceae \\
\hline 海南金星荻 Parathelypteris subimmersa (Ching) Ching & 单裂缝 Monolete & 金星蒴科 Thelypteridaceae & 金星鄀科 Thelypteridaceae \\
\hline 卵果蕨 Phegopteris connectilis (Michx.) Watt & 单裂缝 Monolete & 金星蕨科 Thelypteridaceae & 金星蕨科 Thelypteridaceae \\
\hline
\end{tabular}




\begin{tabular}{|c|c|c|c|}
\hline $\begin{array}{l}\text { 物种 } \\
\text { Species }\end{array}$ & $\begin{array}{l}\text { 孢子裂缝类型 } \\
\text { Spore apertures styles }\end{array}$ & $\begin{array}{l}\text { 科名 Family (秦仁 } \\
\text { 昌,1978a, b) }\end{array}$ & $\begin{array}{l}\text { 科名 Family (Smith et al., } \\
\text { 2006; Christenhusz et al, } \\
\text { 2011; 张宪春等, 2013) }\end{array}$ \\
\hline 延羽卵果蕨 Phegopteris decursive-pinnata (van Hall) Fée & 单裂缝 Monolete & 金星蕨科 Thelypteridaceae & 金星蕨科 Thelypteridaceae \\
\hline 西藏卵果硕 Phegopteris tibetica Ching & 单裂缝 Monolete & 金星葓科 Thelypteridaceae & 金星蒴科 Thelypteridaceae \\
\hline 顶芽新月蕨 Pronephrium cuspidatum (Blume) Holttum & 单裂缝 Monolete & 金星蕨科 Thelypteridaceae & 金星蕨科 Thelypteridaceae \\
\hline 小叶新月蕨 Pronephrium gracilis Ching \& Y. X. Lin & 单裂缝 Monolete & 金星颐科 Thelypteridaceae & 金星茨科 Thelypteridaceae \\
\hline 新月瞢 Pronephrium gymnopteridifrons (Hayata) Holttum & 单裂缝 Monolete & 金星葓科 Thelypteridaceae & 金星蒴科 Thelypteridaceae \\
\hline 河口新月蕨 Pronephrium hekouense Ching \& Y. X. Lin & 单裂缝 Monolete & 金星蒴科 Thelypteridaceae & 金星蕨科 Thelypteridaceae \\
\hline 针毛新月蕨 Pronephrium hirsutum Ching \& Y. X. Lin & 单裂缝 Monolete & 金星锁科 Thelypteridaceae & 金星茨科 Thelypteridaceae \\
\hline 岛生新月藤 Pronephrium insularis (K. Iwats.) Holttum & 单裂缝 Monolete & 金星硕科 Thelypteridaceae & 金星蔜科 Thelypteridaceae \\
\hline 红色新月蕨 Pronephrium lakhimpurense (Rosenst.) Holttum & 单裂缝 Monolete & 金星蕨科 Thelypteridaceae & 金星蕨科 Thelypteridaceae \\
\hline 长柄新月㓹 Pronephrium longipetiolatum (K. Iwats.) Holttum & 单裂缝 Monolete & 金星葓科 Thelypteridaceae & 金星烣科 Thelypteridaceae \\
\hline 硕羽新月蒝 Pronephrium macrophyllum Ching \& Y. X. Lin & 单裂缝 Monolete & 金星硕科 Thelypteridaceae & 金星硕科 Thelypteridaceae \\
\hline 墨脱新月硕 Pronephrium medogense Y.X. Lin & 单裂缝 Monolete & 金星蕨科 Thelypteridaceae & 金星蕨科 Thelypteridaceae \\
\hline 微红新月薜 Pronephrium megacuspe (Baker) Holttum & 单裂缝 Monolete & 金星莜科 Thelypteridaceae & 金星蕨科 Thelypteridaceae \\
\hline 大羽新月蒝 Pronephrium nudatum (Roxb.) Holttum & 单裂缝 Monolete & 金星硕科 Thelypteridaceae & 金星蒝科 Thelypteridaceae \\
\hline 披针新月菜 Pronephrium penangianum (Hook.) Holttum & 单裂缝 Monolete & 金星蕨科 Thelypteridaceae & 金星蕨科 Thelypteridaceae \\
\hline 刚毛新月蕨 Pronephrium setosum Y. X. Lin & 单裂缝 Monolete & 金星颐科 Thelypteridaceae & 金星蕨科 Thelypteridaceae \\
\hline 单叶新月葓 Pronephrium simplex (Hook.) Holttum & 单裂缝 Monolete & 金星葓科 Thelypteridaceae & 金星蒴科 Thelypteridaceae \\
\hline 三羽新月蕨 Pronephrium triphyllum (Sw.) Holttum & 单裂缝 Monolete & 金星蒴科 Thelypteridaceae & 金星萩科 Thelypteridaceae \\
\hline $\begin{array}{l}\text { 羽叶新月蕨 Pronephrium triphyllum var. parishii (Bedd.) C. M. } \\
\text { Kuo }\end{array}$ & 单裂缝 Monolete & 金星蕨科 Thelypteridaceae & 金星蕨科 Thelypteridaceae \\
\hline $\begin{array}{l}\text { 喜马拉雅假毛蕨 Pseudocyclosorus canus (Baker) Holttum \& } \\
\text { Grimes }\end{array}$ & 单裂缝 Monolete & 金星蕨科 Thelypteridaceae & 金星薪科 Thelypteridaceae \\
\hline
\end{tabular}




\begin{tabular}{|c|c|c|c|}
\hline $\begin{array}{l}\text { 物种 } \\
\text { Species }\end{array}$ & $\begin{array}{l}\text { 孢子裂缝类型 } \\
\text { Spore apertures styles }\end{array}$ & $\begin{array}{l}\text { 科名 Family (秦仁 } \\
\text { 昌,1978a, b) }\end{array}$ & $\begin{array}{l}\text { 科名 Family (Smith et al., } \\
\text { 2006; Christenhusz et al, } \\
\text { 2011; 张宪春等, 2013) }\end{array}$ \\
\hline 尾羽假毛蕨 Pseudocyclosorus caudipinnus (Ching) Ching & 单裂缝 Monolete & 金星蕨科 Thelypteridaceae & 金星蕨科 Thelypteridaceae \\
\hline 青岩假毛蕨 Pseudocyclosorus cavaleriei (H. Lév.) Y. X. Lin & 单裂缝 Monolete & 金星葓科 Thelypteridaceae & 金星烣科 Thelypteridaceae \\
\hline 溪边假毛蕨 Pseudocyclosorus ciliatus (Benth.) Ching & 三裂缝 Trilete & 金星蕨科 Thelypteridaceae & 金星蕨科 Thelypteridaceae \\
\hline 苍山假毛蕨 Pseudocyclosorus duclouxii (Christ) Ching & 单裂缝 Monolete & 金星颐科 Thelypteridaceae & 金星茨科 Thelypteridaceae \\
\hline 西南假毛蕨 Pseudocyclosorus esquirolii (Christ) Ching & 单裂缝 Monolete & 金星葓科 Thelypteridaceae & 金星烣科 Thelypteridaceae \\
\hline 镰片假毛䕬 Pseudocyclosorus falcilobus (Hook.) Ching & 单裂缝 Monolete & 金星蒴科 Thelypteridaceae & 金星蕨科 Thelypteridaceae \\
\hline 阔片假毛蕨 Pseudocyclosorus latilobus (Ching) Ching & 单裂缝 Monolete & 金星锁科 Thelypteridaceae & 金星茨科 Thelypteridaceae \\
\hline $\begin{array}{l}\text { 独龙江假毛蕂 Pseudocyclosorus ornatipes Holltum \& J. W. } \\
\text { Grimes }\end{array}$ & 单裂缝 Monolete & 金星蕨科 Thelypteridaceae & 金星鄀科 Thelypteridaceae \\
\hline $\begin{array}{l}\text { 武宁假毛蕨 Pseudocyclosorus paraochthodes Ching ex K. H. } \\
\text { Shing ex J. F. Cheng }\end{array}$ & 单裂缝 Monolete & 金星蕨科 Thelypteridaceae & 金星蕨科 Thelypteridaceae \\
\hline $\begin{array}{l}\text { 双柏假毛蕒 Pseudocyclosorus shuangbaiensis Ching ex Y.X. } \\
\text { Lin }\end{array}$ & 单裂缝 Monolete & 金星蕨科 Thelypteridaceae & 金星蕨科 Thelypteridaceae \\
\hline 普通假毛鄀 Pseudocyclosorus subochthodes (Ching) Ching & 单裂缝 Monolete & 金星蕨科 Thelypteridaceae & 金星蕨科 Thelypteridaceae \\
\hline 西藏假毛蕨 Pseudocyclosorus tibeticus Ching \& Y.X. Lin & 单裂缝 Monolete & 金星蕨科 Thelypteridaceae & 金星蕨科 Thelypteridaceae \\
\hline 假毛蕨 Pseudocyclosorus tylodes (Kunze) Holttum & 单裂缝 Monolete & 金星蕨科 Thelypteridaceae & 金星蕨科 Thelypteridaceae \\
\hline 察隅假毛兴 Pseudocyclosorus zayuensis Ching \& S. K. Wu & 单裂缝 Monolete & 金星罝科 Thelypteridaceae & 金星嵚科 Thelypteridaceae \\
\hline 耳状紫柄㓹 Pseudophegopteris aurita (Hook.) Ching & 单裂缝 Monolete & 金星蒴科 Thelypteridaceae & 金星蕨科 Thelypteridaceae \\
\hline 短柄紫柄蕨 Pseudophegopteris brevipes Ching & 单裂缝 Monolete & 金星蕨科 Thelypteridaceae & 金星蕨科 Thelypteridaceae \\
\hline 密毛紫柄菜 Pseudophegopteris hirtirachis (C. Chr.) Holttum & 单裂缝 Monolete & 金星锁科 Thelypteridaceae & 金星茨科 Thelypteridaceae \\
\hline 星毛紫柄荻 Pseudophegopteris levingei (C. B. Clarke) Ching & 单裂缝 Monolete & 金星蒴科 Thelypteridaceae & 金星鄀科 Thelypteridaceae \\
\hline 禾秆紫柄硕 Pseudophegopteris microstegia (Hook.) Ching & 单裂缝 Monolete & 金星蒴科 Thelypteridaceae & 金星嵚科 Thelypteridaceae \\
\hline
\end{tabular}




\begin{tabular}{|c|c|c|c|}
\hline $\begin{array}{l}\text { 物种 } \\
\text { Species }\end{array}$ & $\begin{array}{l}\text { 孢子裂缝类型 } \\
\text { Spore apertures styles }\end{array}$ & $\begin{array}{l}\text { 科名 Family (秦仁 } \\
\text { 昌,1978a, b) }\end{array}$ & $\begin{array}{l}\text { 科名 Family (Smith et al., } \\
\text { 2006; Christenhusz et al, } \\
\text { 2011; 张宪春等, 2013) }\end{array}$ \\
\hline 毛囊紫柄锁 Pseudophegopteris paludosa (Blume) Ching & 单裂缝 Monolete & 金星蕨科 Thelypteridaceae & 金星蕨科 Thelypteridaceae \\
\hline 紫柄䕬 Pseudophegopteris pyrrhorachis (Kunze) Ching & 单裂缝 Monolete & 金星蒴科 Thelypteridaceae & 金星硕科 Thelypteridaceae \\
\hline $\begin{array}{l}\text { 光叶紫柄硕 Pseudophegopteris pyrrhorachis var. glabrata } \\
\text { (Clarke) Holttum }\end{array}$ & 单裂缝 Monolete & 金星蕨科 Thelypteridaceae & 金星蕨科 Thelypteridaceae \\
\hline 对生紫柄嵚 Pseudophegopteris rectangularis (Zoll.) Holttum & 单裂缝 Monolete & 金星蒴科 Thelypteridaceae & 金星鄀科 Thelypteridaceae \\
\hline 光囊紫柄硕 Pseudophegopteris subaurita (Tagawa) Ching & 单裂缝 Monolete & 金星蒴科 Thelypteridaceae & 金星蕨科 Thelypteridaceae \\
\hline 西藏紫柄硕 Pseudophegopteris tibetana Ching \& S. K. Wu & 单裂缝 Monolete & 金星蕒科 Thelypteridaceae & 金星蕨科 Thelypteridaceae \\
\hline 易贡紫柄嵚 Pseudophegopteris yigongensis Ching & 单裂缝 Monolete & 金星茨科 Thelypteridaceae & 金星蒴科 Thelypteridaceae \\
\hline 云贵紫柄菜 Pseudophegopteris yunkweiensis (Ching) Ching & 单裂缝 Monolete & 金星蓟科 Thelypteridaceae & 金星烣科 Thelypteridaceae \\
\hline 察隅紫柄嵚 Pseudophegopteris zayuensis Ching \& S. K. Wu & 单裂缝 Monolete & 金星蕨科 Thelypteridaceae & 金星臀科 Thelypteridaceae \\
\hline 贯众叶溪边鄀 Stegnogramma cyrtomioides (C. Chr.) Ching & 单裂缝 Monolete & 金星溦科 Thelypteridaceae & 金星蒴科 Thelypteridaceae \\
\hline 屏边溪边蕨 Stegnogramma dictyoclinoides Ching & 单裂缝 Monolete & 金星蕨科 Thelypteridaceae & 金星蕨科 Thelypteridaceae \\
\hline 缙云溪边茨 Stegnogramma diplazioides Ching ex Y. X. Lin & 单裂缝 Monolete & 金星蕨科 Thelypteridaceae & 金星臀科 Thelypteridaceae \\
\hline 兴文溪边蕨 Stegnogramma xingwenensis Ching ex Y. X. Lin & 单裂缝 Monolete & 金星蕨科 Thelypteridaceae & 金星蕨科 Thelypteridaceae \\
\hline 鳞片沼泽蒴 Thelypteris confluens (Thunb.) C. V. Morton & 单裂缝 Monolete & 金星溦科 Thelypteridaceae & 金星蒴科 Thelypteridaceae \\
\hline 沼泽蕨 Thelypteris palustris (Salisb.) Schott & 单裂缝 Monolete & 金星蕨科 Thelypteridaceae & 金星臀科 Thelypteridaceae \\
\hline 毛叶沼泽荻 Thelypteris palustris var. pubescens (Lawson) & 单裂缝 Monolete & 金星蕨科 Thelypteridaceae & 金星蕨科 Thelypteridaceae \\
\hline \multicolumn{4}{|l|}{ Fernald } \\
\hline 长叶滇蕨 Cheilanthopsis elongata (Hook.) Copel. & 单裂缝 Monolete & 岩蕨科 Woodsiaceae & 岩蕨科 Woodsiaceae \\
\hline 滇鄀 Cheilanthopsis indusiosa (Christ) Ching & 单裂缝 Monolete & 岩蕨科 Woodsiaceae & 岩蕨科 Woodsiaceae \\
\hline 膀胱荻 Protowoodsia manchuriensis (Hook.) Ching & 单裂缝 Monolete & 岩蕨科 Woodsiaceae & 岩蕨科 Woodsiaceae \\
\hline 渐尖岩蕨 Woodsia acuminata (Fomin) Sipl. & 单裂缝 Monolete & 岩蕨科 Woodsiaceae & 岩蕨科 Woodsiaceae \\
\hline
\end{tabular}




\begin{tabular}{|c|c|c|c|}
\hline $\begin{array}{l}\text { 物种 } \\
\text { Species }\end{array}$ & $\begin{array}{l}\text { 孢子裂缝类型 } \\
\text { Spore apertures styles }\end{array}$ & $\begin{array}{l}\text { 科名 Family (秦仁 } \\
\text { 昌,1978a, b) }\end{array}$ & $\begin{array}{l}\text { 科名 Family (Smith et al., } \\
\text { 2006; Christenhusz et al, } \\
\text { 2011; 张宪春等, 2013) }\end{array}$ \\
\hline 西疆岩蕨 Woodsia alpina (Boltan) Gray & 单裂缝 Monolete & 岩蕨科 Woodsiaceae & 岩蕨科 Woodsiaceae \\
\hline 蜘蛛岩菜 Woodsia andersonii (Bedd.) Christ & 单裂缝 Monolete & 岩蒴科 Woodsiaceae & 岩蒝科 Woodsiaceae \\
\hline 赤色岩蒴 Woodsia cinnamomea Christ & 单裂缝 Monolete & 岩媭科 Woodsiaceae & 岩蕨科 Woodsiaceae \\
\hline 栗柄岩濒 Woodsia cycloloba Hand.-Mazz. & 单裂缝 Monolete & 岩蕨科 Woodsiaceae & 岩蕨科 Woodsiaceae \\
\hline 疏裂岩硕 Woodsia frondosa Christ & 单裂缝 Monolete & 岩蒝科 Woodsiaceae & 岩蒝科 Woodsiaceae \\
\hline 光岩嵚 Woodsia glabella R. Brown ex Richards. & 单裂缝 Monolete & 岩蒝科 Woodsiaceae & 岩蕨科 Woodsiaceae \\
\hline 华北岩烣 Woodsia hancockii Baker & 单裂缝 Monolete & 岩蒝科 Woodsiaceae & 岩偋科 Woodsiaceae \\
\hline 岩蒴 Woodsia ilvensis (L.) R. Brown & 单裂缝 Monolete & 岩蒝科 Woodsiaceae & 岩蒝科 Woodsiaceae \\
\hline 东亚岩蒴 Woodsia intermedia Tagawa & 单裂缝 Monolete & 岩茨科 Woodsiaceae & 岩蕨科 Woodsiaceae \\
\hline 毛盖岩荻 Woodsia lanosa Hook. & 单裂缝 Monolete & 岩蕨科 Woodsiaceae & 岩蕨科 Woodsiaceae \\
\hline 大囊岩菜 Woodsia macrochlaena Mett. ex Kuhn & 单裂缝 Monolete & 岩蒝科 Woodsiaceae & 岩蒝科 Woodsiaceae \\
\hline 甘南岩蒴 Woodsia macrospora C. Chr. \& Maxon & 单裂缝 Monolete & 岩蒴科 Woodsiaceae & 岩蕨科 Woodsiaceae \\
\hline 妙峰岩蒴 Woodsia oblonga Ching \& S. H. Wu & 单裂缝 Monolete & 岩蕨科 Woodsiaceae & 岩蕨科 Woodsiaceae \\
\hline 冈本氏岩葓 Woodsia okamotoi Tagawa & 单裂缝 Monolete & 岩蒝科 Woodsiaceae & 岩蒝科 Woodsiaceae \\
\hline 嵩县岩嵚 Woodsia pilosa Ching & 单裂缝 Monolete & 岩蒴科 Woodsiaceae & 岩偋科 Woodsiaceae \\
\hline 耳羽岩茨 Woodsia polystichoides D. C. Eaton & 单裂缝 Monolete & 岩䕬科 Woodsiaceae & 岩蕨科 Woodsiaceae \\
\hline 密毛岩葓 Woodsia rosthorniana Diels & 单裂缝 Monolete & 岩蒝科 Woodsiaceae & 岩蒝科 Woodsiaceae \\
\hline 神农岩蒴 Woodsia shennongensis D. S. Jiang \& D. M. Chen & 单裂缝 Monolete & 岩偋科 Woodsiaceae & 岩蒝科 Woodsiaceae \\
\hline 陕西岩蒴 Woodsia shensiensis Ching & 单裂缝 Monolete & 岩蕨科 Woodsiaceae & 岩偋科 Woodsiaceae \\
\hline 山西岩蕨 Woodsia sinica Ching & 单裂缝 Monolete & 岩蒝科 Woodsiaceae & 岩蒝科 Woodsiaceae \\
\hline 等基岩藃 Woodsia subcordata Turcz. & 单裂缝 Monolete & 岩蒝科 Woodsiaceae & 岩蒝科 Woodsiaceae \\
\hline 狭翅短肠烣 Allantodia alata (Christ) Ching & 单裂缝 Monolete & 蹄盖蒴科 Athyriaceae & 蹄盖蕨科 Athyriaceae \\
\hline
\end{tabular}


魏雪苹，张宪春．蒴类植物不同狍子裂缝类型在中国的分布格局. 生物多样性，2016，24(10)：1129-1134 http://www. biodiversity - science. net/CN/10. 17520/biods. 2016219

\begin{tabular}{|c|c|c|c|}
\hline $\begin{array}{l}\text { 物种 } \\
\text { Species }\end{array}$ & $\begin{array}{l}\text { 孢子裂缝类型 } \\
\text { Spore apertures styles }\end{array}$ & $\begin{array}{l}\text { 科名 Family (秦仁 } \\
\text { 昌,1978a, b) }\end{array}$ & $\begin{array}{l}\text { 科名 Family (Smith et al., } \\
\text { 2006; Christenhusz et al, } \\
\text { 2011; 张宪春等, 2013) }\end{array}$ \\
\hline $\begin{array}{l}\text { 奄美短肠葓 Allantodia amamiana (Tagawa) W. M. Chu \& Z. R. } \\
\mathrm{He}\end{array}$ & 单裂缝 Monolete & 蹄盖蕨科 Athyriaceae & 蹄盖蕨科 Athyriaceae \\
\hline 安顺短肠脒 Allantodia anshunica P. S. Wang & 单裂缝 Monolete & 蹄盖蕨科 Athyriaceae & 蹄盖荻科 Athyriaceae \\
\hline 粗徏短肠䕨 Allantodia aspera (Blume) Ching & 单裂缝 Monolete & 蹄盖屏科 Athyriaceae & 蹄盖锁科 Athyriaceae \\
\hline 百山祖短肠蒴 Allantodia baishanzuensis Ching & 单裂缝 Monolete & 蹄盖鄀科 Athyriaceae & 蹄盖锁科 Athyriaceae \\
\hline 美丽短肠嵚 Allantodia bella (C. B. Clarke) Ching & 单裂缝 Monolete & 蹄盖蕨科 Athyriaceae & 蹄盖蕨科 Athyriaceae \\
\hline 长果短肠蕨 Allantodia calogramma (Christ) Ching & 单裂缝 Monolete & 蹄盖嵚科 Athyriaceae & 蹄盖锁科 Athyriaceae \\
\hline $\begin{array}{l}\text { 拟长果短肠茨 Allantodia calogrammoides Ching ex W. M. Chu } \\
\text { \& Z. R. He }\end{array}$ & 单裂缝 Monolete & 蹄盖蕨科 Athyriaceae & 蹄盖蕨科 Athyriaceae \\
\hline 中华短肠蕨 Allantodia chinensis (Baker) Ching & 单裂缝 Monolete & 蹄盖䓲科 Athyriaceae & 蹄盖锁科 Athyriaceae \\
\hline 边生短肠薑 Allantodia contermina (Christ) Ching & 单裂缝 Monolete & 蹄盖屏科 Athyriaceae & 蹄盖锁科 Athyriaceae \\
\hline 黑鳞短肠荻 Allantodia crenata (Sommerf.) Ching & 单裂缝 Monolete & 蹄盖蕨科 Athyriaceae & 蹄盖蕨科 Athyriaceae \\
\hline $\begin{array}{l}\text { 无毛黑鳞短肠茨 Allantodia crenata var. glabra (Tagawa) W. } \\
\text { M. Chu }\end{array}$ & 单裂缝 Monolete & 蹄盖蕨科 Athyriaceae & 蹄盖蕨科 Athyriaceae \\
\hline 毛柄短肠蒴 Allantodia dilatata (Blume) Ching & 单裂缝 Monolete & 蹄盖蕨科 Athyriaceae & 蹄盖蕨科 Athyriaceae \\
\hline 光脚短肠蒴 Allantodia doederleinii (Luerss.) Ching & 单裂缝 Monolete & 蹄盖嵚科 Athyriaceae & 蹄盖锁科 Athyriaceae \\
\hline 独龙江短肠鄀 Allantodia dulongjiangensis W. M. Chu & 单裂缝 Monolete & 蹄盖嵚科 Athyriaceae & 蹄盖锁科 Athyriaceae \\
\hline $\begin{array}{l}\text { 独山短肠葓 Allantodia dushanensis Ching ex W. M. Chu \& Z. } \\
\text { R. He }\end{array}$ & 单裂缝 Monolete & 蹄盖蕨科 Athyriaceae & 蹄盖媭科 Athyriaceae \\
\hline 大型短肠蕒 Allantodia gigantea (Bot.) Ching & 单裂缝 Monolete & 蹄盖蕨科 Athyriaceae & 蹄盖蕨科 Athyriaceae \\
\hline 格林短肠鰀 Allantodia glingensis Ching \& Y. X. Lin & 单裂缝 Monolete & 蹄盖嵚科 Athyriaceae & 蹄盖锁科 Athyriaceae \\
\hline 镰羽短肠蒴 Allantodia griffithii (T. Moore) Ching & 单裂缝 Monolete & 蹄盖嵚科 Athyriaceae & 蹄盖锁科 Athyriaceae \\
\hline
\end{tabular}




\begin{tabular}{|c|c|c|c|}
\hline $\begin{array}{l}\text { 物种 } \\
\text { Species }\end{array}$ & $\begin{array}{l}\text { 孢子裂缝类型 } \\
\text { Spore apertures styles }\end{array}$ & $\begin{array}{l}\text { 科名 Family (秦仁 } \\
\text { 昌,1978a, b) }\end{array}$ & $\begin{array}{l}\text { 科名 Family (Smith et al., } \\
\text { 2006; Christenhusz et al, } \\
\text { 2011; 张宪春等, 2013) }\end{array}$ \\
\hline 薄盖短肠蕨 Allantodia hachijoensis (Nakai) Ching & 单裂缝 Monolete & 蹄盖葓科 Athyriaceae & 蹄盖锁科 Athyriaceae \\
\hline 海南短肠蕨 Allantodia hainanensis Ching & 单裂缝 Monolete & 蹄盖蒴科 Athyriaceae & 蹄盖葓科 Athyriaceae \\
\hline 异果短肠嵚 Allantodia heterocarpa (Ching) Ching & 单裂缝 Monolete & 蹄盖蕨科 Athyriaceae & 蹄盖蕨科 Athyriaceae \\
\hline 褐色短肠蕂 Allantodia himalayensis Ching & 单裂缝 Monolete & 蹄盖蒴科 Athyriaceae & 蹄盖蒴科 Athyriaceae \\
\hline 篦齿短肠蒝 Allantodia hirsutipes (Bedd.) Ching & 单裂缝 Monolete & 蹄盖葓科 Athyriaceae & 蹄盖莜科 Athyriaceae \\
\hline 鳞轴短肠萩 Allantodia hirtipes (Christ) Ching & 单裂缝 Monolete & 蹄盖蕨科 Athyriaceae & 蹄盖蕨科 Athyriaceae \\
\hline 黑鳞鳞轴短肠嵚 Allantodia hirtipes f. nigropaleacea Ching & 单裂缝 Monolete & 蹄盖蒴科 Athyriaceae & 蹄盖蒴科 Athyriaceae \\
\hline 毛鳞短肠瞢 Allantodia hirtisquama Ching \& W. M. Chu & 单裂缝 Monolete & 蹄盖莜科 Athyriaceae & 蹄盖莜科 Athyriaceae \\
\hline 疏裂短肠蒴 Allantodia incompta (Tagawa) Ching & 单裂缝 Monolete & 蹄盖䕋科 Athyriaceae & 蹄盖蕨科 Athyriaceae \\
\hline 金佛山短肠薑 Allantodia jinfoshanicola W. M. Chu & 单裂缝 Monolete & 蹄盖蒴科 Athyriaceae & 蹄盖莜科 Athyriaceae \\
\hline 金平短肠莜 Allantodia jinpingensis W. M. Chu & 单裂缝 Monolete & 蹄盖蒴科 Athyriaceae & 蹄盖蒴科 Athyriaceae \\
\hline 甘肃短肠蕨 Allantodia kansuensis Ching & 单裂缝 Monolete & 蹄盖蕨科 Athyriaceae & 蹄盖蕨科 Athyriaceae \\
\hline 台湾短肠蕨 Allantodia kappanensis (Tagawa) Ching & 单裂缝 Monolete & 蹄盖蕨科 Athyriaceae & 蹄盖蕨科 Athyriaceae \\
\hline 柄鳞短肠嵚 Allantodia kawakamii (Hayata) Ching & 单裂缝 Monolete & 蹄盖偋科 Athyriaceae & 蹄盖偋科 Athyriaceae \\
\hline 阔羽短肠硕 Allantodia latipinnula Ching \& W. M. Chu & 单裂缝 Monolete & 蹄盖蕨科 Athyriaceae & 蹄盖蕨科 Athyriaceae \\
\hline 异裂短肠鄀 Allantodia laxifrons (Rosent.) Ching & 单裂缝 Monolete & 蹄盖蕨科 Athyriaceae & 蹄盖蕨科 Athyriaceae \\
\hline 卵叶短肠蕨 Allantodia leptophylla (Christ) Ching & 单裂缝 Monolete & 蹄盖菜科 Athyriaceae & 蹄盖蒴科 Athyriaceae \\
\hline 浅裂短肠鳜 Allantodia lobulosa (Wall. ex Mett.) Ching & 单裂缝 Monolete & 蹄盖蕨科 Athyriaceae & 蹄盖蕨科 Athyriaceae \\
\hline $\begin{array}{l}\text { 石林短肠茨 Allantodia lobulosa var. shilinicola W. M. Chu \& J. } \\
\text { J. He }\end{array}$ & 单裂缝 Monolete & 蹄盖臀科 Athyriaceae & 蹄盖蕨科 Athyriaceae \\
\hline 阔片短肠蒴 Allantodia matthewii (Copel.) Ching & 单裂缝 Monolete & 蹄盖蒴科 Athyriaceae & 蹄盖蒴科 Athyriaceae \\
\hline 大叶短肠蕨 Allantodia maxima (D. Don) Ching & 单裂缝 Monolete & 蹄盖蕨科 Athyriaceae & 蹄盖蕨科 Athyriaceae \\
\hline
\end{tabular}




\begin{tabular}{|c|c|c|c|}
\hline $\begin{array}{l}\text { 物种 } \\
\text { Species }\end{array}$ & $\begin{array}{l}\text { 孢子裂缝类型 } \\
\text { Spore apertures styles }\end{array}$ & $\begin{array}{l}\text { 科名 Family (秦仁 } \\
\text { 昌,1978a, b) }\end{array}$ & $\begin{array}{l}\text { 科名 Family (Smith et al., } \\
\text { 2006; Christenhusz et al, } \\
\text { 2011; 张宪春等, 2013) }\end{array}$ \\
\hline 墨脱短肠莜 Allantodia medogensis Ching \& S. K. Wu & 单裂缝 Monolete & 蹄盖茨科 Athyriaceae & 蹄盖菜科 Athyriaceae \\
\hline 大羽短肠蒝 Allantodia megaphylla (Baker) Ching & 单裂缝 Monolete & 蹄盖烣科 Athyriaceae & 蹄盖烚科 Athyriaceae \\
\hline 深裂短肠蒴 Allantodia metcalfii (Ching) Ching & 单裂缝 Monolete & 蹄盖茨科 Athyriaceae & 蹄盖茨科 Athyriaceae \\
\hline 江南短肠脄 Allantodia metteniana (Miq.) Ching & 单裂缝 Monolete & 蹄盖茨科 Athyriaceae & 蹄盖谓科 Athyriaceae \\
\hline 小叶短肠茨 Allantodia metteniana var. fauriei (Christ) Ching & 单裂缝 Monolete & 蹄盖烣科 Athyriaceae & 蹄盖嵚科 Athyriaceae \\
\hline 假密果短肠蒴 Allantodia multicaudata (Wall. ex C. B. Clarke) & 单裂缝 Monolete & 蹄盖茨科 Athyriaceae & 蹄盖茨科 Athyriaceae \\
\hline \multicolumn{4}{|l|}{ W. M. Chu } \\
\hline 高大短肠锁 Allantodia muricata (Mett.) W. M. Chu \& Z. R. He & 单裂缝 Monolete & 蹄盖茨科 Athyriaceae & 蹄盖茨科 Athyriaceae \\
\hline 南川短肠偋 Allantodia nanchuanica W. M. Chu & 单裂缝 Monolete & 蹄盖茨科 Athyriaceae & 蹄盖茨科 Athyriaceae \\
\hline 乌鳞短肠蕨 Allantodia nigrosquamosa Ching & 单裂缝 Monolete & 蹄盖茨科 Athyriaceae & 蹄盖茨科 Athyriaceae \\
\hline 日本短肠蕨 Allantodia nipponica (Tagawa) Ching & 单裂缝 Monolete & 蹄盖嵚科 Athyriaceae & 蹄盖嵚科 Athyriaceae \\
\hline 假耳羽短肠薑 Allantodia okudairai (Makino) Ching & 单裂缝 Monolete & 蹄盖茨科 Athyriaceae & 蹄盖茨科 Athyriaceae \\
\hline 卵果短肠葓 Allantodia ovata W. M. Chu & 单裂缝 Monolete & 蹄盖茨科 Athyriaceae & 蹄盖茨科 Athyriaceae \\
\hline 褐柄短肠濒 Allantodia petelotii (Tardieu) Ching & 单裂缝 Monolete & 蹄盖嵚科 Athyriaceae & 蹄盖嵚科 Athyriaceae \\
\hline 假镰羽短肠嵚 Allantodia petri (Tardieu) Ching & 单裂缝 Monolete & 蹄盖茨科 Athyriaceae & 蹄盖茨科 Athyriaceae \\
\hline 羽裂短肠蒴 Allantodia pinnatifidopinnata (Hook.) Ching & 单裂缝 Monolete & 蹄盖茨科 Athyriaceae & 蹄盖茨科 Athyriaceae \\
\hline 双生短肠嵚 Allantodia prolixa (Rosenst.) Ching & 单裂缝 Monolete & 蹄盖烣科 Athyriaceae & 蹄盖烚科 Athyriaceae \\
\hline 矩圆短肠蒴 Allantodia pseudosetigera (Christ) Ching & 单裂缝 Monolete & 蹄盖茨科 Athyriaceae & 蹄盖茨科 Athyriaceae \\
\hline 四棱短肠嵚 Allantodia quadrangulata W. M. Chu & 单裂缝 Monolete & 蹄盖茨科 Athyriaceae & 蹄盖茨科 Athyriaceae \\
\hline 长羽柄短肠脒 Allantodia siamensis (C. Chr.) Ching \& W. M. & 单裂缝 Monolete & 蹄盖茨科 Athyriaceae & 蹄盖茨科 Athyriaceae \\
\hline \multicolumn{4}{|l|}{ Chu } \\
\hline 锡金短肠眇 Allantodia sikkimensis (C. B. Clarke) Ching & 单裂缝 Monolete & 蹄盖茨科 Athyriaceae & 蹄盖䕋科 Athyriaceae \\
\hline
\end{tabular}




\begin{tabular}{|c|c|c|c|}
\hline $\begin{array}{l}\text { 物种 } \\
\text { Species }\end{array}$ & $\begin{array}{l}\text { 孢子裂缝类型 } \\
\text { Spore apertures styles }\end{array}$ & $\begin{array}{l}\text { 科名 Family (秦仁 } \\
\text { 昌,1978a, b) }\end{array}$ & $\begin{array}{l}\text { 科名 Family (Smith et al., } \\
\text { 2006; Christenhusz et al, } \\
\text { 2011; 张宪春等, 2013) }\end{array}$ \\
\hline 肉刺短肠䕬 Allantodia similis W. M. Chu & 单裂缝 Monolete & 蹄盖蕨科 Athyriaceae & 蹄盖锁科 Athyriaceae \\
\hline 密果短肠莜 Allantodia spectabilis (Wall. ex Mett.) Ching & 单裂缝 Monolete & 蹄盖蒴科 Athyriaceae & 蹄盖葓科 Athyriaceae \\
\hline 鳞柄短肠蒴 Allantodia squamigera (Mett.) Ching & 单裂缝 Monolete & 蹄盖蕨科 Athyriaceae & 蹄盖蕨科 Athyriaceae \\
\hline 网脉短肠薜 Allantodia stenochlamys (C. Chr.) Ching & 单裂缝 Monolete & 蹄盖蒴科 Athyriaceae & 蹄盖蒴科 Athyriaceae \\
\hline 楔羽短肠菜 Allantodia subdilatata Ching & 单裂缝 Monolete & 蹄盖葓科 Athyriaceae & 蹄盖莜科 Athyriaceae \\
\hline 棕鳞短肠蕨 Allantodia subintegra Ching \& Y. X. Lin & 单裂缝 Monolete & 蹄盖蕨科 Athyriaceae & 蹄盖蕨科 Athyriaceae \\
\hline 察隅短肠薜 Allantodia subspectabilis Ching \& W. M. Chu & 单裂缝 Monolete & 蹄盖蒴科 Athyriaceae & 蹄盖䕬科 Athyriaceae \\
\hline 肉质短肠蒴 Allantodia succulenta (C. B. Clarke) Ching & 单裂缝 Monolete & 蹄盖莜科 Athyriaceae & 蹄盖媭科 Athyriaceae \\
\hline 东北短肠䯾 Allantodia taquetii (C. Chr.) Ching & 单裂缝 Monolete & 蹄盖䕋科 Athyriaceae & 蹄盖蕨科 Athyriaceae \\
\hline 西藏短肠茨 Allantodia tibetica Ching \& S. K. Wu & 单裂缝 Monolete & 蹄盖蒴科 Athyriaceae & 蹄盖蒴科 Athyriaceae \\
\hline 圆裂短肠硕 Allantodia uraiensis (Rosenst.) Ching & 单裂缝 Monolete & 蹄盖蒴科 Athyriaceae & 蹄盖媭科 Athyriaceae \\
\hline 淡绿短肠嵚 Allantodia virescens (Kunze) Ching & 单裂缝 Monolete & 蹄盖蕨科 Athyriaceae & 蹄盖蕨科 Athyriaceae \\
\hline 冲绳短肠嵚 Allantodia virescens var. okinawaensis (Tagawa) & 单裂缝 Monolete & 蹄盖蕨科 Athyriaceae & 蹄盖蕨科 Athyriaceae \\
\hline \multicolumn{4}{|l|}{ W. M. Chu } \\
\hline $\begin{array}{l}\text { 异基短肠蕨 Allantodia virescens var. sugimotoi (Sa. Kurata) W. } \\
\text { M. Chu }\end{array}$ & 单裂缝 Monolete & 蹄盖蕨科 Athyriaceae & 蹄盖蕨科 Athyriaceae \\
\hline 草绿短肠烚 Allantodia viridescens (Ching) Ching & 单裂缝 Monolete & 蹄盖蒴科 Athyriaceae & 蹄盖蒴科 Athyriaceae \\
\hline 深绿短肠鄀 Allantodia viridissima (Christ) Ching & 单裂缝 Monolete & 蹄盖蕨科 Athyriaceae & 蹄盖蕨科 Athyriaceae \\
\hline 黄志短肠嵚 Allantodia wangii Ching & 单裂缝 Monolete & 蹄盖蒴科 Athyriaceae & 蹄盖蒴科 Athyriaceae \\
\hline 短果短肠钼 Allantodia wheeleri (Baker) Ching & 单裂缝 Monolete & 蹄盖蒴科 Athyriaceae & 蹄盖蒴科 Athyriaceae \\
\hline 耳羽短肠蒴 Allantodia wichurae (Mett.) Ching & 单裂缝 Monolete & 蹄盖蒴科 Athyriaceae & 蹄盖蒴科 Athyriaceae \\
\hline 龙池短肠葓 Allantodia wichurae var. parawichurae (Ching) W. & 单裂缝 Monolete & 蹄盖蒴科 Athyriaceae & 蹄盖莜科 Athyriaceae \\
\hline
\end{tabular}


魏雪苹，张宪春．蒴类植物不同狍子裂缝类型在中国的分布格局. 生物多样性，2016，24(10)：1129-1134 http://www. biodiversity - science. net/CN/10. 17520/biods. 2016219

\begin{tabular}{|c|c|c|c|}
\hline $\begin{array}{l}\text { 物种 } \\
\text { Species }\end{array}$ & $\begin{array}{l}\text { 孢子裂缝类型 } \\
\text { Spore apertures styles }\end{array}$ & $\begin{array}{l}\text { 科名 Family (秦仁 } \\
\text { 昌,1978a, b) }\end{array}$ & $\begin{array}{l}\text { 科名 Family (Smith et al., } \\
\text { 2006; Christenhusz et al, } \\
\text { 2011; 张宪春等, 2013) }\end{array}$ \\
\hline \multicolumn{4}{|l|}{ M. Chu \& Z. R. He } \\
\hline $\begin{array}{l}\text { 假江南短肠葓 Allantodia yaoshanensis (Y. C. Wu) W. M. Chu } \\
\text { \& Z. R. He }\end{array}$ & 单裂缝 Monolete & 蹄盖蕨科 Athyriaceae & 蹄盖蕨科 Athyriaceae \\
\hline 安蕨 Anisocampium cumingianum C. Presl & 单裂缝 Monolete & 蹄盖䓲科 Athyriaceae & 蹄盖菜科 Athyriaceae \\
\hline 华东安葓 Anisocampium sheareri (Baker) Ching ex Y. T. Hsieh & 单裂缝 Monolete & 蹄盖烣科 Athyriaceae & 蹄盖嵚科 Athyriaceae \\
\hline 岳麓山假蹄盖蒴 Athyriopsis abbreviata W. M. Chu & 单裂缝 Monolete & 蹄盖蕨科 Athyriaceae & 蹄盖荻科 Athyriaceae \\
\hline 美丽假蹄盖藓 Athyriopsis concinna Z. R. Wang & 单裂缝 Monolete & 蹄盖嵚科 Athyriaceae & 蹄盖锁科 Athyriaceae \\
\hline 针羽假蹄盖蕨 Athyriopsis conilii (Franch. \& Sav.) Ching & 单裂缝 Monolete & 蹄盖烣科 Athyriaceae & 蹄盖藃科 Athyriaceae \\
\hline 斜升假蹄盖蕨 Athyriopsis dickasonii (M. Kato) W. M. Chu & 单裂缝 Monolete & 蹄盖蕨科 Athyriaceae & 蹄盖荻科 Athyriaceae \\
\hline 二型叶假蹄盖蕨 Athyriopsis dimorphophylla (Koidz.) Ching ex & 单裂缝 Monolete & 蹄盖蕨科 Athyriaceae & 蹄盖蕨科 Athyriaceae \\
\hline \multicolumn{4}{|l|}{ W. M. Chu } \\
\hline 直立介荻 Athyriopsis erecta Z. R. Wang & 单裂缝 Monolete & 蹄盖蕨科 Athyriaceae & 蹄盖荻科 Athyriaceae \\
\hline 假蹄盖蕨 Athyriopsis japonica (Thunb.) Ching & 单裂缝 Monolete & 蹄盖蔹科 Athyriaceae & 蹄盖莏科 Athyriaceae \\
\hline 斜羽假蹄盖荻 Athyriopsis japonica var. oshimensis (Christ) & 单裂缝 Monolete & 蹄盖蕨科 Athyriaceae & 蹄盖蕨科 Athyriaceae \\
\hline \multicolumn{4}{|l|}{ Ching } \\
\hline \multicolumn{4}{|l|}{ \& Z. R. He } \\
\hline 金佛山假蹄盖蕨 Athyriopsis jinfoshanensis Ching \& Z. Y. Liu & 单裂缝 Monolete & 蹄盖蕨科 Athyriaceae & 蹄盖蕨科 Athyriaceae \\
\hline 中日假蹄盖蕨 Athyriopsis kiusiana (Koidz.) Ching & 单裂缝 Monolete & 蹄盖蕨科 Athyriaceae & 蹄盖蕨科 Athyriaceae \\
\hline 昆明假蹄盖蕨 Athyriopsis longipes Ching & 单裂缝 Monolete & 蹄盖蕨科 Athyriaceae & 蹄盖蕨科 Athyriaceae \\
\hline 鲁山假蹄盖蕨 Athyriopsis lushanensis J. X. Li & 单裂缝 Monolete & 蹄盖蕨科 Athyriaceae & 蹄盖鄀科 Athyriaceae \\
\hline 南谷假蹄盖蕨 Athyriopsis minamitanii (Seriz.) Z. R. Wang & 单裂缝 Monolete & 蹄盖蕨科 Athyriaceae & 蹄盖蕨科 Athyriaceae \\
\hline
\end{tabular}




\begin{tabular}{|c|c|c|c|}
\hline $\begin{array}{l}\text { 物种 } \\
\text { Species }\end{array}$ & $\begin{array}{l}\text { 孢子裂缝类型 } \\
\text { Spore apertures styles }\end{array}$ & $\begin{array}{l}\text { 科名 Family (秦仁 } \\
\text { 昌,1978a, b) }\end{array}$ & $\begin{array}{l}\text { 科名 Family (Smith et al., } \\
\text { 2006; Christenhusz et al, } \\
\text { 2011; 张宪春等, 2013) }\end{array}$ \\
\hline 峨眉假蹄盖茨 Athyriopsis omeiensis Z. R. Wang & 单裂缝 Monolete & 蹄盖葓科 Athyriaceae & 蹄盖锁科 Athyriaceae \\
\hline 阔羽假蹄盖蕨 Athyriopsis pachyphylla Ching & 单裂缝 Monolete & 蹄盖媭科 Athyriaceae & 蹄盖葓科 Athyriaceae \\
\hline 毛轴假蹄盖硕 Athyriopsis petersenii (Kunze) Ching & 单裂缝 Monolete & 蹄盖蕨科 Athyriaceae & 蹄盖蕨科 Athyriaceae \\
\hline 阔基假蹄盖蒴 Athyriopsis pseudoconilii (Seriz.) W. M. Chu & 单裂缝 Monolete & 蹄盖蒴科 Athyriaceae & 蹄盖蒴科 Athyriaceae \\
\hline 山东假蹄盖蕨 Athyriopsis shandongensis J. X. Li \& Z. C. Ding & 单裂缝 Monolete & 蹄盖葓科 Athyriaceae & 蹄盖莜科 Athyriaceae \\
\hline 长叶假蹄盖蕨 Athyriopsis tomitaroana (Masam.) P. S. Wang & 单裂缝 Monolete & 蹄盖蕨科 Athyriaceae & 蹄盖蕨科 Athyriaceae \\
\hline 金平蹄盖烣 Athyrium adpressum Ching \& W. M. Chu & 单裂缝 Monolete & 蹄盖蒴科 Athyriaceae & 蹄盖蒴科 Athyriaceae \\
\hline 斜羽蹄盖蒝 Athyrium adscendens Ching & 单裂缝 Monolete & 蹄盖莜科 Athyriaceae & 蹄盖莜科 Athyriaceae \\
\hline 宿蹄盖蕨 Athyrium anisopterum Christ & 单裂缝 Monolete & 蹄盖䕋科 Athyriaceae & 蹄盖蕨科 Athyriaceae \\
\hline 鹿角蹄盖嵚 Athyrium araiostegioides Ching & 单裂缝 Monolete & 蹄盖蒴科 Athyriaceae & 蹄盖蒴科 Athyriaceae \\
\hline 阿里山蹄盖蒝 Athyrium arisanense (Hayata) Tagawa & 单裂缝 Monolete & 蹄盖蒴科 Athyriaceae & 蹄盖蒴科 Athyriaceae \\
\hline 剑叶蹄盖蕨 Athyrium attenuatum (Wall. ex C. B. Clarke) & 单裂缝 Monolete & 蹄盖蕨科 Athyriaceae & 蹄盖蕨科 Athyriaceae \\
\hline \multicolumn{4}{|l|}{ Tagawa } \\
\hline 耳垂蹄盖菜 Athyrium auriculatum Seriz. & 单裂缝 Monolete & 蹄盖葓科 Athyriaceae & 蹄盖偋科 Athyriaceae \\
\hline 宝兴蹄盖荻 Athyrium baoxingense Ching & 单裂缝 Monolete & 蹄盖蕨科 Athyriaceae & 蹄盖蕨科 Athyriaceae \\
\hline 波密蹄盖蕨 Athyrium bomicola Ching & 单裂缝 Monolete & 蹄盖蕨科 Athyriaceae & 蹄盖蕨科 Athyriaceae \\
\hline 圆果蹄盖㓹 Athyrium bucahwangense Ching & 单裂缝 Monolete & 蹄盖菜科 Athyriaceae & 蹄盖蒴科 Athyriaceae \\
\hline 秦氏蹄盖蒴 Athyrium chingianum Z. R. Wang \& X. C. Zhang & 单裂缝 Monolete & 蹄盖蕨科 Athyriaceae & 蹄盖蕨科 Athyriaceae \\
\hline 中越蹄盖嵚 Athyrium christensenii Tardieu & 单裂缝 Monolete & 蹄盖蕨科 Athyriaceae & 蹄盖蕨科 Athyriaceae \\
\hline 芽胞蹄盖蕨 Athyrium clarkei Bedd. & 单裂缝 Monolete & 蹄盖蒴科 Athyriaceae & 蹄盖偋科 Athyriaceae \\
\hline 坡生蹄盖䔸 Athyrium clivicola Tagawa & 单裂缝 Monolete & 蹄盖蒴科 Athyriaceae & 蹄盖蒴科 Athyriaceae \\
\hline 短羽蹄盖蕨 Athyrium contingens Ching \& S. K. Wu & 单裂缝 Monolete & 蹄盖蒴科 Athyriaceae & 蹄盖偋科 Athyriaceae \\
\hline
\end{tabular}


魏雪苹，张宪春．蒴类植物不同狍子裂缝类型在中国的分布格局. 生物多样性，2016，24(10)：1129-1134 http://www. biodiversity - science. net/CN/10. 17520/biods. 2016219

\begin{tabular}{|c|c|c|c|}
\hline $\begin{array}{l}\text { 物种 } \\
\text { Species }\end{array}$ & $\begin{array}{l}\text { 孢子裂缝类型 } \\
\text { Spore apertures styles }\end{array}$ & $\begin{array}{l}\text { 科名 Family (秦仁 } \\
\text { 昌,1978a, b) }\end{array}$ & $\begin{array}{l}\text { 科名 Family (Smith et al., } \\
\text { 2006; Christenhusz et al, } \\
\text { 2011; 张宪春等, 2013) }\end{array}$ \\
\hline 川西蹄盖蕨 Athyrium costulalisorum Ching & 单裂缝 Monolete & 蹄盖嵚科 Athyriaceae & 蹄盖荻科 Athyriaceae \\
\hline 粗柄蹄盖蒴 Athyrium crassipes Ching & 单裂缝 Monolete & 蹄盖烣科 Athyriaceae & 蹄盖烣科 Athyriaceae \\
\hline 合欢山蹄盖蕨 Athyrium cryptogrammoides Hayata & 单裂缝 Monolete & 蹄盖蕨科 Athyriaceae & 蹄盖蕨科 Athyriaceae \\
\hline 拟鳞毛蕨 Athyrium cuspidatum (Bedd.) M. Kato & 单裂缝 Monolete & 蹄盖烣科 Athyriaceae & 蹄盖锁科 Athyriaceae \\
\hline 大相岭蹄盖莜 Athyrium daxianglingense Ching \& H. S. Kung & 单裂缝 Monolete & 蹄盖烣科 Athyriaceae & 蹄盖藃科 Athyriaceae \\
\hline 林光蹄盖鄀 Athyrium decorum Ching & 单裂缝 Monolete & 蹄盖蕨科 Athyriaceae & 蹄盖蕨科 Athyriaceae \\
\hline 翅轴蹄盖蒝 Athyrium delavayi Christ & 单裂缝 Monolete & 蹄盖嵚科 Athyriaceae & 蹄盖锁科 Athyriaceae \\
\hline 薄叶蹄盖媭 Athyrium delicatulum Ching \& S. K. Wu & 单裂缝 Monolete & 蹄盖烣科 Athyriaceae & 蹄盖藃科 Athyriaceae \\
\hline 溪边蹄盖硕 Athyrium deltoidofrons Makino & 单裂缝 Monolete & 蹄盖蕨科 Athyriaceae & 蹄盖蕨科 Athyriaceae \\
\hline 瘦叶蹄盖蕨 Athyrium deltoidofrons var. gracillinum (Ching) & 单裂缝 Monolete & 蹄盖蕨科 Athyriaceae & 蹄盖蕨科 Athyriaceae \\
\hline \multicolumn{4}{|l|}{ Z.R.Wang } \\
\hline 密果蹄盖睰 Athyrium densisorum X. C. Zhang & 单裂缝 Monolete & 蹄盖蕨科 Athyriaceae & 蹄盖蕨科 Athyriaceae \\
\hline 希陶蹄盖嵚 Athyrium dentigerum (Wall. ex C. B. Clarke) & 单裂缝 Monolete & 蹄盖蕨科 Athyriaceae & 蹄盖蕨科 Athyriaceae \\
\hline \multicolumn{4}{|l|}{ Mehra \& Bir } \\
\hline 齿尖蹄盖蕨 Athyrium dentilobum Ching \& S. K. Wu & 单裂缝 Monolete & 蹄盖蕨科 Athyriaceae & 蹄盖蕨科 Athyriaceae \\
\hline 湿生蹄盖蕨 Athyrium devolii Ching & 单裂缝 Monolete & 蹄盖蕨科 Athyriaceae & 蹄盖蕨科 Athyriaceae \\
\hline 疏叶蹄盖䯾 Athyrium dissitifolium (Baker) C. Chr. & 单裂缝 Monolete & 蹄盖鄀科 Athyriaceae & 蹄盖颐科 Athyriaceae \\
\hline 多变蹄盖鄀 Athyrium drepanopterum (Kunze) A. Braun ex & 单裂缝 Monolete & 蹄盖荻科 Athyriaceae & 蹄盖荻科 Athyriaceae \\
\hline \multicolumn{4}{|l|}{ Milde } \\
\hline 毛翼蹄盖蕒 Athyrium dubium Ching & 单裂缝 Monolete & 蹄盖烣科 Athyriaceae & 蹄盖锁科 Athyriaceae \\
\hline 独龙江蹄盖㓹 Athyrium dulongicolum W. M. Chu & 单裂缝 Monolete & 蹄盖蕨科 Athyriaceae & 蹄盖蒴科 Athyriaceae \\
\hline 长叶蹄盖蕨 Athyrium elongatum Ching & 单裂缝 Monolete & 蹄盖蕨科 Athyriaceae & 蹄盖蒴科 Athyriaceae \\
\hline
\end{tabular}




\begin{tabular}{|c|c|c|c|}
\hline $\begin{array}{l}\text { 物种 } \\
\text { Species }\end{array}$ & $\begin{array}{l}\text { 孢子裂缝类型 } \\
\text { Spore apertures styles }\end{array}$ & $\begin{array}{l}\text { 科名 Family (秦仁 } \\
\text { 昌,1978a, b) }\end{array}$ & $\begin{array}{l}\text { 科名 Family (Smith et al., } \\
\text { 2006; Christenhusz et al, } \\
\text { 2011; 张宪春等, 2013) }\end{array}$ \\
\hline 轴果蹄盖锁 Athyrium epirachis (Christ) Ching & 单裂缝 Monolete & 蹄盖蕨科 Athyriaceae & 蹄盖蕨科 Athyriaceae \\
\hline 红柄蹄盖偋 Athyrium erythropodum Hayata & 单裂缝 Monolete & 蹄盖烣科 Athyriaceae & 蹄盖嵚科 Athyriaceae \\
\hline 高超蹄盖嵚 Athyrium excelsius Ching & 单裂缝 Monolete & 蹄盖茨科 Athyriaceae & 蹄盖茨科 Athyriaceae \\
\hline 无盖蹄盖蕨 Athyrium exindusiatum Ching & 单裂缝 Monolete & 蹄盖茨科 Athyriaceae & 蹄盖茨科 Athyriaceae \\
\hline 麦秆蹄盖颐 Athyrium fallaciosum Milde & 单裂缝 Monolete & 蹄盖烣科 Athyriaceae & 蹄盖嵚科 Athyriaceae \\
\hline 方氏蹄盖嵚 Athyrium fangii Ching & 单裂缝 Monolete & 蹄盖茨科 Athyriaceae & 蹄盖茨科 Athyriaceae \\
\hline 喜马拉雅蹄盖鿒 Athyrium fimbriatum (Wall. ex Hook.) T. & 单裂缝 Monolete & 蹄盖茨科 Athyriaceae & 蹄盖茨科 Athyriaceae \\
\hline \multicolumn{4}{|l|}{ Moore } \\
\hline 狭叶蹄盖偋 Athyrium flabellulatum (C. B. Clarke) Tardieu & 单裂缝 Monolete & 蹄盖嵚科 Athyriaceae & 蹄盖嵚科 Athyriaceae \\
\hline 大盖蹄盖藓 Athyrium foliolosum T. Moore ex Sim & 单裂缝 Monolete & 蹄盖茨科 Athyriaceae & 蹄盖嵚科 Athyriaceae \\
\hline 广南蹄盖媭 Athyrium guangnanense Ching & 单裂缝 Monolete & 蹄盖嵚科 Athyriaceae & 蹄盖嵚科 Athyriaceae \\
\hline 海南蹄盖烚 Athyrium hainanense Ching & 单裂缝 Monolete & 蹄盖茨科 Athyriaceae & 蹄盖茨科 Athyriaceae \\
\hline 中锡蹄盖脄 Athyrium himalaicum Ching ex Mehra \& Bir & 单裂缝 Monolete & 蹄盖茨科 Athyriaceae & 蹄盖茨科 Athyriaceae \\
\hline 毛轴蹄盖鄀 Athyrium hirtirachis Ching \& Y. P. Hsu & 单裂缝 Monolete & 蹄盖茨科 Athyriaceae & 蹄盖茨科 Athyriaceae \\
\hline 密羽蹄盖锁 Athyrium imbricatum Christ & 单裂缝 Monolete & 蹄盖茨科 Athyriaceae & 蹄盖茨科 Athyriaceae \\
\hline 凌云蹄盖䕬 Athyrium infrapuberulum Ching & 单裂缝 Monolete & 蹄盖茨科 Athyriaceae & 蹄盖茨科 Athyriaceae \\
\hline 中间蹄盖蕨 Athyrium intermixtum Ching \& P. S. Chiu & 单裂缝 Monolete & 蹄盖蕨科 Athyriaceae & 蹄盖嵚科 Athyriaceae \\
\hline 长江蹄盖蒴 Athyrium iseanum Rosenst. & 单裂缝 Monolete & 蹄盖茨科 Athyriaceae & 蹄盖茨科 Athyriaceae \\
\hline 紫柄蹄盖颐 Athyrium kenzo-satakei Sa. Kurata & 单裂缝 Monolete & 蹄盖茨科 Athyriaceae & 蹄盖茨科 Athyriaceae \\
\hline $\begin{array}{l}\text { 介贵山蹄盖蕨 Athyrium kenzo-satakei var. jieguishanense } \\
\text { (Ching) Z. R. Wang }\end{array}$ & 单裂缝 Monolete & 蹄盖鄀科 Athyriaceae & 蹄盖鄀科 Athyriaceae \\
\hline 仓田蹄盖烣 Athyrium kuratae Seriz. & 单裂缝 Monolete & 蹄盖蕨科 Athyriaceae & 蹄盖蕨科 Athyriaceae \\
\hline
\end{tabular}




\begin{tabular}{|c|c|c|c|}
\hline $\begin{array}{l}\text { 物种 } \\
\text { Species }\end{array}$ & $\begin{array}{l}\text { 孢子裂缝类型 } \\
\text { Spore apertures styles }\end{array}$ & $\begin{array}{l}\text { 科名 Family (秦仁 } \\
\text { 昌,1978a, b) }\end{array}$ & $\begin{array}{l}\text { 科名 Family (Smith et al., } \\
\text { 2006; Christenhusz et al, } \\
\text { 2011; 张宪春等, 2013) }\end{array}$ \\
\hline 泸定蹄盖茨 Athyrium ludingense Z. R. Wang \& L. B. Zhang & 单裂缝 Monolete & 蹄盖葓科 Athyriaceae & 蹄盖锁科 Athyriaceae \\
\hline 川滇蹄盖嵚 Athyrium mackinnonii (C. Hope) C. Chr. & 单裂缝 Monolete & 蹄盖蒴科 Athyriaceae & 蹄盖葓科 Athyriaceae \\
\hline 墨脱蹄盖荻 Athyrium medogense X. C. Zhang & 单裂缝 Monolete & 蹄盖蕨科 Athyriaceae & 蹄盖蕨科 Athyriaceae \\
\hline 狭基蹄盖蒴 Athyrium mehrae Bir & 单裂缝 Monolete & 蹄盖蒴科 Athyriaceae & 蹄盖蒴科 Athyriaceae \\
\hline 黑鳞蹄盖蒝 Athyrium melanolepis (Franch. \& Sav.) Christ & 单裂缝 Monolete & 蹄盖葓科 Athyriaceae & 蹄盖莜科 Athyriaceae \\
\hline 小蹄盖蒴 Athyrium minimum Ching & 单裂缝 Monolete & 蹄盖蕨科 Athyriaceae & 蹄盖蕨科 Athyriaceae \\
\hline 红苞蹄盖屏 Athyrium nakanoi Makino & 单裂缝 Monolete & 蹄盖蒴科 Athyriaceae & 蹄盖䕬科 Athyriaceae \\
\hline 疏羽蹄盖蒝 Athyrium nephrodioides (Baker) Christ & 单裂缝 Monolete & 蹄盖莜科 Athyriaceae & 蹄盖媭科 Athyriaceae \\
\hline 黑足蹄盖蒴 Athyrium nigripes (Blume) T. Moore & 单裂缝 Monolete & 蹄盖蒴科 Athyriaceae & 蹄盖䕬科 Athyriaceae \\
\hline 日本蹄盖䕬 Athyrium niponicum (Mett.) Hance & 单裂缝 Monolete & 蹄盖蒴科 Athyriaceae & 蹄盖蒴科 Athyriaceae \\
\hline 聂拉木蹄盖䔊 Athyrium nyalamense Y. T. Hsieh \& Z. R. Wang & 单裂缝 Monolete & 蹄盖蒴科 Athyriaceae & 蹄盖蒴科 Athyriaceae \\
\hline 峨眉蹄盖蕨 Athyrium omeiense Ching & 单裂缝 Monolete & 蹄盖蕨科 Athyriaceae & 蹄盖蕨科 Athyriaceae \\
\hline 对生蹄盖蒴 Athyrium oppositipinnum Hayata & 单裂缝 Monolete & 蹄盖蒴科 Athyriaceae & 蹄盖蒴科 Athyriaceae \\
\hline 光蹄盖菜 Athyrium otophorum (Miq.) Koidz. & 单裂缝 Monolete & 蹄盖蒴科 Athyriaceae & 蹄盖蒴科 Athyriaceae \\
\hline 裸囊蹄盖蕨 Athyrium pachyphyllum Ching & 单裂缝 Monolete & 蹄盖蕨科 Athyriaceae & 蹄盖蕨科 Athyriaceae \\
\hline 蒈齿蹄盖䓦 Athyrium pectinatum (Wall. ex Mett.) Bedd & 单裂缝 Monolete & 蹄盖蒴科 Athyriaceae & 蹄盖蒴科 Athyriaceae \\
\hline 贵州蹄盖㓹 Athyrium pubicostatum Ching \& Z. Y. Liu & 单裂缝 Monolete & 蹄盖蒴科 Athyriaceae & 蹄盖蒴科 Athyriaceae \\
\hline 密腺蹄盖蕨 Athyrium puncticaule (Blume) T. Moore & 单裂缝 Monolete & 蹄盖蕨科 Athyriaceae & 蹄盖蕨科 Athyriaceae \\
\hline 逆叶蹄盖萩 Athyrium reflexipinnum Hayata & 单裂缝 Monolete & 蹄盖蕨科 Athyriaceae & 蹄盖蕨科 Athyriaceae \\
\hline 轴生蹄盖蕨 Athyrium rhachidosorum (Hand.-Mazz.) Ching & 单裂缝 Monolete & 蹄盖蒴科 Athyriaceae & 蹄盖偋科 Athyriaceae \\
\hline 玫瑰蹄盖鄀 Athyrium roseum Christ & 单裂缝 Monolete & 蹄盖蒴科 Athyriaceae & 蹄盖蒴科 Athyriaceae \\
\hline 岩生蹄盖茨 Athyrium rupicola (Edgew ex C. Hope) C. Chr. & 单裂缝 Monolete & 蹄盖蒴科 Athyriaceae & 蹄盖莜科 Athyriaceae \\
\hline
\end{tabular}




\begin{tabular}{|c|c|c|c|}
\hline $\begin{array}{l}\text { 物种 } \\
\text { Species }\end{array}$ & $\begin{array}{l}\text { 孢子裂缝类型 } \\
\text { Spore apertures styles }\end{array}$ & $\begin{array}{l}\text { 科名 Family (秦仁 } \\
\text { 昌,1978a, b) }\end{array}$ & $\begin{array}{l}\text { 科名 Family (Smith et al., } \\
\text { 2006; Christenhusz et al, } \\
\text { 2011; 张宪春等, 2013) }\end{array}$ \\
\hline 苍山蹄盖蕨 Athyrium schimperi Moug ex Fée & 单裂缝 Monolete & 蹄盖蕨科 Athyriaceae & 蹄盖蕨科 Athyriaceae \\
\hline 绢毛蹄盖葓 Athyrium sericellum Ching & 单裂缝 Monolete & 蹄盖烣科 Athyriaceae & 蹄盖嵚科 Athyriaceae \\
\hline 高山蹄盖偋 Athyrium silvicola Tagawa & 单裂缝 Monolete & 蹄盖茨科 Athyriaceae & 蹄盖茨科 Athyriaceae \\
\hline 中华蹄盖䲞 Athyrium sinense Rupr. & 单裂缝 Monolete & 蹄盖茨科 Athyriaceae & 蹄盖茨科 Athyriaceae \\
\hline 软刺蹄盖葓 Athyrium strigillosum (T. Moore ex Lowe) T. & 单裂缝 Monolete & 蹄盖烣科 Athyriaceae & 蹄盖嵚科 Athyriaceae \\
\hline \multicolumn{4}{|l|}{ Moore ex Salom. } \\
\hline 上毛蹄盖䲞 Athyrium suprapubescense Ching & 单裂缝 Monolete & 蹄盖嵚科 Athyriaceae & 蹄盖荻科 Athyriaceae \\
\hline 腺叶蹄盖葓 Athyrium supraspinescens C. Chr. & 单裂缝 Monolete & 蹄盖烣科 Athyriaceae & 蹄盖媭科 Athyriaceae \\
\hline 三回蹄盖蒴 Athyrium tripinnatum Tagawa & 单裂缝 Monolete & 蹄盖茨科 Athyriaceae & 蹄盖媭科 Athyriaceae \\
\hline 粗脉蹄盖莜 Athyrium venulosum Ching & 单裂缝 Monolete & 蹄盖茨科 Athyriaceae & 蹄盖茨科 Athyriaceae \\
\hline 尖头蹄盖嵚 Athyrium vidalii (Franch. \& Sav.) Nakai & 单裂缝 Monolete & 蹄盖嵚科 Athyriaceae & 蹄盖嵚科 Athyriaceae \\
\hline 松谷蹄盖蒴 Athyrium vidalii var. amabile (Ching) Z. R. Wang. & 单裂缝 Monolete & 蹄盖茨科 Athyriaceae & 蹄盖茨科 Athyriaceae \\
\hline 胎生蹄盖莜 Athyrium viviparum Christ & 单裂缝 Monolete & 蹄盖茨科 Athyriaceae & 蹄盖茨科 Athyriaceae \\
\hline 黑秆蹄盖硕 Athyrium wallichianum Ching & 单裂缝 Monolete & 蹄盖嵚科 Athyriaceae & 蹄盖嵚科 Athyriaceae \\
\hline 启无蹄盖蒴 Athyrium wangii Ching & 单裂缝 Monolete & 蹄盖茨科 Athyriaceae & 蹄盖茨科 Athyriaceae \\
\hline 华中蹄盖蕨 Athyrium wardii (Hook.) Makino & 单裂缝 Monolete & 蹄盖茨科 Athyriaceae & 蹄盖茨科 Athyriaceae \\
\hline 无量山蹄盖蕨 Athyrium wuliangshanense Ching & 单裂缝 Monolete & 蹄盖烣科 Athyriaceae & 蹄盖烚科 Athyriaceae \\
\hline 尖阿蹄盖瞢 Athyrium $\times$ hohuanshanense Yoshik. & 单裂缝 Monolete & 蹄盖茨科 Athyriaceae & 蹄盖茨科 Athyriaceae \\
\hline 黑合蹄盖硕 Athyrium $\times$ pseudocryptogrammoides Yoshik. & 单裂缝 Monolete & 蹄盖茨科 Athyriaceae & 蹄盖烣科 Athyriaceae \\
\hline 禾秆蹄盖薑 Athyrium yokoscense (Franch. \& Sav.) Christ & 单裂缝 Monolete & 蹄盖茨科 Athyriaceae & 蹄盖茨科 Athyriaceae \\
\hline 俞氏蹄盖蒴 Athyrium yui Ching & 单裂缝 Monolete & 蹄盖烣科 Athyriaceae & 蹄盖烚科 Athyriaceae \\
\hline 察隅蹄盖蕨 Athyrium zayuense Z. R. Wang & 单裂缝 Monolete & 蹄盖偋科 Athyriaceae & 蹄盖烣科 Athyriaceae \\
\hline
\end{tabular}




\begin{tabular}{|c|c|c|c|}
\hline $\begin{array}{l}\text { 物种 } \\
\text { Species }\end{array}$ & $\begin{array}{l}\text { 孢子裂缝类型 } \\
\text { Spore apertures styles }\end{array}$ & $\begin{array}{l}\text { 科名 Family (秦仁 } \\
\text { 昌,1978a, b) }\end{array}$ & $\begin{array}{l}\text { 科名 Family (Smith et al., } \\
\text { 2006; Christenhusz et al, } \\
\text { 2011; 张宪春等, 2013) }\end{array}$ \\
\hline 菜蒴 Callipteris esculenta (Retz.) J. Sm. ex T. Moore \& Houlst. & 单裂缝 Monolete & 蹄盖葓科 Athyriaceae & 蹄盖锁科 Athyriaceae \\
\hline 毛轴菜蒴 Callipteris esculenta var. pubescens (Link) Ching & 单裂缝 Monolete & 蹄盖蒴科 Athyriaceae & 蹄盖葓科 Athyriaceae \\
\hline 刺轴菜蕨 Callipteris paradoxa (Fée) T. Moore & 单裂缝 Monolete & 蹄盖蕨科 Athyriaceae & 蹄盖蕨科 Athyriaceae \\
\hline 密羽角睰 Cornopteris approximata W. M. Chu & 单裂缝 Monolete & 蹄盖蒴科 Athyriaceae & 蹄盖蒴科 Athyriaceae \\
\hline 复叶角葓 Cornopteris badia Ching & 单裂缝 Monolete & 蹄盖葓科 Athyriaceae & 蹄盖莜科 Athyriaceae \\
\hline 毛复叶角䯾 Cornopteris badia f. quadripinnatifida (M. Kato) & 单裂缝 Monolete & 蹄盖蕨科 Athyriaceae & 蹄盖蕨科 Athyriaceae \\
\hline \multicolumn{4}{|l|}{ W. M. Chu } \\
\hline 溪生角硕 Cornopteris banahaoensis (C. Chr.) K. Iwats \& Price & 单裂缝 Monolete & 蹄盖菜科 Athyriaceae & 蹄盖蒴科 Athyriaceae \\
\hline 尖羽角硕 Cornopteris christenseniana (Koidz.) Tagawa & 单裂缝 Monolete & 蹄盖䕋科 Athyriaceae & 蹄盖蕨科 Athyriaceae \\
\hline 细齿角睰 Cornopteris crenulatoserrulata (Makino) Nakai & 单裂缝 Monolete & 蹄盖蒴科 Athyriaceae & 蹄盖蒴科 Athyriaceae \\
\hline 角䝫 Cornopteris decurrenti-alata (Hook.) Nakai & 单裂缝 Monolete & 蹄盖偋科 Athyriaceae & 蹄盖偋科 Athyriaceae \\
\hline 毛叶角硕 Cornopteris decurrenti-alata f. pillosella (H. Ito) W. & 单裂缝 Monolete & 蹄盖蕨科 Athyriaceae & 蹄盖蕨科 Athyriaceae \\
\hline \multicolumn{4}{|l|}{ M. Chu } \\
\hline 阔基角嵚 Cornopteris latibasis W. M. Chu & 单裂缝 Monolete & 蹄盖葓科 Athyriaceae & 蹄盖偋科 Athyriaceae \\
\hline 阔片角蕨 Cornopteris latiloba Ching & 单裂缝 Monolete & 蹄盖蕨科 Athyriaceae & 蹄盖蕨科 Athyriaceae \\
\hline 大叶角硕 Cornopteris major W. M. Chu & 单裂缝 Monolete & 蹄盖蕨科 Athyriaceae & 蹄盖蕨科 Athyriaceae \\
\hline 峨眉角蕨 Cornopteris omeiensis Ching & 单裂缝 Monolete & 蹄盖菜科 Athyriaceae & 蹄盖蒴科 Athyriaceae \\
\hline 黑叶角蕨 Cornopteris opaca (Don) Tagawa & 单裂缝 Monolete & 蹄盖蕨科 Athyriaceae & 蹄盖蕨科 Athyriaceae \\
\hline 变光黑叶角蕨 Cornopteris opaca f. glabrescens Sa. Kurata & 单裂缝 Monolete & 蹄盖蕨科 Athyriaceae & 蹄盖蕨科 Athyriaceae \\
\hline 滇南角偋 Cornopteris pseudofluvialis Ching \& W. M. Chu & 单裂缝 Monolete & 蹄盖蒴科 Athyriaceae & 蹄盖偋科 Athyriaceae \\
\hline 全缘网蕨 Dictyodroma formosanum (Rosenst.) Ching & 单裂缝 Monolete & 蹄盖蒴科 Athyriaceae & 蹄盖蒴科 Athyriaceae \\
\hline 海南网蕨 Dictyodroma hainanense Ching & 单裂缝 Monolete & 蹄盖蒴科 Athyriaceae & 蹄盖蒴科 Athyriaceae \\
\hline
\end{tabular}




\begin{tabular}{|c|c|c|c|}
\hline $\begin{array}{l}\text { 物种 } \\
\text { Species }\end{array}$ & $\begin{array}{l}\text { 孢子裂缝类型 } \\
\text { Spore apertures styles }\end{array}$ & $\begin{array}{l}\text { 科名 Family (秦仁 } \\
\text { 昌,1978a, b) }\end{array}$ & $\begin{array}{l}\text { 科名 Family (Smith et al., } \\
\text { 2006; Christenhusz et al, } \\
\text { 2011; 张宪春等, 2013) }\end{array}$ \\
\hline 网蕨 Dictyodroma heterophlebium (Mett.) Ching & 单裂缝 Monolete & 蹄盖葓科 Athyriaceae & 蹄盖锁科 Athyriaceae \\
\hline 云南网蕨 Dictyodroma yunnanense Ching & 单裂缝 Monolete & 蹄盖蒴科 Athyriaceae & 蹄盖葓科 Athyriaceae \\
\hline 白沙双盖蕨 Diplazium basahense Ching & 单裂缝 Monolete & 蹄盖蕨科 Athyriaceae & 蹄盖蕨科 Athyriaceae \\
\hline 厚叶双盖䕬 Diplazium crassiusculum Ching & 单裂缝 Monolete & 蹄盖蒴科 Athyriaceae & 蹄盖蒴科 Athyriaceae \\
\hline 双盖蒴 Diplazium donianum (Mett.) Tardieu & 单裂缝 Monolete & 蹄盖葓科 Athyriaceae & 蹄盖莜科 Athyriaceae \\
\hline 隐脉双盖蕨 Diplazium donianum var. aphanoneuron (Ohwi) & 单裂缝 Monolete & 蹄盖蕨科 Athyriaceae & 蹄盖蕨科 Athyriaceae \\
\hline \multicolumn{4}{|l|}{ Tagawa } \\
\hline 顶羽裂双盖痥 Diplazium donianum var. lobatum Tagawa & 单裂缝 Monolete & 蹄盖蒴科 Athyriaceae & 蹄盖蒴科 Athyriaceae \\
\hline 海南双盖蕨 Diplazium hainanense Ching & 单裂缝 Monolete & 蹄盖䕋科 Athyriaceae & 蹄盖蕨科 Athyriaceae \\
\hline 马鞍山双盖偋 Diplazium maonense Ching & 单裂缝 Monolete & 蹄盖蒴科 Athyriaceae & 蹄盖蒴科 Athyriaceae \\
\hline 薄叶双盖䒴 Diplazium pinfaense Ching & 单裂缝 Monolete & 蹄盖蒴科 Athyriaceae & 蹄盖媭科 Athyriaceae \\
\hline 锯齿双盖嵚 Diplazium serratifolium Ching & 单裂缝 Monolete & 蹄盖蒴科 Athyriaceae & 蹄盖葓科 Athyriaceae \\
\hline 大叶双盖嵚 Diplazium splendens Ching & 单裂缝 Monolete & 蹄盖蒴科 Athyriaceae & 蹄盖蒴科 Athyriaceae \\
\hline 狭鳞双盖烣 Diplazium stenolepis Ching & 单裂缝 Monolete & 蹄盖蒴科 Athyriaceae & 蹄盖媭科 Athyriaceae \\
\hline 介蕨 Dryoathyrium boryanum (Willd.) Ching & 单裂缝 Monolete & 蹄盖蕨科 Athyriaceae & 蹄盖蕨科 Athyriaceae \\
\hline 中华介蕨 Dryoathyrium chinense Ching & 单裂缝 Monolete & 蹄盖蒴科 Athyriaceae & 蹄盖蒴科 Athyriaceae \\
\hline 狭甘介偋 Dryoathyrium confusum Ching \& Y. P. Hsu & 单裂缝 Monolete & 蹄盖蒝科 Athyriaceae & 蹄盖蒴科 Athyriaceae \\
\hline 朝鲜半岛介蕨 Dryoathyrium coreanum (Christ) Tagawa & 单裂缝 Monolete & 蹄盖蕨科 Athyriaceae & 蹄盖蕨科 Athyriaceae \\
\hline 无齿介荻 Dryoathyrium edentulum (Kunze) Ching & 单裂缝 Monolete & 蹄盖蕨科 Athyriaceae & 蹄盖蕨科 Athyriaceae \\
\hline 鄂西介嵚 Dryoathyrium henryi (Baker) Ching & 单裂缝 Monolete & 蹄盖蒴科 Athyriaceae & 蹄盖蒴科 Athyriaceae \\
\hline 华中介蕨 Dryoathyrium okuboanum (Makino) Ching & 单裂缝 Monolete & 蹄盖蒴科 Athyriaceae & 蹄盖蒴科 Athyriaceae \\
\hline 翅轴介蕨 Dryoathyrium pterorachis (Christ) Ching & 单裂缝 Monolete & 蹄盖蒴科 Athyriaceae & 蹄盖蕨科 Athyriaceae \\
\hline
\end{tabular}




\begin{tabular}{|c|c|c|c|}
\hline $\begin{array}{l}\text { 物种 } \\
\text { Species }\end{array}$ & $\begin{array}{l}\text { 孢子裂缝类型 } \\
\text { Spore apertures styles }\end{array}$ & $\begin{array}{l}\text { 科名 Family (秦仁 } \\
\text { 昌,1978a, b) }\end{array}$ & $\begin{array}{l}\text { 科名 Family (Smith et al., } \\
\text { 2006; Christenhusz et al, } \\
\text { 2011; 张宪春等, 2013) }\end{array}$ \\
\hline 刺毛介䓲 Dryoathyrium setigerum Ching ex Y. T. Hsieh & 单裂缝 Monolete & 蹄盖蒴科 Athyriaceae & 蹄盖烣科 Athyriaceae \\
\hline 川东介疹 Dryoathyrium stenopteron (Baker) Ching & 单裂缝 Monolete & 蹄盖锁科 Athyriaceae & 蹄盖硕科 Athyriaceae \\
\hline 峨眉介蕨 Dryoathyrium unifurcatum (Baker) Ching & 单裂缝 Monolete & 蹄盖葓科 Athyriaceae & 蹄盖蒴科 Athyriaceae \\
\hline 绿叶介蕨 Dryoathyrium viridifrons (Makino) Ching & 单裂缝 Monolete & 蹄盖锁科 Athyriaceae & 蹄盖锁科 Athyriaceae \\
\hline 尖片蛾眉蒴 Lunathyrium acutum Ching & 单裂缝 Monolete & 蹄盖锁科 Athyriaceae & 蹄盖媭科 Athyriaceae \\
\hline $\begin{array}{l}\text { 巴嘎蜮眉蕨 Lunathyrium acutum var. bagaense (Ching \& S. K. } \\
\text { Wu) Z. R. Wang }\end{array}$ & 单裂缝 Monolete & 蹄盖锁科 Athyriaceae & 蹄盖莜科 Athyriaceae \\
\hline $\begin{array}{l}\text { 六巴蛾眉蕨 Lunathyrium acutum var. liubaense ( Z. R. Wang) } \\
\text { Z. R. Wang }\end{array}$ & 单裂缝 Monolete & 蹄盖蕨科 Athyriaceae & 蹄盖莜科 Athyriaceae \\
\hline $\begin{array}{l}\text { 大耳蛾眉蕨 Lunathyrium auriculatum W. M. Chu \& Z. R. } \\
\text { Wang ex Z. R. Wang }\end{array}$ & 单裂缝 Monolete & 蹄盖罝科 Athyriaceae & 蹄盖莜科 Athyriaceae \\
\hline $\begin{array}{l}\text { 短羽蛾眉蕨 Lunathyrium brevipinnum Ching \& K. H. Shing ex } \\
\text { Z. R. Wang }\end{array}$ & 单裂缝 Monolete & 蹄盖蕨科 Athyriaceae & 蹄盖蕨科 Athyriaceae \\
\hline 昆明蛾眉嵚 Lunathyrium dolosum (Christ) Ching & 单裂缝 Monolete & 蹄盖锁科 Athyriaceae & 蹄盖蒴科 Athyriaceae \\
\hline 棒狍蛾眉嵚 Lunathyrium emeiense Z. R. Wang & 单裂缝 Monolete & 蹄盖葓科 Athyriaceae & 蹄盖嵚科 Athyriaceae \\
\hline 陕西蛾眉蕨 Lunathyrium giraldii (Christ) Ching & 单裂缝 Monolete & 蹄盖锁科 Athyriaceae & 蹄盖葓科 Athyriaceae \\
\hline 毛轴蛾眉菜 Lunathyrium hirtirachis Ching ex Z. R. Wang & 单裂缝 Monolete & 蹄盖莜科 Athyriaceae & 蹄盖硕科 Athyriaceae \\
\hline 康县蛾眉嵚 Lunathyrium kanghsienense Ching \& Y. P. Hsu & 单裂缝 Monolete & 蹄盖葓科 Athyriaceae & 蹄盖嵚科 Athyriaceae \\
\hline 凉山蛾眉蕨 Lunathyrium liangshanense Ching ex Z. R. Wang & 单裂缝 Monolete & 蹄盖蕨科 Athyriaceae & 蹄盖蕨科 Athyriaceae \\
\hline $\begin{array}{l}\text { 绢毛蛾眉萨 Lunathyrium liangshanense var. sericeum Ching \& } \\
\text { Z. R. Wang ex Z. R. Wang }\end{array}$ & 单裂缝 Monolete & 蹄盖蒴科 Athyriaceae & 蹄盖葓科 Athyriaceae \\
\hline 泸定蛾眉葓 Lunathyrium ludingense Z. R. Wang \& L. B. Zhang & 单裂缝 Monolete & 蹄盖葓科 Athyriaceae & 蹄盖锁科 Athyriaceae \\
\hline
\end{tabular}


魏雪苹，张宪春．蒴类植物不同狍子裂缝类型在中国的分布格局. 生物多样性，2016，24(10)：1129-1134 http://www. biodiversity - science. net/CN/10. 17520/biods. 2016219

\begin{tabular}{|c|c|c|c|}
\hline $\begin{array}{l}\text { 物种 } \\
\text { Species }\end{array}$ & $\begin{array}{l}\text { 孢子裂缝类型 } \\
\text { Spore apertures styles }\end{array}$ & $\begin{array}{l}\text { 科名 Family (秦仁 } \\
\text { 昌,1978a, b) }\end{array}$ & $\begin{array}{l}\text { 科名 Family (Smith et al., } \\
\text { 2006; Christenhusz et al, } \\
\text { 2011; 张宪春等, 2013) }\end{array}$ \\
\hline 墨脱蛾眉蕨 Lunathyrium medogense Ching \& S. K. Wu & 单裂缝 Monolete & 蹄盖葓科 Athyriaceae & 蹄盖烣科 Athyriaceae \\
\hline $\begin{array}{l}\text { 粒腺蛾眉蕨 Lunathyrium medogense var. glanduliferum W. M. } \\
\text { Chu }\end{array}$ & 单裂缝 Monolete & 蹄盖偋科 Athyriaceae & 蹄盖莜科 Athyriaceae \\
\hline 南川蛾眉蒴 Lunathyrium nanchuanense Ching \& Z. Y. Liu & 单裂缝 Monolete & 蹄盖蒴科 Athyriaceae & 蹄盖莜科 Athyriaceae \\
\hline $\begin{array}{l}\text { 东亚蛾眉蕨 Lunathyrium orientale Z. R. Wang \& J. J. Chien ex } \\
\text { J. J. Chien }\end{array}$ & 单裂缝 Monolete & 蹄盖锁科 Athyriaceae & 蹄盖颐科 Athyriaceae \\
\hline $\begin{array}{l}\text { 黄山蛾眉蕨 Lunathyrium orientale var. huangshanense Z. R. } \\
\text { Wang }\end{array}$ & 单裂缝 Monolete & 蹄盖蒴科 Athyriaceae & 蹄盖钼科 Athyriaceae \\
\hline $\begin{array}{l}\text { 九龙蛾眉蕨 Lunathyrium orientale var. jiulungense (Ching) Z. } \\
\text { R. Wang }\end{array}$ & 单裂缝 Monolete & 蹄盖葓科 Athyriaceae & 蹄盖葓科 Athyriaceae \\
\hline 东北蛾眉蕨 Lunathyrium pycnosorum (Christ) Koidz. & 单裂缝 Monolete & 蹄盖莜科 Athyriaceae & 蹄盖莜科 Athyriaceae \\
\hline $\begin{array}{l}\text { 长齿蛾眉蕨 Lunathyrium pycnosorum var. longidens Z. R. } \\
\text { Wang }\end{array}$ & 单裂缝 Monolete & 蹄盖锁科 Athyriaceae & 蹄盖嵚科 Athyriaceae \\
\hline $\begin{array}{l}\text { 华中蛾眉蕨 Lunathyrium shennongense Ching, Boufford \& K. } \\
\text { H. Shing }\end{array}$ & 单裂缝 Monolete & 蹄盖烣科 Athyriaceae & 蹄盖莜科 Athyriaceae \\
\hline 四川蛾眉蕨 Lunathyrium sichuanense Z. R. Wang & 单裂缝 Monolete & 蹄盖锁科 Athyriaceae & 蹄盖蒴科 Athyriaceae \\
\hline $\begin{array}{l}\text { 金佛山蛾眉蕨 Lunathyrium sichuanense var. jinfoshanense Z. } \\
\text { R. Wang }\end{array}$ & 单裂缝 Monolete & 蹄盖硕科 Athyriaceae & 蹄盖萨科 Athyriaceae \\
\hline 锡金蛾眉偋 Lunathyrium sikkimense Ching & 单裂缝 Monolete & 蹄盖硕科 Athyriaceae & 蹄盖锁科 Athyriaceae \\
\hline 河北蛾眉蕂 Lunathyrium vegetius (Kitagawa) Ching & 单裂缝 Monolete & 蹄盖锁科 Athyriaceae & 蹄盖蒴科 Athyriaceae \\
\hline $\begin{array}{l}\text { 密云蛾眉蕨 Lunathyrium vegetius var. miyunense Ching \& Z. } \\
\text { R. Wang }\end{array}$ & 单裂缝 Monolete & 蹄盖莜科 Athyriaceae & 蹄盖锁科 Athyriaceae \\
\hline
\end{tabular}


魏雪苹，张宪春．蒴类植物不同狍子裂缝类型在中国的分布格局. 生物多样性，2016，24(10)：1129-1134 http://www. biodiversity - science. net/CN/10. 17520/biods. 2016219

\begin{tabular}{|c|c|c|c|}
\hline $\begin{array}{l}\text { 物种 } \\
\text { Species }\end{array}$ & $\begin{array}{l}\text { 孢子裂缝类型 } \\
\text { Spore apertures styles }\end{array}$ & $\begin{array}{l}\text { 科名 Family (秦仁 } \\
\text { 昌,1978a, b) }\end{array}$ & $\begin{array}{l}\text { 科名 Family (Smith et al., } \\
\text { 2006; Christenhusz et al, } \\
\text { 2011; 张宪春等, 2013) }\end{array}$ \\
\hline $\begin{array}{l}\text { 壳盖蛾眉茨 Lunathyrium vegetius var. turgidum Ching \& Z. R. } \\
\text { Wang }\end{array}$ & 单裂缝 Monolete & 蹄盖蕨科 Athyriaceae & 蹄盖茨科 Athyriaceae \\
\hline $\begin{array}{l}\text { 湖北蛾眉蕨 Lunathyrium vermiforme Ching, Boufford \& K. H. } \\
\text { Shing }\end{array}$ & 单裂缝 Monolete & 蹄盖蕨科 Athyriaceae & 蹄盖荻科 Athyriaceae \\
\hline 峨山蛾眉睰 Lunathyrium wilsonii (Christ) Ching & 单裂缝 Monolete & 蹄盖蕨科 Athyriaceae & 蹄盖颐科 Athyriaceae \\
\hline $\begin{array}{l}\text { 哈巴蛾眉蕨 Lunathyrium wilsonii var. habaense Ching \& Z. R. } \\
\text { Wang }\end{array}$ & 单裂缝 Monolete & 蹄盖荻科 Athyriaceae & 蹄盖荻科 Athyriaceae \\
\hline $\begin{array}{l}\text { 锐裂蛾眉蕨 Lunathyrium wilsonii var. incisoserratum Ching \& } \\
\text { Z. R. Wang }\end{array}$ & 单裂缝 Monolete & 蹄盖荻科 Athyriaceae & 蹄盖蕨科 Athyriaceae \\
\hline $\begin{array}{l}\text { 大蛾眉蕨 Lunathyrium wilsonii var. maximum Ching \& Z. R. } \\
\text { Wang }\end{array}$ & 单裂缝 Monolete & 蹄盖嵚科 Athyriaceae & 蹄盖鄀科 Athyriaceae \\
\hline $\begin{array}{l}\text { 木里蛾眉蕨 Lunathyrium wilsonii var. muliense Z. R. Wang } \\
\text { 鼎湖山毛轴线盖蕨 Monomelangium dinghushanicum Ching \& } \\
\text { S. H. Wu }\end{array}$ & $\begin{array}{l}\text { 单裂缝 Monolete } \\
\text { 单裂缝 Monolete }\end{array}$ & $\begin{array}{l}\text { 蹄盖烣科 Athyriaceae } \\
\text { 蹄盖蕨科 Athyriaceae }\end{array}$ & $\begin{array}{l}\text { 蹄盖葓科 Athyriaceae } \\
\text { 蹄盖蕨科 Athyriaceae }\end{array}$ \\
\hline $\begin{array}{l}\text { 毛轴线盖荻 Monomelangium pullingeri (Baker) Tagawa } \\
\text { 大围山毛轴线盖苲 Monomelangium pullingeri var. } \\
\text { daweishanicolum W. M. Chu \& Z. R. He }\end{array}$ & $\begin{array}{l}\text { 单裂缝 Monolete } \\
\text { 单裂缝 Monolete }\end{array}$ & $\begin{array}{l}\text { 蹄盖苵科 Athyriaceae } \\
\text { 蹄盖蕨科 Athyriaceae }\end{array}$ & $\begin{array}{l}\text { 蹄盖茨科 Athyriaceae } \\
\text { 蹄盖蕨科 Athyriaceae }\end{array}$ \\
\hline 单叶双盖萨 Neotriblemma lancea (Thunb.) Nakaike & 单裂缝 Monolete & 蹄盖蕨科 Athyriaceae & 蹄盖硕科 Athyriaceae \\
\hline 大叶假冷嵚 Pseudocystopteris atkinsonii (Bedd.) Ching & 单裂缝 Monolete & 蹄盖蕨科 Athyriaceae & 蹄盖蕨科 Athyriaceae \\
\hline 阿墩子假冷鄀 Pseudocystopteris atuntzeensis Ching & 单裂缝 Monolete & 蹄盖蕨科 Athyriaceae & 蹄盖蕨科 Athyriaceae \\
\hline 大卫假冷蕨 Pseudocystopteris davidii (Franch.) Z. R. Wang & 单裂缝 Monolete & 蹄盖蕨科 Athyriaceae & 蹄盖蕨科 Athyriaceae \\
\hline 长根假冷蕨 Pseudocystopteris repens Ching & 单裂缝 Monolete & 蹄盖蕨科 Athyriaceae & 蹄盖菜科 Athyriaceae \\
\hline
\end{tabular}




\begin{tabular}{|c|c|c|c|}
\hline $\begin{array}{l}\text { 物种 } \\
\text { Species }\end{array}$ & $\begin{array}{l}\text { 孢子裂缝类型 } \\
\text { Spore apertures styles }\end{array}$ & $\begin{array}{l}\text { 科名 Family (秦仁 } \\
\text { 昌,1978a, b) }\end{array}$ & $\begin{array}{l}\text { 科名 Family (Smith et al., } \\
\text { 2006; Christenhusz et al, } \\
\text { 2011; 张宪春等, 2013) }\end{array}$ \\
\hline 睫毛盖假冷鄀 Pseudocystopteris schizochlamys Ching & 单裂缝 Monolete & 蹄盖蒴科 Athyriaceae & 蹄盖藃科 Athyriaceae \\
\hline 假冷蒴 Pseudocystopteris spinulosa (Maxim.) Ching & 单裂缝 Monolete & 蹄盖蒴科 Athyriaceae & 蹄盖媭科 Athyriaceae \\
\hline 三角叶假冷偋 Pseudocystopteris subtriangularis (Hook.) Ching & 单裂缝 Monolete & 蹄盖蕨科 Athyriaceae & 蹄盖蕨科 Athyriaceae \\
\hline 荚果硕 Matteuccia struthiopteris (L.) Tadaro & 单裂缝 Monolete & 球子菜科 Onocleaceae & 球子茨科 Onocleaceae \\
\hline 球子嵚 Onoclea sensibilis var. interrupta Maxim. & 单裂缝 Monolete & 球子萨科 Onocleaceae & 球子蒝科 Onocleaceae \\
\hline 中华东方荚果嵚 Pentarhizidium intermedium (C. Chr.) Hayata & 单裂缝 Monolete & 球子蕨科 Onocleaceae & 球子蕨科 Onocleaceae \\
\hline 东方荚果葓 Pentarhizidium orientalis (Hook.) Hyata. & 单裂缝 Monolete & 球子葓科 Onocleaceae & 球子蒴科 Onocleaceae \\
\hline \multirow[t]{2}{*}{ 光叶藤蕨 Stenochlaena palustris (Burm. f.) Bedd. } & 单裂缝 Monolete & 光叶藤蕨科 & 乌毛硕科 Blechnaceae \\
\hline & & Stenochlaenaceae & \\
\hline 乌木硕 Blechnidium melanopus (Hook.) T. Moore & 单裂缝 Monolete & 乌毛蕨科 Blechnaceae & 乌毛蕨科 Blechnaceae \\
\hline 乌毛蕨 Blechnum orientale L. & 单裂缝 Monolete & 乌毛蕨科 Blechnaceae & 乌毛蕨科 Blechnaceae \\
\hline 苏铁蕨 Brainea insignis (Hook.) J. Sm. & 单裂缝 Monolete & 乌毛蕨科 Blechnaceae & 乌毛蕨科 Blechnaceae \\
\hline 崇澍偋 Chieniopteris harlandii (Hook.) Ching & 单裂缝 Monolete & 乌毛蕨科 Blechnaceae & 乌毛蕨科 Blechnaceae \\
\hline 裂羽崇澍蕨 Chieniopteris kempii (Copel.) Ching & 单裂缝 Monolete & 乌毛葓科 Blechnaceae & 乌毛蕨科 Blechnaceae \\
\hline 扫把蕨 Diploblechnum fraseri (A. Cunn.) De Vol & 单裂缝 Monolete & 乌毛蕨科 Blechnaceae & 乌毛蕨科 Blechnaceae \\
\hline 荚囊蕨 Struthiopteris eburnea (Christ) Ching & 单裂缝 Monolete & 乌毛蕨科 Blechnaceae & 乌毛蕨科 Blechnaceae \\
\hline 宽叶荚囊蒴 Struthiopteris hancockii (Hance) Tagawa & 单裂缝 Monolete & 乌毛蕨科 Blechnaceae & 乌毛硕科 Blechnaceae \\
\hline 狗脊鄀 Woodwardia japonica (L. f.) Sm. & 单裂缝 Monolete & 乌毛荻科 Blechnaceae & 乌毛蕨科 Blechnaceae \\
\hline 滇南狗脊硕 Woodwardia magnifica Ching \& P. S. Chiu & 单裂缝 Monolete & 乌毛蕨科 Blechnaceae & 乌毛蕨科 Blechnaceae \\
\hline 东方狗脊葓 Woodwardia orientalis Sw. & 单裂缝 Monolete & 乌毛葓科 Blechnaceae & 乌毛茨科 Blechnaceae \\
\hline 台湾狗脊硕 Woodwardia orientalis var. formosana Rosenst. & 单裂缝 Monolete & 乌毛蕨科 Blechnaceae & 乌毛蕨科 Blechnaceae \\
\hline 顶芽狗脊蕨 Woodwardia unigemmata (Makino) Nakai & 单裂缝 Monolete & 乌毛葓科 Blechnaceae & 乌毛茨科 Blechnaceae \\
\hline
\end{tabular}




\begin{tabular}{|c|c|c|c|}
\hline $\begin{array}{l}\text { 物种 } \\
\text { Species }\end{array}$ & $\begin{array}{l}\text { 孢子裂缝类型 } \\
\text { Spore apertures styles }\end{array}$ & $\begin{array}{l}\text { 科名 Family (秦仁 } \\
\text { 昌,1978a, b) }\end{array}$ & $\begin{array}{l}\text { 科名 Family (Smith et al., } \\
\text { 2006; Christenhusz et al, } \\
\text { 2011; 张宪春等, 2013) }\end{array}$ \\
\hline 肿足菜 Hypodematium crenatum (Forsk.) Kuhn & 单裂缝 Monolete & 肿足蕨科 Hypodematiaceae & 肿足偋科 Hypodematiaceae \\
\hline 稻城肿足蕒 Hypodematium daochengense K. H. Shing & 单裂缝 Monolete & 肿足葓科 Hypodematiaceae & 肿足莜科 Hypodematiaceae \\
\hline 福氏肿足蕨 Hypodematium fordii (Baker) Ching & 单裂缝 Monolete & 肿足蕨科 Hypodematiaceae & 肿足蕨科 Hypodematiaceae \\
\hline 无毛肿足蒴 Hypodematium glabrum Ching ex K. H. Shing & 单裂缝 Monolete & 肿足偋科 Hypodematiaceae & 肿足蒴科 Hypodematiaceae \\
\hline 球腺肿足硕 Hypodematium glandulosopilosum (Tagawa) Ohwi & 单裂缝 Monolete & 肿足硕科 Hypodematiaceae & 肿足莜科 Hypodematiaceae \\
\hline 腺毛肿足荻 Hypodematium glandulosum Ching ex K. H. Shing & 单裂缝 Monolete & 肿足荻科 Hypodematiaceae & 肿足蕨科 Hypodematiaceae \\
\hline 修株肿足嵚 Hypodematium gracile Ching & 单裂缝 Monolete & 肿足偋科 Hypodematiaceae & 肿足蒴科 Hypodematiaceae \\
\hline 光轴肿足蒴 Hypodematium hirsutum (D. Don) Ching & 单裂缝 Monolete & 肿足葓科 Hypodematiaceae & 肿足莜科 Hypodematiaceae \\
\hline 山东肿足蕨 Hypodematium sinense K. Iwats. & 单裂缝 Monolete & 肿足蕨科 Hypodematiaceae & 肿足蕨科 Hypodematiaceae \\
\hline 鳞毛肿足蒴 Hypodematium squamulosopilosum Ching & 单裂缝 Monolete & 肿足偋科 Hypodematiaceae & 肿足蒴科 Hypodematiaceae \\
\hline 台湾肿足嵚 Hypodematium taiwanensis Ching ex K. H. Shing & 单裂缝 Monolete & 肿足硕科 Hypodematiaceae & 肿足媭科 Hypodematiaceae \\
\hline 大膜盖蕨 Leucostegia immersa C. Presl & 单裂缝 Monolete & 骨碎补科 Davalliaceae & 肿足蕨科 Hypodematiaceae \\
\hline 锡金假鳞毛蕨 Lastrea elwesii (Hook. \& Baker) Bedd. & 单裂缝 Monolete & 金星蒴科 Thelypteridaceae & 鳞毛蕨科 Dryopteridaceae \\
\hline 亚洲假鳞毛蕨 Lastrea quelpaertensis (Christ) Copel. & 单裂缝 Monolete & 金星蕨科 Thelypteridaceae & 鳞毛蕨科 Dryopteridaceae \\
\hline 毛枝嵚 Leptorumohra miqueliana (Maxim. ex Franch. \& Sav.) & 单裂缝 Monolete & 金星蕨科 Thelypteridaceae & 鳞毛蕨科 Dryopteridaceae \\
\hline \multicolumn{4}{|l|}{ H. It? } \\
\hline 四回毛枝蕨 Leptorumohra quadripinnata (Hayata) H. Ito & 单裂缝 Monolete & 金星蕨科 Thelypteridaceae & 鳞毛蕨科 Dryopteridaceae \\
\hline 无鳞毛枝钞 Leptorumohra sinomiqueliana (Ching) Tagawa & 单裂缝 Monolete & 金星蕨科 Thelypteridaceae & 鳞毛蕨科 Dryopteridaceae \\
\hline 鱼鳞蒴 Acrophorus paleolatus Pic. Serm. & 单裂缝 Monolete & 球盖䔊科 Peranemaceae & 鳞毛茨科 Dryopteridaceae \\
\hline 小叶红腺蕨 Diacalpe adscendens Ching ex S. H. Wu & 单裂缝 Monolete & 球盖蕨科 Peranemaceae & 鳞毛蕨科 Dryopteridaceae \\
\hline 圆头红腺䁤 Diacalpe annamensis Tagawa & 单裂缝 Monolete & 球盖蘝科 Peranemaceae & 鳞毛蕨科 Dryopteridaceae \\
\hline 红腺蕨 Diacalpe aspidioides Blume & 单裂缝 Monolete & 球盖蕨科 Peranemaceae & 鳞毛蕨科 Dryopteridaceae \\
\hline
\end{tabular}




\begin{tabular}{|c|c|c|c|}
\hline $\begin{array}{l}\text { 物种 } \\
\text { Species }\end{array}$ & $\begin{array}{l}\text { 孢子裂缝类型 } \\
\text { Spore apertures styles }\end{array}$ & $\begin{array}{l}\text { 科名 Family (秦仁 } \\
\text { 昌,1978a, b) }\end{array}$ & $\begin{array}{l}\text { 科名 Family (Smith et al., } \\
\text { 2006; Christenhusz et al, } \\
\text { 2011; 张宪春等, 2013) }\end{array}$ \\
\hline 西藏红腺㓹 Diacalpe aspidioides var. hookeriana (T. Moore) & 单裂缝 Monolete & 球盖茨科 Peranemaceae & 鳞毛脄科 Dryopteridaceae \\
\hline \multicolumn{4}{|l|}{ Ching \& S. H. Wu } \\
\hline 旱生红腺葓 Diacalpe aspidioides var. minor Ching ex S. H. Wu & 单裂缝 Monolete & 球盖蕨科 Peranemaceae & 鳞毛蕨科 Dryopteridaceae \\
\hline 大囊红腺蕨 Diacalpe chinensis Ching \& S. H. Wu & 单裂缝 Monolete & 球盖茨科 Peranemaceae & 鳞毛蕨科 Dryopteridaceae \\
\hline 离轴红腺蕨 Diacalpe christensenae Ching & 单裂缝 Monolete & 球盖嵚科 Peranemaceae & 鳞毛葓科 Dryopteridaceae \\
\hline 光轴红腺荻 Diacalpe laevigata Ching \& S. H. Wu & 单裂缝 Monolete & 球盖蕨科 Peranemaceae & 鳞毛蕨科 Dryopteridaceae \\
\hline 峨眉红腺莎 Diacalpe omeiensis Ching & 单裂缝 Monolete & 球盖茨科 Peranemaceae & 鳞毛蕨科 Dryopteridaceae \\
\hline 柄盖硕 Peranema cyatheoides D. Don & 单裂缝 Monolete & 球盖嵚科 Peranemaceae & 鳞毛蓱科 Dryopteridaceae \\
\hline 东亚柄盖蕨 Peranema cyatheoides var. luzonicum (Copel.) & 单裂缝 Monolete & 球盖蕨科 Peranemaceae & 鳞毛蕨科 Dryopteridaceae \\
\hline \multicolumn{4}{|l|}{ Ching \& S. H. Wu } \\
\hline 弯柄假复叶耳锣 Acrorumohra diffracta (Baker) H. Ito & 单裂缝 Monolete & 鳞毛蕨科 Dryopteridaceae & 鳞毛蕨科 Dryopteridaceae \\
\hline 川滇假复叶耳蕨 Acrorumohra dissecta Ching ex Y. T. Hsieh & 单裂缝 Monolete & 鳞毛蕨科 Dryopteridaceae & 鳞毛蕨科 Dryopteridaceae \\
\hline 草质假复叶耳蕨 Acrorumohra hasseltii (Blume) Ching & 单裂缝 Monolete & 鳞毛蕨科 Dryopteridaceae & 鳞毛蕨科 Dryopteridaceae \\
\hline $\begin{array}{l}\text { 微弯假复叶耳蕨 Acrorumohra subreflexipinna (M. Ogata) H. } \\
\text { Ito }\end{array}$ & 单裂缝 Monolete & 鳞毛蕨科 Dryopteridaceae & 鳞毛蕨科 Dryopteridaceae \\
\hline 衷牢山复叶耳蕨 Arachniodes ailaoshanensis Ching & 单裂缝 Monolete & 鳞毛嵚科 Dryopteridaceae & 鳞毛蕨科 Dryopteridaceae \\
\hline 多羽复叶耳䲞 Arachniodes amoena (Ching) Ching & 单裂缝 Monolete & 鳞毛嵚科 Dryopteridaceae & 鳞毛蕨科 Dryopteridaceae \\
\hline 安顺复叶耳蕨 Arachniodes anshunensis Ching \& Y. T. Hsieh & 单裂缝 Monolete & 鳞毛蕨科 Dryopteridaceae & 鳞毛蕨科 Dryopteridaceae \\
\hline 多芒复叶耳蕨 Arachniodes aristatissima Ching & 单裂缝 Monolete & 鳞毛蕨科 Dryopteridaceae & 鳞毛蕨科 Dryopteridaceae \\
\hline 西南复叶耳葓 Arachniodes assamica (Kuhn) Ohwi & 单裂缝 Monolete & 鳞毛蕨科 Dryopteridaceae & 鳞毛蒴科 Dryopteridaceae \\
\hline 狭长复叶耳葓 Arachniodes attenuata Ching & 单裂缝 Monolete & 鳞毛蕨科 Dryopteridaceae & 鳞毛蕨科 Dryopteridaceae \\
\hline 尾叶复叶耳蕨 Arachniodes caudata Ching & 单裂缝 Monolete & 鳞毛蕨科 Dryopteridaceae & 鳞毛蕨科 Dryopteridaceae \\
\hline
\end{tabular}




\begin{tabular}{|c|c|c|c|}
\hline $\begin{array}{l}\text { 物种 } \\
\text { Species }\end{array}$ & $\begin{array}{l}\text { 孢子裂缝类型 } \\
\text { Spore apertures styles }\end{array}$ & $\begin{array}{l}\text { 科名 Family (秦仁 } \\
\text { 昌,1978a, b) }\end{array}$ & $\begin{array}{l}\text { 科名 Family (Smith et al., } \\
\text { 2006; Christenhusz et al, } \\
\text { 2011; 张宪春等, 2013) }\end{array}$ \\
\hline 大片复叶耳䓲 Arachniodes cavalerii (Christ) Ohwi & 单裂缝 Monolete & 鳞毛蕨科 Dryopteridaceae & 鳞毛蕨科 Dryopteridaceae \\
\hline 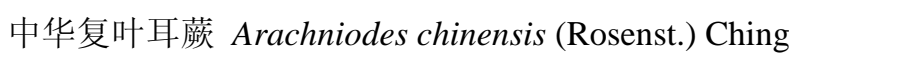 & 单裂缝 Monolete & 鳞毛蕨科 Dryopteridaceae & 鳞毛硕科 Dryopteridaceae \\
\hline 细裂复叶耳蕨 Arachniodes coniifolia (T. Moore) Ching & 单裂缝 Monolete & 鳞毛蕨科 Dryopteridaceae & 鳞毛蕨科 Dryopteridaceae \\
\hline 五回复叶耳锁 Arachniodes decomposita Ching & 单裂缝 Monolete & 鳞毛蕨科 Dryopteridaceae & 鳞毛烣科 Dryopteridaceae \\
\hline 二型复叶耳蕨 Arachniodes dimorphophylla (Hayata) Ching & 单裂缝 Monolete & 鳞毛蕨科 Dryopteridaceae & 鳞毛硕科 Dryopteridaceae \\
\hline 刺头复叶耳蕨 Arachniodes exilis (Hance) Ching & 单裂缝 Monolete & 鳞毛蕨科 Dryopteridaceae & 鳞毛蕨科 Dryopteridaceae \\
\hline 国楣复叶耳蒴 Arachniodes fengii Ching & 单裂缝 Monolete & 鳞毛蕨科 Dryopteridaceae & 鳞毛烣科 Dryopteridaceae \\
\hline 华南复叶耳蕨 Arachniodes festina (Hance) Ching & 单裂缝 Monolete & 鳞毛蕨科 Dryopteridaceae & 鳞毛蒝科 Dryopteridaceae \\
\hline 福建复叶耳硕 Arachniodes fujiangensis Ching & 单裂缝 Monolete & 鳞毛蕨科 Dryopteridaceae & 鳞毛蕨科 Dryopteridaceae \\
\hline 高大复叶耳蕨 Arachniodes gigantea Ching & 单裂缝 Monolete & 鳞毛蕨科 Dryopteridaceae & 鳞毛烣科 Dryopteridaceae \\
\hline 台湾复叶耳蒝 Arachniodes globisora (Hayata) Ching & 单裂缝 Monolete & 鳞毛菜科 Dryopteridaceae & 鳞毛菜科 Dryopteridaceae \\
\hline 渐尖复叶耳蕨 Arachniodes gradata Ching & 单裂缝 Monolete & 鳞毛蕨科 Dryopteridaceae & 鳞毛蕨科 Dryopteridaceae \\
\hline 粗裂复叶耳蕨 Arachniodes grossa (Tardieu \& C. Chr.) Ching & 单裂缝 Monolete & 鳞毛蕨科 Dryopteridaceae & 鳞毛蕨科 Dryopteridaceae \\
\hline 海南复叶耳葓 Arachniodes hainanensis (Ching) Ching & 单裂缝 Monolete & 鳞毛蒴科 Dryopteridaceae & 鳞毛蕨科 Dryopteridaceae \\
\hline 假斜方复叶耳蕨 Arachniodes hekiana Sa. Kurata & 单裂缝 Monolete & 鳞毛蕨科 Dryopteridaceae & 鳞毛蕨科 Dryopteridaceae \\
\hline 云南复叶耳蕨 Arachniodes henryi (Christ) Ching & 单裂缝 Monolete & 鳞毛蕨科 Dryopteridaceae & 鳞毛蕨科 Dryopteridaceae \\
\hline 花坪复叶耳㓹 Arachniodes huapingensis Ching \& P. S. Chiu & 单裂缝 Monolete & 鳞毛蕨科 Dryopteridaceae & 鳞毛鄀科 Dryopteridaceae \\
\hline 湖南复叶耳睰 Arachniodes hunanensis Ching & 单裂缝 Monolete & 鳞毛蕨科 Dryopteridaceae & 鳞毛蕨科 Dryopteridaceae \\
\hline $\begin{array}{l}\text { 壸坪山复叶耳蓱 Arachniodes hupingshanensis S. F. Wu in W. } \\
\text { T. Wang }\end{array}$ & 单裂缝 Monolete & 鳞毛蕨科 Dryopteridaceae & 鳞毛蕨科 Dryopteridaceae \\
\hline 宜兴复叶耳蕨 Arachniodes ishingensis Ching \& Y. T. Hsieh & 单裂缝 Monolete & 鳞毛蕨科 Dryopteridaceae & 鳞毛鄀科 Dryopteridaceae \\
\hline 江西复叶耳偋 Arachniodes jiangxiensis Ching & 单裂缝 Monolete & 鳞毛蕨科 Dryopteridaceae & 鳞毛烣科 Dryopteridaceae \\
\hline
\end{tabular}




\begin{tabular}{|c|c|c|c|}
\hline $\begin{array}{l}\text { 物种 } \\
\text { Species }\end{array}$ & $\begin{array}{l}\text { 孢子裂缝类型 } \\
\text { Spore apertures styles }\end{array}$ & $\begin{array}{l}\text { 科名 Family (秦仁 } \\
\text { 昌,1978a, b) }\end{array}$ & $\begin{array}{l}\text { 科名 Family (Smith et al., } \\
\text { 2006; Christenhusz et al, } \\
\text { 2011; 张宪春等, 2013) }\end{array}$ \\
\hline 金平复叶耳葓 Arachniodes jinpingensis Y. T. Hsieh & 单裂缝 Monolete & 鳞毛蕨科 Dryopteridaceae & 鳞毛烣科 Dryopteridaceae \\
\hline 披针复叶耳媭 Arachniodes lanceolata Y. T. Hsieh & 单裂缝 Monolete & 鳞毛蕨科 Dryopteridaceae & 鳞毛硕科 Dryopteridaceae \\
\hline 溧阳复叶耳蕨 Arachniodes liyangensis Ching \& Y. C. Lan & 单裂缝 Monolete & 鳞毛蕨科 Dryopteridaceae & 鳞毛蕨科 Dryopteridaceae \\
\hline 长羽复叶耳蕨 Arachniodes longipinna Ching & 单裂缝 Monolete & 鳞毛蕨科 Dryopteridaceae & 鳞毛蕨科 Dryopteridaceae \\
\hline 庐山复叶耳葓 Arachniodes lushanensis Ching & 单裂缝 Monolete & 鳞毛蕨科 Dryopteridaceae & 鳞毛硕科 Dryopteridaceae \\
\hline 昂山复叶耳锁 Arachniodes maoshanensis Ching \& P. S. Chiu & 单裂缝 Monolete & 鳞毛蕨科 Dryopteridaceae & 鳞毛蕨科 Dryopteridaceae \\
\hline 湘黔复叶耳蕨 Arachniodes michelii (H. Lév.) Ching ex Y. T. & 单裂缝 Monolete & 鳞毛蕨科 Dryopteridaceae & 鳞毛鄀科 Dryopteridaceae \\
\hline \multicolumn{4}{|l|}{ Hsieh } \\
\hline 南川复叶耳锁 Arachniodes nanchuanensis Ching \& Z. Y. Liu & 单裂缝 Monolete & 鳞毛蕨科 Dryopteridaceae & 鳞毛蕨科 Dryopteridaceae \\
\hline 南靖复叶耳蕨 Arachniodes nanqingensis Ching & 单裂缝 Monolete & 鳞毛蕨科 Dryopteridaceae & 鳞毛烣科 Dryopteridaceae \\
\hline 黑鳞复叶耳蒴 Arachniodes nigrospinosa (Ching) Ching & 单裂缝 Monolete & 鳞毛蕨科 Dryopteridaceae & 鳞毛偋科 Dryopteridaceae \\
\hline 日本复叶耳硕 Arachniodes nipponica (Rosenst.) Ohwi & 单裂缝 Monolete & 鳞毛蕨科 Dryopteridaceae & 鳞毛蕨科 Dryopteridaceae \\
\hline 假西南复叶耳蕨 Arachniodes pseudo-assamica Ching & 单裂缝 Monolete & 鳞毛蕨科 Dryopteridaceae & 鳞毛茨科 Dryopteridaceae \\
\hline 似斜方复叶耳硕 Arachniodes pseudohekiana Sa. Kurata & 单裂缝 Monolete & 鳞毛蕨科 Dryopteridaceae & 鳞毛蕨科 Dryopteridaceae \\
\hline 假长羽复叶耳蕨 Arachniodes pseudolongipinna Ching & 单裂缝 Monolete & 鳞毛蕨科 Dryopteridaceae & 鳞毛蕨科 Dryopteridaceae \\
\hline 缩羽复叶耳蕨 Arachniodes reducta Y. T. Hsieh \& Y. P. Wu & 单裂缝 Monolete & 鳞毛蕨科 Dryopteridaceae & 鳞毛蕨科 Dryopteridaceae \\
\hline 斜方复叶耳㓹 Arachniodes rhomboidea (Wall. ex Mett.) Ching & 单裂缝 Monolete & 鳞毛蕨科 Dryopteridaceae & 鳞毛鄀科 Dryopteridaceae \\
\hline 屋久复叶耳蕨 Arachniodes rhomboidea var. yakusimensis (H. & 单裂缝 Monolete & 鳞毛蕨科 Dryopteridaceae & 鳞毛蕨科 Dryopteridaceae \\
\hline \multicolumn{4}{|l|}{ Ito) W. C. Shieh } \\
\hline 长刺复叶耳葓 Arachniodes setifera Ching & 单裂缝 Monolete & 鳞毛蕨科 Dryopteridaceae & 鳞毛蕨科 Dryopteridaceae \\
\hline 异羽复叶耳蒴 Arachniodes simplicior (Makino) Ohwi & 单裂缝 Monolete & 鳞毛蕨科 Dryopteridaceae & 鳞毛鄀科 Dryopteridaceae \\
\hline 华西复叶耳葓 Arachniodes simulans (Ching) Ching & 单裂缝 Monolete & 鳞毛蕨科 Dryopteridaceae & 鳞毛蕨科 Dryopteridaceae \\
\hline
\end{tabular}




\begin{tabular}{|c|c|c|c|}
\hline $\begin{array}{l}\text { 物种 } \\
\text { Species }\end{array}$ & $\begin{array}{l}\text { 孢子裂缝类型 } \\
\text { Spore apertures styles }\end{array}$ & $\begin{array}{l}\text { 科名 Family (秦仁 } \\
\text { 昌,1978a, b) }\end{array}$ & $\begin{array}{l}\text { 科名 Family (Smith et al., } \\
\text { 2006; Christenhusz et al, } \\
\text { 2011; 张宪春等, 2013) }\end{array}$ \\
\hline 中华斜方复叶耳硕 Arachniodes sinorhomboidea Ching & 单裂缝 Monolete & 鳞毛蕨科 Dryopteridaceae & 鳞毛蕨科 Dryopteridaceae \\
\hline 美丽复叶耳葓 Arachniodes speciosa (D. Don) Ching & 单裂缝 Monolete & 鳞毛蕨科 Dryopteridaceae & 鳞毛硕科 Dryopteridaceae \\
\hline 清秀复叶耳蕨 Arachniodes spectabilis (Ching) Ching & 单裂缝 Monolete & 鳞毛蕨科 Dryopteridaceae & 鳞毛蕨科 Dryopteridaceae \\
\hline 华东复叶耳茨 Arachniodes sporadosora (Kunze) Nakaike & 单裂缝 Monolete & 鳞毛蕨科 Dryopteridaceae & 鳞毛烣科 Dryopteridaceae \\
\hline 天童复叶耳蓱 Arachniodes tiendongensis Ching \& C. F. Zhang & 单裂缝 Monolete & 鳞毛蕨科 Dryopteridaceae & 鳞毛硕科 Dryopteridaceae \\
\hline 中越复叶耳蕨 Arachniodes tonkinensis (Ching) Ching & 单裂缝 Monolete & 鳞毛蕨科 Dryopteridaceae & 鳞毛蕨科 Dryopteridaceae \\
\hline $\begin{array}{l}\text { 武陵山复叶耳蕨 Arachniodes wulingshanensis S. F. Wu in W. } \\
\text { T. Wang }\end{array}$ & 单裂缝 Monolete & 鳞毛蕨科 Dryopteridaceae & 鳞毛蕨科 Dryopteridaceae \\
\hline 雁荡山复叶耳蕨 Arachniodes yandangshanensis Y. T. Hsieh & 单裂缝 Monolete & 鳞毛蕨科 Dryopteridaceae & 鳞毛蕨科 Dryopteridaceae \\
\hline 印江复叶耳锁 Arachniodes yinjiangensis Ching & 单裂缝 Monolete & 鳞毛蕨科 Dryopteridaceae & 鳞毛烣科 Dryopteridaceae \\
\hline 东洋复叶耳蒝 Arachniodes yoshinagae (Makino) Ching & 单裂缝 Monolete & 鳞毛菜科 Dryopteridaceae & 鳞毛菜科 Dryopteridaceae \\
\hline 紫云山复叶耳硕 Arachniodes ziyunshanensis Y. T. Hsieh & 单裂缝 Monolete & 鳞毛蕨科 Dryopteridaceae & 鳞毛蕨科 Dryopteridaceae \\
\hline 拟贯众 Cyclopeltis crenata (Fée) C. Chr. & 单裂缝 Monolete & 鳞毛蕨科 Dryopteridaceae & 鳞毛蕨科 Dryopteridaceae \\
\hline 离脉柳叶薜 Cyrtogonellum caducum Ching & 单裂缝 Monolete & 鳞毛蕨科 Dryopteridaceae & 鳞毛蕨科 Dryopteridaceae \\
\hline 柳叶硕 Cyrtogonellum fraxinellum (Christ) Ching & 单裂缝 Monolete & 鳞毛蕨科 Dryopteridaceae & 鳞毛蕨科 Dryopteridaceae \\
\hline 斜基柳叶蕨 Cyrtogonellum inaequalis Ching & 单裂缝 Monolete & 鳞毛蕨科 Dryopteridaceae & 鳞毛蕨科 Dryopteridaceae \\
\hline $\begin{array}{l}\text { 石生柳叶菜 Cyrtogonellum } \times \text { rupicola P. S. Wang \& X. Y. } \\
\text { Wang }\end{array}$ & 单裂缝 Monolete & 鳞毛蕨科 Dryopteridaceae & 鳞毛蕨科 Dryopteridaceae \\
\hline 西畴柳叶菜 Cyrtogonellum xichouense S. K. Wu \& Mitsuta & 单裂缝 Monolete & 鳞毛蕨科 Dryopteridaceae & 鳞毛鄀科 Dryopteridaceae \\
\hline 单叶鞭叶蕨 Cyrtomidictyum basipinnatum (Baker) Ching & 单裂缝 Monolete & 鳞毛蕨科 Dryopteridaceae & 鳞毛蕨科 Dryopteridaceae \\
\hline 卵状鞭叶蒴 Cyrtomidictyum conjunctum Ching & 单裂缝 Monolete & 鳞毛蕨科 Dryopteridaceae & 鳞毛鄀科 Dryopteridaceae \\
\hline 鞭叶嵚 Cyrtomidictyum lepidocaulon (Hook.) Ching & 单裂缝 Monolete & 鳞毛蕨科 Dryopteridaceae & 鳞毛烣科 Dryopteridaceae \\
\hline
\end{tabular}




\begin{tabular}{|c|c|c|c|}
\hline $\begin{array}{l}\text { 物种 } \\
\text { Species }\end{array}$ & $\begin{array}{l}\text { 孢子裂缝类型 } \\
\text { Spore apertures styles }\end{array}$ & $\begin{array}{l}\text { 科名 Family (秦仁 } \\
\text { 昌,1978a, b) }\end{array}$ & $\begin{array}{l}\text { 科名 Family (Smith et al., } \\
\text { 2006; Christenhusz et al, } \\
\text { 2011; 张宪春等, 2013) }\end{array}$ \\
\hline 等基贯众 Cyrtomium aequibasis (C. Chr.) Ching & 单裂缝 Monolete & 鳞毛蕨科 Dryopteridaceae & 鳞毛蕨科 Dryopteridaceae \\
\hline 镰羽贯众 Cyrtomium balansae (Christ) C. Chr. & 单裂缝 Monolete & 鳞毛蕨科 Dryopteridaceae & 鳞毛蕨科 Dryopteridaceae \\
\hline $\begin{array}{l}\text { 无齿镰羽贯从 Cyrtomium balansae f. edentatum Ching ex K. } \\
\text { H. Shing }\end{array}$ & 单裂缝 Monolete & 鳞毛蕨科 Dryopteridaceae & 鳞毛蕨科 Dryopteridaceae \\
\hline $\begin{array}{l}\text { 刺齿贯众 Cyrtomium caryotideum (Wall. ex Hook. \& Grev.) C. } \\
\text { Presl }\end{array}$ & 单裂缝 Monolete & 鳞毛蕨科 Dryopteridaceae & 鳞毛蕨科 Dryopteridaceae \\
\hline $\begin{array}{l}\text { 粗齿贯众 Cyrtomium caryotideum f. grossedentatum Ching ex } \\
\text { K. H. Shing }\end{array}$ & 单裂缝 Monolete & 鳞毛蕨科 Dryopteridaceae & 鳞毛蕨科 Dryopteridaceae \\
\hline 秦氏贯众 Cyrtomium chingianum P. S. Wang & 单裂缝 Monolete & 鳞毛蕨科 Dryopteridaceae & 鳞毛蕨科 Dryopteridaceae \\
\hline 福建贯众 Cyrtomium conforme Ching & 单裂缝 Monolete & 鳞毛蕨科 Dryopteridaceae & 鳞毛蕨科 Dryopteridaceae \\
\hline 全缘贯众 Cyrtomium falcatum (L. f. ) C. Presl & 单裂缝 Monolete & 鳞毛蕨科 Dryopteridaceae & 鳞毛蕨科 Dryopteridaceae \\
\hline 贯众 Cyrtomium fortunei J. Sm. & 单裂缝 Monolete & 鳞毛蕨科 Dryopteridaceae & 鳞毛蕨科 Dryopteridaceae \\
\hline 宽羽贯众 Cyrtomium fortunei f. latipinnum Ching & 单裂缝 Monolete & 鳞毛蕨科 Dryopteridaceae & 鳞毛蕨科 Dryopteridaceae \\
\hline 多羽贯众 Cyrtomium fortunei f. polypterum (Diels) Ching & 单裂缝 Monolete & 鳞毛蕨科 Dryopteridaceae & 鳞毛蕨科 Dryopteridaceae \\
\hline 惠水贯众 Cyrtomium grossum Christ & 单裂缝 Monolete & 鳞毛蕨科 Dryopteridaceae & 鳞毛蕨科 Dryopteridaceae \\
\hline 贵州贯众 Cyrtomium guizhouene H. S. Kung \& P. S. Wang & 单裂缝 Monolete & 鳞毛蕨科 Dryopteridaceae & 鳞毛蕨科 Dryopteridaceae \\
\hline 单叶贯众 Cyrtomium hemionitis Christ & 单裂缝 Monolete & 鳞毛蕨科 Dryopteridaceae & 鳞毛蕨科 Dryopteridaceae \\
\hline 尖羽贯众 Cyrtomium hookerianum (C. Presl) C. Chr. & 单裂缝 Monolete & 鳞毛蕨科 Dryopteridaceae & 鳞毛蕨科 Dryopteridaceae \\
\hline 宽镰贯众 Cyrtomium latifalcatum S. K. Wu \& Mitsuta & 单裂缝 Monolete & 鳞毛蕨科 Dryopteridaceae & 鳞毛蕨科 Dryopteridaceae \\
\hline 小羽贯众 Cyrtomium lonchitoides (Christ) Christ & 单裂缝 Monolete & 鳞毛蕨科 Dryopteridaceae & 鳞毛蕨科 Dryopteridaceae \\
\hline 大叶贯众 Cyrtomium macrophyllum (Makino) Tagawa & 单裂缝 Monolete & 鳞毛蕨科 Dryopteridaceae & 鳞毛蕨科 Dryopteridaceae \\
\hline 膜叶贯众 Cyrtomium membranifolium Ching \& K. H. Shing ex & 单裂缝 Monolete & 鳞毛蕨科 Dryopteridaceae & 鳞毛蕨科 Dryopteridaceae \\
\hline
\end{tabular}




\begin{tabular}{|c|c|c|c|}
\hline $\begin{array}{l}\text { 物种 } \\
\text { Species }\end{array}$ & $\begin{array}{l}\text { 孢子裂缝类型 } \\
\text { Spore apertures styles }\end{array}$ & $\begin{array}{l}\text { 科名 Family (秦仁 } \\
\text { 昌,1978a, b) }\end{array}$ & $\begin{array}{l}\text { 科名 Family (Smith et al., } \\
\text { 2006; Christenhusz et al, } \\
\text { 2011; 张宪春等, 2013) }\end{array}$ \\
\hline \multicolumn{4}{|l|}{ H. S. Kung } \\
\hline 维西贯众 Cyrtomium neocaryotideum Ching \& K. H. Shing & 单裂缝 Monolete & 鳞毛蕨科 Dryopteridaceae & 鳞毛蒝科 Dryopteridaceae \\
\hline 低头贯众 Cyrtomium nephrolepioides (Christ) Copel. & 单裂缝 Monolete & 鳞毛蕨科 Dryopteridaceae & 鳞毛蕨科 Dryopteridaceae \\
\hline 显脉贯众 Cyrtomium nervosum Ching \& K. H. Shing & 单裂缝 Monolete & 鳞毛菜科 Dryopteridaceae & 鳞毛菜科 Dryopteridaceae \\
\hline 斜基贯众 Cyrtomium obliquum Ching \& K. H. Shing & 单裂缝 Monolete & 鳞毛硕科 Dryopteridaceae & 鳞毛菜科 Dryopteridaceae \\
\hline 峨眉贯众 Cyrtomium omeiense Ching \& K. H. Shing & 单裂缝 Monolete & 鳞毛蕨科 Dryopteridaceae & 鳞毛蕨科 Dryopteridaceae \\
\hline 厚叶贯众 Cyrtomium pachyphyllum (Rosenst.) C. Chr & 单裂缝 Monolete & 鳞毛菜科 Dryopteridaceae & 鳞毛菜科 Dryopteridaceae \\
\hline 鳞毛贯众 Cyrtomium retrosopaleaceum Ching \& K. H. Shing & 单裂缝 Monolete & 鳞毛菜科 Dryopteridaceae & 鳞毛菜科 Dryopteridaceae \\
\hline 尖齿贯众 Cyrtomium serratum Ching \& K. H. Shing & 单裂缝 Monolete & 鳞毛蕨科 Dryopteridaceae & 鳞毛蕨科 Dryopteridaceae \\
\hline 山东贯众 Cyrtomium shandongense J. X. Li & 单裂缝 Monolete & 鳞毛蕨科 Dryopteridaceae & 鳞毛菜科 Dryopteridaceae \\
\hline 邢氏贯众 Cyrtomium shingianum H. S. Kung \& P. S. Wang & 单裂缝 Monolete & 鳞毛菜科 Dryopteridaceae & 鳞毛蒝科 Dryopteridaceae \\
\hline 新宁贯众 Cyrtomium sinningense Ching \& K. H. Shing & 单裂缝 Monolete & 鳞毛蕨科 Dryopteridaceae & 鳞毛蕨科 Dryopteridaceae \\
\hline 台湾贯众 Cyrtomium taiwanense Tagawa & 单裂缝 Monolete & 鳞毛蕨科 Dryopteridaceae & 鳞毛蕨科 Dryopteridaceae \\
\hline 世纬贯众 Cyrtomium tengii Ching \& K. H. Shing & 单裂缝 Monolete & 鳞毛菜科 Dryopteridaceae & 鳞毛菜科 Dryopteridaceae \\
\hline 斜方贯众 Cyrtomium trapezoideum Ching \& K. H. Shing & 单裂缝 Monolete & 鳞毛蕨科 Dryopteridaceae & 鳞毛偋科 Dryopteridaceae \\
\hline 齿盖贯众 Cyrtomium tukusicola Tagawa & 单裂缝 Monolete & 鳞毛蕨科 Dryopteridaceae & 鳞毛蕨科 Dryopteridaceae \\
\hline 单行贯众 Cyrtomium uniseriale Ching & 单裂缝 Monolete & 鳞毛蕨科 Dryopteridaceae & 鳞毛蒝科 Dryopteridaceae \\
\hline 线羽贯众 Cyrtomium urophyllum Ching & 单裂缝 Monolete & 鳞毛蕨科 Dryopteridaceae & 鳞毛蕨科 Dryopteridaceae \\
\hline 武陵贯众 Cyrtomium wulingense S. F. Wu & 单裂缝 Monolete & 鳞毛蕨科 Dryopteridaceae & 鳞毛蕨科 Dryopteridaceae \\
\hline 阔羽贯众 Cyrtomium yamamotoi Tagawa & 单裂缝 Monolete & 鳞毛蕨科 Dryopteridaceae & 鳞毛蒝科 Dryopteridaceae \\
\hline 粗齿阔羽贯众 Cyrtomium yamamotoi var. intermedium (Diels) & 单裂缝 Monolete & 鳞毛蕨科 Dryopteridaceae & 鳞毛菜科 Dryopteridaceae \\
\hline
\end{tabular}




\begin{tabular}{|c|c|c|c|}
\hline $\begin{array}{l}\text { 物种 } \\
\text { Species }\end{array}$ & $\begin{array}{l}\text { 孢子裂缝类型 } \\
\text { Spore apertures styles }\end{array}$ & $\begin{array}{l}\text { 科名 Family (秦仁 } \\
\text { 昌,1978a, b) }\end{array}$ & $\begin{array}{l}\text { 科名 Family (Smith et al., } \\
\text { 2006; Christenhusz et al, } \\
\text { 2011; 张宪春等, 2013) }\end{array}$ \\
\hline 云南贯众 Cyrtomium yunnanense Ching \& K. H. Shing & 单裂缝 Monolete & 鳞毛蕨科 Dryopteridaceae & 鳞毛烣科 Dryopteridaceae \\
\hline 尖齿鳞毛蕒 Dryopteris acutodentata Ching & 单裂缝 Monolete & 鳞毛蕨科 Dryopteridaceae & 鳞毛硕科 Dryopteridaceae \\
\hline 多雄拉鳞毛蕨 Dryopteris alpestris Tagawa & 单裂缝 Monolete & 鳞毛䓲科 Dryopteridaceae & 鳞毛蕨科 Dryopteridaceae \\
\hline 高山金冠鳞毛蕨 Dryopteris alpicola Ching \& Z. R. Wang & 单裂缝 Monolete & 鳞毛蕨科 Dryopteridaceae & 鳞毛烣科 Dryopteridaceae \\
\hline 黑水鳞毛蒴 Dryopteris amurensis Christ & 单裂缝 Monolete & 鳞毛蕨科 Dryopteridaceae & 鳞毛硕科 Dryopteridaceae \\
\hline 狭叶鳞毛莜 Dryopteris angustifrons (Hook.) Kuntze & 单裂缝 Monolete & 鳞毛䓲科 Dryopteridaceae & 鳞毛蕨科 Dryopteridaceae \\
\hline 阿萨姆鳞毛濒 Dryopteris assamensis (C. Hope) C. Chr. \& & 单裂缝 Monolete & 鳞毛蕨科 Dryopteridaceae & 鳞毛烣科 Dryopteridaceae \\
\hline \multicolumn{4}{|l|}{ Ching } \\
\hline 暗鳞鳞毛硕 Dryopteris atrata (Kunze) Ching & 单裂缝 Monolete & 鳞毛䓲科 Dryopteridaceae & 鳞毛蕨科 Dryopteridaceae \\
\hline 多鳞鳞毛蕨 Dryopteris barbigera (T. Moore \& Hook.) Kuntze & 单裂缝 Monolete & 鳞毛蕨科 Dryopteridaceae & 鳞毛烣科 Dryopteridaceae \\
\hline 两色鳞毛葓 Dryopteris bissetiana (Baker) C. Chr. & 单裂缝 Monolete & 鳞毛菜科 Dryopteridaceae & 鳞毛菜科 Dryopteridaceae \\
\hline 西域鳞毛蒴 Dryopteris blanfordii (C. C. Hope) C. Chr. & 单裂缝 Monolete & 鳞毛䓲科 Dryopteridaceae & 鳞毛蕨科 Dryopteridaceae \\
\hline $\begin{array}{l}\text { 黑鳞西域鳞毛蕨 Dryopteris blanfordii ssp. nigrosquamosa } \\
\text { (Ching) Fraser-Jenkins }\end{array}$ & 单裂缝 Monolete & 鳞毛蕨科 Dryopteridaceae & 鳞毛蕨科 Dryopteridaceae \\
\hline 大平鳞毛兴 Dryopteris bodinieri (Christ) C. Chr. & 单裂缝 Monolete & 鳞毛蕨科 Dryopteridaceae & 鳞毛薕科 Dryopteridaceae \\
\hline 假边果鳞毛䕬 Dryopteris caroli-hopei Fraser-Jenk. & 单裂缝 Monolete & 鳞毛蕨科 Dryopteridaceae & 鳞毛烣科 Dryopteridaceae \\
\hline 刺叶鳞毛䕬 Dryopteris carthusiana (Vill.) H. P. Fuchs & 单裂缝 Monolete & 鳞毛蕨科 Dryopteridaceae & 鳞毛蒝科 Dryopteridaceae \\
\hline 阔鳞鳞毛锚 Dryopteris championii (Benth.) C. Chr. & 单裂缝 Monolete & 鳞毛䓲科 Dryopteridaceae & 鳞毛蕨科 Dryopteridaceae \\
\hline 中华鳞毛钼 Dryopteris chinensis (Baker) Koidz. & 单裂缝 Monolete & 鳞毛蕨科 Dryopteridaceae & 鳞毛烣科 Dryopteridaceae \\
\hline 金冠鳞毛蕨 Dryopteris chrysocoma (Christ) C. Chr. & 单裂缝 Monolete & 鳞毛蕨科 Dryopteridaceae & 鳞毛烣科 Dryopteridaceae \\
\hline $\begin{array}{l}\text { 密鳞金冠鳞毛蕨 Dryopteris chrysocoma var. squamosa (C. } \\
\text { Chr) Ching }\end{array}$ & 单裂缝 Monolete & 鳞毛蕨科 Dryopteridaceae & 鳞毛谥科 Dryopteridaceae \\
\hline
\end{tabular}




\begin{tabular}{|c|c|c|c|}
\hline $\begin{array}{l}\text { 物种 } \\
\text { Species }\end{array}$ & $\begin{array}{l}\text { 孢子裂缝类型 } \\
\text { Spore apertures styles }\end{array}$ & $\begin{array}{l}\text { 科名 Family (秦仁 } \\
\text { 昌,1978a, b) }\end{array}$ & $\begin{array}{l}\text { 科名 Family (Smith et al., } \\
\text { 2006; Christenhusz et al, } \\
\text { 2011; 张宪春等, 2013) }\end{array}$ \\
\hline 二型鳞毛䕬 Dryopteris cochleata (Buch.-Ham. ex D. Don) C. & 单裂缝 Monolete & 鳞毛蕨科 Dryopteridaceae & 鳞毛烣科 Dryopteridaceae \\
\hline \multicolumn{4}{|l|}{ Chr. } \\
\hline 混淆鳞毛蕨 Dryopteris commixta Tagawa & 单裂缝 Monolete & 鳞毛蕨科 Dryopteridaceae & 鳞毛蕨科 Dryopteridaceae \\
\hline 连合鳞毛蕨 Dryopteris conjugata Ching & 单裂缝 Monolete & 鳞毛蕨科 Dryopteridaceae & 鳞毛烣科 Dryopteridaceae \\
\hline 东北亚鳞毛嵚 Dryopteris coreanomontana Nakai & 单裂缝 Monolete & 鳞毛蕨科 Dryopteridaceae & 鳞毛硕科 Dryopteridaceae \\
\hline 近中肋鳞毛蕨 Dryopteris costalisora Tagawa & 单裂缝 Monolete & 鳞毛蕨科 Dryopteridaceae & 鳞毛蕨科 Dryopteridaceae \\
\hline 粗茎鳞毛嵚 Dryopteris crassirhizoma Nakai & 单裂缝 Monolete & 鳞毛蕨科 Dryopteridaceae & 鳞毛烣科 Dryopteridaceae \\
\hline 杪椤鳞毛锁 Dryopteris cycadina (Franch. \& Sav.) C. Chr. & 单裂缝 Monolete & 鳞毛蕨科 Dryopteridaceae & 鳞毛偋科 Dryopteridaceae \\
\hline 弯羽鳞毛硕 Dryopteris cyclopeltidiformis C. Chr. & 单裂缝 Monolete & 鳞毛蕨科 Dryopteridaceae & 鳞毛蕨科 Dryopteridaceae \\
\hline 道真鳞毛蕨 Dryopteris daozhenensis P. S. Wang \& X. Y. Wang & 单裂缝 Monolete & 鳞毛蕨科 Dryopteridaceae & 鳞毛茨科 Dryopteridaceae \\
\hline 迷人鳞毛嵚 Dryopteris decipiens (Hook.) Kuntze & 单裂缝 Monolete & 鳞毛蕨科 Dryopteridaceae & 鳞毛蕨科 Dryopteridaceae \\
\hline 深裂迷人鳞毛蕨 Dryopteris decipiens var. diplazioides (Christ) & 单裂缝 Monolete & 鳞毛蕨科 Dryopteridaceae & 鳞毛蕨科 Dryopteridaceae \\
\hline \multicolumn{4}{|l|}{ Ching } \\
\hline 德化鳞毛蕨 Dryopteris dehuaensis Ching \& K. H. Shing & 单裂缝 Monolete & 鳞毛蕨科 Dryopteridaceae & 鳞毛蕨科 Dryopteridaceae \\
\hline 远轴鳞毛蕨 Dryopteris dickinsii (Franch. \& Sav.) C. Chr. & 单裂缝 Monolete & 鳞毛蕨科 Dryopteridaceae & 鳞毛蕨科 Dryopteridaceae \\
\hline 宜昌鳞毛蕨 Dryopteris enneaphylla (Baker) C. Chr. & 单裂缝 Monolete & 鳞毛蕨科 Dryopteridaceae & 鳞毛茨科 Dryopteridaceae \\
\hline $\begin{array}{l}\text { 大宜昌鳞毛菜 Dryopteris enneaphylla var. pseudosieboldii } \\
\text { (Hayata) Tagawa \& K. Iwats }\end{array}$ & 单裂缝 Monolete & 鳞毛蕨科 Dryopteridaceae & 鳞毛蕨科 Dryopteridaceae \\
\hline 红盖鳞毛鰖 Dryopteris erythrosora (A. A. Eaton) Kuntze & 单裂缝 Monolete & 鳞毛蕨科 Dryopteridaceae & 鳞毛蕨科 Dryopteridaceae \\
\hline 广布鳞毛䕨 Dryopteris expansa (C. Presl) Fraser-Jenk. \& Jermy & 单裂缝 Monolete & 鳞毛蕨科 Dryopteridaceae & 鳞毛蕨科 Dryopteridaceae \\
\hline 近纤维鳞毛蕨 Dryopteris fibrillosissima Ching & 单裂缝 Monolete & 鳞毛蕨科 Dryopteridaceae & 鳞毛鄀科 Dryopteridaceae \\
\hline 欧洲鳞毛蕨 Dryopteris filix-mas (L.) Schott & 单裂缝 Monolete & 鳞毛蕨科 Dryopteridaceae & 鳞毛蕨科 Dryopteridaceae \\
\hline
\end{tabular}




\begin{tabular}{|c|c|c|c|}
\hline $\begin{array}{l}\text { 物种 } \\
\text { Species }\end{array}$ & $\begin{array}{l}\text { 孢子裂缝类型 } \\
\text { Spore apertures styles }\end{array}$ & $\begin{array}{l}\text { 科名 Family (秦仁 } \\
\text { 昌,1978a, b) }\end{array}$ & $\begin{array}{l}\text { 科名 Family (Smith et al., } \\
\text { 2006; Christenhusz et al, } \\
\text { 2011; 张宪春等, 2013) }\end{array}$ \\
\hline 台湾鳞毛䕬 Dryopteris formosana (Christ) C. Chr. & 单裂缝 Monolete & 鳞毛蕨科 Dryopteridaceae & 鳞毛烣科 Dryopteridaceae \\
\hline 香鳞毛偋 Dryopteris fragrans (L.) Schott & 单裂缝 Monolete & 鳞毛蒝科 Dryopteridaceae & 鳞毛硕科 Dryopteridaceae \\
\hline 硬果鳞毛蕨 Dryopteris fructuosa (Christ) C. Chr. & 单裂缝 Monolete & 鳞毛蕨科 Dryopteridaceae & 鳞毛蕨科 Dryopteridaceae \\
\hline 黑足鳞毛蕨 Dryopteris fuscipes C. Chr. & 单裂缝 Monolete & 鳞毛蕨科 Dryopteridaceae & 鳞毛烣科 Dryopteridaceae \\
\hline 华北鳞毛脒 Dryopteris goeringiana (Kunze) Koidz. & 单裂缝 Monolete & 鳞毛硕科 Dryopteridaceae & 鳞毛硕科 Dryopteridaceae \\
\hline 广西鳞毛莜 Dryopteris guangxiensis S. G. Lu & 单裂缝 Monolete & 鳞毛蒝科 Dryopteridaceae & 鳞毛蕨科 Dryopteridaceae \\
\hline 裸叶鳞毛蕨 Dryopteris gymnophylla (Baker) C. Chr. & 单裂缝 Monolete & 鳞毛蕨科 Dryopteridaceae & 鳞毛烣科 Dryopteridaceae \\
\hline 裸果鳞毛莜 Dryopteris gymnosora (Makino) C. Chr. & 单裂缝 Monolete & 鳞毛硕科 Dryopteridaceae & 鳞毛硕科 Dryopteridaceae \\
\hline 哈巴鳞毛蕨 Dryopteris habaensis Ching & 单裂缝 Monolete & 鳞毛蕨科 Dryopteridaceae & 鳞毛蕨科 Dryopteridaceae \\
\hline 边生鳞毛蕨 Dryopteris handeliana C. Chr. & 单裂缝 Monolete & 鳞毛蕨科 Dryopteridaceae & 鳞毛烣科 Dryopteridaceae \\
\hline 杭州鳞毛葓 Dryopteris hangchowensis Ching & 单裂缝 Monolete & 鳞毛蕨科 Dryopteridaceae & 鳞毛菜科 Dryopteridaceae \\
\hline 赫章鳞毛蕨 Dryopteris hezhangensis P. S. Wang & 单裂缝 Monolete & 鳞毛蕨科 Dryopteridaceae & 鳞毛蕨科 Dryopteridaceae \\
\hline 木里鳞毛蕨 Dryopteris himachalensis Fraser-Jenk. & 单裂缝 Monolete & 鳞毛蕨科 Dryopteridaceae & 鳞毛蕨科 Dryopteridaceae \\
\hline 乌鳞鳞毛脄 Dryopteris hirtipes (Blume) O. Ktze & 单裂缝 Monolete & 鳞毛蕨科 Dryopteridaceae & 鳞毛蕨科 Dryopteridaceae \\
\hline 桃花岛鳞毛蕨 Dryopteris hondoensis Koidz. & 单裂缝 Monolete & 鳞毛蕨科 Dryopteridaceae & 鳞毛蕨科 Dryopteridaceae \\
\hline 假异鳞毛荻 Dryopteris immixta Ching & 单裂缝 Monolete & 鳞毛蕨科 Dryopteridaceae & 鳞毛蕨科 Dryopteridaceae \\
\hline 深裂鳞毛蕨 Dryopteris incisolobata Ching & 单裂缝 Monolete & 鳞毛鄀科 Dryopteridaceae & 鳞毛鄀科 Dryopteridaceae \\
\hline 平行鳞毛蕨 Dryopteris indusiata (Makino) Yamamoto & 单裂缝 Monolete & 鳞毛蕨科 Dryopteridaceae & 鳞毛蕨科 Dryopteridaceae \\
\hline 羽裂鳞毛蕨 Dryopteris integriloba C. Chr. & 单裂缝 Monolete & 鳞毛蕨科 Dryopteridaceae & 鳞毛蕨科 Dryopteridaceae \\
\hline 粗齿鳞毛蕒 Dryopteris juxtaposita Christ & 单裂缝 Monolete & 鳞毛蕨科 Dryopteridaceae & 鳞毛蕨科 Dryopteridaceae \\
\hline 京鹤鳞毛蒴 Dryopteris kinkiensis Koidz. & 单裂缝 Monolete & 鳞毛蕨科 Dryopteridaceae & 鳞毛鄀科 Dryopteridaceae \\
\hline 近多鳞毛锁 Dryopteris komarovii Kosshinsky & 单裂缝 Monolete & 鳞毛蕨科 Dryopteridaceae & 鳞毛烣科 Dryopteridaceae \\
\hline
\end{tabular}




\begin{tabular}{|c|c|c|c|}
\hline $\begin{array}{l}\text { 物种 } \\
\text { Species }\end{array}$ & $\begin{array}{l}\text { 孢子裂缝类型 } \\
\text { Spore apertures styles }\end{array}$ & $\begin{array}{l}\text { 科名 Family (秦仁 } \\
\text { 昌,1978a, b) }\end{array}$ & $\begin{array}{l}\text { 科名 Family (Smith et al., } \\
\text { 2006; Christenhusz et al, } \\
\text { 2011; 张宪春等, 2013) }\end{array}$ \\
\hline 齿头鳞毛蕨 Dryopteris labordei (Christ) C. Chr. & 单裂缝 Monolete & 鳞毛鄀科 Dryopteridaceae & 鳞毛蕨科 Dryopteridaceae \\
\hline 狭顶鳞毛蒴 Dryopteris lacera (Thunb.) Kuntze & 单裂缝 Monolete & 鳞毛蒝科 Dryopteridaceae & 鳞毛硕科 Dryopteridaceae \\
\hline 脉纹鳞毛蕨 Dryopteris lachoongensis (Bedd.) Nayar \& Kaur & 单裂缝 Monolete & 鳞毛蕨科 Dryopteridaceae & 鳞毛蕨科 Dryopteridaceae \\
\hline 阔基鳞毛蒴 Dryopteris latibasis Ching & 单裂缝 Monolete & 鳞毛蕨科 Dryopteridaceae & 鳞毛烣科 Dryopteridaceae \\
\hline 黑鳞鳞毛硕 Dryopteris lepidopoda Hayata & 单裂缝 Monolete & 鳞毛蒝科 Dryopteridaceae & 鳞毛硕科 Dryopteridaceae \\
\hline 轴鳞鳞毛荻 Dryopteris lepidorachis C. Chr. & 单裂缝 Monolete & 鳞毛蕨科 Dryopteridaceae & 鳞毛蕨科 Dryopteridaceae \\
\hline 两广鳞毛钼 Dryopteris liankwangensis Ching & 单裂缝 Monolete & 鳞毛蕨科 Dryopteridaceae & 鳞毛烣科 Dryopteridaceae \\
\hline 路南鳞毛菜 Dryopteris lunanensis (Christ) C. Chr. & 单裂缝 Monolete & 鳞毛硕科 Dryopteridaceae & 鳞毛蒝科 Dryopteridaceae \\
\hline 边果鳞毛蕨 Dryopteris marginata (C. B. Clarke) Christ & 单裂缝 Monolete & 鳞毛蕨科 Dryopteridaceae & 鳞毛蕨科 Dryopteridaceae \\
\hline 细鳞鳞毛嵚 Dryopteris microlepis (Baker) C. Chr. & 单裂缝 Monolete & 鳞毛蕨科 Dryopteridaceae & 鳞毛烣科 Dryopteridaceae \\
\hline 山地鳞毛葓 Dryopteris monticola (Makino) C. Chr. & 单裂缝 Monolete & 鳞毛蕨科 Dryopteridaceae & 鳞毛菜科 Dryopteridaceae \\
\hline 丽江鳞毛睰 Dryopteris montigena Ching & 单裂缝 Monolete & 鳞毛蕨科 Dryopteridaceae & 鳞毛蕨科 Dryopteridaceae \\
\hline 黑鳞远轴鳞毛脄 Dryopteris namegatae (Sa. Kurata) Sa. Kurata & 单裂缝 Monolete & 鳞毛蕨科 Dryopteridaceae & 鳞毛烣科 Dryopteridaceae \\
\hline 近黑鳞鳞毛蒴 Dryopteris neolepidopoda Ching \& S. K. Wu & 单裂缝 Monolete & 鳞毛蕨科 Dryopteridaceae & 鳞毛蕨科 Dryopteridaceae \\
\hline 近川西鳞毛蕨 Dryopteris neorosthornii Ching & 单裂缝 Monolete & 鳞毛蕨科 Dryopteridaceae & 鳞毛蕨科 Dryopteridaceae \\
\hline 优雅鳞毛蒴 Dryopteris nobilis Ching & 单裂缝 Monolete & 鳞毛蕨科 Dryopteridaceae & 鳞毛烣科 Dryopteridaceae \\
\hline 冯氏鳞毛蕨 Dryopteris nobilis var. fengiana Ching & 单裂缝 Monolete & 鳞毛蒝科 Dryopteridaceae & 鳞毛蒝科 Dryopteridaceae \\
\hline 林芝鳞毛嵚 Dryopteris nyingchiensis Ching & 单裂缝 Monolete & 鳞毛蕨科 Dryopteridaceae & 鳞毛蕨科 Dryopteridaceae \\
\hline 太平鳞毛嵚 Dryopteris pacifica (Nakai) Tagawa & 单裂缝 Monolete & 鳞毛蕨科 Dryopteridaceae & 鳞毛蕨科 Dryopteridaceae \\
\hline 大果鳞毛锁 Dryopteris panda (C. B. Clarke) Christ & 单裂缝 Monolete & 鳞毛蕨科 Dryopteridaceae & 鳞毛蕨科 Dryopteridaceae \\
\hline $\begin{array}{l}\text { 假路南鳞毛蕨 Dryopteris paralunanensis W. M. Chu ex S. G. } \\
\mathrm{Lu}\end{array}$ & 单裂缝 Monolete & 鳞毛蕨科 Dryopteridaceae & 鳞毛蕨科 Dryopteridaceae \\
\hline
\end{tabular}




\begin{tabular}{|c|c|c|c|}
\hline $\begin{array}{l}\text { 物种 } \\
\text { Species }\end{array}$ & $\begin{array}{l}\text { 孢子裂缝类型 } \\
\text { Spore apertures styles }\end{array}$ & $\begin{array}{l}\text { 科名 Family (秦仁 } \\
\text { 昌,1978a, b) }\end{array}$ & $\begin{array}{l}\text { 科名 Family (Smith et al., } \\
\text { 2006; Christenhusz et al, } \\
\text { 2011; 张宪春等, 2013) }\end{array}$ \\
\hline 半岛鳞毛荻 Dryopteris peninsulae Kitag. & 单裂缝 Monolete & 鳞毛蕨科 Dryopteridaceae & 鳞毛蕨科 Dryopteridaceae \\
\hline 柄叶鳞毛葓 Dryopteris podophylla (Hook.) Kuntze & 单裂缝 Monolete & 鳞毛蒝科 Dryopteridaceae & 鳞毛硕科 Dryopteridaceae \\
\hline 蓝色鳞毛蕨 Dryopteris polita Rosenst. & 单裂缝 Monolete & 鳞毛蕨科 Dryopteridaceae & 鳞毛蕨科 Dryopteridaceae \\
\hline 微孔鳞毛蕨 Dryopteris porosa Ching & 单裂缝 Monolete & 鳞毛蕨科 Dryopteridaceae & 鳞毛烣科 Dryopteridaceae \\
\hline 假稀羽鳞毛荹 Dryopteris pseudosparsa Ching & 单裂缝 Monolete & 鳞毛蒝科 Dryopteridaceae & 鳞毛硕科 Dryopteridaceae \\
\hline 凸背鳞毛蕨 Dryopteris pseudovaria (Christ) C. Chr. & 单裂缝 Monolete & 鳞毛蕨科 Dryopteridaceae & 鳞毛蕨科 Dryopteridaceae \\
\hline 蒴状鳞毛钼 Dryopteris pteridiiformis Christ & 单裂缝 Monolete & 鳞毛蕨科 Dryopteridaceae & 鳞毛烣科 Dryopteridaceae \\
\hline 豫陕鳞毛瞢 Dryopteris pulcherrima Ching & 单裂缝 Monolete & 鳞毛硕科 Dryopteridaceae & 鳞毛蒝科 Dryopteridaceae \\
\hline 肿足鳞毛蕨 Dryopteris pulvinulifera (Bedd.) Kuntze & 单裂缝 Monolete & 鳞毛蕨科 Dryopteridaceae & 鳞毛蕨科 Dryopteridaceae \\
\hline 密鳞鳞毛嵚 Dryopteris pycnopteroides (Christ) C. Chr. & 单裂缝 Monolete & 鳞毛蕨科 Dryopteridaceae & 鳞毛烣科 Dryopteridaceae \\
\hline 藏布鳞毛蕨 Dryopteris redactopinnata S. K. Basu \& Panigr. & 单裂缝 Monolete & 鳞毛蕨科 Dryopteridaceae & 鳞毛蕨科 Dryopteridaceae \\
\hline 倒鳞鳞毛鄀 Dryopteris reflexosquamata Hayata & 单裂缝 Monolete & 鳞毛蕨科 Dryopteridaceae & 鳞毛蕨科 Dryopteridaceae \\
\hline 川西鳞毛蕨 Dryopteris rosthornii (Diels) C. Chr. & 单裂缝 Monolete & 鳞毛蕨科 Dryopteridaceae & 鳞毛蕨科 Dryopteridaceae \\
\hline 红褐鳞毛偋 Dryopteris rubrobrunnea $\mathrm{W}$. M. Chu & 单裂缝 Monolete & 鳞毛蕨科 Dryopteridaceae & 鳞毛蕨科 Dryopteridaceae \\
\hline 宽羽鳞毛鄀 Dryopteris ryo-itoana Sa. Kurata & 单裂缝 Monolete & 鳞毛蕨科 Dryopteridaceae & 鳞毛蕨科 Dryopteridaceae \\
\hline 棕边鳞毛蕨 Dryopteris sacrosancta Koidz. & 单裂缝 Monolete & 鳞毛蕨科 Dryopteridaceae & 鳞毛蕨科 Dryopteridaceae \\
\hline 虎耳鳞毛蕨 Dryopteris saxifraga H. Ito & 单裂缝 Monolete & 鳞毛鄀科 Dryopteridaceae & 鳞毛蕨科 Dryopteridaceae \\
\hline 无盖鳞毛蕨 Dryopteris scottii (Bedd.) Ching ex C. Chr. & 单裂缝 Monolete & 鳞毛蕨科 Dryopteridaceae & 鳞毛蕨科 Dryopteridaceae \\
\hline 腺毛鳞毛荻 Dryopteris sericea C. Chr. & 单裂缝 Monolete & 鳞毛蕨科 Dryopteridaceae & 鳞毛蕨科 Dryopteridaceae \\
\hline 刺尖鳞毛蕨 Dryopteris serrato-dentata (Bedd.) Hayata & 单裂缝 Monolete & 鳞毛蕨科 Dryopteridaceae & 鳞毛蕨科 Dryopteridaceae \\
\hline 奇羽鳞毛锣 Dryopteris sieboldii (van Houtte ex Mett.) Kuntze & 单裂缝 Monolete & 鳞毛蕨科 Dryopteridaceae & 鳞毛鄀科 Dryopteridaceae \\
\hline 锡金鳞毛蕨 Dryopteris sikkimensis (Hook.) Kuntze & 单裂缝 Monolete & 鳞毛蕨科 Dryopteridaceae & 鳞毛烣科 Dryopteridaceae \\
\hline
\end{tabular}




\begin{tabular}{|c|c|c|c|}
\hline $\begin{array}{l}\text { 物种 } \\
\text { Species }\end{array}$ & $\begin{array}{l}\text { 孢子裂缝类型 } \\
\text { Spore apertures styles }\end{array}$ & $\begin{array}{l}\text { 科名 Family (秦仁 } \\
\text { 昌,1978a, b) }\end{array}$ & $\begin{array}{l}\text { 科名 Family (Smith et al., } \\
\text { 2006; Christenhusz et al, } \\
\text { 2011; 张宪春等, 2013) }\end{array}$ \\
\hline 高鳞毛蕨 Dryopteris simasakii (H. Ito) Sa. Kurata & 单裂缝 Monolete & 鳞毛蕨科 Dryopteridaceae & 鳞毛烣科 Dryopteridaceae \\
\hline 密鳞高蒝毛硕 Dryopteris simasakii var. paleacea (H. Ito) Sa. & 单裂缝 Monolete & 鳞毛蕨科 Dryopteridaceae & 鳞毛硕科 Dryopteridaceae \\
\hline \multicolumn{4}{|l|}{ Kurata } \\
\hline 纤维鳞毛蕨 Dryopteris sinofibrillosa Ching & 单裂缝 Monolete & 鳞毛蕨科 Dryopteridaceae & 鳞毛蕨科 Dryopteridaceae \\
\hline 落鳞鳞毛蒴 Dryopteris sordidipes Tagawa & 单裂缝 Monolete & 鳞毛硕科 Dryopteridaceae & 鳞毛硕科 Dryopteridaceae \\
\hline 稀羽鳞毛睰 Dryopteris sparsa (Buch.-Ham. ex D. Don) Kuntze & 单裂缝 Monolete & 鳞毛蕨科 Dryopteridaceae & 鳞毛蕨科 Dryopteridaceae \\
\hline 光亮鳞毛钼 Dryopteris splendens (Hook.) Kuntze & 单裂缝 Monolete & 鳞毛蕨科 Dryopteridaceae & 鳞毛蕨科 Dryopteridaceae \\
\hline 褐鳞鳞毛蕨 Dryopteris squamifera Ching \& S. K. Wu & 单裂缝 Monolete & 鳞毛蕨科 Dryopteridaceae & 鳞毛蕨科 Dryopteridaceae \\
\hline 狭鳞鳞毛蕨 Dryopteris stenolepis (Baker) C. Chr. & 单裂缝 Monolete & 鳞毛蕨科 Dryopteridaceae & 鳞毛蕨科 Dryopteridaceae \\
\hline 细叶鳞毛䕬 Dryopteris subatrata Tagawa & 单裂缝 Monolete & 鳞毛蕨科 Dryopteridaceae & 鳞毛蕨科 Dryopteridaceae \\
\hline 裂盖鳞毛钼 Dryopteris subexaltata (Christ) C. Chr. & 单裂缝 Monolete & 鳞毛蕨科 Dryopteridaceae & 鳞毛蕨科 Dryopteridaceae \\
\hline 柳羽鳞毛蕨 Dryopteris subimpressa Loyal & 单裂缝 Monolete & 鳞毛蕨科 Dryopteridaceae & 鳞毛蕨科 Dryopteridaceae \\
\hline 半育鳞毛葓 Dryopteris sublacera Christ & 单裂缝 Monolete & 鳞毛蕨科 Dryopteridaceae & 鳞毛蕨科 Dryopteridaceae \\
\hline 无柄鳞毛蕨 Dryopteris submarginata Rosenst. & 单裂缝 Monolete & 鳞毛蕨科 Dryopteridaceae & 鳞毛蕨科 Dryopteridaceae \\
\hline 近密鳞鳞毛蕨 Dryopteris subpycnopteroides Ching ex & 单裂缝 Monolete & 鳞毛蕨科 Dryopteridaceae & 鳞毛蕨科 Dryopteridaceae \\
\hline \multicolumn{4}{|l|}{ Fraser-Jenk. } \\
\hline 三角鳞毛蕨 Dryopteris subtriangularis (C. Hope) C. Chr. & 单裂缝 Monolete & 鳞毛蕨科 Dryopteridaceae & 鳞毛蕨科 Dryopteridaceae \\
\hline 大明鳞毛睰 Dryopteris tahmingensis Ching & 单裂缝 Monolete & 鳞毛蕨科 Dryopteridaceae & 鳞毛蕨科 Dryopteridaceae \\
\hline 华南鳞毛葓 Dryopteris tenuicula Matthew \& Christ & 单裂缝 Monolete & 鳞毛蕨科 Dryopteridaceae & 鳞毛蕨科 Dryopteridaceae \\
\hline 落叶鳞毛蕨 Dryopteris tenuipes (Rosenst.) Seriz. & 单裂缝 Monolete & 鳞毛蕨科 Dryopteridaceae & 鳞毛蕨科 Dryopteridaceae \\
\hline 陇蜀鳞毛荻 Dryopteris thibetica (Franch.) C. Chr. & 单裂缝 Monolete & 鳞毛蕨科 Dryopteridaceae & 鳞毛蕨科 Dryopteridaceae \\
\hline 定结鳞毛硕 Dryopteris tingiensis Ching \& S. K. Wu ex & 单裂缝 Monolete & 鳞毛蕨科 Dryopteridaceae & 鳞毛蕨科 Dryopteridaceae \\
\hline
\end{tabular}




\begin{tabular}{|c|c|c|c|}
\hline $\begin{array}{l}\text { 物种 } \\
\text { Species }\end{array}$ & $\begin{array}{l}\text { 孢子裂缝类型 } \\
\text { Spore apertures styles }\end{array}$ & $\begin{array}{l}\text { 科名 Family (秦仁 } \\
\text { 昌,1978a, b) }\end{array}$ & $\begin{array}{l}\text { 科名 Family (Smith et al., } \\
\text { 2006; Christenhusz et al, } \\
\text { 2011; 张宪春等, 2013) }\end{array}$ \\
\hline \multicolumn{4}{|l|}{ Fraser-Jenk. } \\
\hline 东京鳞毛蕨 Dryopteris tokyoensis (Matsum. ex Makino) C. & 单裂缝 Monolete & 鳞毛鄀科 Dryopteridaceae & 鳞毛蕨科 Dryopteridaceae \\
\hline \multicolumn{4}{|l|}{ Chr. } \\
\hline 裂羽鳞毛蕨 Dryopteris toyamae Tagawa & 单裂缝 Monolete & 鳞毛蕨科 Dryopteridaceae & 鳞毛蕨科 Dryopteridaceae \\
\hline 观光鳞毛葓 Dryopteris tsoongii Ching & 单裂缝 Monolete & 鳞毛蕨科 Dryopteridaceae & 鳞毛烣科 Dryopteridaceae \\
\hline 同形鳞毛蕨 Dryopteris uniformis (Makino) Makino & 单裂缝 Monolete & 鳞毛䓲科 Dryopteridaceae & 鳞毛茨科 Dryopteridaceae \\
\hline 变异鳞毛蕨 Dryopteris varia (L.) Kuntze & 单裂缝 Monolete & 鳞毛蕨科 Dryopteridaceae & 鳞毛蕨科 Dryopteridaceae \\
\hline 大羽鳞毛蒝 Dryopteris wallichiana (Spreng.) Hylander & 单裂缝 Monolete & 鳞毛蕨科 Dryopteridaceae & 鳞毛烣科 Dryopteridaceae \\
\hline 贵州鳞毛蕨 Dryopteris wallichiana var. kweichowicola (Ching & 单裂缝 Monolete & 鳞毛䓲科 Dryopteridaceae & 鳞毛茨科 Dryopteridaceae \\
\hline \multicolumn{4}{|l|}{ \& P. S. Wang) S. K. Wu } \\
\hline 黄山鳞毛蕨 Dryopteris whangshangensis Ching & 单裂缝 Monolete & 鳞毛蕨科 Dryopteridaceae & 鳞毛蕨科 Dryopteridaceae \\
\hline 细叶鳞毛蒴 Dryopteris woodsiisora Hayata & 单裂缝 Monolete & 鳞毛䓲科 Dryopteridaceae & 鳞毛茨科 Dryopteridaceae \\
\hline 武夷山鳞毛蕨 Dryopteris wuyishanica Ching \& P. S. Chiu & 单裂缝 Monolete & 鳞毛蕨科 Dryopteridaceae & 鳞毛蕨科 Dryopteridaceae \\
\hline 寻乌鳞毛濒 Dryopteris xunwuensis Ching \& K. H. Shing & 单裂缝 Monolete & 鳞毛蒴科 Dryopteridaceae & 鳞毛烣科 Dryopteridaceae \\
\hline 南平鳞毛蕨 Dryopteris yenpingensis C. Chr. \& Ching & 单裂缝 Monolete & 鳞毛蕨科 Dryopteridaceae & 鳞毛茨科 Dryopteridaceae \\
\hline 易贡鳞毛蕨 Dryopteris yigongensis Ching & 单裂缝 Monolete & 鳞毛蕨科 Dryopteridaceae & 鳞毛蕨科 Dryopteridaceae \\
\hline 永德鳞毛嵚 Dryopteris yongdeensis W. M. Chu ex S. G. Lu & 单裂缝 Monolete & 鳞毛蕨科 Dryopteridaceae & 鳞毛烣科 Dryopteridaceae \\
\hline 栗柄鳞毛蒴 Dryopteris yoroii Seriz. & 单裂缝 Monolete & 鳞毛䓲科 Dryopteridaceae & 鳞毛茨科 Dryopteridaceae \\
\hline 永自鳞毛硕 Dryopteris yungtzeensis Ching & 单裂缝 Monolete & 鳞毛蕨科 Dryopteridaceae & 鳞毛蕨科 Dryopteridaceae \\
\hline 贞丰鳞毛葄 Dryopteris zhenfengensis P. S. Wang \& X. Y. & 单裂缝 Monolete & 鳞毛蕨科 Dryopteridaceae & 鳞毛茨科 Dryopteridaceae \\
\hline \multicolumn{4}{|l|}{ Wang } \\
\hline 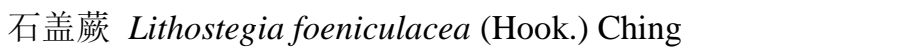 & 单裂缝 Monolete & 鳞毛蕨科 Dryopteridaceae & 鳞毛茨科 Dryopteridaceae \\
\hline
\end{tabular}




\begin{tabular}{|c|c|c|c|}
\hline $\begin{array}{l}\text { 物种 } \\
\text { Species }\end{array}$ & $\begin{array}{l}\text { 孢子裂缝类型 } \\
\text { Spore apertures styles }\end{array}$ & $\begin{array}{l}\text { 科名 Family (秦仁 } \\
\text { 昌,1978a, b) }\end{array}$ & $\begin{array}{l}\text { 科名 Family (Smith et al., } \\
\text { 2006; Christenhusz et al, } \\
\text { 2011; 张宪春等, 2013) }\end{array}$ \\
\hline 棕鳞肉刺蕨 Nothoperanema diacalpioides Ching & 单裂缝 Monolete & 鳞毛蕨科 Dryopteridaceae & 鳞毛蕨科 Dryopteridaceae \\
\hline 大叶肉刺橧 Nothoperanema giganteum Ching & 单裂缝 Monolete & 鳞毛蕨科 Dryopteridaceae & 鳞毛硕科 Dryopteridaceae \\
\hline 有盖肉刺葓 Nothoperanema hendersonii (Bedd.) Ching & 单裂缝 Monolete & 鳞毛蕨科 Dryopteridaceae & 鳞毛蕨科 Dryopteridaceae \\
\hline 无盖肉刺蕨 Nothoperanema shikokianum (Makino) Ching & 单裂缝 Monolete & 鳞毛蕨科 Dryopteridaceae & 鳞毛烣科 Dryopteridaceae \\
\hline 肉刺偋 Nothoperanema squamisetum (Hook.) Ching & 单裂缝 Monolete & 鳞毛蕨科 Dryopteridaceae & 鳞毛硕科 Dryopteridaceae \\
\hline 粗齿黔荻 Phanerophlebiopsis blinii (H. Lév.) Ching & 单裂缝 Monolete & 鳞毛蕨科 Dryopteridaceae & 鳞毛蕨科 Dryopteridaceae \\
\hline 湖南黔硕 Phanerophlebiopsis hunanensis Ching & 单裂缝 Monolete & 鳞毛蕨科 Dryopteridaceae & 鳞毛烣科 Dryopteridaceae \\
\hline 中间黔蒴 Phanerophlebiopsis intermedia Ching & 单裂缝 Monolete & 鳞毛蕨科 Dryopteridaceae & 鳞毛蒝科 Dryopteridaceae \\
\hline 长叶黔荻 Phanerophlebiopsis neopodophylla (Ching) Ching \& & 单裂缝 Monolete & 鳞毛蕨科 Dryopteridaceae & 鳞毛蕨科 Dryopteridaceae \\
\hline \multicolumn{4}{|l|}{ Y. T. Hsieh } \\
\hline 黔蒴 Phanerophlebiopsis tsiangiana Ching & 单裂缝 Monolete & 鳞毛蕨科 Dryopteridaceae & 鳞毛蕨科 Dryopteridaceae \\
\hline 刺叶耳蕨 Polystichum acanthophyllum (Franch.) Christ & 单裂缝 Monolete & 鳞毛蕨科 Dryopteridaceae & 鳞毛蕨科 Dryopteridaceae \\
\hline 欧洲耳硕 Polystichum aculeatum (L.) Roth & 单裂缝 Monolete & 鳞毛蕨科 Dryopteridaceae & 鳞毛蕨科 Dryopteridaceae \\
\hline 尖齿耳硕 Polystichum acutidens Christ & 单裂缝 Monolete & 鳞毛蕨科 Dryopteridaceae & 鳞毛蕨科 Dryopteridaceae \\
\hline 尖头耳蕨 Polystichum acutipinnulum Ching \& Shing & 单裂缝 Monolete & 鳞毛蕨科 Dryopteridaceae & 鳞毛蕨科 Dryopteridaceae \\
\hline 阿当耳嵚 Polystichum adungense Ching \& Fraser-Jenk. ex H. S. & 单裂缝 Monolete & 鳞毛蕨科 Dryopteridaceae & 鳞毛蕨科 Dryopteridaceae \\
\hline \multicolumn{4}{|l|}{ Kung \& L. B. Zhang } \\
\hline 角状耳荻 Polystichum alcicorne (Baker) Diels & 单裂缝 Monolete & 鳞毛蕨科 Dryopteridaceae & 鳞毛蕨科 Dryopteridaceae \\
\hline 高大耳㼳 Polystichum altum Ching ex L. B. Zhang \& H. S. & 单裂缝 Monolete & 鳞毛蕨科 Dryopteridaceae & 鳞毛蕨科 Dryopteridaceae \\
\hline \multicolumn{4}{|l|}{ Kung } \\
\hline 灰绿耳蒴 Polystichum anomalum (Hook. ex Arn.) C. Chr. & 单裂缝 Monolete & 鳞毛蕨科 Dryopteridaceae & 鳞毛鄀科 Dryopteridaceae \\
\hline 节毛耳蕨 Polystichum articulatipilosum H. G. Zhou \& Hua Li & 单裂缝 Monolete & 鳞毛蕨科 Dryopteridaceae & 鳞毛鄀科 Dryopteridaceae \\
\hline
\end{tabular}




\begin{tabular}{|c|c|c|c|}
\hline $\begin{array}{l}\text { 物种 } \\
\text { Species }\end{array}$ & $\begin{array}{l}\text { 孢子裂缝类型 } \\
\text { Spore apertures styles }\end{array}$ & $\begin{array}{l}\text { 科名 Family (秦仁 } \\
\text { 昌,1978a, b) }\end{array}$ & $\begin{array}{l}\text { 科名 Family (Smith et al., } \\
\text { 2006; Christenhusz et al, } \\
\text { 2011; 张宪春等, 2013) }\end{array}$ \\
\hline $\begin{array}{l}\text { 上斜刀羽耳偋 Polystichum assurgentipinnum W. M. Chu \& B. } \\
\text { Y. Zhang }\end{array}$ & 单裂缝 Monolete & 鳞毛蕨科 Dryopteridaceae & 鳞毛蕨科 Dryopteridaceae \\
\hline 小狭叶芽胞耳茨 Polystichum atkinsonii Bedd. & 单裂缝 Monolete & 鳞毛蕨科 Dryopteridaceae & 鳞毛蕨科 Dryopteridaceae \\
\hline 长羽芽胞耳茨 Polystichum attenuatum Tagawa \& K. Iwat. & 单裂缝 Monolete & 鳞毛蕨科 Dryopteridaceae & 鳞毛烣科 Dryopteridaceae \\
\hline 滇东南耳蒴 Polystichum auriculum Ching & 单裂缝 Monolete & 鳞毛蕨科 Dryopteridaceae & 鳞毛硕科 Dryopteridaceae \\
\hline 薄叶耳蕨 Polystichum bakerianum (Atkin. ex Baker) Diels & 单裂缝 Monolete & 鳞毛蕨科 Dryopteridaceae & 鳞毛蕨科 Dryopteridaceae \\
\hline 宝兴耳葓 Polystichum baoxingense Ching \& H. S. Kung & 单裂缝 Monolete & 鳞毛蕨科 Dryopteridaceae & 鳞毛烣科 Dryopteridaceae \\
\hline 二尖耳硕 Polystichum biaristatum (Blume) T. Moore & 单裂缝 Monolete & 鳞毛蕨科 Dryopteridaceae & 鳞毛蒝科 Dryopteridaceae \\
\hline 钳形耳硕 Polystichum bifidum Ching & 单裂缝 Monolete & 鳞毛蕨科 Dryopteridaceae & 鳞毛蕨科 Dryopteridaceae \\
\hline 双胞耳㓹 Polystichum bigemmatum Ching ex L. L. Xiang & 单裂缝 Monolete & 鳞毛蕨科 Dryopteridaceae & 鳞毛蒝科 Dryopteridaceae \\
\hline 川渝耳葓 Polystichum bissectum C. Chr. & 单裂缝 Monolete & 鳞毛菜科 Dryopteridaceae & 鳞毛菜科 Dryopteridaceae \\
\hline 波密耳锁 Polystichum bomiense Ching \& S. K. Wu & 单裂缝 Monolete & 鳞毛蕨科 Dryopteridaceae & 鳞毛蕨科 Dryopteridaceae \\
\hline 喜马拉雅耳蕨 Polystichum brachypterum (Kuntze) Ching & 单裂缝 Monolete & 鳞毛蕨科 Dryopteridaceae & 鳞毛烣科 Dryopteridaceae \\
\hline 布郎耳葓 Polystichum braunii (Spenn.) Fée & 单裂缝 Monolete & 鳞毛蒴科 Dryopteridaceae & 鳞毛蕨科 Dryopteridaceae \\
\hline 基芽耳鄀 Polystichum capillipes (Baker) Diels & 单裂缝 Monolete & 鳞毛蕨科 Dryopteridaceae & 鳞毛蕨科 Dryopteridaceae \\
\hline 栗鳞耳蕨 Polystichum castaneum (C. B. Clarke) Nayar \& Kaur & 单裂缝 Monolete & 鳞毛蕨科 Dryopteridaceae & 鳞毛烣科 Dryopteridaceae \\
\hline 滇耳茨 Polystichum chingae Ching & 单裂缝 Monolete & 鳞毛蕨科 Dryopteridaceae & 鳞毛鄀科 Dryopteridaceae \\
\hline 拟角状耳鄀 Polystichum christii Ching & 单裂缝 Monolete & 鳞毛蕨科 Dryopteridaceae & 鳞毛蕨科 Dryopteridaceae \\
\hline 陈氏耳硕 Polystichum chunii Ching & 单裂缝 Monolete & 鳞毛蕨科 Dryopteridaceae & 鳞毛蕨科 Dryopteridaceae \\
\hline 涪陵耳蒴 Polystichum consimile Ching & 单裂缝 Monolete & 鳞毛蕨科 Dryopteridaceae & 鳞毛蕨科 Dryopteridaceae \\
\hline $\begin{array}{l}\text { 轴果耳蕨 Polystichum costularisorum Ching ex W. M. Chu \& } \\
\text { Z. R. He }\end{array}$ & 单裂缝 Monolete & 鳞毛蕨科 Dryopteridaceae & 鳞毛鄀科 Dryopteridaceae \\
\hline
\end{tabular}




\begin{tabular}{|c|c|c|c|}
\hline $\begin{array}{l}\text { 物种 } \\
\text { Species }\end{array}$ & $\begin{array}{l}\text { 孢子裂缝类型 } \\
\text { Spore apertures styles }\end{array}$ & $\begin{array}{l}\text { 科名 Family (秦仁 } \\
\text { 昌,1978a, b) }\end{array}$ & $\begin{array}{l}\text { 科名 Family (Smith et al., } \\
\text { 2006; Christenhusz et al, } \\
\text { 2011; 张宪春等, 2013) }\end{array}$ \\
\hline 鞭叶耳蒴 Polystichum craspedosorum (Maxim.) Diels & 单裂缝 Monolete & 鳞毛葓科 Dryopteridaceae & 鳞毛蕨科 Dryopteridaceae \\
\hline $\begin{array}{l}\text { 粗脉耳硕 Polystichum crassinervium Ching ex W. M. Chu \& Z. } \\
\text { R. He }\end{array}$ & 单裂缝 Monolete & 鳞毛蕨科 Dryopteridaceae & 鳞毛茨科 Dryopteridaceae \\
\hline 毛发耳葓 Polystichum crinigerum (C. Chr.) Ching & 单裂缝 Monolete & 鳞毛蕨科 Dryopteridaceae & 鳞毛硕科 Dryopteridaceae \\
\hline 楔基耳蒴 Polystichum cuneatiforme W. M. Chu \& Z. R. He & 单裂缝 Monolete & 鳞毛硕科 Dryopteridaceae & 鳞毛嵚科 Dryopteridaceae \\
\hline 圆片耳蒝 Polystichum cyclolobum C. Chr. & 单裂缝 Monolete & 鳞毛颜科 Dryopteridaceae & 鳞毛蒴科 Dryopteridaceae \\
\hline 大关耳蕨 Polystichum daguanense Ching ex L. L. Xiang & 单裂缝 Monolete & 鳞毛蕨科 Dryopteridaceae & 鳞毛蕨科 Dryopteridaceae \\
\hline $\begin{array}{l}\text { 花山耳蕨 Polystichum daguanense var. huashanicola W.M.Chu } \\
\text { \& Z.R.He }\end{array}$ & 单裂缝 Monolete & 鳞毛䛧科 Dryopteridaceae & 鳞毛茨科 Dryopteridaceae \\
\hline 成忠耳菜 Polystichum dangii P. S. Wang & 单裂缝 Monolete & 鳞毛葓科 Dryopteridaceae & 鳞毛蒴科 Dryopteridaceae \\
\hline 洱源耳硕 Polystichum delavayi (Christ) Ching & 单裂缝 Monolete & 鳞毛硕科 Dryopteridaceae & 鳞毛蒝科 Dryopteridaceae \\
\hline 对生耳蕨 Polystichum deltodon (Baker) Diels & 单裂缝 Monolete & 鳞毛烣科 Dryopteridaceae & 鳞毛蒴科 Dryopteridaceae \\
\hline $\begin{array}{l}\text { 刀羽耳葓 Polystichum deltodon var. cultripinnum W. M. Chu \& } \\
\text { Z. R. He }\end{array}$ & 单裂缝 Monolete & 鳞毛烣科 Dryopteridaceae & 鳞毛烣科 Dryopteridaceae \\
\hline 针齿耳菜 Polystichum deltodon var. henryi Christ & 单裂缝 Monolete & 鳞毛烣科 Dryopteridaceae & 鳞毛偋科 Dryopteridaceae \\
\hline 圆顶耳蒴 Polystichum dielsii Christ & 单裂缝 Monolete & 鳞毛茨科 Dryopteridaceae & 鳞毛蕨科 Dryopteridaceae \\
\hline 铺散耳蒴 Polystichum diffundens H. S. Kung \& L. B. Zhang & 单裂缝 Monolete & 鳞毛颜科 Dryopteridaceae & 鳞毛葓科 Dryopteridaceae \\
\hline 分离耳蒴 Polystichum discretum (D. Don) J. Sm & 单裂缝 Monolete & 鳞毛烣科 Dryopteridaceae & 鳞毛蒴科 Dryopteridaceae \\
\hline $\begin{array}{l}\text { 疏羽耳蕨 Polystichum disjunctum Ching ex W. M. Chu \& Z. R. } \\
\mathrm{He}\end{array}$ & 单裂缝 Monolete & 鳞毛蕨科 Dryopteridaceae & 鳞毛蕨科 Dryopteridaceae \\
\hline 杜氏耳蒝 Polystichum duthiei (C. Hope) C. Chr. & 单裂缝 Monolete & 鳞毛硕科 Dryopteridaceae & 鳞毛蓱科 Dryopteridaceae \\
\hline 凸脉耳硕 Polystichum elevatovenusum Ching ex W. M. Chu \& & 单裂缝 Monolete & 鳞毛硕科 Dryopteridaceae & 鳞毛蕨科 Dryopteridaceae \\
\hline
\end{tabular}




\begin{tabular}{|c|c|c|c|}
\hline $\begin{array}{l}\text { 物种 } \\
\text { Species }\end{array}$ & $\begin{array}{l}\text { 孢子裂缝类型 } \\
\text { Spore apertures styles }\end{array}$ & $\begin{array}{l}\text { 科名 Family (秦仁 } \\
\text { 昌,1978a, b) }\end{array}$ & $\begin{array}{l}\text { 科名 Family (Smith et al., } \\
\text { 2006; Christenhusz et al, } \\
\text { 2011; 张宪春等, 2013) }\end{array}$ \\
\hline \multicolumn{4}{|l|}{ Z. R. He } \\
\hline 蚀盖耳蒝 Polystichum erosum Ching \& K. H. Shing & 单裂缝 Monolete & 鳞毛鄀科 Dryopteridaceae & 鳞毛蕨科 Dryopteridaceae \\
\hline 缺耳耳蕨 Polystichum exauriforme H. S. Kung \& L. B. Zhang & 单裂缝 Monolete & 鳞毛蕨科 Dryopteridaceae & 鳞毛蕨科 Dryopteridaceae \\
\hline 尖顶耳蒝 Polystichum excellens Ching & 单裂缝 Monolete & 鳞毛蕨科 Dryopteridaceae & 鳞毛茨科 Dryopteridaceae \\
\hline 杰出耳菜 Polystichum excelsius Ching \& Z. Y. Liu & 单裂缝 Monolete & 鳞毛蕨科 Dryopteridaceae & 鳞毛烣科 Dryopteridaceae \\
\hline 瓦鳞耳蒴 Polystichum fimbriatum Christ & 单裂缝 Monolete & 鳞毛嵚科 Dryopteridaceae & 鳞毛蕨科 Dryopteridaceae \\
\hline 台湾耳茨 Polystichum formosanum Rosenst. & 单裂缝 Monolete & 鳞毛蕨科 Dryopteridaceae & 鳞毛茨科 Dryopteridaceae \\
\hline 寒生耳濒 Polystichum frigidicola H. S. Kung \& L. B. Zhang & 单裂缝 Monolete & 鳞毛蕨科 Dryopteridaceae & 鳞毛烣科 Dryopteridaceae \\
\hline 福贡耳荻 Polystichum fugongense Ching \& W. M. Chu ex H. S. & 单裂缝 Monolete & 鳞毛蕨科 Dryopteridaceae & 鳞毛蕨科 Dryopteridaceae \\
\hline \multicolumn{4}{|l|}{ Kung \& L. B. Zhang } \\
\hline 工布耳蕨 Polystichum gongboense Ching \& S. K. Wu & 单裂缝 Monolete & 鳞毛蕨科 Dryopteridaceae & 鳞毛蕨科 Dryopteridaceae \\
\hline 大叶耳蕨 Polystichum grandifrons C. Chr. & 单裂缝 Monolete & 鳞毛蕨科 Dryopteridaceae & 鳞毛蕨科 Dryopteridaceae \\
\hline 广西耳薜 Polystichum guangxiense W. M. Chu \& H. G. Zhou & 单裂缝 Monolete & 鳞毛蕨科 Dryopteridaceae & 鳞毛茨科 Dryopteridaceae \\
\hline 无盖耳蕨 Polystichum gymnocarpium Ching ex W. M. Chu \& & 单裂缝 Monolete & 鳞毛蕨科 Dryopteridaceae & 鳞毛蕨科 Dryopteridaceae \\
\hline \multicolumn{4}{|l|}{ Z. R. He } \\
\hline 哈巴耳蕨 Polystichum habaense Ching et H. S. Kung & 单裂缝 Monolete & 鳞毛蕨科 Dryopteridaceae & 鳞毛蕨科 Dryopteridaceae \\
\hline 小戟叶耳菜 Polystichum hancockii (Hance) Diels & 单裂缝 Monolete & 鳞毛䓄科 Dryopteridaceae & 鳞毛蕨科 Dryopteridaceae \\
\hline 芒齿耳蕨 Polystichum hecatopterum Diels & 单裂缝 Monolete & 鳞毛蕨科 Dryopteridaceae & 鳞毛蔴科 Dryopteridaceae \\
\hline 草叶耳硕 Polystichum herbaceum Ching \& Z. Y. Liu & 单裂缝 Monolete & 鳞毛蕨科 Dryopteridaceae & 鳞毛茨科 Dryopteridaceae \\
\hline 猴场耳蕨 Polystichum houchangense Ching ex P. S. Wang & 单裂缝 Monolete & 鳞毛蕨科 Dryopteridaceae & 鳞毛蕨科 Dryopteridaceae \\
\hline 川西耳荻 Polystichum huae H. S. Kung \& L. B. Zhang & 单裂缝 Monolete & 鳞毛嵚科 Dryopteridaceae & 鳞毛蕨科 Dryopteridaceae \\
\hline 宜昌耳菜 Polystichum ichangense Christ & 单裂缝 Monolete & 鳞毛蕨科 Dryopteridaceae & 鳞毛葓科 Dryopteridaceae \\
\hline
\end{tabular}




\begin{tabular}{|c|c|c|c|}
\hline $\begin{array}{l}\text { 物种 } \\
\text { Species }\end{array}$ & $\begin{array}{l}\text { 孢子裂缝类型 } \\
\text { Spore apertures styles }\end{array}$ & $\begin{array}{l}\text { 科名 Family (秦仁 } \\
\text { 昌,1978a, b) }\end{array}$ & $\begin{array}{l}\text { 科名 Family (Smith et al., } \\
\text { 2006; Christenhusz et al, } \\
\text { 2011; 张宪春等, 2013) }\end{array}$ \\
\hline 小耳蒴 Polystichum inaense (Tagawa) Tagawa & 单裂缝 Monolete & 鳞毛蕨科 Dryopteridaceae & 鳞毛烣科 Dryopteridaceae \\
\hline 深裂耳蕨 Polystichum incisopinnulum H. S. Kung \& L. B. & 单裂缝 Monolete & 鳞毛蕨科 Dryopteridaceae & 鳞毛硕科 Dryopteridaceae \\
\hline \multicolumn{4}{|l|}{ Zhang } \\
\hline 贡山耳茨 Polystichum integrilimbum Ching \& H. S. Kung & 单裂缝 Monolete & 鳞毛蕨科 Dryopteridaceae & 鳞毛䋏科 Dryopteridaceae \\
\hline 钝裂耳蕨 Polystichum integrilobum (Ching ex Y. T. Hsieh et Na & 单裂缝 Monolete & 鳞毛蕨科 Dryopteridaceae & 鳞毛硕科 Dryopteridaceae \\
\hline \multicolumn{4}{|l|}{ Li) W. M. Chu ex H. S. Kung } \\
\hline 金佛山耳葓 Polystichum jinfoshanense Ching \& Z. Y. Liu & 单裂缝 Monolete & 鳞毛蕨科 Dryopteridaceae & 鳞毛蕨科 Dryopteridaceae \\
\hline 九老洞耳锁 Polystichum jiulaodongense W. M. Chu \& Z. R. He & 单裂缝 Monolete & 鳞毛蕨科 Dryopteridaceae & 鳞毛偋科 Dryopteridaceae \\
\hline 鸡足山耳硕 Polystichum jizhushanense Ching & 单裂缝 Monolete & 鳞毛蕨科 Dryopteridaceae & 鳞毛蕨科 Dryopteridaceae \\
\hline 康定耳荻 Polystichum kangdingense H. S. Kung \& L. B. Zhang & 单裂缝 Monolete & 鳞毛蕨科 Dryopteridaceae & 鳞毛蒝科 Dryopteridaceae \\
\hline 广东耳䓲 Polystichum kwangtungense Ching & 单裂缝 Monolete & 鳞毛蕨科 Dryopteridaceae & 鳞毛偋科 Dryopteridaceae \\
\hline 拉钦耳蕨 Polystichum lachenense (Hook.) Bedd. & 单裂缝 Monolete & 鳞毛蕨科 Dryopteridaceae & 鳞毛蕨科 Dryopteridaceae \\
\hline 亮叶耳屏 Polystichum lanceolatum (Baker) Diels & 单裂缝 Monolete & 鳞毛蕨科 Dryopteridaceae & 鳞毛烣科 Dryopteridaceae \\
\hline 浪荂耳蕨 Polystichum langchungense Ching ex H. S. Kung & 单裂缝 Monolete & 鳞毛蕨科 Dryopteridaceae & 鳞毛蕨科 Dryopteridaceae \\
\hline 宽鳞耳硕 Polystichum latilepis Ching \& H. S. Kung & 单裂缝 Monolete & 鳞毛蕨科 Dryopteridaceae & 鳞毛蕨科 Dryopteridaceae \\
\hline 柔软耳䓲 Polystichum lentum (D. Don) T. Moore & 单裂缝 Monolete & 鳞毛蕨科 Dryopteridaceae & 鳞毛蕨科 Dryopteridaceae \\
\hline 武陵山耳蒴 Polystichum leveillei C. Chr. & 单裂缝 Monolete & 鳞毛蕨科 Dryopteridaceae & 鳞毛鄀科 Dryopteridaceae \\
\hline 正宇耳蕨 Polystichum liui Ching & 单裂缝 Monolete & 鳞毛蕨科 Dryopteridaceae & 鳞毛蕨科 Dryopteridaceae \\
\hline 矛状耳硕 Polystichum lonchitis (L.) Roth & 单裂缝 Monolete & 鳞毛蕨科 Dryopteridaceae & 鳞毛蕨科 Dryopteridaceae \\
\hline 长芒耳茨 Polystichum longiaristatum Ching, Boufford \& K. H. & 单裂缝 Monolete & 鳞毛蕨科 Dryopteridaceae & 鳞毛鄀科 Dryopteridaceae \\
\hline \multicolumn{4}{|l|}{ Shing } \\
\hline 尖齿耳茨 Polystichum longidens Ching \& S. K. Wu & 单裂缝 Monolete & 鳞毛蕨科 Dryopteridaceae & 鳞毛鄀科 Dryopteridaceae \\
\hline
\end{tabular}




\begin{tabular}{|c|c|c|c|}
\hline $\begin{array}{l}\text { 物种 } \\
\text { Species }\end{array}$ & $\begin{array}{l}\text { 孢子裂缝类型 } \\
\text { Spore apertures styles }\end{array}$ & $\begin{array}{l}\text { 科名 Family (秦仁 } \\
\text { 昌,1978a, b) }\end{array}$ & $\begin{array}{l}\text { 科名 Family (Smith et al., } \\
\text { 2006; Christenhusz et al, } \\
\text { 2011; 张宪春等, 2013) }\end{array}$ \\
\hline 长鳞耳偋 Polystichum longipaleatum Christ & 单裂缝 Monolete & 鳞毛嵚科 Dryopteridaceae & 鳞毛藓科 Dryopteridaceae \\
\hline 长柄耳蒝 Polystichum longipes Ching \& S. K. Wu & 单裂缝 Monolete & 鳞毛葓科 Dryopteridaceae & 鳞毛葓科 Dryopteridaceae \\
\hline 长羽耳蕨 Polystichum longipinnulum Nair & 单裂缝 Monolete & 鳞毛蕨科 Dryopteridaceae & 鳞毛蕨科 Dryopteridaceae \\
\hline $\begin{array}{l}\text { 长刺耳蕨 Polystichum longispinosum Ching ex L. B. Zhang \& } \\
\text { H. S. Kung }\end{array}$ & 单裂缝 Monolete & 鳞毛蕨科 Dryopteridaceae & 鳞毛蕨科 Dryopteridaceae \\
\hline 长叶耳蕨 Polystichum longissimum Ching \& Z. Y. Liu & 单裂缝 Monolete & 鳞毛蕨科 Dryopteridaceae & 鳞毛蕨科 Dryopteridaceae \\
\hline 大盖高山耳蒝 Polystichum macrochlaenum Ching \& S. K. Wu & 单裂缝 Monolete & 鳞毛蕨科 Dryopteridaceae & 鳞毛蕨科 Dryopteridaceae \\
\hline 黑鳞耳葓 Polystichum makinoi (Tagawa) Tagawa & 单裂缝 Monolete & 鳞毛蕨科 Dryopteridaceae & 鳞毛蓱科 Dryopteridaceae \\
\hline 镰叶耳锁 Polystichum manmeiense (Christ) Nakaike & 单裂缝 Monolete & 鳞毛蕨科 Dryopteridaceae & 鳞毛蕨科 Dryopteridaceae \\
\hline 黔中耳锁 Polystichum martinii Christ & 单裂缝 Monolete & 鳞毛蕨科 Dryopteridaceae & 鳞毛蕨科 Dryopteridaceae \\
\hline 前原耳锁 Polystichum mayebarae Tagawa & 单裂缝 Monolete & 鳞毛蕨科 Dryopteridaceae & 鳞毛蕨科 Dryopteridaceae \\
\hline 墨脱耳蕨 Polystichum medogense Ching \& S. K. Wu & 单裂缝 Monolete & 鳞毛蕨科 Dryopteridaceae & 鳞毛蕨科 Dryopteridaceae \\
\hline 印西耳蕨 Polystichum mehrae Fraser-Jenk. \& Khullar & 单裂缝 Monolete & 鳞毛蕨科 Dryopteridaceae & 鳞毛蕨科 Dryopteridaceae \\
\hline $\begin{array}{l}\text { 阔基耳茨 Polystichum mehrae f. latifundus H. S. Kung \& L. B. } \\
\text { Zhang }\end{array}$ & 单裂缝 Monolete & 鳞毛蕨科 Dryopteridaceae & 鳞毛蕨科 Dryopteridaceae \\
\hline 美姑耳荻 Polystichum meiguense Ching \& H. S. Kung & 单裂缝 Monolete & 鳞毛蕨科 Dryopteridaceae & 鳞毛蕨科 Dryopteridaceae \\
\hline 乌柄耳硕 Polystichum melanostipes Ching \& H. S. Kung & 单裂缝 Monolete & 鳞毛蕨科 Dryopteridaceae & 鳞毛蕨科 Dryopteridaceae \\
\hline 毛叶耳鄀 Polystichum mollissimum Ching & 单裂缝 Monolete & 鳞毛蕨科 Dryopteridaceae & 鳞毛蕨科 Dryopteridaceae \\
\hline $\begin{array}{l}\text { 条裂耳䓲 Polystichum mollissimum var. laciniatum H. S. Kung } \\
\text { \& L. B. Zhang }\end{array}$ & 单裂缝 Monolete & 鳞毛蕨科 Dryopteridaceae & 鳞毛蕨科 Dryopteridaceae \\
\hline 玉山耳蕨 Polystichum morii Hayata & 单裂缝 Monolete & 鳞毛蕨科 Dryopteridaceae & 鳞毛蕨科 Dryopteridaceae \\
\hline 穆坪耳蕨 Polystichum moupinense (Franch.) Bedd. & 单裂缝 Monolete & 鳞毛蕨科 Dryopteridaceae & 鳞毛蕨科 Dryopteridaceae \\
\hline
\end{tabular}




\begin{tabular}{|c|c|c|c|}
\hline $\begin{array}{l}\text { 物种 } \\
\text { Species }\end{array}$ & $\begin{array}{l}\text { 孢子裂缝类型 } \\
\text { Spore apertures styles }\end{array}$ & $\begin{array}{l}\text { 科名 Family (秦仁 } \\
\text { 昌,1978a, b) }\end{array}$ & $\begin{array}{l}\text { 科名 Family (Smith et al., } \\
\text { 2006; Christenhusz et al, } \\
\text { 2011; 张宪春等, 2013) }\end{array}$ \\
\hline $\begin{array}{l}\text { 伴蘚耳菜 Polystichum muscicola Ching ex W. M. Chu \& Z. R. } \\
\mathrm{He}\end{array}$ & 单裂缝 Monolete & 鳞毛蕨科 Dryopteridaceae & 鳞毛蕨科 Dryopteridaceae \\
\hline 纳雍耳蕨 Polystichum nayongense P. S. Wang \& X. Y. Wang & 单裂缝 Monolete & 鳞毛蕨科 Dryopteridaceae & 鳞毛蕨科 Dryopteridaceae \\
\hline 新正宇耳蕨 Polystichum neoliuii D. S. Jiang & 单裂缝 Monolete & 鳞毛蕨科 Dryopteridaceae & 鳞毛烣科 Dryopteridaceae \\
\hline 革叶耳嵚 Polystichum neolobatum Nakai & 单裂缝 Monolete & 鳞毛蕨科 Dryopteridaceae & 鳞毛硕科 Dryopteridaceae \\
\hline 尼泊尔耳蕨 Polystichum nepalense (Spreng.) C. Chr. & 单裂缝 Monolete & 鳞毛蕨科 Dryopteridaceae & 鳞毛蕨科 Dryopteridaceae \\
\hline 黛鳞耳蒴 Polystichum nigrum Ching \& H. S. Kung & 单裂缝 Monolete & 鳞毛蕨科 Dryopteridaceae & 鳞毛烣科 Dryopteridaceae \\
\hline 宁陕耳蒝 Polystichum ningshenense Ching \& Y. P. Hsu & 单裂缝 Monolete & 鳞毛蕨科 Dryopteridaceae & 鳞毛蒝科 Dryopteridaceae \\
\hline 裸果耳蕨 Polystichum nudisorum Ching & 单裂缝 Monolete & 鳞毛蕨科 Dryopteridaceae & 鳞毛蕨科 Dryopteridaceae \\
\hline 斜羽耳荻 Polystichum obliquum (D. Don) T. Moore & 单裂缝 Monolete & 鳞毛蕨科 Dryopteridaceae & 鳞毛鄀科 Dryopteridaceae \\
\hline $\begin{array}{l}\text { 镇康耳蕨 Polystichum oblongum Ching ex W. M. Chu \& Z. R. } \\
\mathrm{He}\end{array}$ & 单裂缝 Monolete & 鳞毛蕨科 Dryopteridaceae & 鳞毛蕨科 Dryopteridaceae \\
\hline $\begin{array}{l}\text { 疏果耳蕨 Polystichum oligocarpum Ching ex H. S. Kung \& L. } \\
\text { B. Zhang }\end{array}$ & 单裂缝 Monolete & 鳞毛蕨科 Dryopteridaceae & 鳞毛蕨科 Dryopteridaceae \\
\hline 峨眉耳䕋 Polystichum omeiense C. Chr. & 单裂缝 Monolete & 鳞毛蕨科 Dryopteridaceae & 鳞毛蕨科 Dryopteridaceae \\
\hline $\begin{array}{l}\text { 假半育耳茨 Polystichum oreodoxa } \text { Ching ex H. S. Kung \& L. } \\
\text { B. Zhang }\end{array}$ & 单裂缝 Monolete & 鳞毛蕨科 Dryopteridaceae & 鳞毛蕨科 Dryopteridaceae \\
\hline 藏东耳蕨 Polystichum orientalitibeticum Ching & 单裂缝 Monolete & 鳞毛蕨科 Dryopteridaceae & 鳞毛蕨科 Dryopteridaceae \\
\hline 高山耳硕 Polystichum otophorum (Franch.) Bedd. & 单裂缝 Monolete & 鳞毛蕨科 Dryopteridaceae & 鳞毛蕨科 Dryopteridaceae \\
\hline 卵鳞耳蕨 Polystichum ovato-paleaceum (Kodama) Sa. Kurata & 单裂缝 Monolete & 鳞毛蕨科 Dryopteridaceae & 鳞毛蕨科 Dryopteridaceae \\
\hline 拟穆坪耳㓹 Polystichum paramoupinense Ching & 单裂缝 Monolete & 鳞毛蕨科 Dryopteridaceae & 鳞毛鄀科 Dryopteridaceae \\
\hline 小羽耳蕨 Polystichum parvifoliolatum W. M. Chu & 单裂缝 Monolete & 鳞毛蕨科 Dryopteridaceae & 鳞毛鄀科 Dryopteridaceae \\
\hline
\end{tabular}




\begin{tabular}{|c|c|c|c|}
\hline $\begin{array}{l}\text { 物种 } \\
\text { Species }\end{array}$ & $\begin{array}{l}\text { 孢子裂缝类型 } \\
\text { Spore apertures styles }\end{array}$ & $\begin{array}{l}\text { 科名 Family (秦仁 } \\
\text { 昌,1978a, b) }\end{array}$ & $\begin{array}{l}\text { 科名 Family (Smith et al., } \\
\text { 2006; Christenhusz et al, } \\
\text { 2011; 张宪春等, 2013) }\end{array}$ \\
\hline 尖叶耳菜 Polystichum parvipinnulum Tagawa & 单裂缝 Monolete & 鳞毛蕨科 Dryopteridaceae & 鳞毛蒝科 Dryopteridaceae \\
\hline 片马耳蕨 Polystichum pianmaense W. M. Chu & 单裂缝 Monolete & 鳞毛蕨科 Dryopteridaceae & 鳞毛硕科 Dryopteridaceae \\
\hline 乌鳞耳䓲 Polystichum piceo-paleaceum Tagawa & 单裂缝 Monolete & 鳞毛䓲科 Dryopteridaceae & 鳞毛蕨科 Dryopteridaceae \\
\hline 棕鳞耳蕨 Polystichum polyblepharum (Roem. ex Kunze) C. & 单裂缝 Monolete & 鳞毛蕨科 Dryopteridaceae & 鳞毛鄀科 Dryopteridaceae \\
\hline \multicolumn{4}{|l|}{ Presl } \\
\hline 芒刺耳蕨 Polystichum prescottianum (Wall. ex Mett.) T. Moore & 单裂缝 Monolete & 鳞毛蕨科 Dryopteridaceae & 鳞毛蕨科 Dryopteridaceae \\
\hline 锯磷耳蕨 Polystichum prionolepis Hayata & 单裂缝 Monolete & 鳞毛蕨科 Dryopteridaceae & 鳞毛蕨科 Dryopteridaceae \\
\hline 拟栗鳞耳蕨 Polystichum pseudocastaneum Ching \& S. K. Wu & 单裂缝 Monolete & 鳞毛蕨科 Dryopteridaceae & 鳞毛蒝科 Dryopteridaceae \\
\hline 假亮叶耳蕨 Polystichum pseudolanceolatum Ching ex P. S. & 单裂缝 Monolete & 鳞毛䓲科 Dryopteridaceae & 鳞毛蕨科 Dryopteridaceae \\
\hline \multicolumn{4}{|l|}{ Wang } \\
\hline 假黑鳞耳蒴 Polystichum pseudomakinoi Tagawa & 单裂缝 Monolete & 鳞毛蕨科 Dryopteridaceae & 鳞毛蕨科 Dryopteridaceae \\
\hline 菱羽耳嵚 Polystichum pseudorhomboideum H. S. Kung \& L. B. & 单裂缝 Monolete & 鳞毛䓲科 Dryopteridaceae & 鳞毛蕨科 Dryopteridaceae \\
\hline \multicolumn{4}{|l|}{ Zhang } \\
\hline 假线鳞耳菜 Polystichum pseudosetosum Ching \& Z. Y. Liu & 单裂缝 Monolete & 鳞毛蕨科 Dryopteridaceae & 鳞毛蕨科 Dryopteridaceae \\
\hline 洪雅耳蒴 Polystichum pseudoxiphophyllum Ching ex H. S. & 单裂缝 Monolete & 鳞毛蕨科 Dryopteridaceae & 鳞毛蕨科 Dryopteridaceae \\
\hline \multicolumn{4}{|l|}{ Kung } \\
\hline 中缅耳硕 Polystichum punctiferum Christ & 单裂缝 Monolete & 鳞毛蕨科 Dryopteridaceae & 鳞毛烣科 Dryopteridaceae \\
\hline 密果耳菜 Polystichum pycnopterum (Christ) Ching ex W. M. & 单裂缝 Monolete & 鳞毛䓲科 Dryopteridaceae & 鳞毛蕨科 Dryopteridaceae \\
\hline \multicolumn{4}{|l|}{ Chu \& Z. R. He } \\
\hline 昌都耳菜 Polystichum qamdoense Ching \& S. K. Wu & 单裂缝 Monolete & 鳞毛蕨科 Dryopteridaceae & 鳞毛鄀科 Dryopteridaceae \\
\hline 倒鳞耳嵚 Polystichum retrosopaleaceum (Kodama) Tagawa & 单裂缝 Monolete & 鳞毛蕨科 Dryopteridaceae & 鳞毛蒝科 Dryopteridaceae \\
\hline 外卷耳硕 Polystichum revolutum P. S. Wang & 单裂缝 Monolete & 鳞毛薕科 Dryopteridaceae & 鳞毛蒝科 Dryopteridaceae \\
\hline
\end{tabular}


魏雪苹，张宪春．蕨类植物不同孢子裂缝类型在中国的分布格局．生物多样性，2016，24(10)：1129-1134 http://www. biodiversity - science. net/CN/10. 17520/biods. 2016219

\begin{tabular}{|c|c|c|c|}
\hline $\begin{array}{l}\text { 物种 } \\
\text { Species }\end{array}$ & $\begin{array}{l}\text { 孢子裂缝类型 } \\
\text { Spore apertures styles }\end{array}$ & $\begin{array}{l}\text { 科名 Family (秦仁 } \\
\text { 昌,1978a, b) }\end{array}$ & $\begin{array}{l}\text { 科名 Family (Smith et al., } \\
\text { 2006; Christenhusz et al, } \\
\text { 2011; 张宪春等, 2013) }\end{array}$ \\
\hline 斜方刺叶耳䕋 Polystichum rhombiforme Ching \& S. K. Wu & 单裂缝 Monolete & 鳞毛嵚科 Dryopteridaceae & 鳞毛蕨科 Dryopteridaceae \\
\hline 阔鳞耳蒝 Polystichum rigens Tagawa & 单裂缝 Monolete & 鳞毛硕科 Dryopteridaceae & 鳞毛葓科 Dryopteridaceae \\
\hline $\begin{array}{l}\text { 粗壮耳硕 Polystichum robustum Ching ex L. B. Zhang \& H. S. } \\
\text { Kung }\end{array}$ & 单裂缝 Monolete & 鳞毛藃科 Dryopteridaceae & 鳞毛茨科 Dryopteridaceae \\
\hline $\begin{array}{l}\text { 红鳞耳蒴 Polystichum rufopaleaceum Ching ex H. S. Kung \& } \\
\text { L. B. Zhang }\end{array}$ & 单裂缝 Monolete & 鳞毛蕨科 Dryopteridaceae & 鳞毛锁科 Dryopteridaceae \\
\hline $\begin{array}{l}\text { 石生耳蕨 Polystichum saxicola Ching ex H. S. Kung \& L. B. } \\
\text { Zhang }\end{array}$ & 单裂缝 Monolete & 鳞毛蕨科 Dryopteridaceae & 鳞毛蕨科 Dryopteridaceae \\
\hline 半育耳蒴 Polystichum semifertile (C. B. Clarke) Ching & 单裂缝 Monolete & 鳞毛烣科 Dryopteridaceae & 鳞毛蒴科 Dryopteridaceae \\
\hline 刚毛耳蒴 Polystichum setillosum Ching & 单裂缝 Monolete & 鳞毛蕨科 Dryopteridaceae & 鳞毛蕨科 Dryopteridaceae \\
\hline 山东耳菜 Polystichum shandongense J. X. Li \& Y. Wei & 单裂缝 Monolete & 鳞毛硕科 Dryopteridaceae & 鳞毛蒝科 Dryopteridaceae \\
\hline 陕西耳蒴 Polystichum shensiense Christ & 单裂缝 Monolete & 鳞毛烣科 Dryopteridaceae & 鳞毛蒴科 Dryopteridaceae \\
\hline 边果耳蕨 Polystichum shimurae Sa. Kurata ex Seriz. & 单裂缝 Monolete & 鳞毛茨科 Dryopteridaceae & 鳞毛蕨科 Dryopteridaceae \\
\hline 单羽耳葓 Polystichum simplicipinnum Hayata & 单裂缝 Monolete & 鳞毛蕨科 Dryopteridaceae & 鳞毛葓科 Dryopteridaceae \\
\hline 中华耳蕨 Polystichum sinense Christ & 单裂缝 Monolete & 鳞毛烣科 Dryopteridaceae & 鳞毛偋科 Dryopteridaceae \\
\hline $\begin{array}{l}\text { 裂叶耳蕨 Polystichum sinense var. lobatum H. S. Kung \& L. B. } \\
\text { Zhang }\end{array}$ & 单裂缝 Monolete & 鳞毛蕨科 Dryopteridaceae & 鳞毛蕨科 Dryopteridaceae \\
\hline 中华对马耳蓱 Polystichum sinotsus-simense Ching \& Z. Y. Liu & 单裂缝 Monolete & 鳞毛烣科 Dryopteridaceae & 鳞毛蒴科 Dryopteridaceae \\
\hline $\begin{array}{l}\text { 草山耳蕨 Polystichum sozanense Ching ex H. S. Kung \& L. B. } \\
\text { Zhang }\end{array}$ & 单裂缝 Monolete & 鳞毛朠科 Dryopteridaceae & 鳞毛偋科 Dryopteridaceae \\
\hline 密鳞耳蕨 Polystichum squarrosum (D. Don) Fée & 单裂缝 Monolete & 鳞毛硕科 Dryopteridaceae & 鳞毛蓱科 Dryopteridaceae \\
\hline 狭叶芽胞耳偋 Polystichum stenophyllum Christ & 单裂缝 Monolete & 鳞毛硕科 Dryopteridaceae & 鳞毛葓科 Dryopteridaceae \\
\hline
\end{tabular}




\begin{tabular}{|c|c|c|c|}
\hline $\begin{array}{l}\text { 物种 } \\
\text { Species }\end{array}$ & $\begin{array}{l}\text { 孢子裂缝类型 } \\
\text { Spore apertures styles }\end{array}$ & $\begin{array}{l}\text { 科名 Family (秦仁 } \\
\text { 昌,1978a, b) }\end{array}$ & $\begin{array}{l}\text { 科名 Family (Smith et al., } \\
\text { 2006; Christenhusz et al, } \\
\text { 2011; 张宪春等, 2013) }\end{array}$ \\
\hline $\begin{array}{l}\text { 错那耳蕨 Polystichum stenophyllum var. conaense (Ching \& S. } \\
\text { K. Wu) W. M. Chu \& Z. R. He }\end{array}$ & 单裂缝 Monolete & 鳞毛蕨科 Dryopteridaceae & 鳞毛䒽科 Dryopteridaceae \\
\hline 猫儿刺耳蕨 Polystichum stimulans (Kunze ex Mett.) Bedd. & 单裂缝 Monolete & 鳞毛蕨科 Dryopteridaceae & 鳞毛蕨科 Dryopteridaceae \\
\hline 多羽耳蕨 Polystichum subacutidens Ching ex L. L. Xiang & 单裂缝 Monolete & 鳞毛葓科 Dryopteridaceae & 鳞毛蒴科 Dryopteridaceae \\
\hline 粗齿耳葓 Polystichum subdeltodon Ching & 单裂缝 Monolete & 鳞毛硕科 Dryopteridaceae & 鳞毛葓科 Dryopteridaceae \\
\hline 拟流苏耳菜 Polystichum subfimbriatum W. M. Chu \& Z. R. He & 单裂缝 Monolete & 鳞毛蕨科 Dryopteridaceae & 鳞毛蕨科 Dryopteridaceae \\
\hline $\begin{array}{l}\text { 近边耳蕨 Polystichum submarginale (Baker) Ching ex P. S. } \\
\text { Wang }\end{array}$ & 单裂缝 Monolete & 鳞毛蕨科 Dryopteridaceae & 鳞毛蕨科 Dryopteridaceae \\
\hline 秦岭耳茨 Polystichum submite (Christ) Diels & 单裂缝 Monolete & 鳞毛茨科 Dryopteridaceae & 鳞毛蒴科 Dryopteridaceae \\
\hline 钻鳞耳蕨 Polystichum subulatum Ching ex L. B. Zhang & 单裂缝 Monolete & 鳞毛蕨科 Dryopteridaceae & 鳞毛蕨科 Dryopteridaceae \\
\hline 南亚耳茨 Polystichum tacticopterum (Kunze) T. Moore & 单裂缝 Monolete & 鳞毛蕨科 Dryopteridaceae & 鳞毛蕨科 Dryopteridaceae \\
\hline 台中耳蕨 Polystichum taizhongense H. S. Kung & 单裂缝 Monolete & 鳞毛蕨科 Dryopteridaceae & 鳞毛蕨科 Dryopteridaceae \\
\hline 通麦耳蕨 Polystichum tangmaiense H. S. Kung & 单裂缝 Monolete & 鳞毛蕨科 Dryopteridaceae & 鳞毛蕨科 Dryopteridaceae \\
\hline 尾叶耳蕨 Polystichum thomsonii (J. D. Hook.) Bedd. & 单裂缝 Monolete & 鳞毛蕨科 Dryopteridaceae & 鳞毛蕨科 Dryopteridaceae \\
\hline 西藏耳硕 Polystichum tibeticum Ching & 单裂缝 Monolete & 鳞毛蕨科 Dryopteridaceae & 鳞毛蕨科 Dryopteridaceae \\
\hline 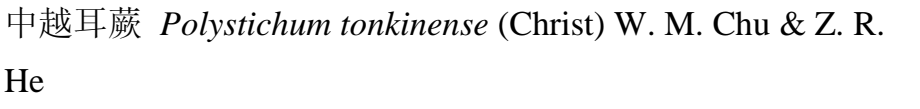 & 单裂缝 Monolete & 鳞毛蕨科 Dryopteridaceae & 鳞毛蕨科 Dryopteridaceae \\
\hline 戟叶耳锁 Polystichum tripteron (Kunze) C. Presl & 单裂缝 Monolete & 鳞毛蕨科 Dryopteridaceae & 鳞毛蕨科 Dryopteridaceae \\
\hline $\begin{array}{l}\text { 井冈山耳濒 Polystichum tsingkanshanense Ching ex K. H. } \\
\text { Shing \& J. F. Cheng }\end{array}$ & 单裂缝 Monolete & 鳞毛蕨科 Dryopteridaceae & 鳞毛萩科 Dryopteridaceae \\
\hline 对马耳鄀 Polystichum tsus-simense (Hook.) J. Sm. & 单裂缝 Monolete & 鳞毛蕨科 Dryopteridaceae & 鳞毛蕨科 Dryopteridaceae \\
\hline 深裂对马耳蒝 Polystichum tsus-simense var. dissectum W. M. & 单裂缝 Monolete & 鳞毛烣科 Dryopteridaceae & 鳞毛蕨科 Dryopteridaceae \\
\hline
\end{tabular}




\begin{tabular}{|c|c|c|c|}
\hline $\begin{array}{l}\text { 物种 } \\
\text { Species }\end{array}$ & $\begin{array}{l}\text { 孢子裂缝类型 } \\
\text { Spore apertures styles }\end{array}$ & $\begin{array}{l}\text { 科名 Family (秦仁 } \\
\text { 昌,1978a, b) }\end{array}$ & $\begin{array}{l}\text { 科名 Family (Smith et al., } \\
\text { 2006; Christenhusz et al, } \\
\text { 2011; 张宪春等, 2013) }\end{array}$ \\
\hline \multicolumn{4}{|l|}{ Chu } \\
\hline 小羽对马耳蕨 Polystichum tsus-simense var. parvipinnulum $\mathrm{W}$. & 单裂缝 Monolete & 鳞毛蕨科 Dryopteridaceae & 鳞毛蕨科 Dryopteridaceae \\
\hline \multicolumn{4}{|l|}{ M. Chu } \\
\hline 细裂耳硕 Polystichum wattii (Bedd.) C. Chr. & 单裂缝 Monolete & 鳞毛蕨科 Dryopteridaceae & 鳞毛蕨科 Dryopteridaceae \\
\hline 剑叶耳䕬 Polystichum xiphophyllum (Baker) Diels & 单裂缝 Monolete & 鳞毛蕨科 Dryopteridaceae & 鳞毛蕨科 Dryopteridaceae \\
\hline 亚东耳菜 Polystichum yadongense Ching \& S. K. Wu & 单裂缝 Monolete & 鳞毛蕨科 Dryopteridaceae & 鳞毛蕨科 Dryopteridaceae \\
\hline 倒叶耳茨 Polystichum yuanum Ching & 单裂缝 Monolete & 鳞毛烣科 Dryopteridaceae & 鳞毛蕨科 Dryopteridaceae \\
\hline 云南耳脄 Polystichum yunnanense Christ & 单裂缝 Monolete & 鳞毛蕨科 Dryopteridaceae & 鳞毛蕨科 Dryopteridaceae \\
\hline 察隅耳蒝 Polystichum zayuense W. M. Chu \& Z. R. He & 单裂缝 Monolete & 鳞毛䓲科 Dryopteridaceae & 鳞毛蕨科 Dryopteridaceae \\
\hline 玉龙蕨 Sorolepidium glaciale Christ & 单裂缝 Monolete & 鳞毛蕨科 Dryopteridaceae & 鳞毛蕨科 Dryopteridaceae \\
\hline 多羽实腨 Bolbitis angustipinna (Hayata) H. Ito & 单裂缝 Monolete & 实鄀科 Bolbitidaceae & 鳞毛蕨科 Dryopteridaceae \\
\hline 刺蕨 Bolbitis appendiculata (Willd.) K. Iwats. & 单裂缝 Monolete & 实茨科 Bolbitidaceae & 鳞毛痰科 Dryopteridaceae \\
\hline 贵州实蕨 Bolbitis christensenii (Ching) Ching & 单裂缝 Monolete & 实硕科 Bolbitidaceae & 鳞毛蕨科 Dryopteridaceae \\
\hline 密叶实蕨 Bolbitis confertifolia Ching & 单裂缝 Monolete & 实鄀科 Bolbitidaceae & 鳞毛蕨科 Dryopteridaceae \\
\hline 紫轴实䔊 Bolbitis costata (C. Presl) Ching & 单裂缝 Monolete & 实茨科 Bolbitidaceae & 鳞毛茨科 Dryopteridaceae \\
\hline 间断实蕨 Bolbitis deltigera (Bedd.) C. Chr. & 单裂缝 Monolete & 实荻科 Bolbitidaceae & 鳞毛蕨科 Dryopteridaceae \\
\hline 疏裂刺锁 Bolbitis fengiana (Ching) S. Y. Dong & 单裂缝 Monolete & 实蕨科 Bolbitidaceae & 鳞毛蕨科 Dryopteridaceae \\
\hline 厚叶实菜 Bolbitis hainanensis Ching \& Chu H. Wang & 单裂缝 Monolete & 实茨科 Bolbitidaceae & 鳞毛茨科 Dryopteridaceae \\
\hline 河口实蕨 Bolbitis hekouensis Ching & 单裂缝 Monolete & 实鄀科 Bolbitidaceae & 鳞毛蕨科 Dryopteridaceae \\
\hline 长叶实蓟 Bolbitis heteroclita (C. Presl) Ching & 单裂缝 Monolete & 实蕨科 Bolbitidaceae & 鳞毛蕨科 Dryopteridaceae \\
\hline 虎克实蕨 Bolbitis hookeriana K. Iwats. & 单裂缝 Monolete & 实蕨科 Bolbitidaceae & 鳞毛蕨科 Dryopteridaceae \\
\hline 长耳刺䓲 Bolbitis longiaurita F. G. Wang \& F. W. Xing & 单裂缝 Monolete & 实蕨科 Bolbitidaceae & 鳞毛烣科 Dryopteridaceae \\
\hline
\end{tabular}


魏雪苹，张宪春．偋类植物不同孢子裂缝类型在中国的分布格局．生物多样性，2016，24(10)：1129-1134 http://www. biodiversity - science. net/CN/10. 17520/biods. 2016219

\begin{tabular}{|c|c|c|c|}
\hline $\begin{array}{l}\text { 物种 } \\
\text { Species }\end{array}$ & $\begin{array}{l}\text { 孢子裂缝类型 } \\
\text { Spore apertures styles }\end{array}$ & $\begin{array}{l}\text { 科名 Family (秦仁 } \\
\text { 昌,1978a, b) }\end{array}$ & $\begin{array}{l}\text { 科名 Family (Smith et al., } \\
\text { 2006; Christenhusz et al, } \\
\text { 2011; 张宪春等, 2013) }\end{array}$ \\
\hline 墨脱刺蕨 Bolbitis medogensis (Ching \& S. K. Wu) S. Y. Dong & 单裂缝 Monolete & 实硕科 Bolbitidaceae & 鳞毛硕科 Dryopteridaceae \\
\hline 根叶刺蕨 Bolbitis rhizophylla (Kaulf.) Hennipman & 单裂缝 Monolete & 实硕科 Bolbitidaceae & 鳞毛葓科 Dryopteridaceae \\
\hline 红柄实蕨 Bolbitis scalpturata (Fée) Ching & 单裂缝 Monolete & 实硕科 Bolbitidaceae & 鳞毛蒴科 Dryopteridaceae \\
\hline 附着实蕨 Bolbitis scandens W. M. Chu ex Ching \& Chu H. & 单裂缝 Monolete & 实蕨科 Bolbitidaceae & 鳞毛蕨科 Dryopteridaceae \\
\hline \multicolumn{4}{|l|}{ Wang } \\
\hline 中华刺偋 Bolbitis sinensis (Baker) K. Iwats. & 单裂缝 Monolete & 实蒴科 Bolbitidaceae & 鳞毛蒴科 Dryopteridaceae \\
\hline 华南实茨 Bolbitis subcordata (Copel.) Ching & 单裂缝 Monolete & 实蕨科 Bolbitidaceae & 鳞毛蕨科 Dryopteridaceae \\
\hline 西藏实硕 Bolbitis tibetica Ching \& S. K. Wu & 单裂缝 Monolete & 实茲科 Bolbitidaceae & 鳞毛蓱科 Dryopteridaceae \\
\hline 镰裂刺嵚 Bolbitis tonkinensis (C.Chr. ex Ching) K.Iwats. & 单裂缝 Monolete & 实硕科 Bolbitidaceae & 鳞毛蒴科 Dryopteridaceae \\
\hline 宽羽实嵚 Bolbitis virens (Hook. \& Grev.) Schott & 单裂缝 Monolete & 实蕨科 Bolbitidaceae & 鳞毛蕨科 Dryopteridaceae \\
\hline 网脉实嵚 Bolbitis $\times$ laxireticulata $\mathrm{K}$. Iwats. & 单裂缝 Monolete & 实硕科 Bolbitidaceae & 鳞毛蒝科 Dryopteridaceae \\
\hline 云南实嵚 Bolbitis $\times$ multipinna $\quad$ F. G. Wang, K. Iwats. \& F. W. & 单裂缝 Monolete & 实蒴科 Bolbitidaceae & 鳞毛蒴科 Dryopteridaceae \\
\hline \multicolumn{4}{|l|}{ Xing } \\
\hline 南仁实藃 Bolbitis × nanjenensis C. M. Kuo & 单裂缝 Monolete & 实硕科 Bolbitidaceae & 鳞毛葓科 Dryopteridaceae \\
\hline 爪哇舌葓 Elaphoglossum angulatum (Blume) Moore & 单裂缝 Monolete & 舌蒴科 Elapoglossaceae & 鳞毛葓科 Dryopteridaceae \\
\hline 南海舌蒴 Elaphoglossum callifolium (Blume) Moore & 单裂缝 Monolete & 舌蒴科 Elapoglossaceae & 鳞毛茨科 Dryopteridaceae \\
\hline 舌硕 Elaphoglossum conforme (Sw.) Schott & 单裂缝 Monolete & 舌鄀科 Elapoglossaceae & 鳞毛蕨科 Dryopteridaceae \\
\hline 吕宋舌菜 Elaphoglossum luzonicum Copel. & 单裂缝 Monolete & 舌蒴科 Elapoglossaceae & 鳞毛葓科 Dryopteridaceae \\
\hline 琼崖舌茨 Elaphoglossum mcclurei Ching & 单裂缝 Monolete & 舌彩科 Elapoglossaceae & 鳞毛硕科 Dryopteridaceae \\
\hline 圆叶舌屏 Elaphoglossum sinii C. Chr. ex Wu & 单裂缝 Monolete & 舌葓科 Elapoglossaceae & 鳞毛硕科 Dryopteridaceae \\
\hline $\begin{array}{l}\text { 云南舌鄀 Elaphoglossum stelligerum (Wall. ex Baker) T. Moore } \\
\text { ex Alston \& Bonner }\end{array}$ & 单裂缝 Monolete & 舌葓科 Elapoglossaceae & 鳞毛魦科 Dryopteridaceae \\
\hline
\end{tabular}




\begin{tabular}{|c|c|c|c|}
\hline $\begin{array}{l}\text { 物种 } \\
\text { Species }\end{array}$ & $\begin{array}{l}\text { 孢子裂缝类型 } \\
\text { Spore apertures styles }\end{array}$ & $\begin{array}{l}\text { 科名 Family (秦仁 } \\
\text { 昌,1978a, b) }\end{array}$ & $\begin{array}{l}\text { 科名 Family (Smith et al., } \\
\text { 2006; Christenhusz et al, } \\
\text { 2011; 张宪春等, 2013) }\end{array}$ \\
\hline 华南舌蕨 Elaphoglossum yoshinagae (Yatabe) Makino & 单裂缝 Monolete & 舌䓲科 Elapoglossaceae & 鳞毛蒝科 Dryopteridaceae \\
\hline 网藤䔊 Lomagramma matthewii (Ching) Holttum & 单裂缝 Monolete & 藤薜科 Lomariopsidaceae & 鳞毛硕科 Dryopteridaceae \\
\hline 墨脱网藤蟩 Lomagramma medogensis Ching \& Y. X. Lin & 单裂缝 Monolete & 藤茨科 Lomariopsidaceae & 鳞毛蕨科 Dryopteridaceae \\
\hline 云南网藤脄 Lomagramma yunnanensis Ching & 单裂缝 Monolete & 藤䒴科 Lomariopsidaceae & 鳞毛蒝科 Dryopteridaceae \\
\hline 滇桂三相葓 Ataxipteris dianguiensis W. M. Chu \& H. G. Zhou & 单裂缝 Monolete & 叉媭科 Aspidiaceae & 鳞毛硕科 Dryopteridaceae \\
\hline 三相菜 Ataxipteris sinii (Ching) Holttum & 单裂缝 Monolete & 叉濒科 Aspidiaceae & 鳞毛蕨科 Dryopteridaceae \\
\hline 海南肋毛偋 Ctenitis decurrentipinnata (Ching) Ching & 单裂缝 Monolete & 叉蒴科 Aspidiaceae & 鳞毛烣科 Dryopteridaceae \\
\hline 二型肋毛蒝 Ctenitis dingnanensis Ching & 单裂缝 Monolete & 叉蒴科 Aspidiaceae & 鳞毛蒝科 Dryopteridaceae \\
\hline 直鳞肋毛锁 Ctenitis eatonii (Baker) Ching & 单裂缝 Monolete & 叉蒴科 Aspidiaceae & 鳞毛蕨科 Dryopteridaceae \\
\hline 桂滇肋毛䕬 Ctenitis guidianensis H. G. Zhou \& W. M. Chu & 单裂缝 Monolete & 叉蒴科 Aspidiaceae & 鳞毛烣科 Dryopteridaceae \\
\hline 银毛肋毛硕 Ctenitis mannii (Hope) Ching & 单裂缝 Monolete & 叉硕科 Aspidiaceae & 鳞毛菜科 Dryopteridaceae \\
\hline 虹鳞肋毛葓 Ctenitis membranifolia R. C. Ching \& C. H. Wang & 单裂缝 Monolete & 叉蒴科 Aspidiaceae & 鳞毛蕨科 Dryopteridaceae \\
\hline 茂兰肋毛钼 Ctenitis molanensis P. S. Wang & 单裂缝 Monolete & 叉蒴科 Aspidiaceae & 鳞毛烣科 Dryopteridaceae \\
\hline 棕鳞肋毛葓 Ctenitis pseudorhodolepis Ching \& Chu H. Wang & 单裂缝 Monolete & 叉蒴科 Aspidiaceae & 鳞毛蕨科 Dryopteridaceae \\
\hline 亮鳞肋毛锁 Ctenitis subglandulosa (Hance) Ching & 单裂缝 Monolete & 叉葓科 Aspidiaceae & 鳞毛蕨科 Dryopteridaceae \\
\hline 云南肋毛蒴 Ctenitis yunnanensis Ching \& Chu H. Wang & 单裂缝 Monolete & 叉蒴科 Aspidiaceae & 鳞毛烣科 Dryopteridaceae \\
\hline 顶囊轴鳞䕬 Dryopsis apiciflora (Wall. ex Mett.) Holttum \& & 单裂缝 Monolete & 叉葓科 Aspidiaceae & 鳞毛蒝科 Dryopteridaceae \\
\hline \multicolumn{4}{|l|}{ Edwards } \\
\hline 膜边轴鳞蕨 Dryopsis clarkei (Baker) Holttum \& P. J. Edwards & 单裂缝 Monolete & 叉蒴科 Aspidiaceae & 鳞毛蕨科 Dryopteridaceae \\
\hline 密羽轴鳞脒 Dryopsis contigua (Ching) Holttum \& P. J. & 单裂缝 Monolete & 叉蒴科 Aspidiaceae & 鳞毛烣科 Dryopteridaceae \\
\hline \multicolumn{4}{|l|}{ Edwards } \\
\hline 粗柄轴鳞菜 Dryopsis crassirachis (Ching) Holttum \& P. J. & 单裂缝 Monolete & 叉濒科 Aspidiaceae & 鳞毛蒝科 Dryopteridaceae \\
\hline
\end{tabular}


魏雪苹，张宪春．蒴类植物不同狍子裂缝类型在中国的分布格局. 生物多样性，2016，24(10)：1129-1134 http://www. biodiversity - science. net/CN/10. 17520/biods. 2016219

\begin{tabular}{|c|c|c|c|}
\hline $\begin{array}{l}\text { 物种 } \\
\text { Species }\end{array}$ & $\begin{array}{l}\text { 孢子裂缝类型 } \\
\text { Spore apertures styles }\end{array}$ & $\begin{array}{l}\text { 科名 Family (秦仁 } \\
\text { 昌,1978a, b) }\end{array}$ & $\begin{array}{l}\text { 科名 Family (Smith et al., } \\
\text { 2006; Christenhusz et al, } \\
\text { 2011; 张宪春等, 2013) }\end{array}$ \\
\hline \multicolumn{4}{|l|}{ Edwards } \\
\hline 波边轴鳞葓 Dryopsis crenata (Ching) Holttum \& P. J. Edwards & 单裂缝 Monolete & 叉蕨科 Aspidiaceae & 鳞毛蕨科 Dryopteridaceae \\
\hline $\begin{array}{l}\text { 独龙江轴鳞蕨 Dryopsis dulongensis (S. K. Wu \& X. Cheng) S. } \\
\text { Y. Dong }\end{array}$ & 单裂缝 Monolete & 叉蕨科 Aspidiaceae & 鳞毛蕨科 Dryopteridaceae \\
\hline $\begin{array}{l}\text { 异鳞轴鳞濒 Dryopsis heterolaena (C. Chr.) Holttum \& P. J. } \\
\text { Edwards }\end{array}$ & 单裂缝 Monolete & 叉蕨科 Aspidiaceae & 鳞毛苲科 Dryopteridaceae \\
\hline $\begin{array}{l}\text { 密羽轴鳞硕 Dryopsis kawakamii (Hayata) Holttum \& P. J. } \\
\text { Edwards }\end{array}$ & 单裂缝 Monolete & 叉蕨科 Aspidiaceae & 鳞毛蕨科 Dryopteridaceae \\
\hline $\begin{array}{l}\text { 泡鳞轴鳞茊 Dryopsis mariformis (Rosenst.) Holttum \& P. J. } \\
\text { Edwards }\end{array}$ & 单裂缝 Monolete & 叉蕨科 Aspidiaceae & 鳞毛蕨科 Dryopteridaceae \\
\hline $\begin{array}{l}\text { 榈鳞轴鳞脄 Dryopsis maximowicziana (Miq.) Holttum \& P. J. } \\
\text { Edwards }\end{array}$ & 单裂缝 Monolete & 叉蕨科 Aspidiaceae & 鳞毛蕨科 Dryopteridaceae \\
\hline 巢形轴鳞蕨 Dryopsis nidus (Baker) Holttum \& P. J. Edwards & 单裂缝 Monolete & 叉蒴科 Aspidiaceae & 鳞毛蕨科 Dryopteridaceae \\
\hline $\begin{array}{l}\text { 怒山轴鳞蕨 Dryopsis silaensis (Ching) Holttum \& P. J. } \\
\text { Edwards }\end{array}$ & 单裂缝 Monolete & 叉茨科 Aspidiaceae & 鳞毛锁科 Dryopteridaceae \\
\hline $\begin{array}{l}\text { 大鳞轴鳞蔽 Dryopsis sphaeropteroides (Baker) Holttum \& P. J. } \\
\text { Edwards }\end{array}$ & 单裂缝 Monolete & 叉鄀科 Aspidiaceae & 鳞毛蕨科 Dryopteridaceae \\
\hline $\begin{array}{l}\text { 疏羽轴鳞蕨 Dryopsis submariformis (Ching \& Chu H. Wang) } \\
\text { Holttum \& P. J. Edwards }\end{array}$ & 单裂缝 Monolete & 叉鄀科 Aspidiaceae & 鳞毛蕨科 Dryopteridaceae \\
\hline $\begin{array}{l}\text { 台湾轴鳞嵚 Dryopsis transmorrisonensis (Hayata) Holttum \& } \\
\text { P. J. Edwards }\end{array}$ & 单裂缝 Monolete & 叉蕨科 Aspidiaceae & 鳞毛鄀科 Dryopteridaceae \\
\hline 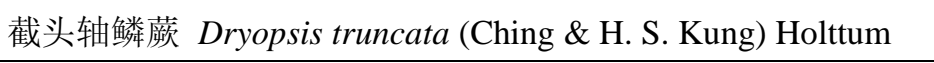 & 单裂缝 Monolete & 叉蕨科 Aspidiaceae & 鳞毛葓科 Dryopteridaceae \\
\hline
\end{tabular}




\begin{tabular}{|c|c|c|c|}
\hline $\begin{array}{l}\text { 物种 } \\
\text { Species }\end{array}$ & $\begin{array}{l}\text { 孢子裂缝类型 } \\
\text { Spore apertures styles }\end{array}$ & $\begin{array}{l}\text { 科名 Family (秦仁 } \\
\text { 昌,1978a, b) }\end{array}$ & $\begin{array}{l}\text { 科名 Family (Smith et al., } \\
\text { 2006; Christenhusz et al, } \\
\text { 2011; 张宪春等, 2013) }\end{array}$ \\
\hline 梵净山轴鳞蕨 Dryopsis wantsingshanica (Ching \& Shing) & 单裂缝 Monolete & 叉蕨科 Aspidiaceae & 鳞毛蕨科 Dryopteridaceae \\
\hline \multicolumn{4}{|l|}{ Holttum \& P. J. Edwards } \\
\hline 傅氏拟鳞毛蕨 Dryopsis $\times$ fauriei Holttum \& P. J. Edwards & 单裂缝 Monolete & 叉蕨科 Aspidiaceae & 鳞毛蕨科 Dryopteridaceae \\
\hline 云南节毛蕨 Lastreopsis microlepioides (Ching) W. M. Chu \& & 单裂缝 Monolete & 叉蕨科 Aspidiaceae & 鳞毛蕨科 Dryopteridaceae \\
\hline \multicolumn{4}{|l|}{ Z. R. He } \\
\hline 海南节毛蕨 Lastreopsis subrecedens Ching & 单裂缝 Monolete & 叉蕨科 Aspidiaceae & 鳞毛蕨科 Dryopteridaceae \\
\hline 台湾节毛蕨 Lastreopsis tenera (R. Brown) Tindale & 单裂缝 Monolete & 叉蕨科 Aspidiaceae & 鳞毛䓄科 Dryopteridaceae \\
\hline 海南符藤蒴 Teratophyllum hainanense S. Y. Dong \& X. C. & 单裂缝 Monolete & 水龙骨科 Polypodiaceae & 鳞毛葓科 Dryopteridaceae \\
\hline \multicolumn{4}{|l|}{ Zhang } \\
\hline 中华藤嵚 Lomariopsis chinensis Ching & 单裂缝 Monolete & 藤蕨科 Lomariopsidaceae & 藤蕨科 Lomariopsidaceae \\
\hline 藤嵚 Lomariopsis cochinchinensis Fée & 单裂缝 Monolete & 藤蕨科 Lomariopsidaceae & 藤蕨科 Lomariopsidaceae \\
\hline 美丽藤蕨 Lomariopsis spectabilis (Kunze) Mett. & 单裂缝 Monolete & 藤蕨科 Lomariopsidaceae & 藤蕨科 Lomariopsidaceae \\
\hline 长叶肾蕨 Nephrolepis biserrata (Sw.) Schott & 单裂缝 Monolete & 肾蕨科 Nephrolepidaceae & 肾偋科 Nephrolepidaceae \\
\hline 耳叶肾偋 Nephrolepis biserrata var. auriculata Ching & 单裂缝 Monolete & 肾偋科 Nephrolepidaceae & 肾偋科 Nephrolepidaceae \\
\hline 肾蕨 Nephrolepis cordifolia (L.) C. Presl & 单裂缝 Monolete & 肾蕨科 Nephrolepidaceae & 肾蕨科 Nephrolepidaceae \\
\hline 薄叶肾蒝 Nephrolepis delicatula (Decne.) Pic. Serm. & 单裂缝 Monolete & 肾葓科 Nephrolepidaceae & 肾蕨科 Nephrolepidaceae \\
\hline 镰叶肾葓 Nephrolepis falcata (Cav.) C. Chr. & 单裂缝 Monolete & 肾蕨科 Nephrolepidaceae & 肾蕨科 Nephrolepidaceae \\
\hline 毛叶肾蕨 Nephrolepis hirsutula (Forst.) C. Presl & 单裂缝 Monolete & 肾偋科 Nephrolepidaceae & 肾偋科 Nephrolepidaceae \\
\hline 爬树蕨 Arthropteris palisotii (Desv.) Alston & 单裂缝 Monolete & 肾蕨科 Nephrolepidaceae & 叉蕨科 Tectariaceae \\
\hline 顶果轴脉鄺 Ctenitopsis acrocarpa Ching & 单裂缝 Monolete & 叉蒴科 Aspidiaceae & 叉蕨科 Tectariaceae \\
\hline 中华轴脉䲞 Ctenitopsis chinensis Ching \& Chu H. Wang & 单裂缝 Monolete & 叉蒴科 Aspidiaceae & 叉偋科 Tectariaceae \\
\hline 毛叶轴脉蕨 Ctenitopsis devexa (Kunze ex Mett.) Ching \& Chu & 单裂缝 Monolete & 叉蕨科 Aspidiaceae & 叉蕨科 Tectariaceae \\
\hline
\end{tabular}




\begin{tabular}{|c|c|c|c|}
\hline $\begin{array}{l}\text { 物种 } \\
\text { Species }\end{array}$ & $\begin{array}{l}\text { 孢子裂缝类型 } \\
\text { Spore apertures styles }\end{array}$ & $\begin{array}{l}\text { 科名 Family (秦仁 } \\
\text { 昌,1978a, b) }\end{array}$ & $\begin{array}{l}\text { 科名 Family (Smith et al., } \\
\text { 2006; Christenhusz et al, } \\
\text { 2011; 张宪春等, 2013) }\end{array}$ \\
\hline \multicolumn{4}{|l|}{ H. Wang } \\
\hline 薄叶轴脉偋 Ctenitopsis dissecta (Forst.) Ching & 单裂缝 Monolete & 叉蕨科 Aspidiaceae & 叉蕨科 Tectariaceae \\
\hline 黑鳞轴脉䕨 Ctenitopsis fuscipes (Wall. ex Bedd.) Ching & 单裂缝 Monolete & 叉蕨科 Aspidiaceae & 叉蕨科 Tectariaceae \\
\hline 海南轴脉偋 Ctenitopsis hainanensis Ching et Chu H. Wang & 单裂缝 Monolete & 叉蒴科 Aspidiaceae & 叉蒴科 Tectariaceae \\
\hline 硕大轴脉偋 Ctenitopsis ingens (Atkinson ex Clarke) Ching & 单裂缝 Monolete & 叉蒴科 Aspidiaceae & 叉蒴科 Tectariaceae \\
\hline 台湾轴脉蕨 Ctenitopsis kusukusensis (Hayata) C. Chr. & 单裂缝 Monolete & 叉蕨科 Aspidiaceae & 叉蕨科 Tectariaceae \\
\hline 粤北轴脉嵚 Ctenitopsis matthewi (Ching) Ching & 单裂缝 Monolete & 叉蕨科 Aspidiaceae & 叉蕨科 Tectariaceae \\
\hline 轴脉蕨 Ctenitopsis sagenioides (Mett.) Ching & 单裂缝 Monolete & 叉蕨科 Aspidiaceae & 叉蕨科 Tectariaceae \\
\hline 光叶轴脉脄 Ctenitopsis sagenioides var. glabrescens Ching \& & 单裂缝 Monolete & 叉蕨科 Aspidiaceae & 叉蕨科 Tectariaceae \\
\hline \multicolumn{4}{|l|}{ Chu H. Wang } \\
\hline 棕毛轴脉败 Ctenitopsis setulosa (Baker) C. Chr. ex Tardieu \& & 单裂缝 Monolete & 叉蕨科 Aspidiaceae & 叉蕨科 Tectariaceae \\
\hline \multicolumn{4}{|l|}{ C. Chr. } \\
\hline 无盖轴脉蓱 Ctenitopsis subsageniacea (Christ) Ching & 单裂缝 Monolete & 叉蕨科 Aspidiaceae & 叉蕨科 Tectariaceae \\
\hline 蒿兴 Ctenopteris curtisii (Baker) Tagawa & 单裂缝 Monolete & 禾叶蕨科 Grammitidaceae & 叉蕨科 Tectariaceae \\
\hline 拟虎尾蒿荻 Ctenopteris merrittii (Copel.) Tagawa & 单裂缝 Monolete & 禾叶鄀科 Grammitidaceae & 叉蕨科 Tectariaceae \\
\hline 南洋蒿蕨 Ctenopteris mollicoma (Nees \& Blume) Kunze & 单裂缝 Monolete & 禾叶蕨科 Grammitidaceae & 叉蕨科 Tectariaceae \\
\hline 光滑蒿蕨 Ctenopteris moultonii (Copel.) C. Chr. \& Tardieu & 单裂缝 Monolete & 禾叶蕨科 Grammitidaceae & 叉蕨科 Tectariaceae \\
\hline 虎尾蒿蕨 Ctenopteris subfalcata (Blume) Kunze & 单裂缝 Monolete & 禾叶蕨科 Grammitidaceae & 叉蕨科 Tectariaceae \\
\hline 细叶蒿蕨 Ctenopteris tenuisecta (Blume) J. Sm. & 单裂缝 Monolete & 禾叶蕨科 Grammitidaceae & 叉蕨科 Tectariaceae \\
\hline 沙皮蕨 Hemigramma decurrens (Hook.) Copel. & 单裂缝 Monolete & 叉蕨科 Aspidiaceae & 叉蕨科 Tectariaceae \\
\hline 台湾黄腺羽蕨 Pleocnemia cumingiana C. Presl & 单裂缝 Monolete & 叉蒴科 Aspidiaceae & 叉蕨科 Tectariaceae \\
\hline 黄腺羽蕨 Pleocnemia winitii Holttum & 单裂缝 Monolete & 叉蕨科 Aspidiaceae & 叉蕨科 Tectariaceae \\
\hline
\end{tabular}




\begin{tabular}{|c|c|c|c|}
\hline $\begin{array}{l}\text { 物种 } \\
\text { Species }\end{array}$ & $\begin{array}{l}\text { 孢子裂缝类型 } \\
\text { Spore apertures styles }\end{array}$ & $\begin{array}{l}\text { 科名 Family (秦仁 } \\
\text { 昌,1978a, b) }\end{array}$ & $\begin{array}{l}\text { 科名 Family (Smith et al., } \\
\text { 2006; Christenhusz et al, } \\
\text { 2011; 张宪春等, 2013) }\end{array}$ \\
\hline 毛轴牙蕨 Pteridrys australis Ching & 单裂缝 Monolete & 叉蕨科 Aspidiaceae & 叉蕨科 Tectariaceae \\
\hline 薄叶牙蕨 Pteridrys cnemidaria (Christ) C. Chr. \& Ching & 单裂缝 Monolete & 叉嵚科 Aspidiaceae & 叉濒科 Tectariaceae \\
\hline 云贵牙蕨 Pteridrys lofouensis (Christ) C. Chr. \& Ching & 单裂缝 Monolete & 叉嵚科 Aspidiaceae & 叉蒴科 Tectariaceae \\
\hline 地耳茨 Quercifilix zeylanica (Houtt.) Copel. & 单裂缝 Monolete & 叉䕬科 Aspidiaceae & 叉蒴科 Tectariaceae \\
\hline 大齿叉葓 Tectaria coadunata (Wall. ex Hook. \& Grev.) C. Chr. & 单裂缝 Monolete & 叉嵚科 Aspidiaceae & 叉蒴科 Tectariaceae \\
\hline 柔毛大齿叉蒴 Tectaria coadunata var. hirsuta Holttum & 单裂缝 Monolete & 叉藃科 Aspidiaceae & 叉偋科 Tectariaceae \\
\hline 下延叉茨 Tectaria decurrens (C. Presl) Copel. & 单裂缝 Monolete & 叉蒴科 Aspidiaceae & 叉偋科 Tectariaceae \\
\hline 大叶叉蕨 Tectaria dubia (Bedd.) Ching & 单裂缝 Monolete & 叉蒴科 Aspidiaceae & 叉蒴科 Tectariaceae \\
\hline 黑柄叉茨 Tectaria ebenina (C. Chr.) Ching & 单裂缝 Monolete & 叉嵚科 Aspidiaceae & 叉蒴科 Tectariaceae \\
\hline 芽胞叉濒 Tectaria fauriei Tagawa & 单裂缝 Monolete & 叉濒科 Aspidiaceae & 叉濒科 Tectariaceae \\
\hline 鳞柄叉蒝 Tectaria griffithii (Baker) C. Chr. & 单裂缝 Monolete & 叉嵚科 Aspidiaceae & 叉濒科 Tectariaceae \\
\hline 粗齿叉蕨 Tectaria grossedentata Ching \& Chu H. Wang & 单裂缝 Monolete & 叉嵚科 Aspidiaceae & 叉嵚科 Tectariaceae \\
\hline 河口叉蕨 Tectaria hekouensis Ching \& Chu H. Wang & 单裂缝 Monolete & 叉藃科 Aspidiaceae & 叉蒴科 Tectariaceae \\
\hline 思茅叉颗 Tectaria herpetocaulos Holttum & 单裂缝 Monolete & 叉嵚科 Aspidiaceae & 叉濒科 Tectariaceae \\
\hline 疮状叉偋 Tectaria impressa (Fée) Holttum & 单裂缝 Monolete & 叉嵚科 Aspidiaceae & 叉嵚科 Tectariaceae \\
\hline 贵州叉蕨 Tectaria kweichowensis Ching \& Chu H. Wang & 单裂缝 Monolete & 叉藃科 Aspidiaceae & 叉蒴科 Tectariaceae \\
\hline 剑叶叉葓 Tectaria leptophylla (C. H. Wright) Ching & 单裂缝 Monolete & 叉嵚科 Aspidiaceae & 叉濒科 Tectariaceae \\
\hline 绿春三叉偋 Tectaria luchunensis S. K. Wu & 单裂缝 Monolete & 叉蒴科 Aspidiaceae & 叉偋科 Tectariaceae \\
\hline 中形叉嵚 Tectaria media Ching & 单裂缝 Monolete & 叉藃科 Aspidiaceae & 叉蒴科 Tectariaceae \\
\hline 掌状叉葓 Tectaria morsei( Baker) P. J. Edwards ex S. Y. Dong & 单裂缝 Monolete & 叉斴科 Aspidiaceae & 叉硕科 Tectariaceae \\
\hline 条裂叉䔊 Tectaria phaeocaulis (Rosenst.) C. Chr. & 单裂缝 Monolete & 叉嵚科 Aspidiaceae & 叉蒴科 Tectariaceae \\
\hline 多形叉蒴 Tectaria polymorpha (Wall. ex Hook.) Copel. & 单裂缝 Monolete & 叉偋科 Aspidiaceae & 叉偋科 Tectariaceae \\
\hline
\end{tabular}


魏雪苹，张宪春．蕨类植物不同孢子裂缝类型在中国的分布格局．生物多样性，2016，24(10)：1129-1134 http://www. biodiversity - science. net/CN/10. 17520/biods. 2016219

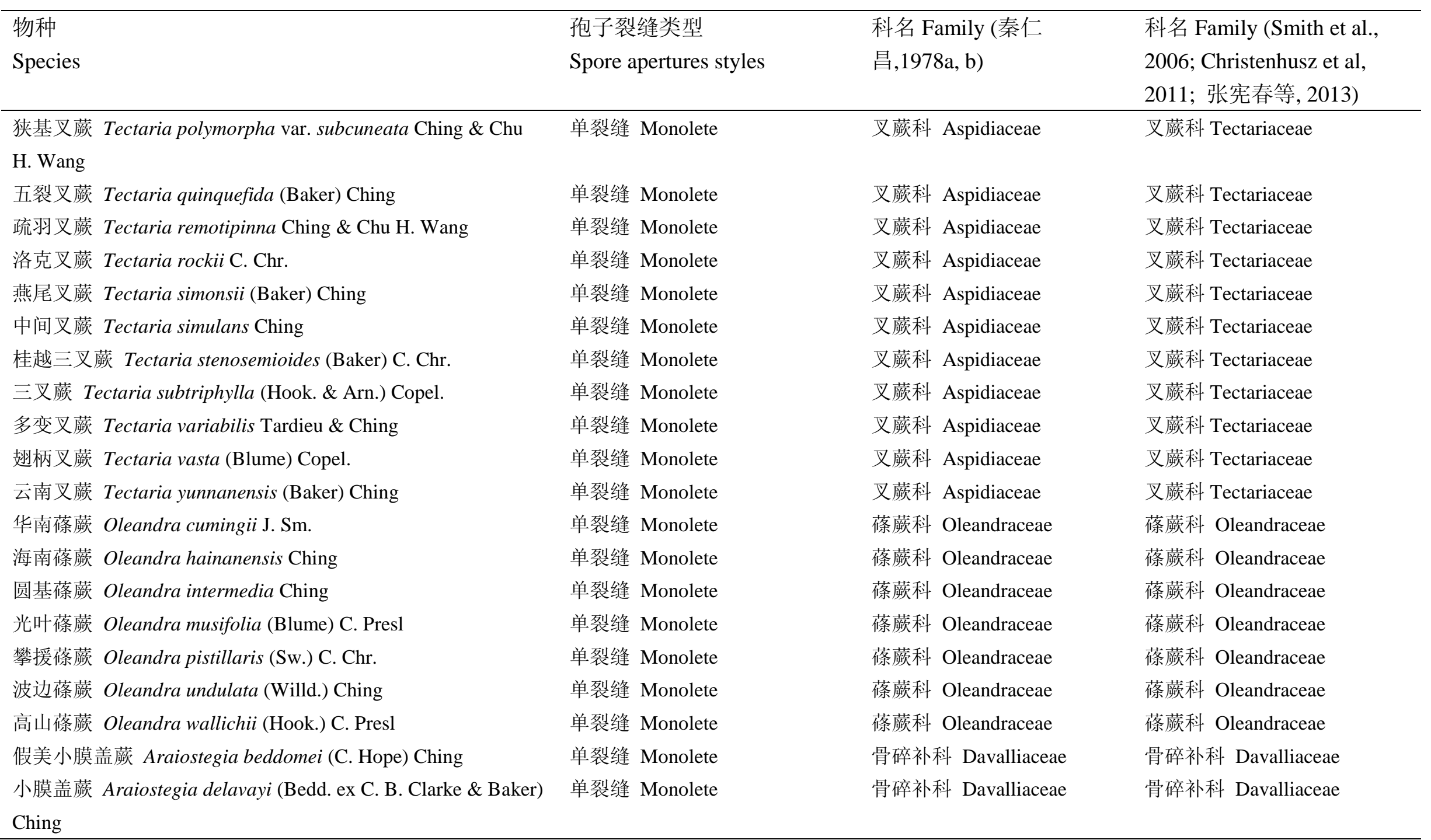




\begin{tabular}{|c|c|c|c|}
\hline $\begin{array}{l}\text { 物种 } \\
\text { Species }\end{array}$ & $\begin{array}{l}\text { 孢子裂缝类型 } \\
\text { Spore apertures styles }\end{array}$ & $\begin{array}{l}\text { 科名 Family (秦仁 } \\
\text { 昌,1978a, b) }\end{array}$ & $\begin{array}{l}\text { 科名 Family (Smith et al., } \\
\text { 2006; Christenhusz et al, } \\
\text { 2011; 张宪春等, 2013) }\end{array}$ \\
\hline 细裂小膜盖偋 Araiostegia faberiana (C. Chr.) Ching & 单裂缝 Monolete & 骨碎补科 Davalliaceae & 骨碎补科 Davalliaceae \\
\hline 宿枝小膜盖蘐 Araiostegia hookeri (Bedd.) Ching & 单裂缝 Monolete & 骨碎补科 Davalliaceae & 骨碎补科 Davalliaceae \\
\hline 绿叶小膜盖蕨 Araiostegia imbricata Ching & 单裂缝 Monolete & 骨碎补科 Davalliaceae & 骨碎补科 Davalliaceae \\
\hline 大膜盖䓲 Araiostegia immersa (Wall. ex Hook.) C. Presl & 单裂缝 Monolete & 骨碎补科 Davalliaceae & 骨碎补科 Davalliaceae \\
\hline 台湾小膜盖蕨 Araiostegia parvipinnata (Hayata) Copel. & 单裂缝 Monolete & 骨碎补科 Davalliaceae & 骨碎补科 Davalliaceae \\
\hline 鳞轴小膜盖蕨 Araiostegia perdurans (Christ) Copel. & 单裂缝 Monolete & 骨碎补科 Davalliaceae & 骨碎补科 Davalliaceae \\
\hline 长片小膜盖烣 Araiostegia pseudocystopteris (Kunze) Copel. & 单裂缝 Monolete & 骨碎补科 Davalliaceae & 骨碎补科 Davalliaceae \\
\hline 美小膜盖嵚 Araiostegia pulchra (D. Don) Copel. & 单裂缝 Monolete & 骨碎补科 Davalliaceae & 骨碎补科 Davalliaceae \\
\hline 云南小膜盖蕨 Araiostegia yunnanensis (Christ) Copel. & 单裂缝 Monolete & 骨碎补科 Davalliaceae & 骨碎补科 Davalliaceae \\
\hline 云桂骨碎补 Davallia amabilis Ching & 单裂缝 Monolete & 骨碎补科 Davalliaceae & 骨碎补科 Davalliaceae \\
\hline 华南骨碎补 Davallia austrosinica Ching & 单裂缝 Monolete & 骨碎补科 Davalliaceae & 骨碎补科 Davalliaceae \\
\hline 麻栗坡骨碎补 Davallia brevisora Ching & 单裂缝 Monolete & 骨碎补科 Davalliaceae & 骨碎补科 Davalliaceae \\
\hline 云南骨碎补 Davallia cylindrica Ching & 单裂缝 Monolete & 骨碎补科 Davalliaceae & 骨碎补科 Davalliaceae \\
\hline 假脉骨碎补 Davallia denticulata (Burm. f. ) Mett. ex Kuhn & 单裂缝 Monolete & 骨碎补科 Davalliaceae & 骨碎补科 Davalliaceae \\
\hline 大叶骨碎补 Davallia formosana Hayata & 单裂缝 Monolete & 骨碎补科 Davalliaceae & 骨碎补科 Davalliaceae \\
\hline 骨碎补 Davallia mariesii T. Moore ex Baker & 单裂缝 Monolete & 骨碎补科 Davalliaceae & 骨碎补科 Davalliaceae \\
\hline 阔叶骨碎补 Davallia solida (Forst.) Sw. & 单裂缝 Monolete & 骨碎补科 Davalliaceae & 骨碎补科 Davalliaceae \\
\hline 长叶阴石硕 Humata assamica (Bedd.) C. Chr. & 单裂缝 Monolete & 骨碎补科 Davalliaceae & 骨碎补科 Davalliaceae \\
\hline 阿里山阴石蕨 Humata chrysanthemifolia Hayata & 单裂缝 Monolete & 骨碎补科 Davalliaceae & 骨碎补科 Davalliaceae \\
\hline 杯盖阴石硕 Humata griffithiana (Hook.) C. Chr. & 单裂缝 Monolete & 骨碎补科 Davalliaceae & 骨碎补科 Davalliaceae \\
\hline 马来阴石蕨 Humata pectinata (Sm.) Desv. & 单裂缝 Monolete & 骨碎补科 Davalliaceae & 骨碎补科 Davalliaceae \\
\hline 半圆盖阴石菜 Humata platylepis (Baker) Ching & 单裂缝 Monolete & 骨碎补科 Davalliaceae & 骨碎补科 Davalliaceae \\
\hline
\end{tabular}




\begin{tabular}{|c|c|c|c|}
\hline $\begin{array}{l}\text { 物种 } \\
\text { Species }\end{array}$ & $\begin{array}{l}\text { 孢子裂缝类型 } \\
\text { Spore apertures styles }\end{array}$ & $\begin{array}{l}\text { 科名 Family (秦仁 } \\
\text { 昌,1978a, b) }\end{array}$ & $\begin{array}{l}\text { 科名 Family (Smith et al., } \\
\text { 2006; Christenhusz et al, } \\
\text { 2011; 张宪春等, 2013) }\end{array}$ \\
\hline 阴石蕨 Humata repens (L. f.) J. Small ex Diels & 单裂缝 Monolete & 骨碎补科 Davalliaceae & 骨碎补科 Davalliaceae \\
\hline 鳞叶阴石蕨 Humata trifoliata Cav. & 单裂缝 Monolete & 骨碎补科 Davalliaceae & 骨碎补科 Davalliaceae \\
\hline 圆盖阴石蕨 Humata tyermannii T. Moore & 单裂缝 Monolete & 骨碎补科 Davalliaceae & 骨碎补科 Davalliaceae \\
\hline 热带阴石蕂 Humata vestita (Blume) T. Moore & 单裂缝 Monolete & 骨碎补科 Davalliaceae & 骨碎补科 Davalliaceae \\
\hline 秦氏假钻毛萨 Paradavallodes chingiae (Ching) Ching & 单裂缝 Monolete & 骨碎补科 Davalliaceae & 骨碎补科 Davalliaceae \\
\hline 膜叶假钻毛蕨 Paradavallodes membranulosum (Wall. ex & 单裂缝 Monolete & 骨碎补科 Davalliaceae & 骨碎补科 Davalliaceae \\
\hline \multicolumn{4}{|l|}{ Hook.) Ching } \\
\hline 假钻毛蒴 Paradavallodes multidentatum (Hook. \& Baker) & 单裂缝 Monolete & 骨碎补科 Davalliaceae & 骨碎补科 Davalliaceae \\
\hline \multicolumn{4}{|l|}{ Ching } \\
\hline 顶生剑蕨 Loxogramme acroscopa C. Chr. & 三裂缝 Trilete & 剑蕨科 Loxogrammaceae & 水龙骨科 Polypodiaceae \\
\hline 黑鳞剑菜 Loxogramme assimilis Ching & 三裂缝 Trilete & 剑硕科 Loxogrammaceae & 水龙骨科 Polypodiaceae \\
\hline 中华剑蕨 Loxogramme chinensis Ching & 三裂缝 Trilete & 剑䓲科 Loxogrammaceae & 水龙骨科 Polypodiaceae \\
\hline 西藏剑菜 Loxogramme cuspidata (Zenker) M. G. Price & 单裂缝 Monolete & 剑蕨科 Loxogrammaceae & 水龙骨科 Polypodiaceae \\
\hline 褐柄剑偋 Loxogramme duclouxii Chirst & 三裂缝 Trilete & 剑烣科 Loxogrammaceae & 水龙骨科 Polypodiaceae \\
\hline 台湾剑烣 Loxogramme formosana Nakai & 单裂缝 Monolete & 剑蕨科 Loxogrammaceae & 水龙骨科 Polypodiaceae \\
\hline 匙叶剑偋 Loxogramme grammitoides (Baker) C. Chr. & 三裂缝 Trilete & 剑蕨科 Loxogrammaceae & 水龙骨科 Polypodiaceae \\
\hline 内卷剑硕 Loxogramme involuta (D. Don) C. Presl & 单裂缝 Monolete & 剑烣科 Loxogrammaceae & 水龙骨科 Polypodiaceae \\
\hline 老街剑偋 Loxogramme lankokiensis (Rosenst.) C. Chr. & 三裂缝 Trilete & 剑蕨科 Loxogrammaceae & 水龙骨科 Polypodiaceae \\
\hline 拟内卷剑䓲 Loxogramme porcata M. G. Price & 单裂缝 Monolete & 剑蕨科 Loxogrammaceae & 水龙骨科 Polypodiaceae \\
\hline 柳叶剑蕨 Loxogramme salicifolia (Makino) Makino & 单裂缝 Monolete & 剑蕨科 Loxogrammaceae & 水龙骨科 Polypodiaceae \\
\hline 雨蒴 Gymnogrammitis dareiformis (Hook.) Ching ex Tardieu \& & 单裂缝 Monolete & 雨蕨科 & 水龙骨科 Polypodiaceae \\
\hline C. Chr. & & Gymnogrammitidaceae & \\
\hline
\end{tabular}




\begin{tabular}{|c|c|c|c|}
\hline $\begin{array}{l}\text { 物种 } \\
\text { Species }\end{array}$ & $\begin{array}{l}\text { 孢子裂缝类型 } \\
\text { Spore apertures styles }\end{array}$ & $\begin{array}{l}\text { 科名 Family (秦仁 } \\
\text { 昌,1978a, b) }\end{array}$ & $\begin{array}{l}\text { 科名 Family (Smith et al., } \\
\text { 2006; Christenhusz et al, } \\
\text { 2011; 张宪春等, 2013) }\end{array}$ \\
\hline 连珠蒴 Aglaomorpha meyeniana Schott & 单裂缝 Monolete & 槲蕨科 Drynariaceae & 水龙骨科 Polypodiaceae \\
\hline 团叶葪蕨 Drynaria bonii Christ & 单裂缝 Monolete & 槲蒴科 Drynariaceae & 水龙骨科 Polypodiaceae \\
\hline 川滇葪硕 Drynaria delavayi Christ & 单裂缝 Monolete & 槲荻科 Drynariaceae & 水龙骨科 Polypodiaceae \\
\hline 毛葪菜 Drynaria mollis Bedd. & 单裂缝 Monolete & 檞葓科 Drynariaceae & 水龙骨科 Polypodiaceae \\
\hline 小葪蕨 Drynaria parishii (Bedd.) Bedd. & 单裂缝 Monolete & 檞葓科 Drynariaceae & 水龙骨科 Polypodiaceae \\
\hline 石莲姜葪蕨 Drynaria propinqua (Wall. ex Mett.) J. Sm. ex & 单裂缝 Monolete & 槲鄀科 Drynariaceae & 水龙骨科 Polypodiaceae \\
\hline \multicolumn{4}{|l|}{ Bedd. } \\
\hline 栋叶葪锁 Drynaria quercifolia (L.) J. Sm. & 单裂缝 Monolete & 槲蕨科 Drynariaceae & 水龙骨科 Polypodiaceae \\
\hline 硬叶葪蕨 Drynaria rigidula (Sw.) Bedd. & 单裂缝 Monolete & 檞蕨科 Drynariaceae & 水龙骨科 Polypodiaceae \\
\hline 葪嵚 Drynaria roosii Nakaike & 单裂缝 Monolete & 槲蕨科 Drynariaceae & 水龙骨科 Polypodiaceae \\
\hline 秦岭桷蕨 Drynaria sinica Diels & 单裂缝 Monolete & 槲蒴科 Drynariaceae & 水龙骨科 Polypodiaceae \\
\hline 顶育蕨 Photinopteris acuminata C. V. Morton & 单裂缝 Monolete & 檞蕨科 Drynariaceae & 水龙骨科 Polypodiaceae \\
\hline 崖姜薜 Pseudodrynaria coronans (Wall. ex Mett.) Ching & 单裂缝 Monolete & 檞蕨科 Drynariaceae & 水龙骨科 Polypodiaceae \\
\hline 鹿角蒝 Platycerium wallichii Hook. & 单裂缝 Monolete & 鹿角蒝科 Platyceriaceae & 水龙骨科 Polypodiaceae \\
\hline 尾状节肢蕨 Arthromeris caudata Ching \& Y. X. Lin & 单裂缝 Monolete & 水龙骨科 Polypodiaceae & 水龙骨科 Polypodiaceae \\
\hline 贯众叶节肢薜 Arthromeris cyrtomioides S.G. Lu \& C. D. Xu & 单裂缝 Monolete & 水龙骨科 Polypodiaceae & 水龙骨科 Polypodiaceae \\
\hline 美丽节肢脄 Arthromeris elegans Ching & 单裂缝 Monolete & 水龙骨科 Polypodiaceae & 水龙骨科 Polypodiaceae \\
\hline 片马节肢菜 Arthromeris elegans f. pianmaensis S. G. Lu & 单裂缝 Monolete & 水龙骨科 Polypodiaceae & 水龙骨科 Polypodiaceae \\
\hline 琉璃节肢蕨 Arthromeris himalayensis (Hook.) Ching & 单裂缝 Monolete & 水龙骨科 Polypodiaceae & 水龙骨科 Polypodiaceae \\
\hline 中间节肢薜 Arthromeris intermedia Ching & 单裂缝 Monolete & 水龙骨科 Polypodiaceae & 水龙骨科 Polypodiaceae \\
\hline 节肢䕬 Arthromeris lehmannii (Mett.) Ching & 单裂缝 Monolete & 水龙骨科 Polypodiaceae & 水龙骨科 Polypodiaceae \\
\hline 龙头节肢茨 Arthromeris lungtauensis Ching & 单裂缝 Monolete & 水龙骨科 Polypodiaceae & 水龙骨科 Polypodiaceae \\
\hline
\end{tabular}




\begin{tabular}{|c|c|c|c|}
\hline $\begin{array}{l}\text { 物种 } \\
\text { Species }\end{array}$ & $\begin{array}{l}\text { 孢子裂缝类型 } \\
\text { Spore apertures styles }\end{array}$ & $\begin{array}{l}\text { 科名 Family (秦仁 } \\
\text { 昌,1978a, b) }\end{array}$ & $\begin{array}{l}\text { 科名 Family (Smith et al., } \\
\text { 2006; Christenhusz et al, } \\
\text { 2011; 张宪春等, 2013) }\end{array}$ \\
\hline 多羽节肢菜 Arthromeris mairei (Brause) Ching & 单裂缝 Monolete & 水龙骨科 Polypodiaceae & 水龙骨科 Polypodiaceae \\
\hline 墨脱节肢硕 Arthromeris medogensis Ching \& Y. X. Lin & 单裂缝 Monolete & 水龙骨科 Polypodiaceae & 水龙骨科 Polypodiaceae \\
\hline 黑鳞节肢蕨 Arthromeris nigropaleacea S. G. Lu & 单裂缝 Monolete & 水龙骨科 Polypodiaceae & 水龙骨科 Polypodiaceae \\
\hline 柳叶节肢茨 Arthromeris salicifolia Ching \& Y. X. Lin & 单裂缝 Monolete & 水龙骨科 Polypodiaceae & 水龙骨科 Polypodiaceae \\
\hline 康定节肢茨 Arthromeris tatsienensis (Franch. \& Bureau ex & 单裂缝 Monolete & 水龙骨科 Polypodiaceae & 水龙骨科 Polypodiaceae \\
\hline \multicolumn{4}{|l|}{ Christ) Ching } \\
\hline 狭羽节肢荻 Arthromeris tenuicauda (Hook.) Ching & 单裂缝 Monolete & 水龙骨科 Polypodiaceae & 水龙骨科 Polypodiaceae \\
\hline 厚毛节肢菜 Arthromeris tomentosa W. M. Chu & 单裂缝 Monolete & 水龙骨科 Polypodiaceae & 水龙骨科 Polypodiaceae \\
\hline 单行节肢蕨 Arthromeris wallichiana (Spreng.) Ching & 单裂缝 Monolete & 水龙骨科 Polypodiaceae & 水龙骨科 Polypodiaceae \\
\hline 灰背节肢䕋 Arthromeris wardii (C. B. Clarke) Ching & 单裂缝 Monolete & 水龙骨科 Polypodiaceae & 水龙骨科 Polypodiaceae \\
\hline 显脉尖嘴嵚 Belvisia annamensis (C. Chr.) S. H. Fu & 单裂缝 Monolete & 水龙骨科 Polypodiaceae & 水龙骨科 Polypodiaceae \\
\hline 隐柄尖嘴蕨 Belvisia henryi (Hieron. ex C. Chr.) S. H. Fu & 单裂缝 Monolete & 水龙骨科 Polypodiaceae & 水龙骨科 Polypodiaceae \\
\hline 尖嘴蕨 Belvisia mucronata (Fée) Copel. & 单裂缝 Monolete & 水龙骨科 Polypodiaceae & 水龙骨科 Polypodiaceae \\
\hline 高平菜 Caobangia squamata A. R. Smith \& X. C. Zhang & 单裂缝 Monolete & 水龙骨科 Polypodiaceae & 水龙骨科 Polypodiaceae \\
\hline 戟蕨 Christiopteris tricuspis (Hook.) Christ & 单裂缝 Monolete & 水龙骨科 Polypodiaceae & 水龙骨科 Polypodiaceae \\
\hline 掌叶线嵚 Colysis digitata (Baker) Ching & 单裂缝 Monolete & 水龙骨科 Polypodiaceae & 水龙骨科 Polypodiaceae \\
\hline 异叶线荻 Colysis diversifolia W. M. Chu & 单裂缝 Monolete & 水龙骨科 Polypodiaceae & 水龙骨科 Polypodiaceae \\
\hline 线蕨 Colysis elliptica (Thunb.) Ching & 单裂缝 Monolete & 水龙骨科 Polypodiaceae & 水龙骨科 Polypodiaceae \\
\hline 曲边线蕨 Colysis elliptica var. flexiloba (Christ) L. Shi \& X. C. & 单裂缝 Monolete & 水龙骨科 Polypodiaceae & 水龙骨科 Polypodiaceae \\
\hline \multicolumn{4}{|l|}{ Zhang } \\
\hline 长柄变种 Colysis elliptica var. longipes (Ching) L. Shi \& X. C. & 单裂缝 Monolete & 水龙骨科 Polypodiaceae & 水龙骨科 Polypodiaceae \\
\hline
\end{tabular}




\begin{tabular}{|c|c|c|c|}
\hline $\begin{array}{l}\text { 物种 } \\
\text { Species }\end{array}$ & $\begin{array}{l}\text { 孢子裂缝类型 } \\
\text { Spore apertures styles }\end{array}$ & $\begin{array}{l}\text { 科名 Family (秦仁 } \\
\text { 昌,1978a, b) }\end{array}$ & $\begin{array}{l}\text { 科名 Family (Smith et al., } \\
\text { 2006; Christenhusz et al, } \\
\text { 2011; 张宪春等, 2013) }\end{array}$ \\
\hline $\begin{array}{l}\text { 滇浅蕨 Colysis elliptica var. pentaphylla (Baker) L. Shi \& X. C. } \\
\text { Zhang }\end{array}$ & 单裂缝 Monolete & 水龙骨科 Polypodiaceae & 水龙骨科 Polypodiaceae \\
\hline 宽羽线蕨 Colysis elliptica var. pothifolia Ching & 单裂缝 Monolete & 水龙骨科 Polypodiaceae & 水龙骨科 Polypodiaceae \\
\hline 断线荻 Colysis hemionitidea (C. Presl) C. Presl & 单裂缝 Monolete & 水龙骨科 Polypodiaceae & 水龙骨科 Polypodiaceae \\
\hline 贯叶线偋 Colysis hemitoma (Hance) Ching & 单裂缝 Monolete & 水龙骨科 Polypodiaceae & 水龙骨科 Polypodiaceae \\
\hline 矩圆线蕨 Colysis henryi (Baker) Ching & 单裂缝 Monolete & 水龙骨科 Polypodiaceae & 水龙骨科 Polypodiaceae \\
\hline 绿叶线層 Colysis leveillei (Christ) Ching & 单裂缝 Monolete & 水龙骨科 Polypodiaceae & 水龙骨科 Polypodiaceae \\
\hline 长柄线菜 Colysis pedunculata (Hook. \& Grev.) Ching & 单裂缝 Monolete & 水龙骨科 Polypodiaceae & 水龙骨科 Polypodiaceae \\
\hline 宽羽线苲 Colysis pothifolia (Buch.-Ham. ex D. Don) C. Presl & 单裂缝 Monolete & 水龙骨科 Polypodiaceae & 水龙骨科 Polypodiaceae \\
\hline 褐叶线嵚 Colysis wrightii (Hook.) Ching & 单裂缝 Monolete & 水龙骨科 Polypodiaceae & 水龙骨科 Polypodiaceae \\
\hline 新店线硕 Colysis $\times$ shintenensis (Hayata) H. Ito & 单裂缝 Monolete & 水龙骨科 Polypodiaceae & 水龙骨科 Polypodiaceae \\
\hline 抱树莲 Drymoglossum piloselloides (L.) C. Presl & 单裂缝 Monolete & 水龙骨科 Polypodiaceae & 水龙骨科 Polypodiaceae \\
\hline 丝带蒴 Drymotaenium miyoshianum (Makino) Makino & 单裂缝 Monolete & 水龙骨科 Polypodiaceae & 水龙骨科 Polypodiaceae \\
\hline $\begin{array}{l}\text { 肉质伏石蕨 Lemmaphyllum carnosum (J. Sm. ex Hook.) C. } \\
\text { Presl }\end{array}$ & 单裂缝 Monolete & 水龙骨科 Polypodiaceae & 水龙骨科 Polypodiaceae \\
\hline 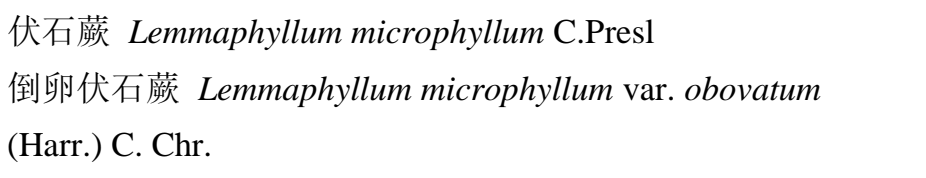 & $\begin{array}{l}\text { 单裂缝 Monolete } \\
\text { 单裂缝 Monolete }\end{array}$ & $\begin{array}{l}\text { 水龙骨科 Polypodiaceae } \\
\text { 水龙骨科 Polypodiaceae }\end{array}$ & $\begin{array}{l}\text { 水龙骨科 Polypodiaceae } \\
\text { 水龙骨科 Polypodiaceae }\end{array}$ \\
\hline 贴生骨牌硕 Lepidogrammitis adnascens Ching & 单裂缝 Monolete & 水龙骨科 Polypodiaceae & 水龙骨科 Polypodiaceae \\
\hline 披针骨牌锁 Lepidogrammitis diversa (Rosenst.) Ching & 单裂缝 Monolete & 水龙骨科 Polypodiaceae & 水龙骨科 Polypodiaceae \\
\hline 抱石莲 Lepidogrammitis drymoglossoides (Baker) Ching & 单裂缝 Monolete & 水龙骨科 Polypodiaceae & 水龙骨科 Polypodiaceae \\
\hline 长叶骨牌烣 Lepidogrammitis elongata Ching & 单裂缝 Monolete & 水龙骨科 Polypodiaceae & 水龙骨科 Polypodiaceae \\
\hline
\end{tabular}




\begin{tabular}{|c|c|c|c|}
\hline $\begin{array}{l}\text { 物种 } \\
\text { Species }\end{array}$ & $\begin{array}{l}\text { 孢子裂缝类型 } \\
\text { Spore apertures styles }\end{array}$ & $\begin{array}{l}\text { 科名 Family (秦仁 } \\
\text { 昌,1978a, b) }\end{array}$ & $\begin{array}{l}\text { 科名 Family (Smith et al., } \\
\text { 2006; Christenhusz et al, } \\
\text { 2011; 张宪春等, 2013) }\end{array}$ \\
\hline 中间骨牌嵚 Lepidogrammitis intermedia Ching & 单裂缝 Monolete & 水龙骨科 Polypodiaceae & 水龙骨科 Polypodiaceae \\
\hline 甘肃骨牌硕 Lepidogrammitis kansuensis Ching & 单裂缝 Monolete & 水龙骨科 Polypodiaceae & 水龙骨科 Polypodiaceae \\
\hline 梨叶骨牌荻 Lepidogrammitis pyriformis Ching & 单裂缝 Monolete & 水龙骨科 Polypodiaceae & 水龙骨科 Polypodiaceae \\
\hline 骨牌蒴 Lepidogrammitis rostrata (Bedd.) Ching & 单裂缝 Monolete & 水龙骨科 Polypodiaceae & 水龙骨科 Polypodiaceae \\
\hline $\begin{array}{l}\text { 鳞果星蕨 Lepidomicrosorium buergerianum (Miq.) Ching \& K. } \\
\text { H. Shing }\end{array}$ & 单裂缝 Monolete & 水龙骨科 Polypodiaceae & 水龙骨科 Polypodiaceae \\
\hline $\begin{array}{l}\text { 云南鳞果星蕨 Lepidomicrosorium hymenodes (Kunze) L. Shi \& } \\
\text { X. C. Zhang }\end{array}$ & 单裂缝 Monolete & 水龙骨科 Polypodiaceae & 水龙骨科 Polypodiaceae \\
\hline 海南瓦韦 Lepisorus affinis Ching & 单裂缝 Monolete & 水龙骨科 Polypodiaceae & 水龙骨科 Polypodiaceae \\
\hline 天山瓦韦 Lepisorus albertii (Regel) Ching & 单裂缝 Monolete & 水龙骨科 Polypodiaceae & 水龙骨科 Polypodiaceae \\
\hline 狭叶瓦韦 Lepisorus angustus Ching & 单裂缝 Monolete & 水龙骨科 Polypodiaceae & 水龙骨科 Polypodiaceae \\
\hline 黄瓦韦 Lepisorus asterolepis (Baker) Ching & 单裂缝 Monolete & 水龙骨科 Polypodiaceae & 水龙骨科 Polypodiaceae \\
\hline 两色瓦韦 Lepisorus bicolor Ching & 单裂缝 Monolete & 水龙骨科 Polypodiaceae & 水龙骨科 Polypodiaceae \\
\hline 从生瓦韦 Lepisorus cespitosus Y. X. Lin & 单裂缝 Monolete & 水龙骨科 Polypodiaceae & 水龙骨科 Polypodiaceae \\
\hline 网眼瓦韦 Lepisorus clathratus (C. B. Clarke) Ching & 单裂缝 Monolete & 水龙骨科 Polypodiaceae & 水龙骨科 Polypodiaceae \\
\hline 汇生瓦韦 Lepisorus confluens W. M. Chu & 单裂缝 Monolete & 水龙骨科 Polypodiaceae & 水龙骨科 Polypodiaceae \\
\hline 扭瓦韦 Lepisorus contortus (Christ) Ching & 单裂缝 Monolete & 水龙骨科 Polypodiaceae & 水龙骨科 Polypodiaceae \\
\hline 粗柄瓦韦 Lepisorus crassipes Ching \& Y. X. Lin & 单裂缝 Monolete & 水龙骨科 Polypodiaceae & 水龙骨科 Polypodiaceae \\
\hline 高山瓦韦 Lepisorus eilophyllus (Diels) Ching & 单裂缝 Monolete & 水龙骨科 Polypodiaceae & 水龙骨科 Polypodiaceae \\
\hline 片马瓦韦 Lepisorus elegans Ching \& W. M. Chu ex W. M. Chu & 单裂缝 Monolete & 水龙骨科 Polypodiaceae & 水龙骨科 Polypodiaceae \\
\hline 吉隆瓦韦 Lepisorus gyirongensis Ching \& S. K. Wu & 单裂缝 Monolete & 水龙骨科 Polypodiaceae & 水龙骨科 Polypodiaceae \\
\hline 瑶山瓦韦 Lepisorus kuchenensis (Y. C. Wu) Ching & 单裂缝 Monolete & 水龙骨科 Polypodiaceae & 水龙骨科 Polypodiaceae \\
\hline
\end{tabular}




\begin{tabular}{|c|c|c|c|}
\hline $\begin{array}{l}\text { 物种 } \\
\text { Species }\end{array}$ & $\begin{array}{l}\text { 孢子裂缝类型 } \\
\text { Spore apertures styles }\end{array}$ & $\begin{array}{l}\text { 科名 Family (秦仁 } \\
\text { 昌,1978a, b) }\end{array}$ & $\begin{array}{l}\text { 科名 Family (Smith et al., } \\
\text { 2006; Christenhusz et al, } \\
\text { 2011; 张宪春等, 2013) }\end{array}$ \\
\hline 庐山瓦韦 Lepisorus lewisii (Baker) Ching & 单裂缝 Monolete & 水龙骨科 Polypodiaceae & 水龙骨科 Polypodiaceae \\
\hline 丽江瓦韦 Lepisorus likiangensis Ching \& S. K. Wu & 单裂缝 Monolete & 水龙骨科 Polypodiaceae & 水龙骨科 Polypodiaceae \\
\hline 长叶瓦韦 Lepisorus longus Ching & 单裂缝 Monolete & 水龙骨科 Polypodiaceae & 水龙骨科 Polypodiaceae \\
\hline 带叶瓦韦 Lepisorus loriformis (Wall. ex Mett.) Ching & 单裂缝 Monolete & 水龙骨科 Polypodiaceae & 水龙骨科 Polypodiaceae \\
\hline 绿春瓦韦 Lepisorus luchunensis Y.X. Lin & 单裂缝 Monolete & 水龙骨科 Polypodiaceae & 水龙骨科 Polypodiaceae \\
\hline 大瓦韦 Lepisorus macrosphaerus (Baker) Ching & 单裂缝 Monolete & 水龙骨科 Polypodiaceae & 水龙骨科 Polypodiaceae \\
\hline 宝岛瓦韦 Lepisorus magasorus (C. Chr.) Ching & 单裂缝 Monolete & 水龙骨科 Polypodiaceae & 水龙骨科 Polypodiaceae \\
\hline 有边瓦韦 Lepisorus marginatus Ching & 单裂缝 Monolete & 水龙骨科 Polypodiaceae & 水龙骨科 Polypodiaceae \\
\hline 墨脱瓦韦 Lepisorus medogensis Ching \& Y. X. Lin & 单裂缝 Monolete & 水龙骨科 Polypodiaceae & 水龙骨科 Polypodiaceae \\
\hline 白边瓦韦 Lepisorus morrisonensis (Hayata) H. Ito & 单裂缝 Monolete & 水龙骨科 Polypodiaceae & 水龙骨科 Polypodiaceae \\
\hline 聂拉木瓦韦 Lepisorus nyalamensis Ching \& S. K. Wu & 单裂缝 Monolete & 水龙骨科 Polypodiaceae & 水龙骨科 Polypodiaceae \\
\hline 粤瓦韦 Lepisorus obscurevenulosus (Hayata) Ching & 单裂缝 Monolete & 水龙骨科 Polypodiaceae & 水龙骨科 Polypodiaceae \\
\hline 鳞瓦韦 Lepisorus oligolepidus (Baker) Ching & 单裂缝 Monolete & 水龙骨科 Polypodiaceae & 水龙骨科 Polypodiaceae \\
\hline 百华山瓦韦 Lepisorus paohuashanensis Ching & 单裂缝 Monolete & 水龙骨科 Polypodiaceae & 水龙骨科 Polypodiaceae \\
\hline 台湾瓦韦 Lepisorus papakensis (Masam.) Ching \& Y. X. Lin & 单裂缝 Monolete & 水龙骨科 Polypodiaceae & 水龙骨科 Polypodiaceae \\
\hline 长瓦韦 Lepisorus pseudonudus Ching & 单裂缝 Monolete & 水龙骨科 Polypodiaceae & 水龙骨科 Polypodiaceae \\
\hline 拟乌苏里瓦韦 Lepisorus pseudo-ussuriensis Tagawa & 单裂缝 Monolete & 水龙骨科 Polypodiaceae & 水龙骨科 Polypodiaceae \\
\hline 棕鳞瓦韦 Lepisorus scolopendrium (Ham. ex D. Don.) Mehra & 单裂缝 Monolete & 水龙骨科 Polypodiaceae & 水龙骨科 Polypodiaceae \\
\hline 中华瓦韦 Lepisorus sinensis (Christ) Ching & 单裂缝 Monolete & 水龙骨科 Polypodiaceae & 水龙骨科 Polypodiaceae \\
\hline 黑鳞瓦韦 Lepisorus sordidus (C. Chr.) Ching & 单裂缝 Monolete & 水龙骨科 Polypodiaceae & 水龙骨科 Polypodiaceae \\
\hline 狭带瓦韦 Lepisorus stenistus (C. B. Clarke) Y. X. Lin & 单裂缝 Monolete & 水龙骨科 Polypodiaceae & 水龙骨科 Polypodiaceae \\
\hline 连珠瓦韦 Lepisorus subconfluens Ching & 单裂缝 Monolete & 水龙骨科 Polypodiaceae & 水龙骨科 Polypodiaceae \\
\hline
\end{tabular}




\begin{tabular}{|c|c|c|c|}
\hline $\begin{array}{l}\text { 物种 } \\
\text { Species }\end{array}$ & $\begin{array}{l}\text { 孢子裂缝类型 } \\
\text { Spore apertures styles }\end{array}$ & $\begin{array}{l}\text { 科名 Family (秦仁 } \\
\text { 昌,1978a, b) }\end{array}$ & $\begin{array}{l}\text { 科名 Family (Smith et al., } \\
\text { 2006; Christenhusz et al, } \\
\text { 2011; 张宪春等, 2013) }\end{array}$ \\
\hline 滇瓦韦 Lepisorus sublinearis (Baker) Ching & 单裂缝 Monolete & 水龙骨科 Polypodiaceae & 水龙骨科 Polypodiaceae \\
\hline 拟鳞瓦韦 Lepisorus suboligolepidus Ching & 单裂缝 Monolete & 水龙骨科 Polypodiaceae & 水龙骨科 Polypodiaceae \\
\hline 太白瓦韦 Lepisorus thaipaiensis Ching \& S. K. Wu & 单裂缝 Monolete & 水龙骨科 Polypodiaceae & 水龙骨科 Polypodiaceae \\
\hline 瓦韦 Lepisorus thunbergianus (Kaulf. ) Ching & 单裂缝 Monolete & 水龙骨科 Polypodiaceae & 水龙骨科 Polypodiaceae \\
\hline 西藏瓦韦 Lepisorus tibeticus Ching \& S. K. Wu & 单裂缝 Monolete & 水龙骨科 Polypodiaceae & 水龙骨科 Polypodiaceae \\
\hline 阔叶瓦韦 Lepisorus tosaensis (Makino) H. Ito & 单裂缝 Monolete & 水龙骨科 Polypodiaceae & 水龙骨科 Polypodiaceae \\
\hline 软毛瓦韦 Lepisorus tricholepis K. H. Shing ex Y. X. Lin & 单裂缝 Monolete & 水龙骨科 Polypodiaceae & 水龙骨科 Polypodiaceae \\
\hline 乌苏里瓦韦 Lepisorus ussuriensis (Regel \& Maack) Ching & 单裂缝 Monolete & 水龙骨科 Polypodiaceae & 水龙骨科 Polypodiaceae \\
\hline 云南瓦韦 Lepisorus xiphiopteris (Baker) W. M. Chu ex Y. X. & 单裂缝 Monolete & 水龙骨科 Polypodiaceae & 水龙骨科 Polypodiaceae \\
\hline \multicolumn{4}{|l|}{ Lin } \\
\hline 薄唇蕨 Leptochilus axillaris (Cav.) Kaulf. & 单裂缝 Monolete & 水龙骨科 Polypodiaceae & 水龙骨科 Polypodiaceae \\
\hline 心叶薄唇蕨 Leptochilus cantoniensis (Baker) Ching & 单裂缝 Monolete & 水龙骨科 Polypodiaceae & 水龙骨科 Polypodiaceae \\
\hline 似薄唇硕 Leptochilus decurrens Blume & 单裂缝 Monolete & 水龙骨科 Polypodiaceae & 水龙骨科 Polypodiaceae \\
\hline 篦齿荻 Metapolypodium manmeiense (Christ) Ching & 单裂缝 Monolete & 水龙骨科 Polypodiaceae & 水龙骨科 Polypodiaceae \\
\hline 江南星蕨 Microsorum fortunei (T. Moore) Ching & 单裂缝 Monolete & 水龙骨科 Polypodiaceae & 水龙骨科 Polypodiaceae \\
\hline 羽裂星蕨 Microsorum insigne (Blume) Copel. & 单裂缝 Monolete & 水龙骨科 Polypodiaceae & 水龙骨科 Polypodiaceae \\
\hline 膜叶星鄀 Microsorum membranaceum (D. Don) Ching & 单裂缝 Monolete & 水龙骨科 Polypodiaceae & 水龙骨科 Polypodiaceae \\
\hline 龙骨星鄀 Microsorum membranaceum var. carinatumW. M. & 单裂缝 Monolete & 水龙骨科 Polypodiaceae & 水龙骨科 Polypodiaceae \\
\hline \multicolumn{4}{|l|}{ Chu \& Z. R. He } \\
\hline 有翅星蕨 Microsorum pteropus (Blume) Copel. & 单裂缝 Monolete & 水龙骨科 Polypodiaceae & 水龙骨科 Polypodiaceae \\
\hline 星蕨 Microsorum punctatum (L.) Copel. & 单裂缝 Monolete & 水龙骨科 Polypodiaceae & 水龙骨科 Polypodiaceae \\
\hline 网脉星蕨 Microsorum reticulatum Ching ex L. Shi & 单裂缝 Monolete & 水龙骨科 Polypodiaceae & 水龙骨科 Polypodiaceae \\
\hline
\end{tabular}




\begin{tabular}{|c|c|c|c|}
\hline $\begin{array}{l}\text { 物种 } \\
\text { Species }\end{array}$ & $\begin{array}{l}\text { 孢子裂缝类型 } \\
\text { Spore apertures styles }\end{array}$ & $\begin{array}{l}\text { 科名 Family (秦仁 } \\
\text { 昌,1978a, b) }\end{array}$ & $\begin{array}{l}\text { 科名 Family (Smith et al., } \\
\text { 2006; Christenhusz et al, } \\
\text { 2011; 张宪春等, 2013) }\end{array}$ \\
\hline 广叶星蒴 Microsorum steerei (Harr.) Ching & 单裂缝 Monolete & 水龙骨科 Polypodiaceae & 水龙骨科 Polypodiaceae \\
\hline 表面星蕨 Microsorum superficiale (Blume) Ching & 单裂缝 Monolete & 水龙骨科 Polypodiaceae & 水龙骨科 Polypodiaceae \\
\hline 显脉星蕨 Microsorum zippelii (Blume) Ching & 单裂缝 Monolete & 水龙骨科 Polypodiaceae & 水龙骨科 Polypodiaceae \\
\hline 扇荄 Neocheiropteris palmatopedata (Baker) Christ & 单裂缝 Monolete & 水龙骨科 Polypodiaceae & 水龙骨科 Polypodiaceae \\
\hline 三叉扇硕 Neocheiropteris triglossa (Baker) Ching & 单裂缝 Monolete & 水龙骨科 Polypodiaceae & 水龙骨科 Polypodiaceae \\
\hline 剑叶盾蕨 Neolepisorus ensatus (Thunb.) Ching & 单裂缝 Monolete & 水龙骨科 Polypodiaceae & 水龙骨科 Polypodiaceae \\
\hline 小盾茨 Neolepisorus minor W. M. Chu & 单裂缝 Monolete & 水龙骨科 Polypodiaceae & 水龙骨科 Polypodiaceae \\
\hline 盾菜 Neolepisorus ovatus (Bedd.) Ching & 单裂缝 Monolete & 水龙骨科 Polypodiaceae & 水龙骨科 Polypodiaceae \\
\hline 三角叶盾鄀 Neolepisorus ovatus f. deltoideus (Baker) Ching & 单裂缝 Monolete & 水龙骨科 Polypodiaceae & 水龙骨科 Polypodiaceae \\
\hline 蟹爪盾蓟 Neolepisorus ovatusf. doryopteris (Christ) Ching & 单裂缝 Monolete & 水龙骨科 Polypodiaceae & 水龙骨科 Polypodiaceae \\
\hline 截基盾嵚 Neolepisorus truncatus Ching \& P. S. Wang & 单裂缝 Monolete & 水龙骨科 Polypodiaceae & 水龙骨科 Polypodiaceae \\
\hline $\begin{array}{l}\text { 灰鳞假瘤蓱 Phymatopteris albopes (C. Chr. \& Ching) Pic. } \\
\text { Serm. }\end{array}$ & 单裂缝 Monolete & 水龙骨科 Polypodiaceae & 水龙骨科 Polypodiaceae \\
\hline $\begin{array}{l}\text { 芒刺假瘤蕨 Phymatopteris cartilagineo-serrata (Ching \& S. K. } \\
\text { Wu) S. G. Lu }\end{array}$ & 单裂缝 Monolete & 水龙骨科 Polypodiaceae & 水龙骨科 Polypodiaceae \\
\hline 白茎假瘤嵚 Phymatopteris chrysotricha (C. Chr.) Pic. Serm. & 单裂缝 Monolete & 水龙骨科 Polypodiaceae & 水龙骨科 Polypodiaceae \\
\hline 交连假瘤硕 Phymatopteris conjuncta (Ching) Pic. Serm. & 单裂缝 Monolete & 水龙骨科 Polypodiaceae & 水龙骨科 Polypodiaceae \\
\hline 钝羽假瘤蕨 Phymatopteris conmixta (Ching) Pic. Serm. & 单裂缝 Monolete & 水龙骨科 Polypodiaceae & 水龙骨科 Polypodiaceae \\
\hline 耿马假瘤蕨 Phymatopteris connexa (Ching) Pic. Serm. & 单裂缝 Monolete & 水龙骨科 Polypodiaceae & 水龙骨科 Polypodiaceae \\
\hline $\begin{array}{l}\text { 紫柄假瘤蕂 Phymatopteris crenatopinnata (C. B. Clarke) Pic. } \\
\text { Serm. }\end{array}$ & 单裂缝 Monolete & 水龙骨科 Polypodiaceae & 水龙骨科 Polypodiaceae \\
\hline 十字假瘤葓 Phymatopteris cruciformis (Ching) Pic. Serm. & 单裂缝 Monolete & 水龙骨科 Polypodiaceae & 水龙骨科 Polypodiaceae \\
\hline
\end{tabular}




\begin{tabular}{|c|c|c|c|}
\hline $\begin{array}{l}\text { 物种 } \\
\text { Species }\end{array}$ & $\begin{array}{l}\text { 孢子裂缝类型 } \\
\text { Spore apertures styles }\end{array}$ & $\begin{array}{l}\text { 科名 Family (秦仁 } \\
\text { 昌,1978a, b) }\end{array}$ & $\begin{array}{l}\text { 科名 Family (Smith et al., } \\
\text { 2006; Christenhusz et al, } \\
\text { 2011; 张宪春等, 2013) }\end{array}$ \\
\hline 指叶假瘤硕 Phymatopteris dactylina (Christ) Pic. Serm. & 单裂缝 Monolete & 水龙骨科 Polypodiaceae & 水龙骨科 Polypodiaceae \\
\hline 大围山假瘤葓 Phymatopteris daweishanensis S. G. Lu & 单裂缝 Monolete & 水龙骨科 Polypodiaceae & 水龙骨科 Polypodiaceae \\
\hline 掌叶假瘤蕨 Phymatopteris digitata (Ching) Pic. Serm. & 单裂缝 Monolete & 水龙骨科 Polypodiaceae & 水龙骨科 Polypodiaceae \\
\hline 黑鳞假瘤鄀 Phymatopteris ebenipes (Hook.) Pic. Serm. & 单裂缝 Monolete & 水龙骨科 Polypodiaceae & 水龙骨科 Polypodiaceae \\
\hline $\begin{array}{l}\text { 毛轴黑鳞假瘤䓲 Phymatopteris ebenipes var. oakesii (C. B. } \\
\text { Clarke) Satija \& Bir }\end{array}$ & 单裂缝 Monolete & 水龙骨科 Polypodiaceae & 水龙骨科 Polypodiaceae \\
\hline $\begin{array}{l}\text { 大叶玉山假瘤蕨 Phymatopteris echinospora (Tagawa) Pic. } \\
\text { Serm. }\end{array}$ & 单裂缝 Monolete & 水龙骨科 Polypodiaceae & 水龙骨科 Polypodiaceae \\
\hline 恩氏假瘤荻 Phymatopteris engleri (Luerss.) Pic. Serm. & 单裂缝 Monolete & 水龙骨科 Polypodiaceae & 水龙骨科 Polypodiaceae \\
\hline $\begin{array}{l}\text { 锡金假瘤烣 Phymatopteris erythrocarpa (Mett. ex Kuhn) Pic. } \\
\text { Serm. }\end{array}$ & 单裂缝 Monolete & 水龙骨科 Polypodiaceae & 水龙骨科 Polypodiaceae \\
\hline 镰羽假瘤硕 Phymatopteris falcatopinnata (Hayata) S. G. Lu & 单裂缝 Monolete & 水龙骨科 Polypodiaceae & 水龙骨科 Polypodiaceae \\
\hline 刺齿假瘤蕨 Phymatopteris glaucopsis (Franch.) Pic. Serm. & 单裂缝 Monolete & 水龙骨科 Polypodiaceae & 水龙骨科 Polypodiaceae \\
\hline 大果假瘤蕨 Phymatopteris griffithiana (Hook.) Pic. Serm. & 单裂缝 Monolete & 水龙骨科 Polypodiaceae & 水龙骨科 Polypodiaceae \\
\hline 海南假瘤蕨 Phymatopteris hainanensis (Ching) Pic. Serm. & 单裂缝 Monolete & 水龙骨科 Polypodiaceae & 水龙骨科 Polypodiaceae \\
\hline 金鸡脚假瘤蕨 Phymatopteris hastata (Thunb.) Pic. Serm. & 单裂缝 Monolete & 水龙骨科 Polypodiaceae & 水龙骨科 Polypodiaceae \\
\hline 昆明假瘤蒴 Phymatopteris hirtella (Ching) Pic. Serm. & 单裂缝 Monolete & 水龙骨科 Polypodiaceae & 水龙骨科 Polypodiaceae \\
\hline $\begin{array}{l}\text { 圆齿假瘤葓 Phymatopteris incisocrenata Ching ex W. M. Chu } \\
\text { \& S. G. Lu }\end{array}$ & 单裂缝 Monolete & 水龙骨科 Polypodiaceae & 水龙骨科 Polypodiaceae \\
\hline 丽江假瘤蕨 Phymatopteris likiangensis (Ching) Pic. Serm. & 单裂缝 Monolete & 水龙骨科 Polypodiaceae & 水龙骨科 Polypodiaceae \\
\hline 宽底假瘤蕨 Phymatopteris majoensis (C. Chr.) Pic. Serm. & 单裂缝 Monolete & 水龙骨科 Polypodiaceae & 水龙骨科 Polypodiaceae \\
\hline 弯弓假瘤葓 Phymatopteris malacodon (Hook.) Pic. Serm. & 单裂缝 Monolete & 水龙骨科 Polypodiaceae & 水龙骨科 Polypodiaceae \\
\hline
\end{tabular}




\begin{tabular}{|c|c|c|c|}
\hline $\begin{array}{l}\text { 物种 } \\
\text { Species }\end{array}$ & $\begin{array}{l}\text { 孢子裂缝类型 } \\
\text { Spore apertures styles }\end{array}$ & $\begin{array}{l}\text { 科名 Family (秦仁 } \\
\text { 昌,1978a, b) }\end{array}$ & $\begin{array}{l}\text { 科名 Family (Smith et al., } \\
\text { 2006; Christenhusz et al, } \\
\text { 2011; 张宪春等, 2013) }\end{array}$ \\
\hline 乌鳞假瘤蕨 Phymatopteris nigropaleacea (Ching) S. G. Lu & 单裂缝 Monolete & 水龙骨科 Polypodiaceae & 水龙骨科 Polypodiaceae \\
\hline 毛叶假瘤蒴 Phymatopteris nigrovenia (Christ) Pic. Serm. & 单裂缝 Monolete & 水龙骨科 Polypodiaceae & 水龙骨科 Polypodiaceae \\
\hline $\begin{array}{l}\text { 长圆假瘤茨 Phymatopteris oblongifolia (S. K. Wu) W. M. Chu } \\
\text { \& S. G. Lu in H. Li. }\end{array}$ & 单裂缝 Monolete & 水龙骨科 Polypodiaceae & 水龙骨科 Polypodiaceae \\
\hline 圆顶假瘤葓 Phymatopteris obtusa (Ching) Pic. Serm. & 单裂缝 Monolete & 水龙骨科 Polypodiaceae & 水龙骨科 Polypodiaceae \\
\hline 峨眉假瘤荻 Phymatopteris omeiensis (Ching) Pic. Serm. & 单裂缝 Monolete & 水龙骨科 Polypodiaceae & 水龙骨科 Polypodiaceae \\
\hline 尖裂假瘤钼 Phymatopteris oxyloba (Wall. ex Kunze) Pic. Serm. & 单裂缝 Monolete & 水龙骨科 Polypodiaceae & 水龙骨科 Polypodiaceae \\
\hline 透明叶假瘤菜 Phymatopteris pellucidifolia (Hayata) Pic. Serm. & 单裂缝 Monolete & 水龙骨科 Polypodiaceae & 水龙骨科 Polypodiaceae \\
\hline 片马假瘤鄀 Phymatopteris pianmaensis W. M. Chu & 单裂缝 Monolete & 水龙骨科 Polypodiaceae & 水龙骨科 Polypodiaceae \\
\hline 展羽假瘤锁 Phymatopteris quasidivaricata (Hayata) Pic. Serm. & 单裂缝 Monolete & 水龙骨科 Polypodiaceae & 水龙骨科 Polypodiaceae \\
\hline 潒叶假瘤菜 Phymatopteris rhynchophylla (Hook.) Pic. Serm. & 单裂缝 Monolete & 水龙骨科 Polypodiaceae & 水龙骨科 Polypodiaceae \\
\hline 陕西假瘤蕨 Phymatopteris shensiensis (Christ) Pic. Serm. & 单裂缝 Monolete & 水龙骨科 Polypodiaceae & 水龙骨科 Polypodiaceae \\
\hline 相似假瘤嵚 Phymatopteris similis (Ching) W. M. Chu & 单裂缝 Monolete & 水龙骨科 Polypodiaceae & 水龙骨科 Polypodiaceae \\
\hline 尾尖假瘤鄀 Phymatopteris stewartii (Bedd.) Pic. Serm. & 单裂缝 Monolete & 水龙骨科 Polypodiaceae & 水龙骨科 Polypodiaceae \\
\hline 斜下假瘤荻 Phymatopteris stracheyi (Ching) Pic. Serm. & 单裂缝 Monolete & 水龙骨科 Polypodiaceae & 水龙骨科 Polypodiaceae \\
\hline 苍山假瘤濒 Phymatopteris subebenipes (Ching) Pic. Serm. & 单裂缝 Monolete & 水龙骨科 Polypodiaceae & 水龙骨科 Polypodiaceae \\
\hline 台湾假瘤蕨 Phymatopteris taiwanensis (Tagawa) Pic. Serm. & 单裂缝 Monolete & 水龙骨科 Polypodiaceae & 水龙骨科 Polypodiaceae \\
\hline 细柄假瘤蕨 Phymatopteris tenuipes (Ching) Pic. Serm. & 单裂缝 Monolete & 水龙骨科 Polypodiaceae & 水龙骨科 Polypodiaceae \\
\hline $\begin{array}{l}\text { 西藏假瘤蕨 Phymatopteris tibetana (Ching \& S. K. Wu) W. M. } \\
\text { Chu }\end{array}$ & 单裂缝 Monolete & 水龙骨科 Polypodiaceae & 水龙骨科 Polypodiaceae \\
\hline 三指假瘤蕨 Phymatopteris triloba (Houtt.) Pic. Serm. & 单裂缝 Monolete & 水龙骨科 Polypodiaceae & 水龙骨科 Polypodiaceae \\
\hline 三出假瘤蕨 Phymatopteris trisecta (Baker) Pic. Serm. & 单裂缝 Monolete & 水龙骨科 Polypodiaceae & 水龙骨科 Polypodiaceae \\
\hline
\end{tabular}




\begin{tabular}{|c|c|c|c|}
\hline $\begin{array}{l}\text { 物种 } \\
\text { Species }\end{array}$ & $\begin{array}{l}\text { 孢子裂缝类型 } \\
\text { Spore apertures styles }\end{array}$ & $\begin{array}{l}\text { 科名 Family (秦仁 } \\
\text { 昌,1978a, b) }\end{array}$ & $\begin{array}{l}\text { 科名 Family (Smith et al., } \\
\text { 2006; Christenhusz et al, } \\
\text { 2011; 张宪春等, 2013) }\end{array}$ \\
\hline 无量山假瘤菜 Phymatopteris wuliangshanensis W. M. Chu & 单裂缝 Monolete & 水龙骨科 Polypodiaceae & 水龙骨科 Polypodiaceae \\
\hline 屋久假瘤嵚 Phymatopteris yakushimensis (Makino) Pic. Serm. & 单裂缝 Monolete & 水龙骨科 Polypodiaceae & 水龙骨科 Polypodiaceae \\
\hline 光亮瘤硕 Phymatosorus cuspidatus (D. Don) Pic. Serm. & 单裂缝 Monolete & 水龙骨科 Polypodiaceae & 水龙骨科 Polypodiaceae \\
\hline 阔鳞瘤硕 Phymatosorus hainanensis (Noot.) S. G. Lu & 单裂缝 Monolete & 水龙骨科 Polypodiaceae & 水龙骨科 Polypodiaceae \\
\hline 矛叶瘤荻 Phymatosorus lanceus (Ching \& Chu H. Wang) S. G. & 单裂缝 Monolete & 水龙骨科 Polypodiaceae & 水龙骨科 Polypodiaceae \\
\hline \multicolumn{4}{|l|}{$\mathrm{Lu}$} \\
\hline 多羽瘤茨 Phymatosorus longissimus (Blume) Pic. Serm. & 单裂缝 Monolete & 水龙骨科 Polypodiaceae & 水龙骨科 Polypodiaceae \\
\hline 显脉瘤嵚 Phymatosorus membranifolius (R. Brown) S. G. Lu & 单裂缝 Monolete & 水龙骨科 Polypodiaceae & 水龙骨科 Polypodiaceae \\
\hline 瘤荻 Phymatosorus scolopendria (Burm. f.) Pic. Serm. & 单裂缝 Monolete & 水龙骨科 Polypodiaceae & 水龙骨科 Polypodiaceae \\
\hline 深波宽带鄀 Platygyria sinuata Ching \& S. K. Wu & 单裂缝 Monolete & 水龙骨科 Polypodiaceae & 水龙骨科 Polypodiaceae \\
\hline 川西宽带鄀 Platygyria soulieana (Christ) X. C. Zhang \& Q. R. & 单裂缝 Monolete & 水龙骨科 Polypodiaceae & 水龙骨科 Polypodiaceae \\
\hline \multicolumn{4}{|l|}{ Liu } \\
\hline 多变宽带茨 Platygyria variabilis Ching \& S. K. Wu & 单裂缝 Monolete & 水龙骨科 Polypodiaceae & 水龙骨科 Polypodiaceae \\
\hline 宽带硕 Platygyria waltonii (Ching) Ching \& S. K. Wu & 单裂缝 Monolete & 水龙骨科 Polypodiaceae & 水龙骨科 Polypodiaceae \\
\hline 耳基宽带㓹 Platygyria $\times$ inaequibasis Ching \& S. K. Wu & 单裂缝 Monolete & 水龙骨科 Polypodiaceae & 水龙骨科 Polypodiaceae \\
\hline 尖齿拟水龙骨 Polypodiastrum argutum (Wall. ex Hook. Hook.) & 单裂缝 Monolete & 水龙骨科 Polypodiaceae & 水龙骨科 Polypodiaceae \\
\hline \multicolumn{4}{|l|}{ Ching } \\
\hline 川拟水龙骨 Polypodiastrum dielseanum (C. Chr.) Ching & 单裂缝 Monolete & 水龙骨科 Polypodiaceae & 水龙骨科 Polypodiaceae \\
\hline 友水龙骨 Polypodiodes amoena (Wall. ex Mett.) Ching & 单裂缝 Monolete & 水龙骨科 Polypodiaceae & 水龙骨科 Polypodiaceae \\
\hline 红杆水龙骨 Polypodiodes amoena var. duclouxi (Christ) Ching & 单裂缝 Monolete & 水龙骨科 Polypodiaceae & 水龙骨科 Polypodiaceae \\
\hline 柔毛水龙骨 Polypodiodes amoena var. pilosa (C. B. Clarke) & 单裂缝 Monolete & 水龙骨科 Polypodiaceae & 水龙骨科 Polypodiaceae \\
\hline
\end{tabular}




\begin{tabular}{|c|c|c|c|}
\hline $\begin{array}{l}\text { 物种 } \\
\text { Species }\end{array}$ & $\begin{array}{l}\text { 孢子裂缝类型 } \\
\text { Spore apertures styles }\end{array}$ & $\begin{array}{l}\text { 科名 Family (秦仁 } \\
\text { 昌,1978a, b) }\end{array}$ & $\begin{array}{l}\text { 科名 Family (Smith et al., } \\
\text { 2006; Christenhusz et al, } \\
\text { 2011; 张宪春等, 2013) }\end{array}$ \\
\hline 滇越水龙骨 Polypodiodes bourretii (C. Chr. \& Tardieu) W. M. & 单裂缝 Monolete & 水龙骨科 Polypodiaceae & 水龙骨科 Polypodiaceae \\
\hline \multicolumn{4}{|l|}{ Chu } \\
\hline 中华水龙骨 Polypodiodes chinensis (Christ) S. G. Lu & 单裂缝 Monolete & 水龙骨科 Polypodiaceae & 水龙骨科 Polypodiaceae \\
\hline 镰羽水龙骨 Polypodiodes falcipinnula S. K. Wu \& J. Murata & 单裂缝 Monolete & 水龙骨科 Polypodiaceae & 水龙骨科 Polypodiaceae \\
\hline 台湾水龙骨 Polypodiodes formosana (Baker) Ching & 单裂缝 Monolete & 水龙骨科 Polypodiaceae & 水龙骨科 Polypodiaceae \\
\hline 喜马拉雅水龙骨 Polypodiodes hendersonii (Bedd.) Fraser-Jenk. & 单裂缝 Monolete & 水龙骨科 Polypodiaceae & 水龙骨科 Polypodiaceae \\
\hline 濑水龙骨 Polypodiodes lachnopus (Wall. ex Hook.) Ching & 单裂缝 Monolete & 水龙骨科 Polypodiaceae & 水龙骨科 Polypodiaceae \\
\hline 栗柄水龙骨 Polypodiodes microrhizoma (C. B. Clarke ex & 单裂缝 Monolete & 水龙骨科 Polypodiaceae & 水龙骨科 Polypodiaceae \\
\hline \multicolumn{4}{|l|}{ Baker) Ching } \\
\hline 日本水龙骨 Polypodiodes niponica (Mett.) Ching & 单裂缝 Monolete & 水龙骨科 Polypodiaceae & 水龙骨科 Polypodiaceae \\
\hline 腺叶水龙骨 Polypodiodes niponica var. glandulosa P. S. Wang & 单裂缝 Monolete & 水龙骨科 Polypodiaceae & 水龙骨科 Polypodiaceae \\
\hline 假毛柄水龙骨 Polypodiodes pseudolachnopus S. G. Lu & 单裂缝 Monolete & 水龙骨科 Polypodiaceae & 水龙骨科 Polypodiaceae \\
\hline 假友水龙骨 Polypodiodes subamoena (C. B. Clarke) Ching & 单裂缝 Monolete & 水龙骨科 Polypodiaceae & 水龙骨科 Polypodiaceae \\
\hline 光茎水龙骨 Polypodiodes wattii (Bedd.) Ching & 单裂缝 Monolete & 水龙骨科 Polypodiaceae & 水龙骨科 Polypodiaceae \\
\hline 东北多足蕨 Polypodium virginianum L. & 单裂缝 Monolete & 水龙骨科 Polypodiaceae & 水龙骨科 Polypodiaceae \\
\hline 欧亚多足蕨 Polypodium vulgare L. & 单裂缝 Monolete & 水龙骨科 Polypodiaceae & 水龙骨科 Polypodiaceae \\
\hline 贴生石韦 Pyrrosia adnascens (Sw.) Ching & 单裂缝 Monolete & 水龙骨科 Polypodiaceae & 水龙骨科 Polypodiaceae \\
\hline 钻生石韦 Pyrrosia adnascens f. calcicola K. H. Shing & 单裂缝 Monolete & 水龙骨科 Polypodiaceae & 水龙骨科 Polypodiaceae \\
\hline 石蓀 Pyrrosia angustissima (Gies. ex Diels) Tagawa \& K. Iwats. & 单裂缝 Monolete & 水龙骨科 Polypodiaceae & 水龙骨科 Polypodiaceae \\
\hline 相近石韦 Pyrrosia assimilis (Baker) Ching & 单裂缝 Monolete & 水龙骨科 Polypodiaceae & 水龙骨科 Polypodiaceae \\
\hline 波氏石韦 Pyrrosia bonii (Christ ex Gies.) Ching & 单裂缝 Monolete & 水龙骨科 Polypodiaceae & 水龙骨科 Polypodiaceae \\
\hline 布施石韦 Pyrrosia boothii (Hook.) Ching & 单裂缝 Monolete & 水龙骨科 Polypodiaceae & 水龙骨科 Polypodiaceae \\
\hline
\end{tabular}




\begin{tabular}{|c|c|c|c|}
\hline $\begin{array}{l}\text { 物种 } \\
\text { Species }\end{array}$ & $\begin{array}{l}\text { 孢子裂缝类型 } \\
\text { Spore apertures styles }\end{array}$ & $\begin{array}{l}\text { 科名 Family (秦仁 } \\
\text { 昌,1978a, b) }\end{array}$ & $\begin{array}{l}\text { 科名 Family (Smith et al., } \\
\text { 2006; Christenhusz et al, } \\
\text { 2011; 张宪春等, 2013) }\end{array}$ \\
\hline 光石韦 Pyrrosia calvata (Baker) Ching & 单裂缝 Monolete & 水龙骨科 Polypodiaceae & 水龙骨科 Polypodiaceae \\
\hline 尾叶石韦 Pyrrosia caudifrons Ching & 单裂缝 Monolete & 水龙骨科 Polypodiaceae & 水龙骨科 Polypodiaceae \\
\hline 下延石韦 Pyrrosia costata (C. Presl) Tagawa \& K. Iwats. & 单裂缝 Monolete & 水龙骨科 Polypodiaceae & 水龙骨科 Polypodiaceae \\
\hline 华北石韦 Pyrrosia davidii (Baker) Ching & 单裂缝 Monolete & 水龙骨科 Polypodiaceae & 水龙骨科 Polypodiaceae \\
\hline 轳毛石韦 Pyrrosia drakeana (Franch.) Ching & 单裂缝 Monolete & 水龙骨科 Polypodiaceae & 水龙骨科 Polypodiaceae \\
\hline 琼崖石韦 Pyrrosia eberhardtii (Christ) Ching & 单裂缝 Monolete & 水龙骨科 Polypodiaceae & 水龙骨科 Polypodiaceae \\
\hline 卷毛石韦 Pyrrosia flocculosa (D. Don) Ching & 单裂缝 Monolete & 水龙骨科 Polypodiaceae & 水龙骨科 Polypodiaceae \\
\hline 西南石韦 Pyrrosia gralla (Gies.) Ching & 单裂缝 Monolete & 水龙骨科 Polypodiaceae & 水龙骨科 Polypodiaceae \\
\hline 戟叶石韦 Pyrrosia hastata (Thunb. ex Houtt.) Ching & 单裂缝 Monolete & 水龙骨科 Polypodiaceae & 水龙骨科 Polypodiaceae \\
\hline 纸质石韦 Pyrrosia heteractis (Mett. ex. Kuhn) Ching & 单裂缝 Monolete & 水龙骨科 Polypodiaceae & 水龙骨科 Polypodiaceae \\
\hline 平滑石韦 Pyrrosia laevis (J. Sm. ex Bedd.) Ching & 单裂缝 Monolete & 水龙骨科 Polypodiaceae & 水龙骨科 Polypodiaceae \\
\hline 披针叶石韦 Pyrrosia lanceolata (L.) Farwell & 单裂缝 Monolete & 水龙骨科 Polypodiaceae & 水龙骨科 Polypodiaceae \\
\hline 线叶石韦 Pyrrosia linearifolia (Hook.) Ching & 单裂缝 Monolete & 水龙骨科 Polypodiaceae & 水龙骨科 Polypodiaceae \\
\hline 石韦 Pyrrosia lingua (Thunb.) Farwell & 单裂缝 Monolete & 水龙骨科 Polypodiaceae & 水龙骨科 Polypodiaceae \\
\hline 南洋石韦 Pyrrosia longifolia (Burm. f.) Morton & 单裂缝 Monolete & 水龙骨科 Polypodiaceae & 水龙骨科 Polypodiaceae \\
\hline 蔓氏石韦 Pyrrosia mannii (Gies.) Ching & 单裂缝 Monolete & 水龙骨科 Polypodiaceae & 水龙骨科 Polypodiaceae \\
\hline 松田氏石韦 Pyrrosia matsudae (Hayata) Tagawa & 单裂缝 Monolete & 水龙骨科 Polypodiaceae & 水龙骨科 Polypodiaceae \\
\hline 裸叶石韦 Pyrrosia nuda (Gies.) Ching & 单裂缝 Monolete & 水龙骨科 Polypodiaceae & 水龙骨科 Polypodiaceae \\
\hline 裸茎石韦 Pyrrosia nudicaulis Ching & 单裂缝 Monolete & 水龙骨科 Polypodiaceae & 水龙骨科 Polypodiaceae \\
\hline 钱币石韦 Pyrrosia nummulariifolia (Sw.) Ching & 单裂缝 Monolete & 水龙骨科 Polypodiaceae & 水龙骨科 Polypodiaceae \\
\hline 长圆石韦 Pyrrosia oblonga Ching & 单裂缝 Monolete & 水龙骨科 Polypodiaceae & 水龙骨科 Polypodiaceae \\
\hline 有柄石韦 Pyrrosia petiolosa (Christ) Ching & 单裂缝 Monolete & 水龙骨科 Polypodiaceae & 水龙骨科 Polypodiaceae \\
\hline
\end{tabular}




\begin{tabular}{|c|c|c|c|}
\hline $\begin{array}{l}\text { 物种 } \\
\text { Species }\end{array}$ & $\begin{array}{l}\text { 孢子裂缝类型 } \\
\text { Spore apertures styles }\end{array}$ & $\begin{array}{l}\text { 科名 Family (秦仁 } \\
\text { 昌,1978a, b) }\end{array}$ & $\begin{array}{l}\text { 科名 Family (Smith et al., } \\
\text { 2006; Christenhusz et al, } \\
\text { 2011; 张宪春等, 2013) }\end{array}$ \\
\hline 棫叶石韦 Pyrrosia polydactyla (Hance) Ching & 单裂缝 Monolete & 水龙骨科 Polypodiaceae & 水龙骨科 Polypodiaceae \\
\hline 柔软石韦 Pyrrosia porosa (C. Presl) Hovenk. & 单裂缝 Monolete & 水龙骨科 Polypodiaceae & 水龙骨科 Polypodiaceae \\
\hline 平线石韦 Pyrrosia porosa var. mollissima (Ching) K. H. Shing & 单裂缝 Monolete & 水龙骨科 Polypodiaceae & 水龙骨科 Polypodiaceae \\
\hline 庐山石韦 Pyrrosia sheareri (Baker) Ching & 单裂缝 Monolete & 水龙骨科 Polypodiaceae & 水龙骨科 Polypodiaceae \\
\hline 神农石韦 Pyrrosia shennongensis K. H. Shing & 单裂缝 Monolete & 水龙骨科 Polypodiaceae & 水龙骨科 Polypodiaceae \\
\hline 相似石韦 Pyrrosia similis Ching & 单裂缝 Monolete & 水龙骨科 Polypodiaceae & 水龙骨科 Polypodiaceae \\
\hline 狭叶石韦 Pyrrosia stenophylla (Bedd.) Ching & 单裂缝 Monolete & 水龙骨科 Polypodiaceae & 水龙骨科 Polypodiaceae \\
\hline 柱状石韦 Pyrrosia stigmosa (Sw.) Ching & 单裂缝 Monolete & 水龙骨科 Polypodiaceae & 水龙骨科 Polypodiaceae \\
\hline 线毛石韦 Pyrrosia subfurfuracea (Hook.) Ching & 单裂缝 Monolete & 水龙骨科 Polypodiaceae & 水龙骨科 Polypodiaceae \\
\hline 中越石韦 Pyrrosia tonkinensis (Gies.) Ching & 单裂缝 Monolete & 水龙骨科 Polypodiaceae & 水龙骨科 Polypodiaceae \\
\hline 棱脉偋 Schellolepis persicifolia (Desv.) Pic. Serm. & 单裂缝 Monolete & 水龙骨科 Polypodiaceae & 水龙骨科 Polypodiaceae \\
\hline 穴果棱脉蕨 Schellolepis subauriculata (Blume) J. Sm. & 单裂缝 Monolete & 水龙骨科 Polypodiaceae & 水龙骨科 Polypodiaceae \\
\hline 毛鳞蒴 Tricholepidium normale (D. Don) Ching & 单裂缝 Monolete & 水龙骨科 Polypodiaceae & 水龙骨科 Polypodiaceae \\
\hline \multirow[t]{2}{*}{ 睫毛蕨 Pleurosoriopsis makinoi (Maxim. ex Makino) Fomin } & 单裂缝 Monolete & 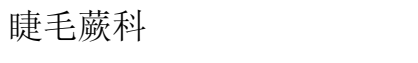 & 水龙骨科 Polypodiaceae \\
\hline & & Pleurosoriopsidaceae & \\
\hline 短叶荷包蕨 Calymmodon asiaticus Copel. & 三裂缝 Trilete & 禾叶烣科 Grammitidaceae & 水龙骨科 Polypodiaceae \\
\hline 疏毛荷包蕨 Calymmodon gracilis (Fée) Copel. & 三裂缝 Trilete & 禾叶葓科 Grammitidaceae & 水龙骨科 Polypodiaceae \\
\hline 无毛禾叶䰻 Grammitis adspersa Blume & 三裂缝 Trilete & 禾叶鄀科 Grammitidaceae & 水龙骨科 Polypodiaceae \\
\hline 太武禾叶蒴 Grammitis congener Blume & 三裂缝 Trilete & 禾叶屏科 Grammitidaceae & 水龙骨科 Polypodiaceae \\
\hline 短柄禾叶蒴 Grammitis dorsipila (Christ) C. Chr. \& Tardieu & 三裂缝 Trilete & 禾叶硕科 Grammitidaceae & 水龙骨科 Polypodiaceae \\
\hline 大禾叶荻 Grammitis intromissa (Christ) Parris & 三裂缝 Trilete & 禾叶蕨科 Grammitidaceae & 水龙骨科 Polypodiaceae \\
\hline 拟禾叶蕨 Grammitis jagoriana (Mett.) Tagawa & 三裂缝 Trilete & 禾叶偋科 Grammitidaceae & 水龙骨科 Polypodiaceae \\
\hline
\end{tabular}




\begin{tabular}{|c|c|c|c|}
\hline $\begin{array}{l}\text { 物种 } \\
\text { Species }\end{array}$ & $\begin{array}{l}\text { 孢子裂缝类型 } \\
\text { Spore apertures styles }\end{array}$ & $\begin{array}{l}\text { 科名 Family (秦仁 } \\
\text { 昌,1978a, b) }\end{array}$ & $\begin{array}{l}\text { 科名 Family (Smith et al., } \\
\text { 2006; Christenhusz et al, } \\
\text { 2011; 张宪春等, 2013) }\end{array}$ \\
\hline 长孢禾叶偋 Grammitis nuda Tagawa & 三裂缝 Trilete & 禾叶茨科 Grammitidaceae & 水龙骨科 Polypodiaceae \\
\hline 毛禾叶䔊 Grammitis reinwardtii Blume & 三裂缝 Trilete & 禾叶硕科 Grammitidaceae & 水龙骨科 Polypodiaceae \\
\hline 叉毛锯蕨 Micropolypodium cornigerum (Baker) X. C. Zhang & 三裂缝 Trilete & 禾叶鄀科 Grammitidaceae & 水龙骨科 Polypodiaceae \\
\hline 锯茨 Micropolypodium okuboi (Yatabe) Hayata & 三裂缝 Trilete & 禾叶茨科 Grammitidaceae & 水龙骨科 Polypodiaceae \\
\hline 锡金锯蕨 Micropolypodium sikkimense (Hieron.) X. C. Zhang & 三裂缝 Trilete & 禾叶䓲科 Grammitidaceae & 水龙骨科 Polypodiaceae \\
\hline 缘生穴子硕 Prosaptia contigua (G. Forst.) C. Presl & 三裂缝 Trilete & 禾叶鄀科 Grammitidaceae & 水龙骨科 Polypodiaceae \\
\hline 穴子偋 Prosaptia khasyana (Hook.) C. Chr. \& Tardieu & 三裂缝 Trilete & 禾叶䕋科 Grammitidaceae & 水龙骨科 Polypodiaceae \\
\hline 琼崖穴子濒 Prosaptia obliquata (Blume) Mett. & 三裂缝 Trilete & 禾叶硕科 Grammitidaceae & 水龙骨科 Polypodiaceae \\
\hline 革舌濒 Scleroglossum pusillum (Blume) Alderw. & 三裂缝 Trilete & 禾叶薕科 Grammitidaceae & 水龙骨科 Polypodiaceae \\
\hline
\end{tabular}

参考文献:

Ching RC (1978a) The Chinese fern families and genera: systematic arrangement and historical origin. Acta Phytotaxonomica Sinica, 16(3),

1-19. (in Chinese) [秦仁昌 (1978a) 中国蕨类植物科属的系统排列和历史来源. 植物分类学报, 16(3), 1-19.]

Ching RC (1978b) The Chinese fern families and genera: systematic arrangement and historical origin (cont.). Acta Phytotaxonomica Sinica,

16(4), 16-37. (in Chinese) [秦仁昌 (1978b) 中国蕨类植物科属的系统排列和历史来源(续). 植物分类学报, 16(4), 16-37.]

Christenhusz MJM, Zhang XC, Schneider H (2011) A linear sequence of extant families and genera of lycophytes and ferns. Phytotaxa, 19,

$7-54$.

Smith AR, Pryer KM, Schuettpelz E, Korall P, Schneider H, Wolf PG (2006) A classification for extant ferns. Taxon, 55, 705-731.

Zhang XC, Wei R, Liu HM, He LJ, Wang L, Zhang GM (2013) Phylogeny and classification of the extant lycophytes and ferns from China. 
魏雪苹，张宪春．偋类植物不同狍子裂㖓类型在中国的分布格局．生物多样性，2016，24(10)：1129-1134 http://www. biodiversity - science. net/CN/10. 17520/biods. 2016219

Chinese Bulletin of Botany, 48, 119-137. (in Chinese with English abstract) [张宪春，卫然，刘红梅，何丽娟，王丽，张钢民 (2013) 中 国现代石松类和蕨类的系统发育与分类系统. 植物学报, 48, 119-137.] 